\title{
SYMBIOTIC RELATIONSHIPS IN PATIENTS' ENGAGEMENTS WITH PRACTICE NURSES
}

\author{
By \\ Elsa Lally
}

A thesis submitted to the Victoria University of Wellington

in fulfilment of the requirements for the degree of

Doctor of Philosophy

in Nursing

Victoria University of Wellington

2014 


\begin{abstract}
Practice nurses engaging with patients is a daily activity in general practice. However, there is little research to assess these relationships from a primary health care, general practice standpoint. The purpose of this new and original research was to explore from patients' perspectives what occurs in general practice, and to establish how the engagements patients have with practice nurses influences patients' health and well-being. The conceptualisation of symbiotic relationships between practice nurses, general practitioners receptionists and patients described in this study, shows how these relationships work in practice, and how they shaped patients' perspectives of their engagements in the general practice setting. Although each person's role was independent and capable of existing without the other, a mutually beneficial close association was developed.
\end{abstract}

From the experiences of 15 patients from seven rural and urban general practices in New Zealand, using Narrative Inquiry methodology informed by life course theory and White's (2010) dimensions of well-being, the co-constructed stories gathered from the participants were analysed applying a modification of McCormack's (2001) multiple lens model. Findings from the individual participant stories revealed three major themes - general practice activity, health focused practice, and professional comforting. Each of these themes described aspects of the participants' relationships and engagements with practice nurses that contributed to their health and well-being. The co-constructed stories described participants' relationships and engagements, not only with practice nurses but also with general practitioners and receptionists. The presence of the (often unseen) overarching doctor and of practice nurses filling the gap in patients' care was evident. Patients described practice nurses as both support for the doctor and as autonomous practitioners. Ease of access to practice nurses significantly contributed to patients obtaining competent health promoting care. Particularly cogent were the findings that practice nurses directly contributed to patients' health and well-being through nurses' skilled compassion and skilled companionship. Nurses actively listened to patients' concerns, suggesting strategies to move patients forward, while at the same time, providing space for them to move at their own pace. Receptionists were viewed as the 'fronts people' of the practice who triaged patients' health concerns, making decisions relating to whom the patient consulted, the doctor or the nurse.

By building on existing theories in Narrative Inquiry methodology, data collection and analysis, this research makes an important contribution to nursing knowledge. It provides new 
perspectives about nurse-patient relationships, as well as other relationships within general practice. The research also demonstrates that while there has been a significant increase in collaboration between nurses and general practitioners over time, this collaboration is distinct from the symbiotic relationships described. The findings have implications for health professionals' everyday practice, and for Primary Health Organisations and District Health Boards when undertaking health professional education and funding reviews. Future research into patients' relationships with practice nurses, doctors and receptionists, and how these relationships contribute to patients' health and well-being is necessary.

Key words: practice nursing, patients' perspectives, well-being, Narrative Inquiry, life course, symbiosis. 


\section{Acknowledgements}

My first acknowledgement must be to my primary supervisor Dr Kathy Nelson, and secondary supervisor Dr Kay de Vries, who replaced Dr Margi Martin and Dr Pamela Wood. Their unstinting generous support, advice, and feedback enabled me to complete this degree. I acknowledge and thank the lecturers and staff of the Graduate School of Nursing, Midwifery and Health at Victoria University of Wellington. It was a pleasure to meet so many inspirational people. I also deeply appreciate the Faculty Research Grants that assisted my travel to interview participants, and to attend conferences in Melbourne and Nelson.

I am very grateful for the support of my friends and colleagues especially Diane Auld, Marie McElhinney, Cynthia Wensley, Amanda Arnold and Ellie O’Donnell who willingly accepted the challenge of reading my thesis from their points of view. Also, my sister-in-law Kath Lally who spent many pencil-filled hours examining my work for grammatical errors and sense-making. I am indebted to Joyce Griffin whose offer to read the final draft of my thesis was sincerely accepted. I offer my thanks to all the participants in the study who initially gave their time, and then continued their interest in the outcome of my research. I also acknowledge the love and support of my husband David, and my family who listened to my anxieties about my progress. Finally, but not least, I thank my past and present $\mathrm{PhD}$ colleagues who have provided me with encouragement and ideas. It has been a privilege to have met such motivated and enlightened individuals and I wish them well. 


\section{Table of Contents}

SYMBIOTIC RELATIONSHIPS IN PATIENTS' ENGAGEMENTS WITH

PRACTICE NURSES.

Abstract ................................................................................................................ ii

Acknowledgements .......................................................................................................iv

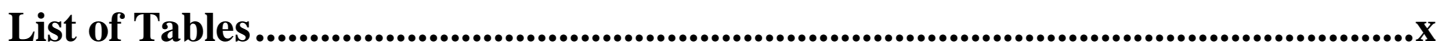

List of Figures ............................................................................................................

Glossary .......................................................................................................................

Chapter 1 Introduction and overview of the inquiry ..............................................1

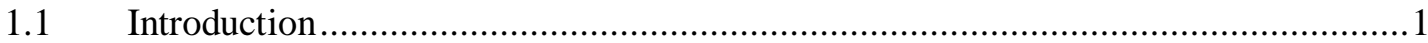

1.1.1 The role of a practice nurse in general practice in New Zealand ............................. 1

1.1.2 Why I wanted to study practice nurse-patient engagements and relationships........... 3

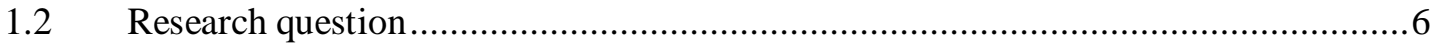

1.2.1 Aim

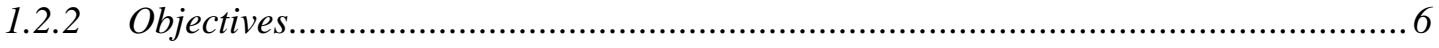

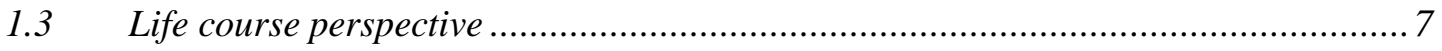

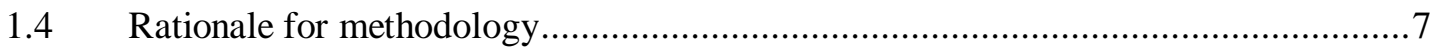

1.4.1 Key writers who influenced my decisions ........................................................ 8

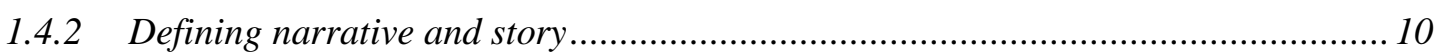

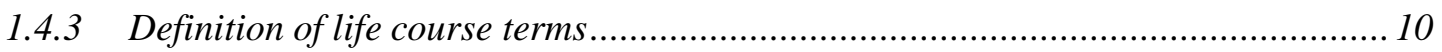

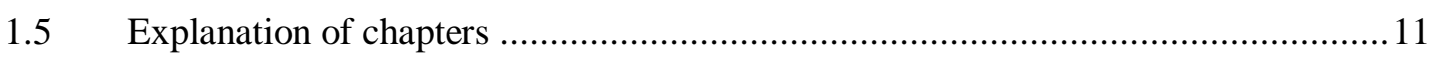

Chapter 2 An overview of general practice and practice nursing ......................14

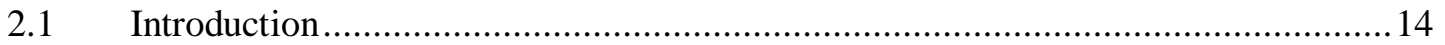

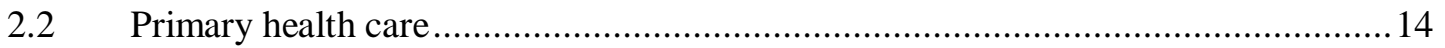

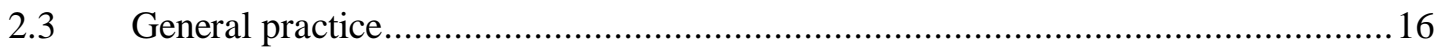

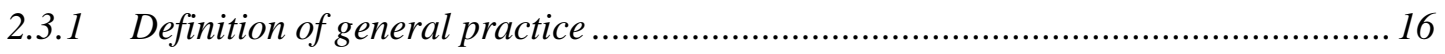

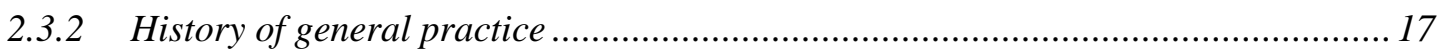

2.3.3 Access and funding general practice services........................................................ 19

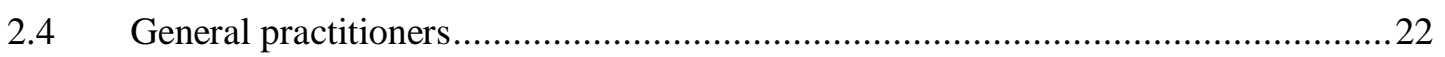

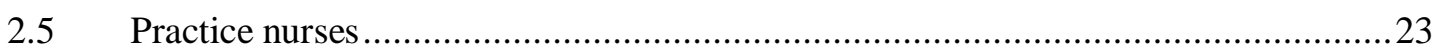

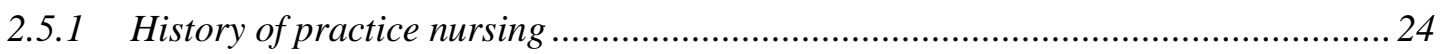

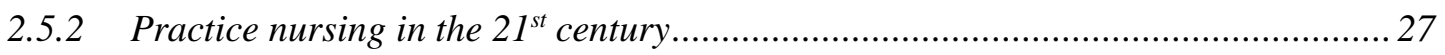

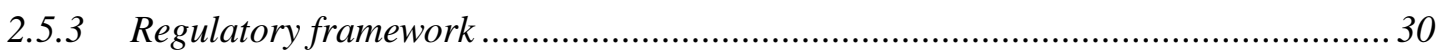

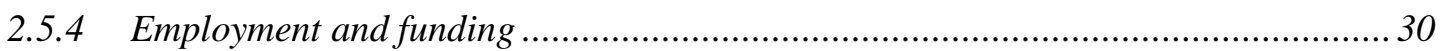

2.6 Practice managers, administrators and medical receptionists ..................................31

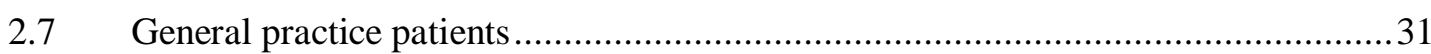


2.8 Practice nurse engagements and relationships with patients 32

2.8.1 Engagements and relationships with patients from my practice nurse perspective .. 33

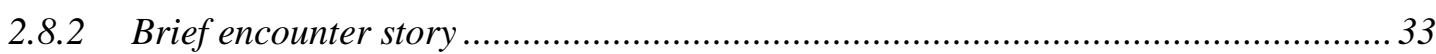

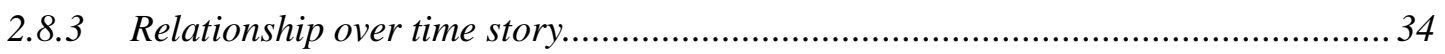

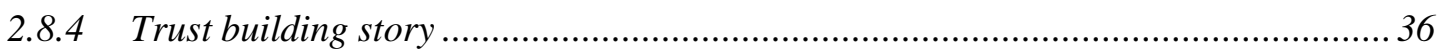

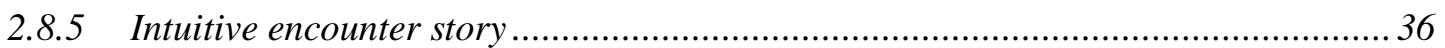

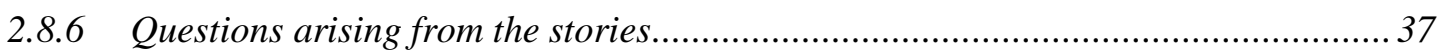

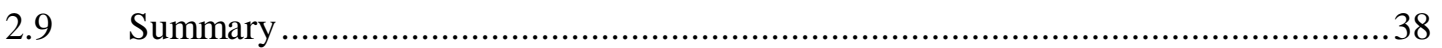

Chapter 3 Literature review of nurse-patient relationships ..............................39

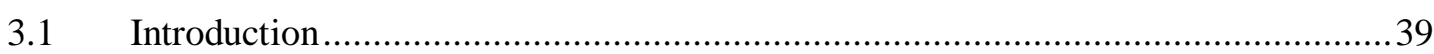

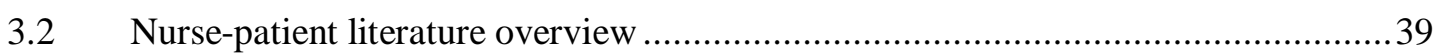

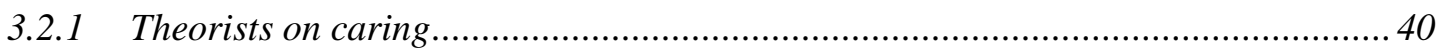

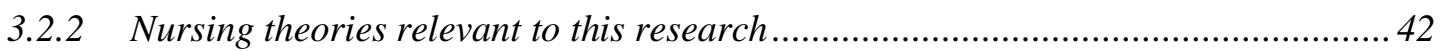

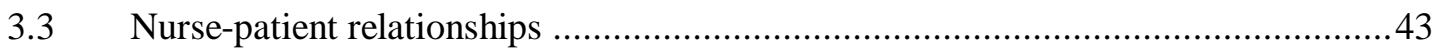

3.3.1 Nurse-patient relationships from patients' perspectives ....................................... 44

3.3.2 Alternative perspectives of nurse-patient relationship …..................................... 47

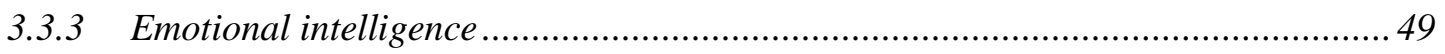

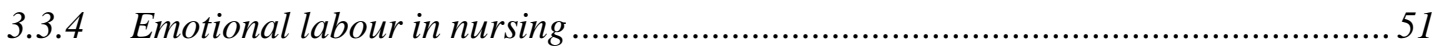

3.3.5 Practice nurse-patient relationships in general practice ....................................... 57

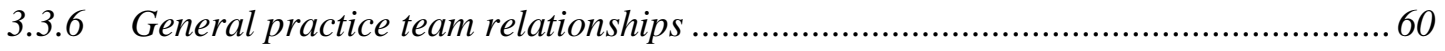

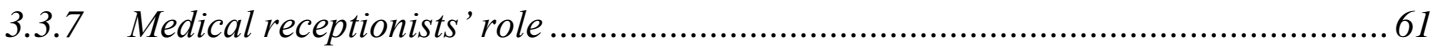

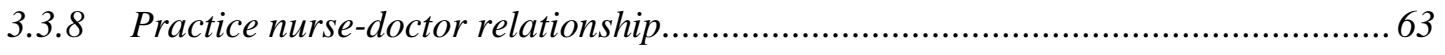

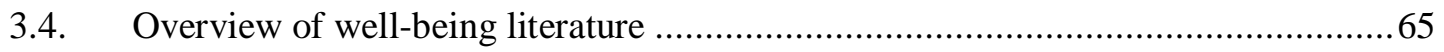

3.4.1 Well-being from a community health research perspective …................................6 68

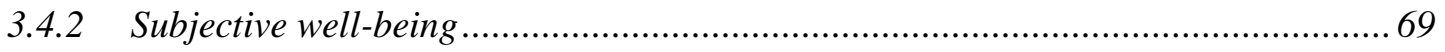

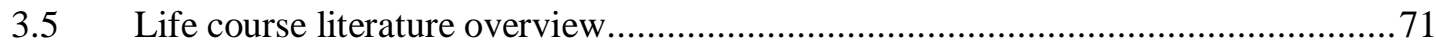

3.5.1 Life course from a community perspective ........................................................... 73

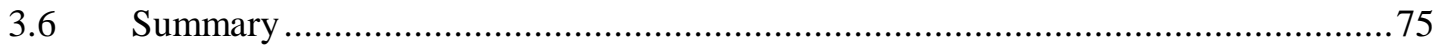

Chapter 4 Methodology ......................................................................................77

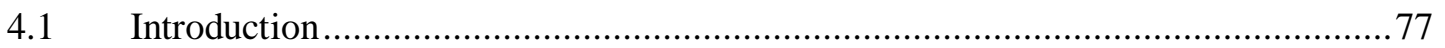

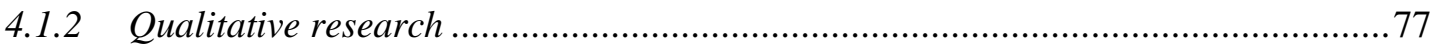

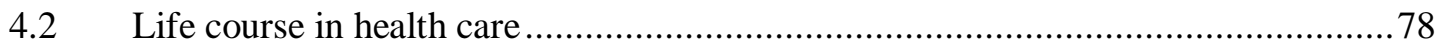

4.2.1 Life course, Primary Health Care and practice nurses ......................................... 79

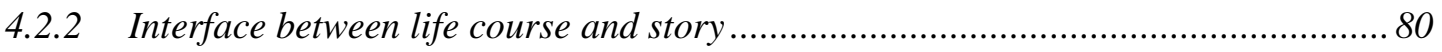

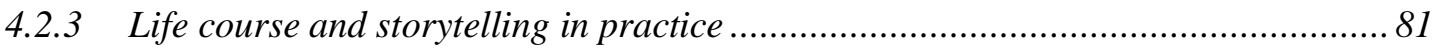

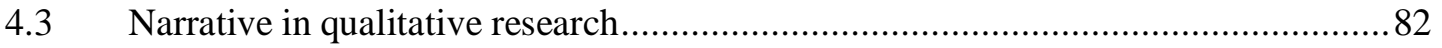




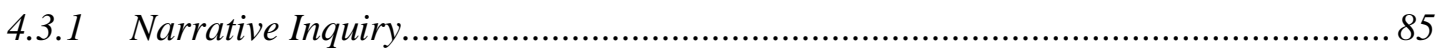

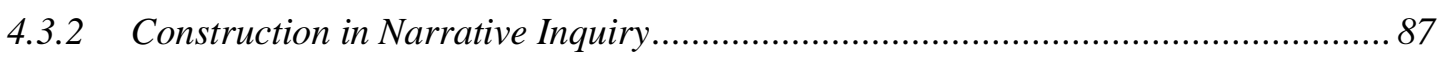

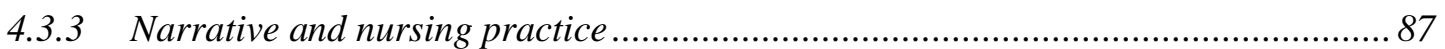

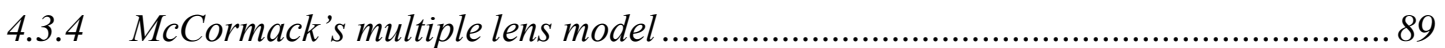

4.4 Positioning my research argument and decisions .................................................90

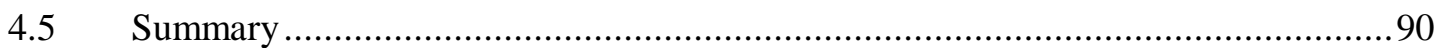

Chapter 5 Methods...........................................................................................92

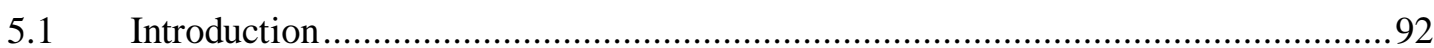

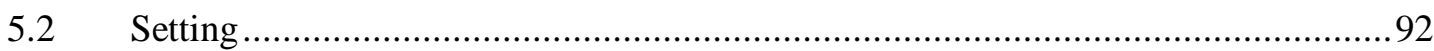

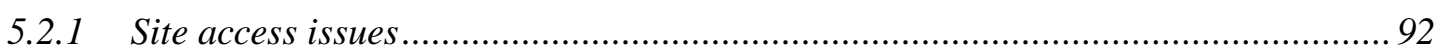

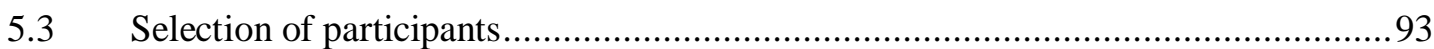

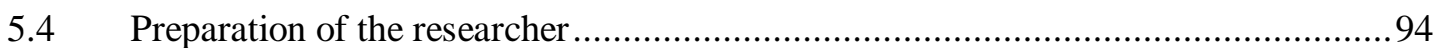

5.5 Interviewing for a Narrative Inquiry methodology ….............................................95

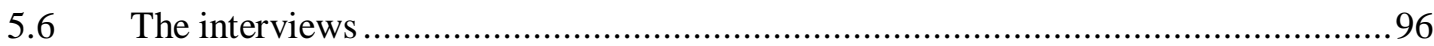

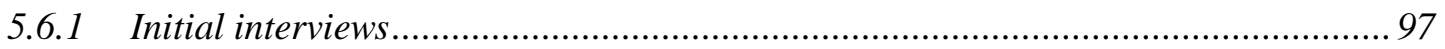

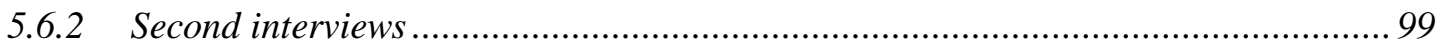

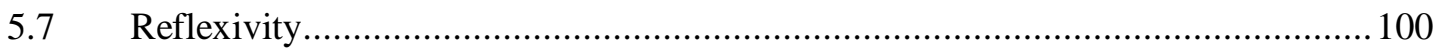

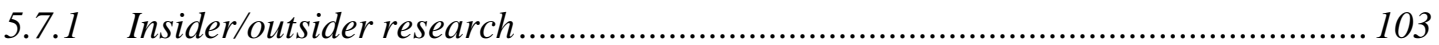

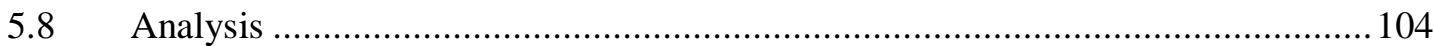

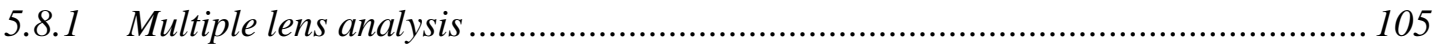

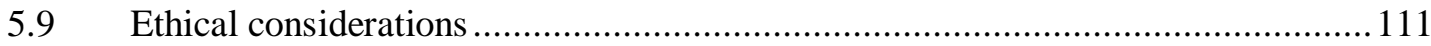

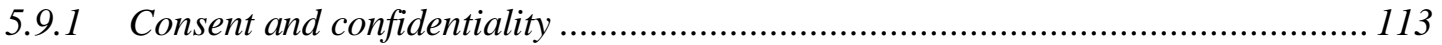

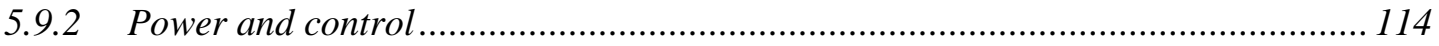

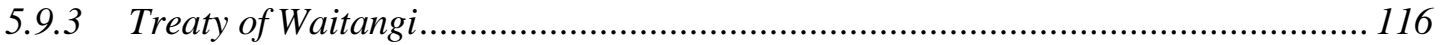

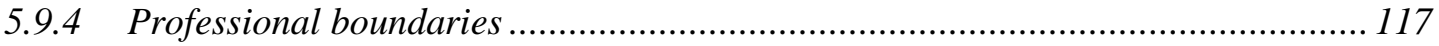

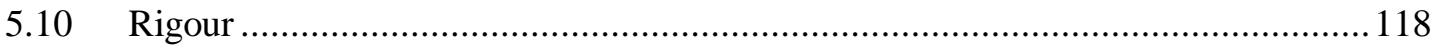

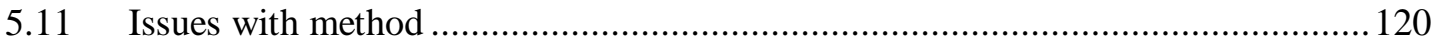

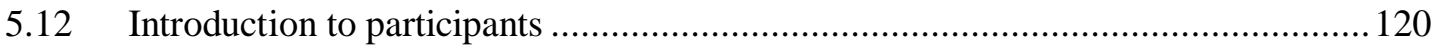

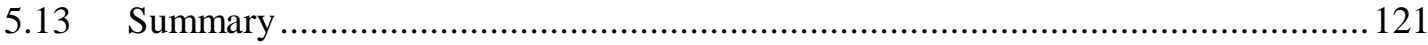

Chapter 6 Participants and their stories of their relationships with practice nurses

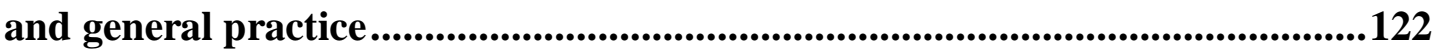

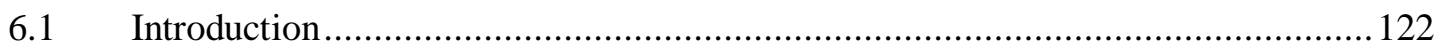

6.2 Kay's story: Doctors are good, but I would rather talk to the practice nurse ...........122

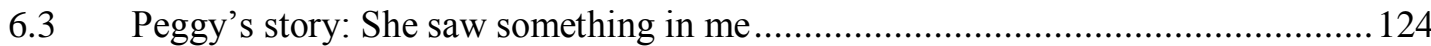

6.4 Bert's story: They all seem to be the same; it's like seeing a second doctor ...........125

6.5 Katriona's story: She's really support for the doctor............................................... 126 


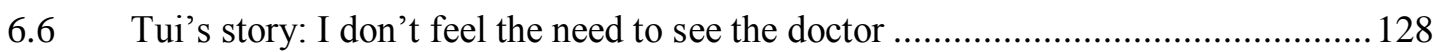

6.7 Mere's story: We're so very different; chit-chat allays my fears ..........................129

6.8 Jack's story: She gave me confidence that I was going to last...............................131

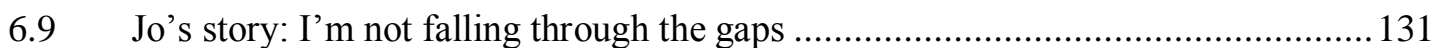

6.10 Pango's story: I'm coming for that risk assessment you have been chasing me for 133

6.11 Sam's story: They will hold my hand if necessary ...............................................134

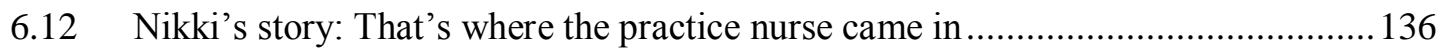

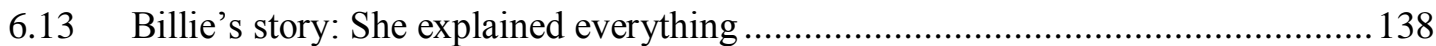

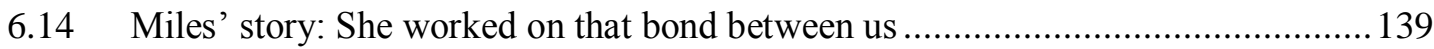

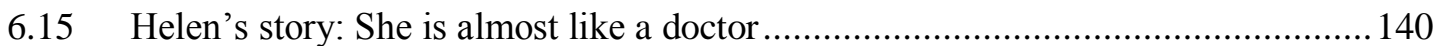

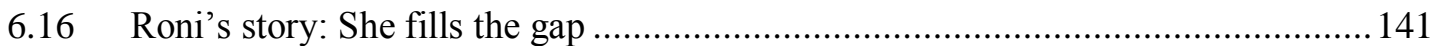

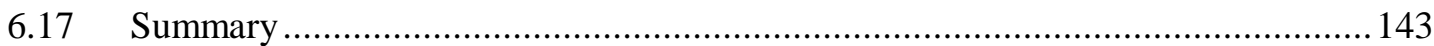

Chapter 7 Participants' relationships and engagements with practice nurses144

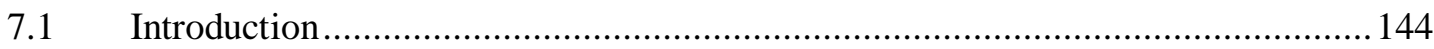

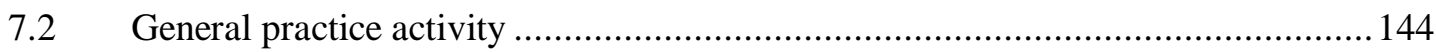

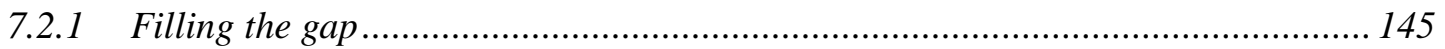

7.2.2 From beck and call, to beckoning and calling .................................................. 146

7.2.3 Medical receptionist as 'fronts people' ............................................................ 151

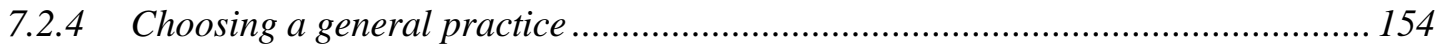

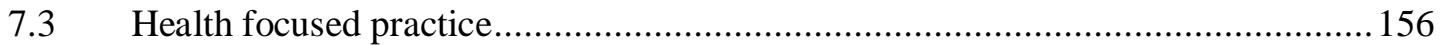

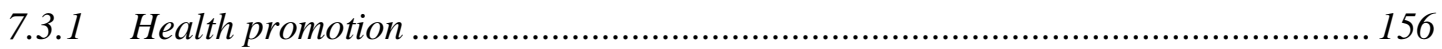

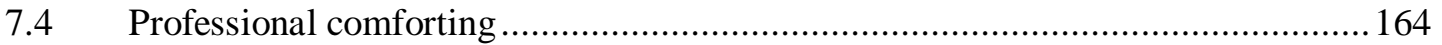

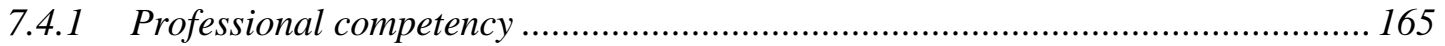

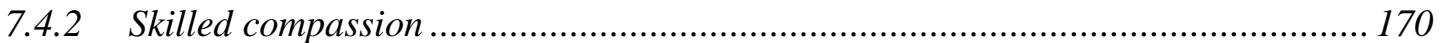

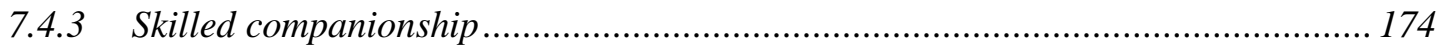

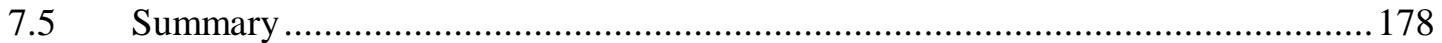

Chapter 8 Discussion ...............................................................................179

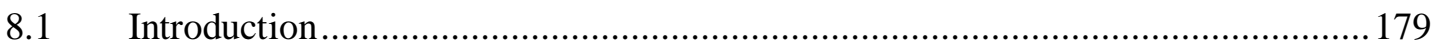

8.2 Overarching GP presence and practice nurses filling the gap .............................. 180

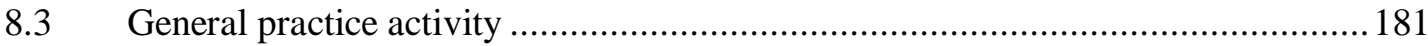

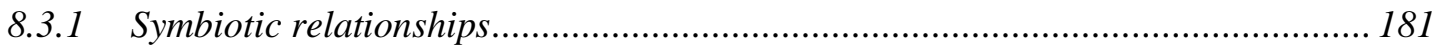

8.3.2 From beck and call to beckoning and calling ................................................ 183

8.3.3 Determinants in general practice selection ….................................................... 185

8.3.4 Receptionists as 'fronts people' ....................................................................... 186

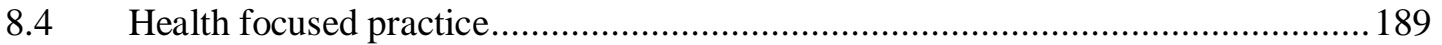

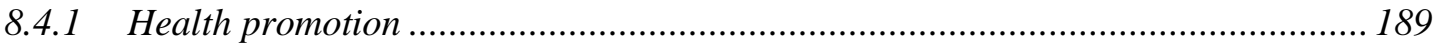


8.4.2 Enablement: Facilitation and impediments ....................................................... 189

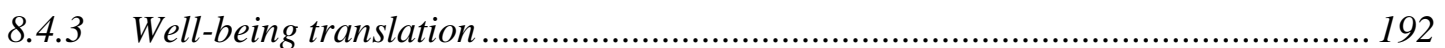

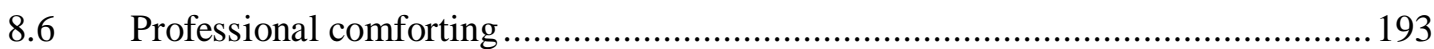

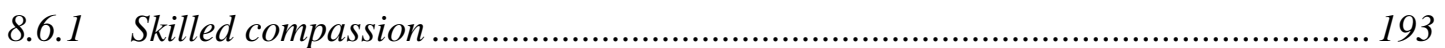

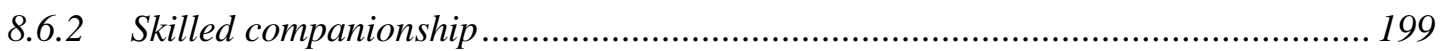

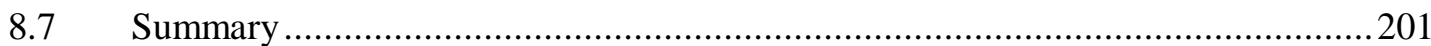

Chapter 9 Study critique and conclusion ...................................................202

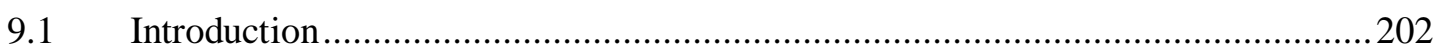

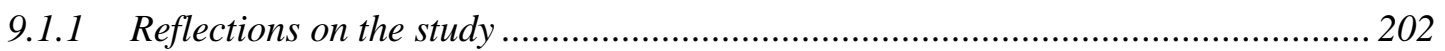

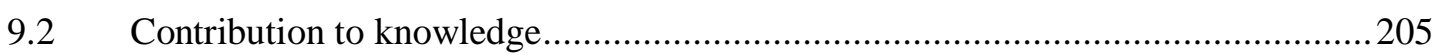

9.3 Contribution to methodology and method .......................................................207

9.4 Methodological and method critique and study limitations .................................208

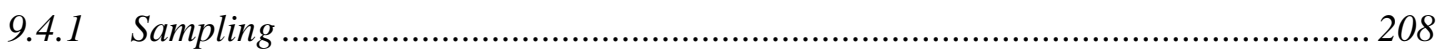

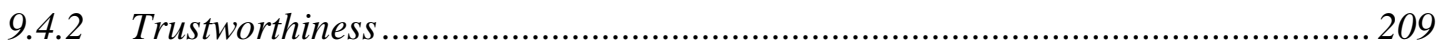

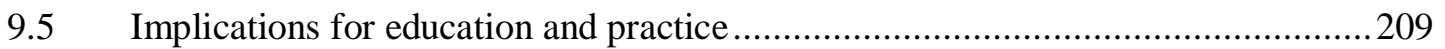

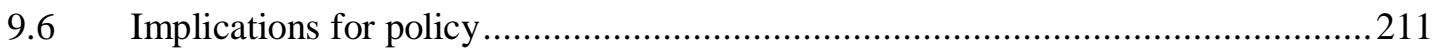

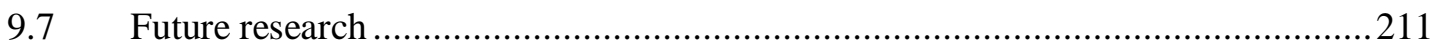

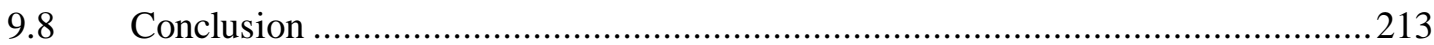

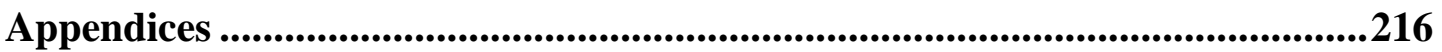

Appendix 1 Locality Organisation Consent ….....................................................................2216

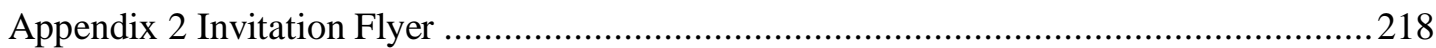

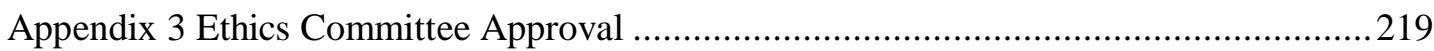

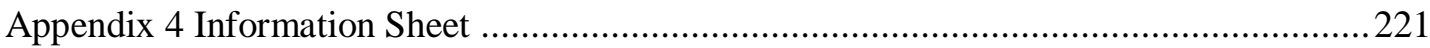

Appendix 5 Ethics Committee approval to interview patients from my practice ................224

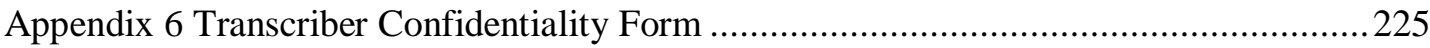

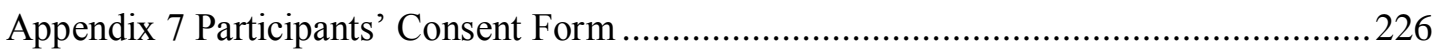

Appendix 8 Sample of Story Co-construction and Reflective Analytical Mind Map..........228

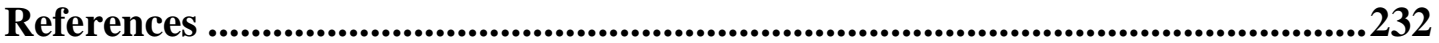




\section{List of Tables}

Table 1. Emotional Intelligence Framework: Domains and Competencies ......................50

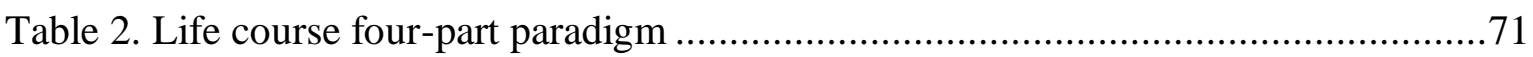

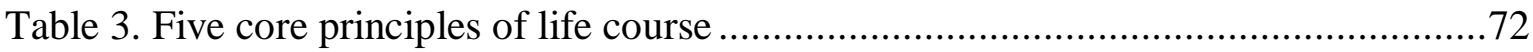

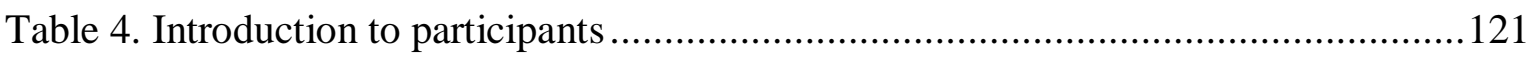

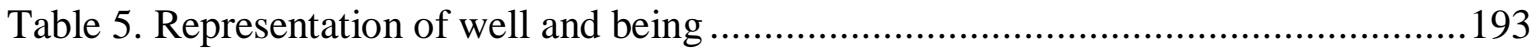

\section{List of Figures}

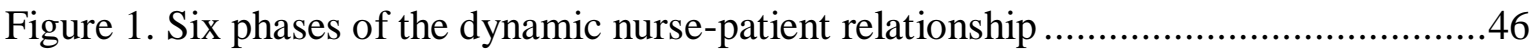

Figure 2. Well-being triangle illustrating the three dimensions ......................................67

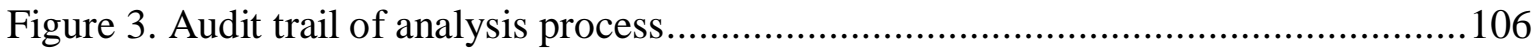

Figure 4. Schematic representation of the development of individual interpretive stories

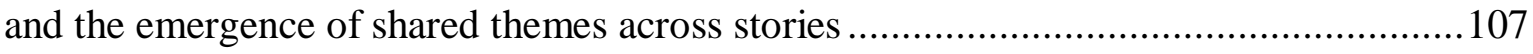

Figure 5. Schematic representation of the themes and well-being ................................ 144

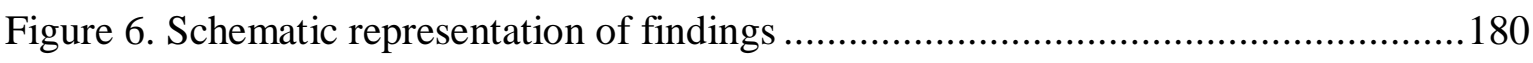

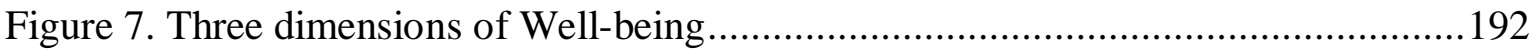




\section{Glossary}

Accident Compensation Corporation (ACC): Provides comprehensive, no fault, personal injury cover for all New Zealand residents and visitors to New Zealand.

Chronic Conditions Management (CCM): Linking primary health care and secondary services, CCM is a patient focused primary health care programme to support people with chronic conditions such as respiratory disease, heart disease, arthritis, diabetes. Delivery of the programme may be shared between general practitioners and practice nurses.

Care Plus: New Zealand government primary health care programme located in general practice targeting people with high health needs due to chronic conditions, acute medical or mental health needs, or terminal illness. The expectation is that patients on the programme will see the practice nurse or general practitioner three monthly, or more often if required. The patient's need for the programme is reassessed annually.

Green Prescription: Health professionals' written advice to a patient to be physically active as part of the patient's health management.

Healthy Lifestyle Programme: Primary health care programme usually delivered by practice nurses to promote patients' healthy nutrition and healthy exercise.

Smoking Cessation Programme: Includes the provision of smoking cessation services to individuals and groups in both primary and secondary settings. Practice nurses often provide this service.

Vascular Risk Assessments (VRA): A programme delivered in general practice to assess a persons' risk of heart attack or stroke in the following five years. Target groups include people over the age of 65 , or if they had experienced vascular events, the assessments were annual. Maori are offered assessments 5 or 10 years earlier. As of 2013, this programme was not funded by all Primary Health Organisations. 
Well Man and Well Woman Checks: Often delivered by practice nurses, these regular checks are a comprehensive assessment of a person's health. The time between checks is negotiated between the patient and practice nurse or doctor. 


\section{Chapter 1 Introduction and overview of the inquiry}

\subsection{Introduction}

The World Health Organisation held its first primary health care international conference on health promotion in 1986 in Ottawa, Canada. The resulting Ottawa Charter for Health Promotion (World Health Organisation, 1986) launched a series of actions among international governments, organisations and local communities to advance people's health through better health promotion. It was envisaged that these health promoting activities would increase people's control over their health choices. In the Commonwealth countries of Australia, Canada, New Zealand and the United Kingdom (UK), government directed and funded health care changes facilitated the Charter's health promotion policy. Responding to the Charter, in New Zealand the aims and objectives of the Primary Health Care Strategy (PHCS) (King, 2001) were designed to provide a clear direction for the future development of primary health care (PHC). The Strategy states that there is evidence of the specific contributions that PHC makes in the community and emphasises the crucial role of nurses in its successful implementation. This nursing emphasis provides the impetus for nurses to explore a range of options that focus on adding value, not only to their work with individual patients, ${ }^{1}$ but also to the practice population. Through their engagement with practice nurses, patients are expected to benefit from this PHC policy. However, it is not well understood how practice nurses and patients' relationships contribute to patients' health and well-being, and by extension, the health of the community. This thesis documents my exploration of that relationship, and presents the findings of a study that asked general practice patients how their relationships with practice nurses contributed to their health and well-being.

\subsubsection{The role of a practice nurse in general practice in New Zealand}

Practice nurses are generalist registered nurses who are usually employed by a general practitioner (GP), often providing first point of contact care. They deliver a broad set of primary care services, including undifferentiated general consultations (Hefford, et al., 2010). The New Zealand definition of a practice nurse, now commonly referred to as a PHC nurse, is similar to that of the UK, Australia and Canada:

Primary health care nurses are registered nurses with knowledge and expertise in primary health care practice. Primary health care nurses work autonomously and

\footnotetext{
${ }^{1}$ For the purposes of this study, a patient is a person who is registered to receive, or is receiving medical care.
} 
collaboratively to promote, improve and restore health. Primary health care nursing encompasses population health, health promotion, disease prevention, wellness care, first point of contact care and disease management across the lifespan. The setting, and the ethnic and cultural grouping of the people determine models of practice. Partnership with people - individuals, whānau, communities and populations - to achieve the shared goal of health for all, is central to Primary health care nursing. (Ministry of Health, 2003b, p. 9)

Each nurse is required to maintain their competency based practicing certificate by continuing to work within their defined scope of practice as well as undertaking a minimum level of continuing education. The Nursing Council of New Zealand (2009) states that:

Registered nurses are accountable for ensuring all health services they provide are consistent with their education and assessed competence, meet legislative requirements, and are supported by appropriate standards....Competence is the combination of skills, knowledge, attitudes, values and abilities that underpin the effective performance as a nurse. (para. 1)

Engaging with people throughout their life course, from the very young to the very elderly, the role of practice nurses includes a large variety of nursing activities. For example, routine childhood immunisations, well health checks, which include sexual health, healthy lifestyle interventions such as smoking cessation, and healthy nutrition and exercise support. These are available to patients registered with, or casually attending a general practice. Vascular risk assessments (VRA) (see Glossary), chronic conditions management and education, and overseeing screening through the cervical and breast screening programmes, are also provided. Wound care, ear care, counselling, telephone triage and advice, informing people of their test results, and ongoing management, and triage are included in their daily work. Consultations with people visiting the area (e.g., tourists) and those who reside in the community and have known the practice nurse for a long time, might range from one-off brief visits of 5-10 minutes, to engagements lasting 30 minutes or more. The nurse records details of consultations and health data in the patient's clinical record. 


\subsubsection{Why I wanted to study practice nurse-patient engagements and relationships}

At the time I began this study, I had been a part-time practice nurse for about 22 years, 15 of which were with the one GP in his rural practice. During those early years, there was another part-time practice nurse who also acted as practice administrator, and one receptionist who worked in the mornings. The practice nurses took over reception duties in the afternoon. Despite having occasionally worked as a relieving nurse at other practices prior to this practice, I had no previous specialist knowledge of practice nursing, and very little experience as a receptionist. What I learnt was task focused and, until practice nurses organised their own education, these tasks were usually taught by my employing GP. Tasks included ear syringing, wound care and giving immunisations. Aware of some of my knowledge deficits, I attended every education session available at that time. Nevertheless, I felt I lacked theoretical depth to my knowledge of nursing and patient care. Consequently, in 1995 I began study to up-grade my hospital nursing training qualification to a Bachelor of Nursing degree. This learning process increased my knowledge of patientcentred care and raised my awareness of how my way of nursing may be received by people who wanted to express their own health and well-being choices. I found I valued the thought provoking, constancy and length of formal study, and in 2002 I completed my Masters of Arts (Applied) degree in Nursing through Victoria University of Wellington. My research used an Action Research approach and looked at language and nursing practice to improve communication in the context of ear syringing (Lally, 2002). Following the solo GP's semi-retirement then retirement, numerous locum doctors from many parts of the world were employed to provide GP cover. These doctors, some whom only had English as a second language, stayed for a few days or weeks, to 12 months. This fluidity of GPs facilitated my developing a role in independent nurse-led patient care. However, I continued to puzzle about nursing and nursing knowledge, and how diverse patient engagements and relationships influenced patients' health decisions. These questions led me to further study.

My philosophy of nursing is patient-centred and I found the tension between gathering health outcome data for District Health Boards (DHBs) and Primary Health Organisations (PHOs) (described in Section 2.2) contrasted sharply with a holistic approach to caring for patients. To meet government required Health Performance Indicators to receive applicable funding allocation, especially for those populations most at risk, general practices are required to provide data by completing the appropriate electronic or paper forms, and 
sending them to the DHB or PHO. By virtue of their role, practice nurses are usually responsible for gathering much of this health data from patients. However, the type of data required such as the number of Body Mass Indexes measured, VRAs accomplished, Diabetic Reviews completed, and patients' smoking status recorded, do not reveal the full extent of the work of practice nurses, nor the communicative, relational processes in which these outcomes are achieved. In my experience, and discussion with other health professionals, the need to complete electronic documentation at the time of a consultation can distract the clinician from engaging fully with the patient. The performance indicators do not require evidence of the humanistic, skilled know-how and action, the relational, emotional, interpersonal and tacit knowledge work that nurses engage in with patients. Also missing is the influence of these aspects of practice nursing on the health and wellbeing outcomes for people. Critical information of how engagements and relationships between patients and practice nurses contribute to patients' choices about their health and well-being is not only absent from the official forms, but also poorly reported in the nursing literature.

Even though I understood the reasoning behind gathering population health data, the idea for this research arose from my frustration at what I perceived as tick-box health care that failed to gather information about what genuinely occurred during the nurse-patient engagement. A study that views the practice nurse-patient consultation and engagement from the patient's perspective, identifying the unobserved and often intuitive, unrecorded aspects of the practice nurse work would, I believe, contribute to improved health outcomes. A deeper understanding of the practice nurse-patient relationship from patients' perspectives would demonstrate, not only to nurses, but also to employers and policy makers, the importance patients place in that relationship, and how they perceived its effect on their health and well-being.

During my years of practice nursing, I heard many stories from practice nurses and patients describing how the nurse-patient relationship they developed made a difference to the patient's health and well-being. While literature searches found multiple studies involving nurse-patient relationships generally, there were few with a PHC or community nursing focus. Community nursing studies often were from the perspectives of nurses working in the broader community rather than in the general practice setting. Studies relating to nurses working in general practice were scarce, and research from general practice patients' 
perspectives of their relationship with practice nurses were uncommon but are starting to appear in the literature. A semi-structured telephone interview study by Halcomb, Peters, and Davies (2013) reports on consumers (patients) perceptions of the role and work of general practice nurses in New Zealand. These authors found that despite some confusion of practice nurses' role, consumers valued their relationships with practice nurses and were satisfied with their service delivery. They concluded that greater clarity around the practice nurse role and scope of practice may enhance their utilisation. A British grounded theory study (Stoddart \& Bugge, 2012) applies observation and semi-structured interviews of practice nurses and patients in order to understand the social meanings and understandings brought to the interaction. Fyers (2008) Narrative Inquiry study highlights the practice nursing presence in general practice in New Zealand. Using nurses' accounts of patients' stories, Fyers revealed the complex nature of practice nurses' work, and the importance of the nurse-patient relationship, continuity of care and the significance of the autonomous and speciality aspects of nurses' work. Although the two New Zealand based studies provide some understanding of the nurse-patient relationship in New Zealand, no research was found which specifically focused on patients' perceptions of how their relationships with practice nurses contributed to their health and well-being.

Given that listening to patients' stories could enhance the engagement environment and patients' human agency, the research question arose from the need to gain further insight into the nurse-patient relationship. Improved understanding of factors in the relationship will be useful to enable nurses to work in a genuine partnership with patients to support change to take place. Moreover, interpreting patients' accounts of this relationship, would uncover aspects of engagements not usually recorded. The results of the research, while benefiting patients, are also important for practice nurses' continuing education. In addition, they have significance for nurses' employers, DHBs and PHOs policymakers, educationists, and other PHC providers, when making practice policy and practice nurse role decisions. By exploring these relationships from patients' perspectives, and revealing the hidden nature of practice nursing that contributes to patients' health and well-being, the research will add to the already large body of knowledge of nurse-patient relationships.

Initially, I considered collecting practice nurses' stories to describe what they perceived contributed to patients' health and well-being. However, a study of this nature would only reveal nurses' interpretations of their contributions, or what they recall patients' conveyed 
to them. It would not uncover patients' own stories of their experiences. Therefore, I decided to focus solely on patients' stories. This patient-centred approach better portrays patients' experiences without nurses' interpretations influencing the findings. It also allows readers of the study to understand and gain insight into how the relationship between patients and nurses may contribute to health outcomes. Because my practice nurse experience is from a rural practice perspective, ${ }^{2}$ to add a wider range of practice populations and practice nurse encounters, I also recruited patients from an urban setting. Fifteen general practice patients from the Nelson and Motueka regions in New Zealand consented to participate in the research.

\subsection{Research question}

From patients' perspectives, how do their relationships with practice nurses contribute to their health and well-being?

\subsubsection{Aim}

To explore how patients' experiences of their relationships and engagements with practice nurses contribute to their health and well-being.

\subsubsection{Objectives}

1. Describe different aspects of the practice nurse-patient engagement and relationships

2. Identify factors in the practice nurse-patient relationship that patients believe contributes to their health and well-being

3. Identify other general practice relational factors that contribute to patients' health and well-being.

The first two objectives were part of the original study, but later I added the third objective to discuss and ensure that what emerged from the participants' stories was fully positioned as part of the research. Actively listening by being responsive and reflexive with patients who wish to tell stories of life events is a significant characteristic of the practice nurse role. Patients may describe the birth of their first or last child, the years spent planting and picking tobacco and fruit in the Nelson/Motueka region, their possibly life-threatening health event, or how they cut their finger. However, in day-to-day practice nursing, time

\footnotetext{
${ }^{2}$ I worked in a rural practice in Motueka.
} 
constraints curtail recording a life-review or life-history, and only the most relevant details are documented (Clausen, 1998). Even though applying life course in a study focusing on people's episodic encounters (such as consultations with practice nurses) is different to that which life course is usually associated, it was a logical choice for me to apply a life-course theoretical orientation to my research.

\subsection{Life course perspective}

The life course perspective of Daaleman and Elder (2007) emphasises a way of relating to people in their contexts over their life-span. As a practice nurse, I engaged with people whose life choices had been influenced and adapted by historical, cultural, economic and social factors that had occurred in their life. These influences and adaptations occurred independently of where they might be in their life course trajectory or health pathways. The five principles of life course I chose to inform my research are those described by Elder and Kirkpatrick Johnson (2000): Human development and aging as life-long processes, Human agency, Historical time and place, Timing of events in life, and Linked lives. These principles are examined in detail in Chapter 3.

\subsection{Rationale for methodology}

Practice nurses are recipients, not only of patients' health stories, but also of their life events. These stories may be told episodically over time, or in brief, one-off engagements. Patients' stories can make up a large part of nurse-patient engagements, therefore, a methodology that provided me with the opportunity to listen to patients' stories of their experiences with practice nurses, and with general practice as a whole, became significant. The chosen methodology shapes the inquiry and has assumptions about how we know the world or gain knowledge of it (Denzin \& Lincoln, 2005). Qualitative researchers study phenomena in their natural setting, attempting to make sense of, or interpret things, and the meanings people bring to them. It can be used to reveal the relationship between the person asking the questions and what is known about a topic, issue, or experience (Denzin \& Lincoln). It is this enquiring of people how they see their world and the people in that world, which resonated with me. I considered several qualitative approaches including Appreciative Inquiry, Gadamerian Hermeneutical Philosophy, Interpretative Description, and Narrative Inquiry. I chose Narrative Inquiry, as I believed it was the most fitting way to achieve my aims. By creating space, Narrative Inquiry allows participants to relate their accounts and stories of their engagements with practice nurses in their own time, without 
undue direction from me, as the researcher. It can also empower participants' human agency, influencing their decisions of what to reveal or withhold during the interview. To generate new knowledge, and to achieve an inclusive, humanistic and reflective study, I linked the theoretical orientations of the life course principles, especially timing and human agency, with the stories participants shared with nurses.

\subsubsection{Key writers who influenced my decisions}

Many writers informed my thinking and contributed to my decision to explore patients' stories of their engagements and relationships with practice nurses. The numerous approaches to qualitative research are clearly described by Riessman (1993, 2008), Silverman (1997), Denzin and Lincoln (2005), and Chase (2005). These writers elaborate on what different research approaches mean, and provide direction in interpreting narrative accounts and stories. The explanation of methodology and methodological issues by Crotty (1998) and Mason (2002) were crucial to my decision to take an epistemological constructionist perspective. By taking a pragmatic, common sense approach (Andrews, Squire, \& Tamboukou, 2008), I established a methodology compatible with my question.

During my exploration of Narrative Inquiry and storytelling research, the writings of Frank (2000), Lawler (2002), Mason (2002), Paley and Eva (2005) and Riessman (2008) were salient. Their work challenged my perceptions and reasoning, at the same time providing me with a way forward in finding a fitting definition of narrative or story to inform my analysis. Of particular significance was the interpretative story work of McCormack (2001). Her framework presented me with a method of scrutinising the interview transcripts that respected the storyteller and their stories. McCormack analysed stories by viewing them through the multiple lenses of active listening, narrative processes, language, context, and moments. This method suited the purpose of my research and was particularly cogent with my analytical process.

Kleiman's (2009) humanistic nursing lens emulated my personal nursing philosophy in which the person is viewed in context with their environment, culture, history, and life experience, in a nurturing, interpersonal encounter. Being aware, having a global apprehension of the person, being open, empathetic, caring and connected, is accentuated in the nurse-patient relationship (Kleiman). This holistic, humanistic approach was 
germane to my research question and the manner in which the personal interviews might be undertaken.

Carson and Fairbairn (2002) and Frank (2000) also influenced my thinking. They emphasised key concepts of patient-centred listening, learning, and leadership, the acceptance of different beliefs, and lives in which these beliefs made sense. To gain knowledge from the interviews, it was essential I remained participant-centred, while simultaneously acknowledging my listener/researcher position in their stories. It was also critical that, to be culturally safe and ethical, I was aware of my own culture, ethnicity, history, and time in my life that I was undertaking this research, as well as how it might influence my perspective and analysis of the interviews (Carson \& Fairbairn; Frank; McCormack, 2001). From the perspective of a researcher, to enable me to observe, listen, and be reflexive, I required detachment of my nursing self from my researcher self.

The philosophies and practices of Carson and Fairbairn (2002), Frank (2000), Kleiman (2009), McCormack (2001) and Riessman (2008), led me to further consider the work of Ricouer (1981, 1984). For Ricoeur, like Labov (1972, 2006), written and told stories are changed when read or heard and they are not completed until the reader or listener has read or heard them (Andrews, 2008). Understanding occurs from reliving the events that produced the story. Ricoeur contends that narratives are not autonomous, and the worlds of the readers, texts, speakers and listeners must be brought together. This integration of speakers and listeners is apparent in my work as a practice nurse and is implicit in my research question.

In life course inquiry, the individual is placed "in the driving seat" (Clausen, 1998, p. 184) concentrating on the identity and sense of self (self-hood) of the person. It is the person, who is integrating the events and experiences, giving them meaning and making changes, encountering new relationships and circumstances. It is the person, who makes decisions about changes or holding the current course. Clausen claims that someone with a strong sense of identity and positive feelings about life enjoys a greater sense of control and thereby human agency. Consistent with this perspective, Elder and Kirkpatrick Johnson's (2000) exploration and elaboration of life course theory was most vividly expressed in participants' subjective accounts of their life experience. 
Alongside McCormack (2001), White's (2010) subjective, relational and material dimensions of well-being afforded a coherent foundation from which to help direct my analysis of patients' experiences. An understanding of the breadth and depth of White's dimensions and my experience as a practice nurse added rigour and validity to my methodological structure. The dimensions represented an emic perspective giving authenticity to my actions as a researcher, and between my work and experience as a practice nurse and as a researcher. This perspective is in line with Theodosius's (2008) assertion that congruency between her work as a nurse on the ward and as a researcher was an important validity characteristic in her qualitative research. The work of the scholars discussed in this section resonated with my health-promoting role as a practice nurse. They also helped me identify and confirm a Narrative Inquiry methodological approach to my question.

\subsubsection{Defining narrative and story}

Not all narratives are stories because some just report on events, such as newspaper articles. However, all stories are regarded as narratives (Frank, 2000; Lawler, 2002; Paley \& Eva, 2005; Riessman, 2008). 'Story' as narrative, is a form of expression recognisable as a story, that is, having a clear sequential order that connects events in a meaningful way, and, based on time, has a plot, a beginning, middle and end. Nevertheless, in my work as a practice nurse, I was aware that the personal stories of patients can take some time for the sequential order to be uncovered. Similarly, during the interviews, participants often narrated accounts of their interactions with practice nurses, as well as narrating a story within a story. For example, participants might begin their account of their engagements with practice nurses, but augment it by telling another story that may not, at first, be obviously connected with the original story. My interpretation of these accounts and stories became each participant's individual research story (see Chapter 6). From my understanding of the diversity of perspectives and meanings of narrative in qualitative research, I chose to use narrative and story interchangeably. A discussion of narrative in qualitative research is provided in Section 4.3.

\subsubsection{Definition of life course terms}

In the literature, terms such as life-span, life-history, life-cycle, and life-review/life-story at times appeared blurred in their meaning. They are also sometimes interchangeable despite their differences. Life-span is the period of life from birth to death. Life-span studies focus 
on developmental trajectories across the span of a life, giving little attention to the contextual, life patterns and historical time and place (Elder \& Kirkpatrick Johnson, 2000). Life-history typically alludes to a chronology of events and activities across life domains, such as residence, make-up of the household, education, work-life and family events. It includes a person's own reports and other sources of data (Elder \& Kirkpatrick Johnson). Life-history focuses on the individual's level of action, but researchers need to have both life-course and life-history to fully understand social change (Giele \& Elder, 1998). Lifecycle describes a sequence of events in the life course. It has a distinct meaning in population studies where it refers to the reproductive process from one generation to the next. Life-review/life-story are social science terms attributed to a person's effort to reexamine events or long sequences from the past. Life-story is exclusively the person's subjective, retrospective report of past experiences and the meaning it has for that person (Elder \& Kirkpatrick Johnson). Nevertheless, because it did not have a clear beginning, plot, and clear end, it is not a story (Clausen, 1998). However, episodes of the life course do have a beginning, plot, and end, but life course itself is an incomplete collection of such narratives. For Jung (1963) the story of life begins somewhere at a particular point we happen to remember (Clausen). Atkinson (1998) defined life-story as "the story a person chooses to tell about a life he or she has lived, told as completely and honestly as possible, what is remembered of it, and what the teller wants others to know of it" (p. 8). A life story can cover the time from birth to the present, or before and beyond, and it included important events, experiences and feelings of a lifetime. Life-story and life-history are the same entity, therefore, interchangeable (Atkinson). Given the nature of this research, I use life-story to describe participants' episodic encounters with practice nurses.

\subsection{Explanation of chapters}

This first chapter presented an introduction to the thesis and my reasons for choosing to undertake this research. It also portrayed the importance I placed in knowledge development, especially in the area of PHC and practice nursing in particular. The development of my thinking and the reasoning behind my choice of methodology and method were clarified, including how patients' life course is implicit in all nursing engagements. Writers who influenced my decisions and chosen terms were also introduced. 
Outlined in Chapter 2 is the background to the study. It examines the history and role of PHC and general practice, and describes practice nurse consultations and engagements with patients. The regulatory structure for practice nurses is explained followed by descriptions of the users of general practice and practice nurse services. Depictions of contrasting patient engagements with practice nurses are also portrayed. Questions arising from the examples conclude this chapter.

The purpose of Chapter 3 is to position gaps in knowledge of the practice nurse-patient relationship from patients' perspectives. From my nurse's lens, in four sections, it reviews nurse-patient literature examining selected nursing theorists. It includes an exploration of what is known and unknown about nurse-patient relationships generally, and in the general practice setting. The nature of well-being and White's (2010) three well-being dimensions is described, and the chapter concludes with an examination of life course theory and its place in this study.

Chapter 4 examines the positioning of my research approach to answer the study question. This includes a brief history of qualitative research, Narrative Inquiry, and story and narrative in nursing practice. I also discuss the interconnectedness of life course theory and patient-centred care. The background to my decisions to take a constructionist approach to the study, as well as McCormack's (2001) interpretative lens model for analysing narrative research are explored. The positioning of my research concludes this chapter.

The study setting, access to sites, sample selection, and data collection using narrative interviews are the focus of Chapter 5. The reflexivity section scrutinizes the insideroutsider conundrum in interviewing participants, especially those from my own practice. My method of data analysis identifies ethical considerations implicit in narrative research such as, consent and confidentiality, cultural safety, and professional boundaries. Issues of the trustworthiness of the analysis, and the study method are also addressed.

Chapter 6 introduces the participants and tells their life-stories of where they were in their life course and health and well-being pathways. The stories describe not only participants' relationships and engagements with practice nurses, but also their relationship with the general practice as a whole. 
The main research findings are presented in Chapter 7. The notion of the overarching presence of the higher-powered doctor, and of practice nurses 'filling a gap' provide an umbrella under which the themes of 'general practice activity,' 'health focused practice' and 'professional comfort' are identified. The findings related to practice nurses' 'skilled compassion,' and 'skilled companionship' (Campbell, 1984) are also examined. The awareness of symbiotic relationships existing between not only the doctor and the nurse, but also encompassing the patient and receptionist, are noted. Also emphasised, are the triaging activities of the receptionist, as well as the reasons participants chose a general practice.

The discussion in Chapter 8 reveals the significance of my findings in relation to participants' health and well-being. Throughout the chapter, commentary and literature are used to discuss how practice nurses filled the gap in the participants and patients' care. Also discussed is the evolution of the practice nurse role, and the influence of the receptionist when people choose a general practice or to consult a doctor or nurse on a particular occasion.

Chapter 9 concludes the thesis with reflections on the study and its contribution to patient care, knowledge and methodology. A critique and study limitations section is followed by implications for education, policy and future research. A summary of how the study findings fills a gap in the literature from patients' perspectives concludes the chapter. 


\section{Chapter 2 An overview of general practice and practice nursing}

\subsection{Introduction}

People engage with PHC professionals throughout their life course. Most people access health care via their general practice which provides, but is not limited to, GP and practice nurse services. To aid understanding of the delivery of PHC services and the role of practice nurses, this chapter describes PHC in New Zealand and compares it with Australia, Canada and the UK. My decision to include these countries arose not only because they belong to the Commonwealth of Nations sharing many similarities in PHC provision, and employ practice nurses, but because they also possess unique differences. Moreover, like New Zealand, Canada and Australia have indigenous populations.

Although the focus is on New Zealand, the direction of PHC and general practice in the four countries was examined. I trace the historical development, similarities and differences of funding approaches, roles of the general practice team and services they deliver. This includes the evolution of the practice nurse position, practice nurses' regulatory structures and competencies, and how, why and by whom they are employed. From my perspective as a practice nurse, I describe the nature of the nurse-patient relationship, tracing the different ages and stages in patients' life course. Examples of previous engagements I had with patients are included. Questions about what is known about these relationships and how they influence patients' lives and well-being are raised.

The chapter begins with a description of PHC, including a brief historical over-view of general practice. Regulations governing GPs, access to, and funding of general practice services, and the general practice team (GPs, practice nurses, practice managers, administrators and receptionists) are examined. The practice nurse role, and who general practice patients are, is described. Finally, stories of practice nurse-patient engagements from my perspective as a practice nurse are presented. Sources for this chapter include policy documents from the four countries, and personal communication with practice nurses, health care administrators and GPs.

\subsection{Primary health care}

Approximately 40 years ago, the World Health Organisation (WHO) Alma Ata conference on PHC (1978) declared that "primary health care is care that is accessible and affordable to individuals, the community and the country, with methods that are practical, 
scientifically sound and socially acceptable" (World Health Organisation, 1998, p. 3). The declaration urged governments to formulate national policies to incorporate PHC into their national health systems, and to place people at the centre of health care. This personcentred care was the paradigm shift in thinking that mobilised the PHC movement and led to a series of changes in health services internationally. Previously, health care was directed at correcting ill health, rather than at socially, economically and environmentally sound health maintenance policies. Person-centred care is perceived as being continuous, integrative and comprehensive, involving the participation of patients, families and communities (World Health Organisation, 2008).

Policy documents from the four countries describe the on-going PHC reforms, including the formation of primary health organisations, named Primary Health Organisations (PHO) in New Zealand, Primary Care Trusts (PCTs) in the UK, Medicare Locals in Australia, and Family Health Teams and PHOs in Canada, which are responsible for services in their local areas. These services encompass a broad range of health and preventative care, including health education, counselling, disease prevention and screening (Australian Government, 2010; Department of Health, 2011b; Health Canada, 2004; Ministry of Health, 2011c). The reforms include interprofessional health care models involving GPs, practice nurses, community nurses, midwives, dieticians, mental health and social workers, and other allied health professionals. In each country, people usually need to enrol with a PHO to receive free or subsidised care. After-hours care is typically provided by GPs, or in the case of emergencies, or unavailability of a GP, emergency departments (Department of Health, 2011a; Gauld, 2011; Harrison, Gregory, Mundle, \& Boyle, 2011; Ministry of Health, 2011e). Australia, Canada and New Zealand endeavour to provide culturally safe health programmes for their indigenous populations to help reduce health disparities, (Australian Government Department of Health and Ageing, 2011; Health Canada, 2006; Ministry of Health, 2008b). While oral health care is usually free to children under 18 in all the countries, only primary care in the UK funds high street optometrists.

To reduce the burden of disease in the community (WHO, 2008), the New Zealand government, through the Ministry of Health (MOH), launched the PHCS (King, 2001). This Strategy included the establishment of PHOs, setting a new direction and vision for PHC services. In New Zealand, the 31 PHOs are not for profit organisations responsible for providing care to their enrolled populations (Finlayson, Sheridan, Cumming, \& Fowler, 
2012). They are funded by 20 District Health Boards (DHBs) using a population based formula. PHOs support the provision of essential PHC through general practices and the community including iwi (defined as Māori tribe or kinship group), midwives and nongovernment organisations. This comprehensive PHC service is similar to that of the UK, Australia and Canada (Department of Health, 2011b; Health Canada, 2006; Phillips, 2010). Similarly, New Zealanders have access to 24 hour triage and health service through Healthline (Ministry of Health, 2012a). The Royal New Zealand Plunket Society through Plunketline provides a 24 hour service for parents and caregivers who request advice about their infants and children (Plunket, 2012).

Similar to what happened in the UK, Canada and Australia, the PHCS identified PHC nurses (PHCN) as being instrumental to the successful implementation of this Strategy. In New Zealand, PHCN is the umbrella term for nurses working in community-based settings and include, but not limited to, Plunket nurses, district nurses, hospice nurses, prison nurses, public health nurses, nurses working in occupational health or schools, practice nurses, Healthline nurses, sexual health and youth nurses, and mental health nurses (King, 2001). Primary health care nurses are mainly employed by general practices, GPs, Māori and Pacific providers, PHOs (McKinlay, 2006), Non-Governmental Organisations (NGOs), DHBs and the MOH. Practice nurses are the largest group of PHCNs $(n=3,751)$ (Nursing Council of New Zealand, 2011), with the majority working in the general practice environment (Ministry of Health, 2003c). In all four countries, general practice significantly underpins the health care system.

\subsection{General practice}

\subsubsection{Definition of general practice}

The work of general practice health professionals encompasses diagnosis and management of ill-health events, continuity of care, health promotion, illness prevention, and screening. With the exception of emergency care, access to secondary services in most countries is usually through a GP (London \& Saul, 2005). The availability of GPs has been reliably associated with improved health outcomes, with general practice often being the first point of contact for health services (Austin, 2003). Nurses were not present in the early development of general practice. 
Each country has its own definitions of general practice (Australian General Practice Training, 2012; Government of Alberta, 2011a; Royal College of General Practitioners, 2012), For New Zealand, the Royal New Zealand College of General Practitioners (2012) states that general practice is:

An academic and scientific discipline with its own educational content, research, evidence base and clinical activity. It is a clinical specialty orientated to PHC. It is a first level service that requires improving, maintaining, restoring and coordinating people's health. It focuses on patient needs and enhancing the network among local communities, other health and non-health agencies. (para 3)

Equally, general practices in New Zealand collaborate with other agencies such as hospital specialists, hospital outpatient and emergency departments, hospital and independent pharmacists, optometrists, chiropodists, physiotherapists and some alternative health services, Māori Health providers, mental and physical health and disability support services, and care givers. In addition to government funding and patient co-payments, general practice services are also sometimes funded by the Accident Compensation Corporation (ACC) scheme (see Glossary) and other accident insurance companies. Other links involve the community, family/whanau, and other GPs (Ministry of Health, 2011b).

\subsubsection{History of general practice}

Over time, the character of general practice has changed. In the UK, although there had been progress in training doctors and changes in regulations relating to who could practice medicine, it was not until 1913 that GPs became responsible for providing PHC within a national system funded by the state. Previously, medical care was financed through insurance schemes for people working in named industries, but not their dependents. In 1946, the National Health Service (NHS) Act defined the structure of the NHS (Simon, 2009). However, concerns around training, work and payment of GPs continued, and remains an issue for many doctors. General practice was relatively autonomous until the 1990s when government health reforms emphasised the need for high quality service that was accessible, flexible and efficient (Charles-Jones, Latimer, \& May, 2003) leading to the formation of PCTs. However, with increasing economic pressures, the UK government introduced the Health and Social Care Act, 2012, that presented substantial changes to the way the National Health Service was to be organised. The way primary health care could 
be funded may possibly lead to GPs charging for their services (Campbell, 2013; Nuffieldtrust, 2013; The King's Fund, 2013; Williams, 2013).

In 1914 in Canada, most graduating doctors took work in private practice as GPs. In remote areas, GPs were on-call, working 24 hours per day, seven days per week. Although poorly paid, GPs were expected to gain personal, psychological satisfaction from the person-centred doctor-patient relationship. The insurance based Medicare system was gradually introduced through all the States from the late 1960s (Canadian Museum of Civilization Corporation, 2010) relieving some of the work and financial pressure.

For Australians, the concept of a GP arrived with the first settlers (Bollen \& Saltman, 2000). However, the discipline of general practice is more recent; it is closely linked to health insurance and the development of the government supported Medicare Insurance scheme. Similar to Canada, prior to the 1950s, graduating doctors spent a number of years in community-based general practices. In 1953, the Royal College of General Practitioners (RCGP) was formed, emphasising that GPs belonged to a specialist group with equal status with other specialities such as surgeons (Bollen \& Saltman). Although not verified by literature, the arrival of doctors in New Zealand probably followed a similar path to Australia. In New Zealand in the early part of the last century, nearly all doctors were generalists (McWhinney, 1998). In the mid 20 ${ }^{\text {th }}$ century generalist practice emerged as a vocational discipline of family medicine (Pullon, 2008b). Like Australia, this specialist group initially belonged to the British Royal College of General Practitioners, but by 1979, it had gained independence from this group and became the Royal New Zealand College of General Practitioners (Royal New Zealand College of General Practitioners, 2013).

Continuing disputes between governments and the medical profession, between 1938 and 1983, the New Zealand health system developed as a dual arrangement of public and private provision (Marshall, 2003; New Zealand Parliament, 2009; Quin, 2009). However, escalating health expenditure and health service inequities became a source of concern to governments and the health sector. In 1941, the General Medical Services (GMS) scheme was introduced, with government subsidies for GP visits. Over time, the subsidy did not keep up with inflation and GPs supplemented their incomes by user co-payments, resulting in increased fees for patients and creating further health care inequalities (Quin). A series of reviews (The Barrowclough Committee, 1953; The Department of Health Review, 1969; 
The Royal Commission on Social Security, 1972; and A Health Service for New Zealand, 1975) highlighted the problem of health service funding (New Zealand Parliament, 2009). Despite these reviews, GPs continued to be independent providers with no direct contract with the government into the 1980s. Although hospital care was free of monetary charge, consulting a GP was not, and many people chose to use the hospital system for primary care (Quin). Using the hospital was also influenced by GPs, reducing the hours they worked in evenings and weekends. While most GPs continue to work in private practice, they might also work for Māori health providers or community governed providers (Crengle, 2004) such as the Newtown Union Health Service in Wellington (Coppell, 2010).

Most general practices in New Zealand are small, with a mean of three GPs and median of one GP (Raymont \& Cumming, 2009). Hence, they resemble families rather than teams in large organisations, with human relationships shaping the practice environment (Finlayson \& Raymont, 2012). There is increasing acknowledgement that by amalgamating with other practices, not only the cost of administering the practices may be reduced using different general practice business and funding models, but also, there is increased collegial support for doctors (Pullon, 2008b). While most general practices continue to be private businesses, owned and governed by GPs who employ the nursing, reception and administrative staff, an increasing number of GPs work from practices owned by nurses, trusts, communities, or by DHBs (Pullon) and PHOs. Some general practice companies have bought practices, taking over the management role. For example, the West Coast DHB owns several practices (Topham-Kindley, 2010), and Nelson Bays PHO also owns practices (M. Gibbs, [PHO general practice regional facilitator] personal communication, February 3, 2012). In response to the reluctance of doctors to buy practices, and the increasing administration burden, there is a tendency for a sole practice manager to manage several practices with the assistance of the practices' administrative staff. This administrative and financial liability has also seen an increase in practice amalgamations (Gibbs).

\subsubsection{Access and funding general practice services}

Through NHS funding, the UK is the only country where PHC is currently free to patients, even to those who are not UK residents (Avert International HIV \& AIDS Charity, 2012). In Australia, the Federal Government funds and administers the national health insurance 
scheme (Medicare National Subsidy Scheme). Through this system, the eight states and territories are autonomous, administering health services to their populations subject to funding agreements (The Commonwealth Fund, 2012). The level of a state's contribution depends on people's ability to pay (Expatforum.com, 2012). Australian citizens and permanent residents, as well as visitors and people on temporary visas from countries that have reciprocal arrangements with Australia, are covered by Medicare (The Commonwealth Fund). Canada also has fee-for-service and health insurance plans (Makarenko, 2010). To be eligible for public insurance plans people must be a resident of the country, but each province and territory is responsible for establishing its own specific residency requirements (Healy \& Hall, 2011; The Commonwealth Fund). In contrast, New Zealand PHC is funded by a partial capitated and some fee-for-service payment from the state for consultations and pharmaceuticals. Capitation funding to PHOs subsidises the cost of people's consultations in general practice but these are supplemented by substantial copayments from patients (The Commonwealth Fund, 2012). In addition to capitated funding, the $\mathrm{MOH}$ has initiated a number of services to improve management of chronic diseases and extend innovative PHC nursing care services, attracting additional funding (Cumming, Mays, \& Gribben, 2008; Finlayson, et al., 2012). However, although there has been some targeting for people on low incomes or have high health needs, there continues to be inequalities in accessing health care. People with lower incomes and Māori often do not access health services as often as might be expected (The Commonwealth Fund).

Although people usually access general practice through the funded schemes, they may also access general practice services privately (BUPA United Kingdom, 2012; Find Private Clinics.ca, 2012; General Practice Australia, 2010; New Zealandnow.govt.nz, 2012). Access to private health care insurance and services are available for those people who choose to pay the premiums. In New Zealand, people who have private health insurance are also eligible for public health care (New Zealandnow.govt.nz). Some general practices receive PHO funding to provide low cost access for patients allowing all enrolled patients to be charged low co-payments by general practices, or access free care (Finlayson, et al., 2012). However, there are conditions and restraints around which general practices might apply for this funding. Eligibility criteria for the Very Low Cost Access payments are limited to PHOs and practices currently charging, or prepared to reduce, their fees for standard consultations to the specific thresholds: 
Zero fees for children 0-5 years, $\$ 11.50$ maximum for children 6-17 years, $\$ 17.00$ maximum for all adults 18 years and over. New practices to the programme must meet the eligibility criteria of $50 \%$ high needs population (defined as Māori, Pacific or New Zealand Deprivation Index quintile 5). (Ministry of Health, 2011d). (para. 3)

Additional funding is provided for rural services (Cumming, et al., 2008). The definition of rural and remote populations is difficult to class and varies between countries. In New Zealand, the seven areas in the Urban/Rural Profile are:

Highly Rural/Remote Areas, Rural Area with Low Urban Influence, Independent Urban Area, Rural Area with Moderate Urban Influence, Rural Area with High Urban Influence, Satellite Urban Community, Main Urban Area. Highly Rural/Remote Areas contain 48.4 percent of New Zealand's land area, are home to 1.6 percent of the population, have a population density of 0.5 people per square kilometre, are rural areas where there is minimal dependence on urban area in terms of employment, or where there is a very small employed population. Rural areas with Low Urban Influence contain 35.8 percent of NZ's land area are home to 5.5 percent of the population, have a population density of 2.3 people per square kilometre, are defined as areas with a strong rural focus in which the majority of the population in these areas works in a rural area, are areas where it is unlikely that many people living in these areas are employed in a main urban area, although some may work in a minor urban area. (National Health Committee, 2010, p. 101)

While it closed in 2002, the Centre for Rural Health provided training for nurses and doctors working in rural areas. In 2013, this training was provided by postgraduate programmes run by universities and polytechnics in New Zealand. To address the health needs of people living in rural areas, the Rural Innovation Fund (RIF) was set up by the $\mathrm{MOH}$ in 2007 to assist and support rural health practices in delivering effective services and programmes. PHC providers such as GPs, nurses, midwives, dentists, pharmacists and allied health professionals may apply for funding to support projects that benefit patients in their communities (Ministry of Health, 2012b). The ACC and the MOH fund St John Ambulance to provide the Primary Response in Medical Emergency (PRIME) programme. This programme offers training in medical emergencies for doctors and nurses working in 
rural areas. There were 297 registered nurses working in rural areas (Nursing Council of New Zealand, 2011).

Taking into account the Australian geography, demography, remoteness and isolation of their localities, the Dedicated Rural Primary Health Services (RPHS) programme aims to improve access to a range of primary and allied health care services and activities for rural and remote communities. A programme is also dedicated to Aboriginal and Torres Strait Islander Health (Australian Government Department of Health and Ageing, 2010). In the UK, notably Scotland and Wales, frameworks to deliver health care to rural and remote areas are implemented (Llywodraeth Cymru Welsh Government, 2011; Remote and Rural Steering Group, 2007). For people in remote locations in Canada, the government has increased funding to augment the care provided by nurses to people in remote and rural areas, including First Nation and Inuit people (Health Canada, 2012).

\subsection{General practitioners}

Historically, the concept of a family doctor was of a GP who owned, and remained, at the one practice for most of his or her career, caring for families throughout their life course. Due to the chronic shortage of GPs, this longitudinal concept of GP care has changed (Woodroffe, 2006). Although the structure of the health system is altering the face of general practice, continuity of care and personal service continue to be perceived as values to maintain (Ross \& Kenrick, 2011). However, there are emerging trends for GPs to work part-time, out-source after-hours care, and, especially in larger practices, doctors are less likely to become practice owners. These changes make it increasingly difficult for patients to see the same doctor or nurse. In rural areas where the retaining and recruiting of GPs is especially problematic, registered nurses are increasingly being used to take on more of the traditional work of GPs such as chronic conditions management (Goodyear-Smith \& Janes, 2008; Woodroffe, 2006). Shortages of GPs in rural areas are also found in the UK (especially Scotland), and Australia and Canada where the distances from health services are much greater than in New Zealand and the UK. To address GP shortages, overseastrained permanent and locum doctors are recruited to work in New Zealand on limited term contracts (Kearns, Myers, Adair, Coster, \& Coster, 2006).

In all four countries, GPs provide a broad range of health and preventative services, including health education, counselling, disease prevention and screening (Ministry of 
Health, 2011c). GPs usually act as team leaders who may designate certain roles and activities to other team members, for example, nurses and receptionists. However, doctors can practise as GPs without specialist qualifications in general practice or primary health care (C. Trewavas, practice manager, personal communication, June 3, 2010). To consult the GP, patients commonly make appointments via receptionists. While GPs take:

'ultimate responsibility' for those decisions with the patient...This does not preclude the responsibility that everyone has for their actions, or detract from the professionalism of others in the team, but it is an acknowledgment that there has to be a final arbiter of care, and it is in the course of natural justice that this role should be undertaken by the most qualified person in the team. (Scott-Jones, 2009, p. 6)

To maintain health and safety standards, government statutory frameworks regulate health professionals in all four countries. Nursing and medical councils set standards of practice to which doctors and nurses must meet (Australian Medical Council, 2012; General Medical Council, 2012; Medical Council of Canada, 2012; Medical Council of New Zealand, 2011; Nursing Council of New Zealand, 2009). These countries' primary health organisations also have clinical governance frameworks that direct the provision of primary health care within the community. In New Zealand, PHOs develop their own clinical governance framework to suit the needs of the community, at the same time meeting the requirements of the PHO Performance Management Programme. This programme includes the clinical effectiveness, quality assurance, provider education and development, clinical audit and continuing quality improvement, risk management, and research and development (Kane, 2005).

\subsection{Practice nurses}

The role of practice nurses in the four countries has become increasingly specialised. In some New Zealand practices, this has led to the employment of second level nurses (Enrolled Nurses) who undertake the more traditional tasks such as blood pressure checks, electrocardiograms, and wound care. The employment of enrolled nurses releases practice nurses to continue to up-skill, facilitating more effective and efficient care (Allard, Frego, Katz, \& Halas, 2010; Woodward, 2006). The employment of health care assistants (HCA) also benefit patients by freeing up doctors, nurses' and managers' time (Health Workforce New Zealand, 2011). 


\subsubsection{History of practice nursing}

Following the 1965 GP Charter, nurses in the UK entered general practices to assist GPs with treatment room tasks (Roscoe, 2012) including many non-nursing tasks. The following story from a UK practice nurse describes the early practice nurse role and is similar to practice nurses' experiences in the other countries:

I started practice nursing back in 1969 when my GP asked me if I would work with him in a new surgery he was building. Previously the surgery was held in a room in his house; quite the norm back then! I didn't know of the existence of any other doctor's nurses until I went on a newly established course for practice nurses in 1989. At that time, nobody else worked in the surgery apart from the sole GP and me. We were a dispensing country practice; prescriptions were all handwritten; I made up tonics, lotions and potions; counted out pills into bottles which bore handwritten labels - dispensed and labelled by me. I greeted every patient that walked through the door - no appointments then. We carried on until the last one had been seen. I got the notes out and filed them away at the end of surgery; took all the phone calls, arranged the visits - "put them on the list and I will go and visit" was the doctor's way of dealing with them. I ordered drugs from the wholesaler, I chaperoned whenever needed, administered vaccines to babies and adults, performed blood pressure checks, assisted in minor ops, did dressings and helped with antenatal checks. I cut up rolls of gauze to make dressing squares; these were kept in piles in a clean draw as were the cotton-wool balls made from cotton-wool. All socially clean! All vaccines were kept on the shelf - no refrigerator. The smallpox vaccine did go home with the GP at the end of the day to go into his fridge. If one blood sample a week was taken that was unusual, and I had to wrap the bottle in cotton-wool, find a suitable box, wrap it up and take it to the Post Office to be sent to the laboratory at the hospital 25 miles away. We had a brilliant working relationship and I loved every minute of it, to the extent that I had one week's holiday a year. I was paid cash-in-hand each week, depending on what the GP thought was appropriate! How different things are today. (Practicenursing.co.UK discussion site, personal communication, March 21, 2012)

The first published study of practice nurses' work in the UK was in 1976 when two GPs with a practice population of 5,500 consisting of both rural and urban patients, employed a 
nurse to triage calls, provide first visits (after discussion with doctor), give immunisations, assist at antenatal clinics, and routinely visit older and disabled patients (Smith \& Mottram, 1976). The nurse needed wide experience, preferably hospital outpatients, and to be able to drive a car. Doctors gave nurses comprehensive instructions about what to do in any given situation. Nurses utilised in this way were viewed positively by the patients and by doctors: Provided a nurse with the right temperament and extensive clinical experience is obtained, and suitable safeguards are used, we think that she can be used for making first visits to patients, and the replies to a questionnaire sent to the patients showed that most patients agreed and welcomed the scheme. (Smith \& Mottram, p. 764)

To assist the rural GP and help with rural GP retention problems, in New Zealand, practice nurses have been employed by GPs since 1969 (Docherty, 1996; Hounsell, 2000). Without consultation with nursing organisations, this change occurred following an approach to the government by the then New Zealand Division of the British College of General Practitioners, now Royal New Zealand College of General Practitioners (RNZCGP), to employ registered nurses to assist GPs, and for clerical duties. Doctors were permitted to charge patients for nursing services (O'Connor, 2009). However, following the 1970 introduction of the Practice Nurse Subsidy Scheme (PNSS), the Medical Association of New Zealand recommended that its members who took advantage of the scheme should not charge patients a fee for services provided solely by the nurse (McLennan, 1983). Although this was the beginning of the practice nurse role in New Zealand, a large number of nurses were not given any specific training for their job, and few engaged in in-service education (O'Connor). Consequently, practice nurses were often professionally isolated and under pressure to undertake work they were not trained for (Hounsell, 2000).

The PNSS initially paid 50\% of the rural, but not urban practice nurses' salaries. In 1974, this was increased to $100 \%$ and was offered to both rural and urban practices under certain conditions (McLennan, 1983). The extension of the subsidy led to a corresponding increase in the number of practice nurses employed in urban as well as rural practices (Hounsell, 2000). However, over time, this subsidy was reduced to $50 \%$, and with the government changes in the provision of PHC in 2001, the PNSS was added to the capitated practice funding (Ministry of Health, 2007a). This rendered it invisible to employers and nurses. Despite the change, practice nurses were still paid via the GP. 
Although the role of the practice nurse had significantly evolved in the four countries, it continues to be characterised by its unique inter-professional relationship with the GP (Docherty, 1996; Keleher, Joyce, Parker, \& Piterman, 2007; McKinlay, 2006). The PHCS (King, 2001) stated that nurses were "crucial" to its successful implementation, but neither funding or employment structures were changed to enable nurses to respond to the challenges (Minto, 2006). Nevertheless, there was an increasing degree of autonomy for practice nurses in New Zealand. This was evidenced by the number of nurse-only consultations reported by the 2006/07 National Health Survey (Ministry of Health, 2008b). In 2002/03 the proportion of consultations by men who saw a PHC nurse only, in the previous 12 months was $12.0 \%$ rising to $20.7 \%$ in 2006/07. For women, in 2002/03 the number was $18.8 \%$ rising to $33.5 \%$ in $2006 / 07$.

Even though there was gradual development of the practice nurse role in the four countries, it was not until a shift in focus to primary care disease prevention and health promotion in the 1990s, that the number of practice nurses increased and their role expanded. This was due to the recognition of their positive impact on the delivery of health care (Woodward, 2006). In 2001, the Australian Government introduced the Nursing in General Practice Initiative to provide support to general practitioners in rural and remote communities in order for them to employ practice nurses (Keleher, et al., 2007; Price, 2007). In the UK, following the new General Medical Services (GMS) contract in 2004, new payments to GPs for services such as health promotion, chronic disease management and other targeted payments, practice nursing became one of the fastest growing fields of nursing, not only in the number of nurses, but the scope of work they engaged in (Gemmell, Campbell, Hann, \& Sibbald, 2009; Woodward). Following a similar process, but less clearly defined, the roles of Australian practice nurses were influenced by the personal characteristics of the nurse, the practice patient population, the business model of the practice, and the manner in which, nationally, the health system was provided (Halcomb, Patterson, \& Davidson, 2006; Keleher, et al., 2007). In all four countries, practice nurses have diverse roles, often forging their own unique responsibilities where they worked (Watts, et al., 2004). Most nurses consider themselves responsible for developing their role within the primary care team (Eve, Hodgkin, Quinney, \& Waller, 2000). However, UK practice nurses are utilised to a greater extent and provide a wider breadth of care, compared to nurses in Australia and New Zealand (Hoare, Mills, \& Francis, 2012). In Australia, practice nurses are generally 
limited to traditional nursing tasks and assisting the GP (Halcomb, et al., 2006), whereas, in New Zealand and the UK, practice nurses undertake chronic disease management that was previously carried out by GPs (Stewart, Dyas, Brown, \& Kendrick, 2006). In Canada, this role is more likely to be undertaken by nurse practitioners (NP) rather than the practice generalist registered nurses (Allard, et al., 2010). In New Zealand, programmes such as Care Plus and Healthy Lifestyle (see Glossary) that target people with chronic conditions, are increasingly run via nurse-led clinics (Rodenburg, Dryden, \& Rodrigo, 2007). Such nurse clinics represent a key change for practice nursing and Chronic Conditions Management (CCM) fits within the nursing role. This nursing input is highly valued by patients (Finlayson, Sheridan, \& Cumming, 2009). Although registered nurses have been employed in Canadian general family practices for many decades, there continued to be no nationally defined role. However, to help address this issue, in 1982 the first Family Practice Nurse conference was held, leading to nurses forming family practice nursing associations (Canadian Family Practice Nurses Association, 2011). Nevertheless, nurses continued to experience constraints in their abilities to fully utilise their skills (Allard et al.).

\subsubsection{Practice nursing in the $21^{\text {st }}$ century}

In the UK (Royal College of Nursing, 2012), Australia (Australian Government Department of Health and Ageing, 2012), Canada (Government of Alberta, 2011b) and New Zealand, practice nurses offer services such as health advice, immunisation, cancer and sexual health screening, chronic conditions management, wound and ear care, and counselling (McKinlay, 2006). Six roles of practice nurses identified by Phillips et al. (2009) include patient carer, organiser, quality controller, problem solver, educator and agent of connectivity. Many of these roles include patient teaching which is a significant part of the highly trained practice nurses' work (Heaphy, 2007). Nurses also liaise with hospital specialists, PHC nurses, such as sexual health nurses, district nurses and outreach nurses, pharmacists and other allied health professionals and organisations. Practice nurses are often responsible for maintaining recall registers for services such as immunisation, breast and cervical screening, and annual diabetes checks (Minto, 2004). However, there is no national consistency of how many of these services are provided, and all practice nurses do not necessarily deliver each service. Some nurses also continue to report undertaking a range of non-nursing activities (Allard, et al., 2010; Mills \& Fitzgerald, 2008; Yerrell \& Reed, 1997) that usually occur in mainly small practices where the employment situation 
and structure of the practice is not easily changed. Triaging patients whom receptionists directed to practice nurses is also a significant responsibility for practice nurses (CharlesJones, et al., 2003; Fyers, 2008). Practice nurse experience in the UK, Canada and Australia (Allard, et al., 2010; Mills \& Fitzgerald, 2008; Watts, et al., 2004; Yerrell \& Reed, 1997) is consistent with the findings of McKinlay (2006) and Hefford et al. (2010). Hefford et al. carried out a practice nurse cost-benefit analysis for the New Zealand MOH. Their findings confirm that actual nursing roles in primary care vary markedly between practices, between nurse consults, and the breadth of role. Moreover, while many practices manage their nurses efficiently, other practices are reluctant to change (Finlayson et al., 2009.

Consistent with the UK, Australia and Canada (Allard, et al., 2010; Hoare, et al., 2012), practice nurse education in New Zealand has evolved from local practice nurse committees organising their own education sessions, to seminars and courses provided by pharmaceutical companies and Independent Practitioner Associations (IPAs), DHBs, PHOs. Other health-focused groups such as the Family Planning Association, Cancer Society, Immunisation Advisory Centre and tertiary education providers also contribute to education opportunities for nurses. These courses provide practice nurses with certification of their professional development. Notwithstanding, educational funding, support and opportunities vary between practices and between regions, and paid time within and after working hours to attend these sessions, is often limited. While there is contestable Health Workforce New Zealand funding awarded to nurses to assist them achieve postgraduate qualifications up to Masters level in areas such as diabetes, and chronic conditions management (Nelson Marlborough District Health Board, 2011), there is no commitment to guarantee financial support for practice nurses postgraduate study pathways. Employer support and encouragement for practice nurses to gain Practice Nurse Accreditation (now called PHC Nurses Professional Development and Recognition Programme [PDRP]) demonstrating their ongoing commitment to improving patient care, also remains inconsistent (D. Auld, [practice nurse] personal communication, September 27, 2012).

In Jack's (2002) opinion, the strength of practice nursing lies in the holistic way in which patients are treated, with care based on research rather than the ritualistic undertaking of tasks allocated by the GP. Nurses have worked long and hard to assert themselves as a distinct speciality within PHC and change the perception of being "hand maidens of the 
GP” (Jack, p. 18). However, literature from all four countries describe practice nurses relying on years of experience and accumulated knowledge, with no connection to a national PHC nursing framework requiring specific qualifications (Docherty, Sheridan, \& Kenealy, 2008; Meadley, Conway, \& McMillan, 2004). This lack of a national framework and standard means that the work of practice nurses is not easily understood or measured by other health professionals, managers or governments (Minto, 2004). Practice nurses have attempted to meaningfully contribute to PHC by undertaking further study, and offering nurse-led clinics, but a lack of clear articulation of their role has created contradictions in their scope of practice in the workplace (Allard, et al., 2010; Mills \& Fitzgerald, 2008; Minto, 2004; Yerrell \& Reed, 1997). In New Zealand, nurses who have taken advantage of the funding provided by the $\mathrm{MOH}$ to advance their nursing qualifications are often constrained by their employment situation and PHO environment (Docherty, et al., 2008; McKinlay, 2006). Aligned with the UK (Woodward, 2006) and Australia (Halcomb, et al., 2006), key barriers to the expansion of the nursing role have been:

Employer-employee relationship between GPs and practice nurses, GP's attitudes, lack of support and motivation from GPs, the current funding structures, poor remuneration, heavy workloads, lack of educational opportunities, lack of leadership, lack of physical resources, and patients not recognising the nurses as autonomous health professionals. (Finlayson, et al., 2009, p. 61)

Despite these adversities, a few practice nurses have become general practice partners, practice managers, or sit on PHO Boards of Governance. While there continues to be significant management inequalities in their attempts to promote their knowledge and skills, it is a choice that many nurses have made (Finlayson, et al., 2009; Roscoe, 2012; Woodward, 2006). Even though some practice nurses become nurse prescribers (Woodward), nurse prescribing practises vary between countries. However, although practice nurses may not be certified prescribers, they may administer medicines for named conditions under 'standing orders' (Ministry of Health, 2012c) These formalised, written GP directives facilitate and direct practice nurse treatment and management pathways. "Standing orders provide a safe and effective method of extending the role of practice nurses and increasing access to services for patients" (Scott-Jones \& Lawrenson, 2008, p. 110). In the UK, this method is known as 'patient group directions.' 


\subsubsection{Regulatory framework}

The primary concern of practice nurses in the four countries is the safety of the public. To maintain standards of practice, UK nurses are regulated by the Nursing and Midwifery Order 2001 (Legislation.govt.UK., 2002). Australian nurses are controlled by their nursing and midwifery board and supported by the Australian Health Practitioner Regulation Agency 2009 (Australian Nursing and Midwifery Board (ANMB) \& Australian Health Practitioner Regulation Agency (AHPRA), 2012). Canadian registered nurses are regulated by the Health Professions Act 2005 and the College of Registered Nurses. The Nursing Council of New Zealand (NZNC) is presently the statutory body which administers nursing practice in New Zealand by setting and monitoring standards of practice in the interests of the public and the profession.

In 2004, legislation governing the NZNC changed from the Nursing Act 1997 to the Health Practitioners Competence Assurance Act 2003 (HPCAA). Mechanisms in the HPCAA are designed to ensure that all health practitioners are competent and fit to practise their professions for the duration of their professional lives (Ministry of Health, 2003a). All four countries have similar statements relating to nurse accountability. For example, in the UK:

Nurses and midwives hold a position of responsibility and other people rely on them. They are professionally accountable to the NMC, as well as having a contractual accountability to their employer and are accountable to the law for their actions. (Nursing and Midwifery Council, 2009, para 2)

\subsubsection{Employment and funding}

In all four countries, nurses are usually directly employed and paid by GPs. Australian and New Zealand practice nurses may also be independently contracted, or work under a combination of both (Australian Government Department of Health and Ageing 2012); R. Boizard [GP], personal communication, October 10, 2010; M. McElhinney [practice nurse], personal communication, December 5, 2010). In both these countries, general practices receive additional government or publicly funded payments or subsidies for specific tasks provided by the nurse (see Section 2.3.3) to which patients may also make a co-payment. While New Zealand nurses and GPs deem nurses to be 'providers' of these services, this is seldom reflected in the financial or auditing framework of general practice 
(Minto, 2004). With the introduction of updated computer technology $y^{3}$ and knowledgeable administrators, it should be possible to track much of the income generated by practice nurses. However, this income continues to be paid to the practice and GP, rather than the nurse (Boyd \& Clark, 2006; New Zealand Nurses Organisation \& College of Nurses Aotearoa (NZ), 2007).

\subsection{Practice managers, administrators and medical receptionists}

Well-trained and well-organised practice managers are crucial to the success of any general practice and practice managers need to be "recognised as fully fledged health professionals in primary health care" (Pullon, 2008b, p. 303). Like Australia, Canada and the UK, in New Zealand some small practices with one or two GPs, practice managers might undertake both receptionist and administration responsibilities. However, with the increasing trend to larger practices, their role has evolved to include overall day-to-day management, leadership and operational expertise to the practice including oversight of Practice Management Systems. Their work necessitates balancing tensions between public funding versus private enterprise, and governmental influence and funding compliance (Practice Managers and Administrators New Zealand, 2011).

The role of the receptionist is particularly important for patients' access to, and their interactions with, general practice (Proudfoot, et al., 2007). Medical receptionists act as an access point to general practice and are generally the public face, and gate-keepers of, a practice. Receptionists manage the patient appointment procedures and collection of any consultation fee. They may also engage with pharmacists, hospital administrators, specialists, ambulance service, police, and other health care providers.

\subsection{General practice patients}

General practice patients comprise of people from a diverse range of cultures, ethnicities and ages and stages in their individual life course; from the very young to the very elderly; the healthy to the very ill. People's utilisation of general practice services may be selfdirected, initiated by the practice, or organised to meet governmental and PHO health targets. The most common reason people visit a GP is for short-term illness, followed by routine check-up or advice (Ministry of Health, 2008a). In New Zealand, some practices,

\footnotetext{
${ }^{3}$ New Zealand has one of the world's highest rates of information technology (IT) use among primary care physicians (The Commonwealth Fund, 2012).
} 
especially those with higher deprivation indexes, have increased numbers of people with greater health needs (Ministry of Health). People with chronic conditions such as diabetes, cardiovascular and respiratory conditions engage with general practice services more often than those who attend for health promotion and health maintenance. Women are more likely to access general practice services than men, but ethnicity and the severity of a problem contribute significantly to explaining women's, but not men's, utilisation of GPs (Jatrana \& Crampton, 2009).

\subsection{Practice nurse engagements and relationships with patients}

In all four countries, the usual form of practice nurses work with patients is one-to-one, face-to-face, with scheduled and non-scheduled consultations. The length of a consultation is customarily determined by the purpose of the visit. A significant aspect of practice nurses' work is engaging with patients via the telephone. In New Zealand, nurses regularly contact patients by land-line, cell-phone and text messaging systems, while letters are sent to people not able to be contacted by these means. Reasons for these calls include supporting someone to give up smoking, providing a lifestyle consultation, checking on children who have been immunised, or patients recently discharged from hospital, and following up bereaved families. Increasingly, the development and use of information technology continues to facilitate patient access to the practice and practice nurses. Telephone consultations can include patients asking for health advice, and people requesting results of tests, with discussion of any possible follow-up. Nurses triage telephone calls for those patients who require advice for problems such as chest pain, earache, an accident, or influenza type symptoms. Triage is perceived by practice nurses as providing expert assessments, enabling patients to access the most appropriate care (Charles-Jones, et al., 2003). All relevant calls and actions should be routinely documented in patients' clinical records. In smaller practices, such as the one in which I worked, or practices with one or two practice nurses, there are occasions when telephone calls are planned, reducing conflict with patient consultations. In larger practices with a number of practice nurses, interruptions are less problematic (E. O’Donnell [practice nurse], personal communication, June 6, 2010); D. Auld [practice nurse] December 5, 2010). Nurses in these practices often have designated roles such as 'triage nurse' who receives all patient related telephone, cell-phone and email enquiries, or 'clinical nurse' who engages with patients for chronic conditions management for example. These roles are usually rotated. 


\subsubsection{Engagements and relationships with patients from my practice nurse perspective}

Working as a practice nurse, I was in a position to care for people of many cultures and ethnicities. I engaged with, and observed, the health and well-being of people throughout their life course ages and stages and health pathways. To illustrate practice nurse-patient relationships and engagements, the remainder of this chapter presents stories from my practice. These accounts range from brief, one-off encounters, where I would be unlikely to meet the person again, to long-term, on-going relationships, where I regularly engaged with patients.

Brief encounters may occur when patients arrive at the practice on the off-chance the practice nurse has time to see them. Reasons for such encounters include routine vitamin b12 injections, requests to check their blood pressure because they have a headache, the doctor told them to "pop in" for the nurse to monitor a change in their medication, or because they have a minor wound requiring a small dressing. On other occasions, the receptionist may refer a patient who has unexpectedly become unwell, and wants to know if they need to see the doctor, to the nurse for assessment. Often there are tourists requesting a repeat prescription.

The following short sketches of exemplary practice draw out my experience of relational engagements that I believe contributed to patients' health and well-being. While the stories I chose to describe my practice and relationships with patients are mine, they were specifically selected to reveal the intricacies of the engagements, including the concepts of intuition and sensitivity. The selections were informed through discussions with my practice nurse colleagues and peers at peer review meetings and seminars, and what they revealed about experiences of their relationships and engagements with patients. The stories, written in 2009 as part of a reflection exercise to inform my practice, correspond with my belief that these narratives are universally familiar to other practice nurses. In writing these stories, identifying features were removed and each patient given a pseudonym. None of these patients were research participants.

\subsubsection{Brief encounter story}

Holly was a young woman, a visitor to the practice, and unknown to me. She had scheduled a practice nurse appointment. Although the receptionist may indicate on the computer screen the reason for a consultation, on this occasion I had no prior knowledge of 
the cause of her visit. Observing her as I walked into the waiting room, Holly appeared nervous, did not smile, and looked away when I invited her, by name, to come to my consulting room. After smiling and introducing myself, I asked the reason for her visit and how I could help her. She told me she was due for her contraceptive injection, showing me the card with that day's date. I began the clinical process of enquiring the length of time she had been using this type of contraception and if she experienced any problems associated with it. Reporting no issues, I proceeded to gain her informed consent for the injection. After taking her blood pressure and relaying the result to her, I showed her the label on the prefilled syringe, ensuring we both knew I was giving her the correct injection. Preferring to stand rather than lay down, she promptly exposed her hip and part of her buttock, which, after establishing the correct site, I gave the injection. As we chatted about her travels and where her next stop was, I took the opportunity to ask her if there was anything more I could help her with, such as a cervical smear, if it were due. I also established that she felt safe with her travelling companions. Following the usual after injection advice, I wrote the next due date for the injection on a card and gave it to her. The length of this encounter was 10 minutes, and I have not seen her again.

Reviewing her clinical record, I found that it did not reveal anything other than the recording of the clinical details such as consent for the injection gained, details of the injection and site, the next due date, and she felt safe in her relationships. Reflecting on this encounter, I was unable to recall clearly what was said or expressed, but some of what was revealed in the above summary is crucial to nurses' work. For example, I gained the impression from her demeanour, lack of eye contact, reticent and depersonalised answers to my questions that she was reluctant to come to an unfamiliar practice nurse if there was another way of getting her needs met. Further, I sensitively understood that Holly wanted to 'keep to herself,' retaining her emotional disconnection from me.

\subsubsection{Relationship over time story}

I have known April and her children, two almost grown-up young men and a younger girl, for a number of years. Morbidly obese, health and social difficulties have resulted in April accessing governmental financial support. April presented as a pleasant, outgoing, loquacious person who informed me of her desire to lose weight, eat healthily and exercise each day. However, over time, I became cognisant not only of her shyness, but that interacting with people outside her small social group was very difficult for her. April was 
a 'giving' person, and I knew from earlier visits, that members of her family and their friends had relied on her for accommodation and transport. She also opened her home to extended family and friends who sometimes lived with her for periods of time. While April wanted to achieve her goals, she found there were other life issues that took priority.

Over the years, I had contemplated what assistance I could give April, or how I could encourage her. Nothing that we planned in partnership had resulted in any noticeable difference. Even the thought of joining a casual walking group of four to six people with varied abilities, led by a person she knew, and a distance that would be achievable, appeared too intimidating for April. On one occasion, during a routine Care Plus consultation, I needed to leave the room for a short period. On my return, I found her reading my Accreditation with Expert Endorsement Certificate. "I agree with that," April commented. Asking for clarification, she remarked that she always felt better after she had seen me, and that I was easy to talk to. She found talking about her troubles helped her, and she appreciated the ideas and strategies I suggested she could try to help her achieve the changes she wanted. My non-judgemental encouragement was motivating for her, and I did not "tell her off like some nurses did."

Given that people have control over their own actions, as a nurse, one of the tensions in nurse-patient relationships is that, for some people it is very difficult to prioritise their actions. Commonly, there are reasons other life events take precedence. Reflecting on this consultation brought several issues to the surface. Even though I believed that the visit did not proceed as I would have preferred, and that I had been unable to help her, she considered that my professional skill and knowledge, and my empathy, insight, understanding, compassion, body language, verbal and non-verbal communication, did make a difference to her emotional well-being, if not her physical health. Further, this engagement was significant because, by April's recognition of my certificate, it reminded me of the humanistic aspect of nursing. April's comments intensified my belief that, no matter what my personal feelings were about the effort involved in building and maintaining a healing, therapeutic relationship, it can, and does affect and influence people's health and well-being. As April's story revealed, this is the case even if the outcome might not be the one that was originally planned. A review of April's clinical record also did not portray the emotional intelligence and emotional labour that I required to work with her. 


\subsubsection{Trust building story}

Referred to me by the GP, Bea enrolled in the smoking cessation and healthy lifestyle programmes. In her late $40 \mathrm{~s}$, Bea, her husband and two teenage children had recently relocated to the town where she found work in a supermarket. During the first consultation, Bea was genial, and, with encouragement, discussed her nutrition, lifestyle and smoking habits. However, she told me little about her family, and I gained the impression from her facial expressions and reticent replies to my casual social talk enquiries, she had reservations about answering them.

Over the following weeks, Bea returned for follow-up appointments. While she had quit smoking and was managing that aspect well, the nutritional and exercise part of her plans were not going as well as she had hoped. Together, we worked on her motivational blocks, and ways she might increase her physical activities that did not add to her fatigue after work. Continuing to focus on these issues, it took several weeks to discern she had grownup children living in another town, and she was missing them. Still further time passed before she told me about her adolescent daughter who was experiencing social difficulties at school. The combination of these issues was making a significant impact on her life and her ability to change her lifestyle.

Sitting back in her chair, Bea continued her overall story, telling me her daughter had now left school and was studying at home. Bea said she felt incredibly angry and frustrated about her inability to hold responsible the perpetrators of her daughter's unhappiness. Her daughter did not want Bea to talk to them, or for the school counsellors or teachers to know. To help her, I drew on my own experiences of the frustration and anger when events occurred at my children's school that I had no control over or have input into resolving. By the lessening of tension in Bea's face, I gained the impression that by sharing my experience, expressing sympathy and kindness, she was finding some relief and increased level of well-being.

\subsubsection{Intuitive encounter story}

Through his regular attendance at nurse consultations to help monitor his medication as well as his general health, I had known Bob for a number of years. On this occasion, and at the same time he was readying himself to leave the room, we casually "chatted" about 
gardening and his dog. Offhandedly, he commented that he could not spend long in the garden before he needed to rest. He blamed his slowness on his West Coast upbringing where life is lived at a more leisurely pace, and he had just got slower over time. Although I was aware he was in his late 70s with a chronic heart condition that impacted on his physical activities, I was at loss to explain what it was that made me ask him to sit down with me again and investigate what he meant by "not long" (five minutes). Knowing there were other patients waiting, I could have commiserated with him or waved goodbye, but it was immediately obvious to me his comment required further investigation. The weakness and fatigue he described were not 'normal' for him and did not fit well with his medical diagnosis and treatment. On reflection, and with an appreciation of emotional intelligence, I became aware of the sequence of his overall story during that consultation. If I had been asked to articulate what had triggered my actions, I would have said that I did not recognise anything other than what I perceived as using my practical, logical, clinical, nursing knowledge, and experience of my own practice. I would have rationalised it as being the usual practice of experienced nurses; it was just something competent nurses who applied their education, experience, intuition and common sense automatically did.

\subsubsection{Questions arising from the stories}

There is abundant literature relating to nurse-patient relationships and what it might mean in specific nursing disciplines and individual nurse-patient encounters (Christensen, 1990; Fyers, 2008; Kleiman, 2009; Li, 2002; Peplau, 1997; Theodosius, 2008). These writings demonstrate the positive contribution effective nurse-patient relationships have on patients' health and well-being. While this contribution can be taken for granted, my stories raised questions about the practice nurse-patient relationship of which little is known. For example, patients' perspectives of their relationship with practice nurses is not well understood. It is also unclear if nurses sharing personal details during a consultation is perceived as assisting patient agency or unwarranted, unwanted social chat. It is not well recognised how the practice nurse-patient relationship facilitates change, or what it is patients' value in the relationship. It is not known what patients recall about the relationship and why it is remembered. Is it the practical help, options and advice they receive, or perhaps the feeling of being cared for through the emotional work of practice nurses that influences their health and well-being? Is it all of these? 


\subsection{Summary}

In general practice, patients may engage with practice nurses at any time over their life course. Patients are often well and appropriately managing any health issues they might experience with minimal assistance from the practice nurse or doctor. Maintaining an international comparison with the UK, Canada and Australia, this chapter provided an overview of PHC. It began with an account of the history of primary care and its foundation in the 1989 WHO Charter, and general practice, proceeding to the present day and the formation of each country's model of PHO. The processes by which patients accessed general practice were explained, as well as identifying the practice team members of doctors, nurses and administration staff. The work of practice nurses, their regulatory structures and their employment in general practice were described. While some international variations were revealed such as the development of practice nurse services and nomenclature, the similarities outweighed the differences in the provision of PHC services between countries. Stories from my own practice as a practice nurse completed the chapter.

Because understanding relationships is fundamental to this thesis, the following chapter reviews the literature around nurse-patient relationships generally. It also presents an appraisal of literature relevant to my narrative and storytelling methodology, life course, well-being, emotional intelligence and emotional labour, that are significant factors in the relationship. 


\section{Chapter 3 Literature review of nurse-patient relationships}

\subsection{Introduction}

Nurse-patient relationships have been an area of intensive research over time, with theories of nursing and nurse-patient relationships emerging since Nightingale (1860). In the context of PHC, studies of these relationships are less apparent with much of the literature focused on GP-patient relationships rather than practice nurse-patient relationships. Taking a nurse focused approach, this chapter is in four sections. The first section examines the seminal and contemporary nurse theories of Peplau (1952, 1992, 1997), Christensen (1990) and Kleiman (2009) who were influential in knowledge development of nurse-patient relationships. These theorists were chosen because they provided three different, but complementary, nursing philosophies spanning several decades. Nurse-patient relationships are discussed in section two, with emphasis placed on these relationships from patients' perspectives. Given that practice nurses engage with 'vulnerable' populations, management of their own emotions is a significant aspect of nurses' work. The business model of Emotional Intelligence (Goleman, 1995) and its application in nursing, as well as Hochschild's (1979) sociological theory of emotional labour, are relevant to this discussion. While these theories were developed outside the realm of nursing, their work holds considerable significance to nursing practice and nurse-patient relationships. Well-being and its pertinence to nursing practice and health outcomes for patients is a central concept in my research, and in the third section I examine White's (2010) sociological concept of well-being. Practice nurses also engage with people over their life course, and the fourth section considers the theoretical orientation of life course theorists Elder and Rockwell (1979), Elder and Kirkpatrick Johnson (2000) and Daaleman and Elder (2007) for their relevance to practice nursing and nursing practice. This chapter provides the foundation from which to examine practice nurse-patient relationships from patients' perspectives.

\subsection{Nurse-patient literature overview}

In a review of the historical nursing development literature, Armstrong (1983) argues that the evolution of contemporary nurse-patient relationships is a fabrication; "a myth...constructed around the historical constancy of the nurse-patient relationship" (p. 45). Nurse-patient relationships of the past, where the patient obeyed the nurse's instructions, have been transformed through the historical and social understandings of each era. Through each historical period, what is understood about relationships between 
nurses and patients is defined by their time and place in history. Armstrong claims that nursing theories reflect the different realities throughout their development, echoing the interests of nurses of that time. These theories led to the deeply held assumption that caring is the heart of nursing, involving a close relationship between nurse and patient. $\mathrm{He}$ concludes that while the image of the caring nurse has existed possibly since the time of Nightingale (1860), behind the myth is "only an ephemeral crystallisation of various lines of social analysis" (p. 459).

Following a review of Peplau's (1952, 1997) work, McCarthy and Aquino-Russell (2009) support Armstrong's (1983) position. Prior to the 1960s, the patient was perceived as a biological entity where the nurse observed and monitored an objective body with bodily functions. These authors show that preceding Peplau's $(1952,1997)$ theory of Interpersonal Relations, psychiatric patients were perceived as objects to be observed rather than subjects with whom a relationship could be formed. However, using the same historical evidence, later analysis does emphasise a subjective patient, whose monitored body also reveals the emotional identity of the patient. This surveillance of both objective and subjective aspects of patient care culminated in a new identity for the patient as a 'whole person,' and new meanings of the nurse-patient relationship (McCarthy \& AquinoRussell).

Unlike Armstrong (1983), Magnello (2012) contends that Nightingale's approach to administering care to patients not only addresses the physiological and physical well-being of patients, but also their mental health and sensitivity to their needs. In today's terms, this approach to nursing care is called holistic. Nightingale understood the effect of illness and infirmity, and the impact they had on the activities of daily living, family relationships, as well as on family finances (MacQueen, 2007). For Nightingale, providing humane, sensitive care to the sick in a nurturing environment that promoted health and healing was the heart of nursing (Kleiman, 2009). Concepts of care extending beyond the individual or illness to family and community, strongly resonate with, and correspond with my experience of practice nursing.

\subsubsection{Theorists on caring}

Paterson and Zderad (1976) describe the caring practises of nurses as a nurturing response to a call for help, and are directed towards 'helping' and 'becoming.' For these authors, 
caring is the core of nursing practice and central to forming a relationship that creates trust, which in turn, builds confidence. From this lens, trust refers to patients' unquestioning belief in, and reliance on nurses. To formalise their humanistic nursing theory, Paterson and Zderad wove humanism, existentialism and phenomenology into a methodological framework (Kleiman, 2009). To develop her theory of Humanistic Nursing theory that embodied all forms of caring, Kleiman (2009) utilised the theories of Golberg (1998) and Paterson and Zderad. For Kleiman, caring encompasses not only the physical, mental, emotional and spiritual caring where nurses express their emotions to patients, but also the conviction that nurses' sharing was an indication of their humanness. This humanness is exemplified through Kleiman's concept of "pathic touch" that may be conveyed physically or verbally, as well as silently, through facial expression, demonstrating concern for self, others and things, and practical wisdom. Like Golberg, Kleiman believes that while some elements such as presencing, touch and healing are physical in nature, other elements such as empathy, giving hope, love, religion, and transcendence, are emotional or spiritual in character. These concepts show that the humanistic connection between the patient and the nurse occurs when the authentic presence reveal the way people really are (Kleiman).

Forming much of the theoretical foundation for nursing practice, the caring process involves values, intent, knowledge, commitment and actions, grounding transpersonal relationships (Watson, 1999). Caring in nursing is reciprocal, enabling nurses to effectively form relationships with patients (Warelow, Edward, \& Vinek, 2008). These authors portray the caring nurse as one who draws on personal, empirical and ethical knowledge that brings the art of nursing alive. Like Nightingale, this art of nursing means that contextual circumstances are attached to the relationship; that not only is the patient cared for, but it also includes the family, lifestyle and other factors that affect the patient.

Emphasising that caring and nurturing, as well as professional nursing judgement, are involved in nurse-patient relationships, Fosbinder (1994) and Halldorsdotttir (2008) conducted their research into the relationships of hospitalised patients. This research resulted in the introduction of their own theoretical models of the relationship from patients' perspectives. These, and other authors, support the view that, when engaging with people, the prerequisites for the development of the nurse-patient relationship are the perceived nurses' caring, wisdom and competence (Christensen, 1990; Kleiman, 2009; Paterson \& Zderad, 1976; Warelow et al., 2008). 


\subsubsection{Nursing theories relevant to this research}

The medical model of admission followed by treatment, then discharge predominated in adult psychiatric nursing (Aldridge, 2006). The inadequacy of this model led Peplau (1952) to develop her theory of Interpersonal Relations which is underpinned by existential phenomenology and humanistic psychology (Gastmans, 1998). It was Peplau's integration of nursing theory into practice that provided a framework to guide nursing practice, and is her main contribution to the science of nursing (McCarthy \& Aquino-Russell, 2009). Peplau (1992) based her theory on the assumption that "what goes on between people can be noticed, explained, understood, and, if detrimental, changed" (p. 14). Similar to later theorists (Goleman, 1995; Hochschild, 1979; Theodosius, 2008), Peplau believed that because nurses did not have the power to change patients' behaviours, it was incumbent on nurses to control the signals or messages they send to patients. The signals that nurses send to patients act as motivation that changes patient behaviours (Theodosius).

Prior to Peplau's (1952) Interpersonal Relations theory, patients were viewed as objects of surveillance rather than subjects and participants in the relationship (Armstrong, 1983; McCarthy \& Aquino-Russell 2009). However, Peplau claimed that professional nursing was both an art and a science. The art of nursing is expressed by the caring, compassionate, concern and advocacy that enhances patients' comfort and well-being. The science of nursing reflects not only the knowledge and understanding of a broad range of bodily and psychosocial problems, but also health promotion and maintenance, which have increasing prominence in practice nurses' work. Nursing roles depicted in her model are: stranger, resource person, teacher, leader, surrogate, and counsellor. She also describes three intersecting basic phases of orientation, working, and termination. During each phase the patient expresses needs that require nursing intervention in unique ways (Lakeman, 2012).

Recent studies using Peplau's $(1952,1997)$ theory, suggest that although historical, her model of Interpersonal Relations is a valid concept for contemporary health care systems. Hrabe (2005) examined the applicability of Peplau's model in the context of computermediated communications in mental health. Although using this computer system following Peplau's model may be useful in caring for people with anxiety or depressive disorders, he found that it was essential that both nurses and patients understood the limitations of the approach. In a study aimed to aid recruitment and retention of research 
participants, Penckofer, Byn, Mumby and Estwing (2011) explored American nurse-patient relationships during the research process. These authors conclude that Peplau's phases are applicable in caring for people with co-morbidities and as a foundation for the recruitment and retention of research participants. From a historical perspective, Caldwell, Sclafani, Piren and Toree (2012) investigated Peplau's contribution to the development of the Clinical Nurse Specialists and Psychiatric Nurse Practitioner roles, and show how she influenced the contributions of psychiatric nursing services in the community that led to the development of these nursing roles.

Peplau's (1997) phases are similar to those later espoused by New Zealand nursing theorist Christensen (1990) in her Nursing Partnership theory. In Christensen's theory, a partnership occurs when the nurse offers "learned expertise to a person who is passing through a health related experience" (p. 25). However, during hospitalisation, Christensen proposed that rather than the nurse being in charge of the process, as Peplau argues, the patient and nurse work in partnership through three passages. These passages include entering a new partnership, or settling in during the transition from the 'old' life to the 'new' life; negotiating the nursing partnership through the on-going process of working together to lessen the impact of hospitalisation; and leaving the partnership or going home that reverses the transition from 'new' to 'old'. Christensen's theory continues to have relevance to contemporary hospital experience.

\subsection{Nurse-patient relationships}

Nurse-patient relationships involve an emotional connection between people, that is always present and is fundamental to every moment of nursing practice (Hartrick Doane \& Varcoe, 2005). This emotional association is made apparent through the nurses' competency and their possession of the knowledge and experience of professional wisdom (Halldorsdottir, 2008; Kleiman, 2009).

Relationships in nursing are perceived as qualitatively different from the "relative positions of two objects in time and space" (Armstrong, 1983, p. 457). They are between two subjects, the nurse and patient. This special relationship is achieved through caring for the patient's basic functions and being at the patient's side (Armstrong). Human relating is a caring process because it involves beliefs, intent, knowledge, commitment and actions of the people in the relationship (Watson, 1988). Relationships develop intersubjectively, 
with both nurse and patient choosing to reveal or conceal aspects of themselves in response to their interactions (Aranda \& Street, 1999). The relational experience is not only health promoting, but is also a way of connecting and engaging with people. This connection becomes transformative when the nurse presents a 'way of being' that is relational, looks at the 'whole' person, and listens to how their life experiences influences their health (Hartrick, 2002). That is, the nurse-patient relationship is essential to the therapeutic potential of nursing (Paterson \& Zderad, 1976; Peplau, 1997; Williams, 2001). It is the nurse's genuine caring of, and for, the patient as a person, which influences the progress of the relationship (Williams).

The common thread amongst all these authors is the centrality of nurses' caring, professional competence and effective communication in nurse-patient relationships. However, the concepts have only been described from the hospital context. Absent from these theories was clarification around their applicability with other health care settings such as PHC and general practice. Nevertheless, similar to Armstrong (1983) and Christensen (1990), Kuo, Chin and Chou's (2012) study examined how the concept of partnership in general practice adapts and diversifies with social changes and paradigm shifts. These latter authors conclude that in most medical centres, nurses endeavour to provide patient-centred care by including the concept of partnership, that is shown by respect and caring, and utilising strategies such as emancipation, enlightenment and empowerment.

\subsubsection{Nurse-patient relationships from patients' perspectives}

Given the importance of nurse-patient relationships, it is surprising that there is little understanding of these relationships in general practice. What is understood is mainly from a nursing perspective, consequently, the patients' viewpoint is not recorded. There are numerous nurses' descriptions of quality care, but patients' perspectives of satisfaction with nursing care is not clearly defined in the literature (Fosbinder, 1994). Fosbinder's ethnographic study of 40 acute care hospitalised adult patients and 12 nurses in Britain, shows that the primary focus of patients' comments relate to the interactive style of the nurses, rather than the task undertaken. Language both nurses and patients can understand, and the reciprocal nature of interpersonal competence, is advantageous to the relationship. Fosbinder's theory of Interpersonal Competencies describes four processes of: "translating," "getting to know you," "establishing trust," and "going the extra mile." 
Nurses translate information and teach; get to know the patient through personal sharing, being friendly and making an emotional connection with the nurse; establish trust by being in charge, anticipating patient needs, following through and enjoying the job; and going the extra mile by being a friend, and doing more than expected. While similarities with other theorists (e.g., Christensen, 1990; Kleiman, 2009; Peplau, 1997) are evident, Fosbinder's model views the nurse-patient relationship as one that urges not only professional competencies, but also emotional intelligence competencies (Emotional Intelligence is discussed in Section 3.3.3). From patients' perspectives, nurses' interpersonal competence is of immense significance, and further research to include other patient populations and cultures is required (Fosbinder).

The few studies from patients' perspectives led Boscart (2010) to pursue a quantitative project to study the perspectives of 40 patients in Canadian Chronic Care facilities. Boscart developed two scales to assess which attributes of the nurse-patient relationship are most important, and what attributes of the relationship were experienced. She found that relational availability, promoting quality of daily life, recognising and supporting choice, forming connections and supporting human uniqueness, are very important to patients.

For Halldorsdottir (2008), the "nurse-patient relationship is the core of nursing and theory development, and the end-goal of all theoretical work, and therefore, central in all scientific endeavours in nursing" (p. 644). Like Hartrick (1998), she believes that through authenticity and responsiveness, nurses have the opportunity to make a profound difference to people's health. From a patient's perspective, there is a spiritual connection that is experienced as a bond of energy, and that "the highest quality of this connection is the lifegiving nurse-patient relationship which is greatly empowering for the patient" (p. 645). Halldorsdottir bases her theory of Synthesised Dynamics in the nurse-patient relationship from a patient's standpoint on her 20-year appraisal of these relationships from various perspectives. By listening to former Icelandic hospital patients in earlier phenomenological and psychoneuroimmunology studies, and by theorising about human communication and the dynamics of the relationship, Halldorsdottir describes six phases of the dynamic nursepatient relationship which are illustrated in Figure 1.

Contrary to Peplau $(1952,1997)$ and Christensen (1990) who packaged their nursing theories into three phases or passages from connection to disconnection, Halldorsdottir 
(2008) unpacked the relationship from patients' perspective into six main developmental phases of the nurse-patient connection. While Halldorsdottir's model appears more complex than Peplau's, what both have in common is the centrality and significance they identified in understanding the relationship between patient and nurse. Notably dissimilar, is Peplau's belief that nurses remain in charge of the relationship and at a professional distance, always being aware of the patient as someone who is vulnerable and is looking for ways to personalise the relationship. However, Halldorsdottir encourages the "dialectic nature of the relationship that maintained a comfortable distance of respect and compassion" (p. 646), where the patient and nurse remove the "mask of anonymity" (p. 647). Here, the nurse shares some of her own self with the patient, but only enough to personalise the engagement. In one sense, this supports Fosbinder's (1994) stance, but is in contrast to her (Fosbinder's) conclusion that patients value the nurse being in charge and anticipating patient needs. A limitation of Halldorsdottir's (2008) study concerns context and standpoints. The number, gender and ethnicity of patients are not presented, and although taken from 20 years of listening to patients' perspectives, the patients' own views are not recorded. Also unknown are the contexts in which the hospital based data were gathered.

1. Reaching out and initiating the connection which may be instituted by either patient or nurse.

2. Removing the mask of anonymity by eliminating the stereotypes of the patient or nurse to enable them to recognise each other as people.

3. Acknowledgement of the connection by the patient, expressed as patients' instinctively knowing when the connection is made.

4. Reaching a level of truthfulness when patients feel that the nurse is on their side and they are not alone.

5. Reaching a level of solidarity through disclosure, the patient feels that the nurse is on his or her side, they are not alone and they feel like a human being.

6. True negotiation of care when the patient and nurse know each other and the nurse is better able to understand the patient and the patient's world.

\section{Figure 1. Six phases of the dynamic nurse-patient relationship}

Note. Adapted from Halldorsdottir, S. (2008). The dynamics of the nurse-patient relationship: Introduction of a synthesized theory from the patient's perspective. Scandinavian Journal of Caring Sciences, 22(4), 647. 
Halldorsdottir's (2008) theory is more in line with that of Jonsdottir, Litchfield and Pharris (2004), Theodosius (2008) and Kleiman (2009). For Jonsdottir et al. the dialogic process is fundamental to the nurse-patient relationship and partnership where the nurse is fully present and actively listening to the patient. Similarly, Theodosius urges nurses to recognise that nursing care is a collaborative partnership in which the nurse and patient work together. Kleiman places emphasis on nurses "holding the patient in unconditional warm regard as a fellow human being” (p. 243). This mutually responsive dialogue is not directed by the nurse, but is revealed in the conversational flow where new understanding and meanings are created from patients' experiences. However, challenging the concept of partnership, Armstrong (1983) argues that while relationships (such as those described by Halldorsdottir [2008] and others), are perceived as empowering for the patient, a true partnership may not be possible. Likewise, May (1992) suggests that by nurses extending their clinical view beyond the body to social and non-clinical knowledge of patients, the relationship may not be reciprocal because the nurse defines her own personal, professional and objective boundaries. McDonald, Rogers and MacDonald (2008) point out that such boundaries reflect the understanding that caring involves power differentials of hierarchy and dependence between patient and nurse.

\subsubsection{Alternative perspectives of nurse-patient relationship}

Unlike the contention in some nursing literature that nurses use caring practices such as listening, comforting, therapeutic touch, giving of themselves, and partnership, McDonald et al. (2008) suggest an alternative perspective of the nurse-patient relationship. In the context of primary care, their in-depth semi-structured interviews of 25 nurses from two UK PHCT examined the notion of dependence and identity of both nurses and patients. The results show that although nurses talked of partnership and empowering patients to self-manage their chronic conditions, they also felt a responsibility for patient outcomes. McDonald et al. describe this relationship as between "mother and child rather than a meeting of equals" (p. 298). Their suggestion that nurses are reluctant to relinquish their nurturing or control over their 'children' is in line with earlier research by Coyle (1999). In the context where nurses are dependent on the recognition of patients for their identity, McDonald et al. argue that ambiguity exists between nurses' professional ethics, respect for patient autonomy, and the demands of the health system to meet targets, causes nurses' stress and dissatisfaction. Nevertheless, practitioners need to be sensitive to the personal value and worth of their patients. By understanding how their manner and work contribute 
to or undermine, the patient's self-worth, practitioners may come to comprehend that expressions of patient dissatisfaction are not a threat to their professional identity, but a response to perceived challenges to the patient's sense of self-confidence (McDonald et al.). It cannot be assumed that participants experienced dissatisfaction or disempowerment by the British government's stipulation that nurses meet health system targets, nor that participants were aware of constraints to practice nurses practise in meeting those targets. Moreover, the perspectives of patients who episodically utilise practice nurse services may not be the same or similar to other patients. Not apparent in McDonald et al.'s study, were the experiences of patients who were not consulting practice nurses for on-going chronic conditions management.

Through the lens of GP-patient relationships, the two following studies have implications for nurse-patient relationships. Annandale and Hunt (1998) examined data collected during the baseline contact with participants in the 35 year old cohort of a longitudinal study from the West of Scotland Twenty-07 Study (Medical Research Council: Social and Public Health Sciences Unit, 1986). To interview participants in their own homes, they engaged qualified social interviewers followed-up by nurses trained in these techniques. Annandale and Hunt's aim was to explore reasons why patients felt dissatisfied with their GP, and why some patients did nothing to resolve the issues while others took action. They conclude that there is often lack of closure to many disagreements, and that the relationship between participants' felt disagreements and their actions, are complex. It is not clear from Annandale and Hunt's study whether the nurses who undertook the interviewing were known to the participants, or were chosen from outside the general practice context. Annandale and Hunt recommend further research into reasons patients chose to, or chose not to take action when disagreements arise with doctors.

Coyle's (1999) grounded theory research examined 41 UK patients' dissatisfaction with medical practitioners' care generally, and described the "personal identity threat" (p. 107) experienced by participants. Being treated as non-persons or objects in the hospital production line or GP practice, and by having little attention paid to the patient as a person, was perceived by participants as a personal identity threat. Participants also felt stereotyped by gender, culture and education. Women, especially those over 65 or under 24 , encountered infantilisation by being chastised, or having decisions made for them by 
the doctor. Coyle found that the objectification of individuals by doctors resulted in undermining participants' individuality, feelings, personal knowledge and experience.

A strength of the above PHC based studies lies in their focus on general practice rather than hospitalised patients, however, the results are transferable to other health contexts. They not only highlight the challenges facing patients when engaging with health professionals, they draw attention to how both patients and health professionals perceive each other's identities and the sense of value of, and threats to, these identities. Furthermore, they demonstrate diverse aspects of relational awareness and emotional intelligence.

Within the context of professional relationships, nurses' beliefs, values and concerns have been acquired either consciously or unconsciously through life experiences, the environment, heritage and traditions (Paterson \& Zderad, 1976). This life course knowledge and understanding brings a humanistic perspective to the relationship, and Annandale and Hunt (1998), Coyle (1999), Nystrom (2007) and McDonald et al. (2008) argue that the nurses' insight into their own personalities and behaviour may facilitate connection between nurse and patient. This personal knowledge is consistent with Goleman's (1995) concept of emotional intelligence.

\subsubsection{Emotional intelligence}

Emotional intelligence is "the capacity for recognising our feelings and those of others: for motivating ourselves, and for managing emotions well in ourselves and in our relationships" (Goleman, 1995, p. 317). Although emotional intelligence has a long history, the most recognised of three models is Goleman's Mixed or Performance Model. By comparing self-reports and reports from nearly 600 corporate managers, professionals and graduate students, Goleman developed his emotional intelligence framework by using the Emotional Intelligence Competency Inventory and Method (Kooker, Shoultz, \& Codier, 2007). Later, he refined his original model to four domains of self-awareness, selfmanagement, social awareness, and social/relationship management, each with additional competencies. The emotional intelligence framework is found in psychology, industrial and organisational psychology, neuroscience, developmental cognition, education, clinical health practice, counselling, organisational development, and business management (Kooker et al.). Their adaptation of Goleman's four domains are set out in Table 1. 
To gain insight into issues facing workforce development and retention, Kooker et al. (2007) applied the emotional intelligence framework in a purposive, qualitative study analysing the professional practice in the stories of 16 American nurses. Participants were drawn from acute care, ambulatory care, and urban and rural nurses. Kooker et al. found that, while all the domains and competences were identified across the stories, the domains of social awareness, social management and self-awareness were the most common. They established that factors such as organisational barriers conflicted with nurses' intuition and knowledge of their nursing work, but that by using emotional intelligence concepts, fresh insights into ways in which nurses engage with patients may improve nurse retention and patient outcomes.

\section{Table 1. Emotional Intelligence Framework: Domains and Competencies}

\begin{tabular}{|l|l|}
\hline $\begin{array}{l}\text { 1. Self-awareness } \\
\text { domain }\end{array}$ & $\begin{array}{l}\text { Emotional self-awareness: Recognising one's emotions and their effects. } \\
\text { Accurate self-assessment: Knowing one's strengths and limits } \\
\text { Self-confidence: A strong sense of one's self-worth and capabilities. }\end{array}$ \\
\hline $\begin{array}{l}\text { 2. Social awareness } \\
\text { domain }\end{array}$ & $\begin{array}{l}\text { Empathy: Understanding others and taking an active interest in their } \\
\text { concerns. } \\
\text { Service orientation: Recognising and meeting customers' needs. } \\
\text { Organisational awareness: Empathising at the organisational level. }\end{array}$ \\
\hline $\begin{array}{l}\text { 3. Self-management } \\
\text { domain }\end{array}$ & $\begin{array}{l}\text { Emotional self-control: Keeping disruptive emotions and impulses under } \\
\text { control. } \\
\text { Trustworthiness: Displaying honesty and integrity. } \\
\text { Conscientiousness: Demonstrating responsibility in managing oneself. } \\
\text { Adaptability: Flexibility in adapting to changing situations or obstacles. } \\
\text { Achievement drive/orientation: The guiding drive to meet an internal } \\
\text { standard of excellence. } \\
\text { Initiative: Readiness to act. }\end{array}$ \\
\hline $\begin{array}{l}\text { 4. Social/relationship } \\
\text { management domain }\end{array}$ & $\begin{array}{l}\text { Developing others: Sensing others' development needs and bolstering } \\
\text { their abilities. } \\
\text { Influence: Wielding interpersonal influence tactics. } \\
\text { Communication: Sending clear and convincing messages. } \\
\text { Conflict management: Resolving disagreements. } \\
\text { (Visionary) Leadership: Inspiring and guiding groups of people. } \\
\text { Change catalyst: Initiating or managing change. } \\
\text { Building bonds: Nurturing instrumental relationships. } \\
\text { Teamwork and collaboration: Creating a shared vision and synergy in } \\
\text { teamwork and working with others toward shared goals. }\end{array}$ \\
\hline
\end{tabular}

Note. Adapted from Kooker, B.M., Shoultz, J. \& Codier, E.E. (2007). Identifying emotional intelligence in professional nursing practice. Journal of Professional Nursing, 23(1), 30-36. Table represented with permission from author.

With the aim of gaining a greater understanding of emotional intelligence and nursing, Smith, Profetto-McGrath and Cummings (2009) reviewed 39 articles focusing on emotional intelligence and nursing education, nursing practice, clinical decision-making, 
and clinical leadership. These authors identified that there is widespread support for emotional intelligence concepts in nursing, and it is essential to nursing practice. However, despite this support, there is a lack of consensus about the meaning of emotional intelligence. Because emotional intelligence affected ethical decision-making, critical thinking and evidence and knowledge used in practice, there is a demonstrable need for it to be explicit in nursing education (Smith et al.). It is also a significant factor in the calibre of leaders, and influenced retention of nurses and quality of care (Kooker et al., 2007; Smith et al.). Smith et al. question how different people with different skills perceive understanding and management of emotions and note that emotional intelligence skills develop over time, and have more relevance to some occupations than others. They also recommend further research into how the concepts relate to nursing practice.

\subsubsection{Emotional labour in nursing}

The domains and competencies of emotional intelligence may be linked to the concept of emotional labour described by Hochschild (1979). She defines emotion as "bodily cooperation with an image, a thought, a memory - a co-operation of which the individual is aware” (p. 551). Hochschild applies 'emotion' and 'feeling' interchangeably, although she recognises that 'emotion' also describes a state of being overcome, where 'feeling' does not. Using the terms 'emotion management' 'emotion work' and 'deep acting' synonymously, Hochschild states that learning how to 'do' emotion management took emotion work. Hochschild depicts 'emotional labour' as emotion work used as a commodity for commercial value. Fundamental to her classifications, is the distinction between emotion management and emotional labour. She explains this as the difference between what people may express in public and what they may communicate in private. Theodosius (2008) emphasises that emotion work/management is presented as part of our daily lives, whereas emotional labour occurs at work as a commodity that is sold for a wage. When exercising emotional labour, the person (nurse) induces or suppresses her emotions in order that her facial expressions and body language produces a feeling in others, such as being cared for in a friendly and safe place (Hochschild, 1983). Occupations that involve emotional labour share three characteristics of "face-to-face or voice contact with the public, the requirement of the worker to produce an emotional state in another person, such as gratitude, and allowing the employer, through training and supervision, to exercise a degree of control over the emotional activities of the employee" (Smith, 1991, p. 76). 
Both Goffman (1976) and Hochschild (1979) acknowledge the influence of social rules and culture in any given context. Society defines how we should act in certain situations whether we want to or not. Hochschild interprets this as 'feeling rules'. However, she argues that Goffman's actors actively manage outer expressions of social behaviour, but pay little attention to inner feelings or their management. Hochschild contends that the ability to visually express what one should, or ought to do in any given situation is 'surface acting', while the feeling and memory that activates emotional expression is 'deep acting'. People who engage in surface acting, act without feeling or the feeling is blurred, while emotion management "focuses on a full range of emotions and feelings, and its focus on conscious and deliberate efforts to shape feeling" (p. 559). The appropriateness of the feeling is assessed by comparing feeling and the situation, not by examining the feeling in isolation. Emotion work refers to the act of trying to change in degree or quality, an emotion or feeling. Working on the feeling is the same as managing emotion, or deep acting (Hochschild). Although these notions of shifting or suppressing feeling share similarities, they differ by working on shaping feeling in oneself. For example, in a social exchange, acts of display between people, such as gestures of greeting, or "angry outburst and apology, are measured against what is reasonably owed by the other" (p. 568). In these situations, the exchange may be both superficial surface acting, and also deep acting. The quality of the exchange and emotion work involved is a gesture in social exchange (Hochschild).

However, de Raeve (2002) contends that nurses are not serving customers as flight attendants do $;^{4}$ rather they respond to vulnerable and often frightened people who were dependent on their help. She further contends that nurses need to be self-reflective in their engagements with patients, and that deepening their understanding of compassion has nothing to do with either deep or surface acting.

Drawing on her findings from a previous study (Smith, 1987), in which she investigated the English hospital ward learning environment for student nurses and its relationship to the quality of nursing, Smith (1991) examined the extent to which the patient-centred philosophies of the nursing process are applied in the classroom, with emphasis on the notion of students as emotional labourers. She shows that the emotional aspects of caring

\footnotetext{
${ }^{4}$ Hochschild's original research involved air hostesses [cabin crew].
} 
associated with the nursing process emerge as a significant factor in their relationship with patients. Smith uses Hochschild's (1983) definition of emotional labour (suppressing feeling to produce an outward appearance of calm) to analyse patients' and nurses' accounts of the nurses' caring role. Descriptions from student nurse participants demonstrated that while nurses were expected to 'do' emotional labour, patients' comments also established their own methods of 'doing' emotional labour. Smith describes a two-way relationship, and how emotional labour was managed by joking and social talk. She also examined situations where nurses chose to withdraw their emotional labour, such as when patients were not 'nice' to nurses, generating nurses' feelings of disengagement. Instead of professionally responding, nurses chose to avoid the patient, withholding their compassion and understanding, and providing only basic care.

Smith (1991) also identified students' constraints to caring practice during their transitions from beginner student to final year student. For beginner students, the nursing model and 'caring', although not always clearly defined to students, is important. For final year students, the medical model rather than the nursing model fitted more closely with the technology and tasks they experienced in the hospital wards. The study highlights the importance of 'good' role models in demonstrating effective communication skills, rather than as a subject taught in the classroom. Smith addresses the assumption in the literature that nurses care, are aware of what caring is, and know how to communicate care in the nurse-patient relationships. She concluded that neither tutors nor students have adopted the nursing process as a philosophy with which to inform training and complex feelings. Rather, they use it as a work method. Patients' experiences of the withdrawal of emotional labour leading to their disengagement from nurses, is not addressed in her study, nor is how 'good' role modelling demonstrated by nurses, explained.

Although Smith's (1991) study was undertaken at a time when nursing students were trained in hospitals rather than tertiary institutions, her findings retain their relevance to contemporary nursing education. Seventeen years later, from a New Zealand nurse educators' perspective, Wilson and Carryer's (2008) research has similar findings. Noting that within nursing literature, the terms emotional intelligence, emotional labour and emotional competence are used interchangeably, and, similar to Hochschild $(1979,1983)$ and Smith, Wilson and Carryer define emotional labour as engagements guided by social conventions that demonstrate awareness of other people's emotions and assists nurses in 
regulating their own emotions. The nurse educator focus groups in Wilson and Carryer's study shared their views of the challenges they encountered when assessing students' development of emotional competence during the three-year Bachelor of Nursing degree. The nurse educators described their feelings and opinions of how theory and practice environments influenced student nurses' development of emotional competence, maintaining that competent nurses need to demonstrate the ability to communicate effectively (Nursing Council of New Zealand, 2009). Within the context of the educators shared understanding of emotional competence, Hochschild's $(1976,1983)$ concepts of emotional management and emotional labour were established. Like Smith (1991), nurse educators regarded emotional competence as a foundational concept for nursing education, with knowledge of emotional intelligence competencies with shared understandings supporting this communicative process. Wilson and Carryer assert that the ability to communicate emotional competence is a prerequisite for nurse educators and practising nurses who work alongside students.

Not addressed in Wilson and Carryer's (2008) study, but raised by Hochschild (1983) and Theodosius (2008), is the concept of patients as 'consumers' (Halcomb, et al., 2013) or 'clients,' which signals a more service orientated perspective of nurses' work. Similar to Smith (1991), there is an assumption that nurse tutors will be able to role model emotional competency to nursing students. Wilson and Carryer do not indicate how tutors' own emotional competence can be assessed or how they might demonstrate it to students, especially in a classroom context. It is also unclear from their study if student nurses' emotion work/management is constrained by their student status.

Nurse scholars have long argued for the use of the broader concept of 'emotion work' to recognise the autonomous and discretionary affective practices in which nurses engaged on behalf of patients (Miller, et al., 2008). These authors define nursing emotion work as the "management of the emotions of self and others in order to improve patient care" (p. 332). Seeking to enhance collaborative nursing practice, Miller et al. examined nursing emotion work and interprofessional collaboration in General Internal Medicine wards in three Canadian hospitals. The qualitative research methods they applied included non-participant observation, shadowing and semi-structured interviews with nursing, medical and allied professionals. This mixed method approach lent robustness and trustworthiness to the study (Miller et al.). They established that nurses' collaborations with other professionals 
are influenced by emotion work considerations. Significant factors underpinning nurses' interprofessional disengagement include failure of the interdisciplinary teams to recognise the importance of nursing's core caring values, and that the establishment and maintenance of their sense of comradeship conflicted with those of physicians (Miller et al.). This finding is analogous to Smith's (1991) and Theodosius's (2008) assertion that nurses may disengage from patients when their emotional intelligence and sense of self and selfmanagement controls are challenged. It is unclear how many participants from each profession and allied health professional took part in the study. The gender, ages, culture and ethnicities are also unstated, raising questions about differences that might be experienced among these groups.

It is clear that from diverse chronological times and research topics, knowledge of emotional intelligence and emotion work/management and emotional labour, strengthened nurses' education and work. However, constraints to practising a nursing rather than a medical model of health care in hospital environments was demonstrated by the increased demand for nurses to be proficient in complex nursing tasks leaving less time to spend emotionally engaging with patients (Theodosius, 2008). These studies have applicability in the general practice setting where similar developments and changing expectations in practice nurse roles are experienced. Like hospital nurses, practice nurses strive to meet the needs of patients and employers, as well as the demands of government health priorities.

From another perspective, Li (2002) argues that emotional labour concerns not only management of feelings but may be perceived as caring, because caring involves both the emotional and technical skills of the nurse. Li applied an ethnomethodologicalethnographical perspective in her study examining the 'doing' of psychosocial care of palliative care patients to the broader concepts of nursing as a form of emotional labour. Situated in two British hospices and one general hospital, Li theorises that "psychosocial care is enacted in emotional labour through 'symbiotic niceness' that was co-produced and co-performed in interaction by participants" (p. 18). Through listening, observing and recording nurses' talk she establishes how they identified and labelled patients, such as 'lovely' or 'obnoxious,' and how they used their emotional labour to manage engagements with very ill patients. Observing encounters between nurses, and between nurses and patients, Li shows the 'niceness' of nurses to be simultaneously feeding and growing from the 'niceness' between nurses themselves, as well as between the patients and nurses. 
Patients rewarded nurses with opportunities to produce the impression of professional niceness through social etiquette by expressing gratitude, saying 'thank you,' exchanging humour and using body language to portray niceness. Emotional labour, in the sense of emotional skills and technical competence, as well as symbiotic niceness was identified in the management of feelings and emotional caring by nurses in their relationship with patients. Nurses worked at being nice to 'good' patients bringing rewards of niceness in return. Li also describes times when nurses felt professionally obliged to be nice to patients they did not like or found troublesome.

Similar to Smith (1991), under certain circumstances, Li (2002) found that nurses might withdraw their emotional labour while continuing to provide 'care' for a patient. Li concludes that while 'symbiotic niceness' may be a skill common to everyone, it is also a competence for certain groups of professionals to achieve. This notion of emotional competence is congruent with Smith's contention that both patients and nurses 'do' emotion work. Li chose to define emotional labour in terms of the degree of effort, or emotional cost nurses and patients put in to change their feelings and behaviours when engaging with each other or with those who have power over them. Li's study integrates several definitions of emotional labour that includes aspects of care and caring, while at the same time, she illuminates the different forms of niceness and competence through the care of palliative care patients.

Li's (2002) work is significant. She shows that relationships between nurses and patients and among nurses themselves are not only distinct, but that they are also co-produced. This co-production is made apparent through the relationships between palliative care nurses, and between these nurses and terminally ill patients. The absence of research methodological details of writers to whom she refers, limits the trustworthiness of the study findings.

Emotion management and emotional labour is the focus of a study examining how nurses on one ward in an English hospital manifested emotional labour (Theodosius, 2008). To gain an in-depth understanding of the nurses' lives on the ward, and to experience what they experienced, Theodosius worked as a registered nurse on the same ward. Over 14 months, she observed nurses at work, and analysed the audio diaries of 15 nurses. Similar to $\mathrm{Li}$ (2002), Theodosius found that emotional labour in nursing is an exchange involving 
"interaction between both parties that is predicated on the relationship they have together" (p. 43). While acknowledging Hochschild's (1983) ground-breaking biopsychosocial approach to her theory of emotion, Theodosius argues that there is physicality of emotion which is experienced and managed, and "it is connected to the conscious and unconscious emotion memory" (p. 87) such as the 'fight or flight' mechanism.

Emotional labour encompasses three characteristics: Therapeutic Emotional Labour, Instrumental Emotional Labour and Collegial Emotional Labour (Theodosius, 2008). Therapeutic emotional labour is essential for nurses to be able to manage their own emotions for the benefit of patients. To achieve this, and in line with Peplau $(1952,1992)$, nurses need to be aware of their own feelings as well as those of patients, and how these feelings might affect patients at the time of the interaction. Motivation for instrumental emotional labour is carried out as a direct result of clinical nursing intervention, while collegial emotional labour is found in the relationships nurses have with each other and members of the interdisciplinary team. Because communications may go astray, or collegial conflicts occur, especially in times of stress, nurses' collegial emotional labour is vital (Theodosius).

In response to Smith's (1991) contention that nurses may withdraw their emotional labour in certain situations, Theodosius (2008) argues that nurses disengage from patients to "protect themselves not only from uncooperative or abusive patients, but from the power of others to complain" (p. 43). To augment understanding of this phenomenon, she calls for future research to examine ways in which student nurses learn communicative behaviours and better professionally manage their own emotions. In the context of her familiarity with the ward nurses' experiences, Theodosius was in a position to identify the diverse meanings of nurses' emotion and emotional labour. Theodosius extends Hochshild's (1983) theory by enhancing its relevancy for contemporary nursing practice. She also supplements Li's (2002) assertion that nurses require technical competence, or technical emotional labour. Although Theodosius's retention and use of the nurses' stories enhances the trustworthiness of the study, she does not address patients' emotion management.

\subsubsection{Practice nurse-patient relationships in general practice}

Three UK studies germane to PHC, general practice and practice nurses, are those of Millar, Garland, Ross, Kendrick and Burns (1999), Morgan and Moffatt (2008), and Peters, 
Wearden, Morriss, Dowrick and Lovell (2011). The increasing demand for the care of people with severe and ongoing mental illness to be overseen by general practice health professionals has important implications for care and practice nurses (Millar et al., 1999). Millar et al. followed up participants taking part in a randomised control trial (RCT) involving London practice nurses that investigated the effectiveness of training and structured assessment on clinical and social outcomes of patients receiving maintenance medication of depot antipsychotics. Their aim was to explore current practice, confidence, and priorities for training in relation to these patients. Semi-structured interviews with open and closed questions were used to interview 39 practice nurses who had taken part in the RCT. Millar et al. found that some nurses claimed to be knowledgeable about schizophrenia and medication side effects, while others wanted more training, not only for nurses, but also for the primary care team. The health and well-being outcomes of patients who were assessed by nurses with limited knowledge, is not addressed in this study. Even though some nurses may have the necessary knowledge and expertise, how it was evaluated and by whom, is also not described. Given the focus was on practice nurses' experiences, the mental health patients' experiences of practice nurses' expertise and knowledge of the mental health assessment processes were not obtained.

Collecting data from the perspectives of nurses and patients was also the aim of a two-part study into nurse-led leg ulcer care in an English community health setting. For this project, Morgan and Moffatt (2008a, b) examined the challenges within the nurse-patient relationship with regard to patients' compliance with leg ulcer care. In part one, they applied a descriptive qualitative methodology using single semi-structured interviews to explore five non-concordant patients' experiences of their leg ulcer care. The participants included both sexes and a range of ages. Some of the participants described being physically disabled or emotionally reluctant to leave home because of their condition, while others talked of attending the hospital on the way home from work, or the clinic at weekends. Morgan and Moffatt (2008a) found that participants not only faced challenges in care, but also in their relationship with nurses. In line with Millar et al. (1999), this occurred when participants felt that nurses did not accept or understand the life balance between looking after their ulcer, and maintaining their sense of self and their identity within the family and community. Morgan and Moffatt conclude that effective nursepatient relationships centre on nurses seeking to understand the patients' perspectives, and to deliver care accordingly. Their contention, that building trustful therapeutic nurse- 
patient relationships where patients are not 'labelled' is at the heart of nursing, aligns with the conclusions of other authors such as Hochschild (1983), Smith (1999), Li (2002) and Theodosius (2008).

Morgan and Moffatt's (2008a) findings are applicable to other nursing contexts such as general practice where there may be a number of nurses who undertake long-term care such as ulcer care. What is not known from this study is whether the participants selfidentified as 'non-concordant.' Given that patients' ulcers were non-healing, Morgan and Moffatt did not disclose whether participants were given a choice of nurse or timing, or if there was continuity of carer as well as care.

In part two, Morgan and Moffatt (2008b) interviewed the four community nursing teams responsible for the patients with non-healing leg ulcers from the first study. They emphasise that retaining each of the four focus groups' original nursing teams ensured naturally occurring data were collected in the context in which they were generated. It also provided a sense of security within the group. Morgan and Moffatt found that nurses labelled patients as 'difficult', 'non-compliant' and 'un-cooperative', and that this labelling of patients as 'good' or 'bad' led to discrepancies in care. They also raised the difficulty nurses experienced in maintaining resources such as dressing material and being able to visit the patient as often as their professional knowledge indicated. The study discusses the critical function of nurse-patient and nurse-nurse communication. It also describes the nurses' emphasis on the ulcer rather than the patient as a whole person because the nurses felt they were there to treat the ulcer rather than care for the patient's emotional issues. Morgan and Moffatt acknowledge the small sample size and the preservation of community nurses in their original groups as limitations, and it is unclear if integrative group interviews, which included all the nurses, would have reached the same conclusions or offered a broader perspective.

Also located in England, using a RCT, Peters et al. (2011) studied two different nursedelivered psychological interventions for patients with chronic fatigue syndrome/myalgic encephalitis in primary care. In addition to the focus of the trial, that was to evaluate each nurse-led intervention compared to GP care, they aimed to identify potential barriers and solutions that could arise if these approaches were implemented within routine practice. Participants included three experienced female trial nurses, three supervisors and 46 
patients of both sexes aged over 18. Nurses were trained in providing Pragmatic Rehabilitation and Supportive Listening therapies and received two-weekly supervision from psychologists. Interviews were undertaken in patients' own homes.

Despite nurses receiving training in the psychological interventions, similar to Millar et al. (1999) and Morgan and Moffatt (2008a, b), Peters et al. (2011) demonstrate that tensions continue to exist between patients and nurses. Patient participants challenged nurses' clinical, medical and therapeutic expertise and nurses' apparent lack of understanding of patients' own knowledge and management practices. Patient participants often had complex co-morbidities including mental health issues that required nurses to adapt therapy to suit patients. However, Peters et al. found that solutions to these tensions might be resolved through expert and peer supervision. They report that therapeutic relationships created over time, are critical in ensuring that patients and therapists' illness beliefs are aligned with the therapeutic approach and that this alignment was essential in engaging patients in treatment. When attempting to make changes to their lifestyles, patients value the nurses' listening skills and validation of their perspectives. Collecting data from three different perspectives added credibility to the study findings.

\subsubsection{General practice team relationships}

In business organisations, high-quality teamwork has been found to increase staff and client satisfaction, which in turn, contributed to innovation (Finlayson \& Raymont, 2012). Based on this model in general practice, there has been more effort to improve teamwork. Nevertheless, these authors emphasise that due to the hierarchical nature of general practice, practice nurses may be hesitant to hold their employers or owners to account. Notwithstanding that teamwork is an essential element in providing care for patients, literature relating to relationships between health professionals and reception or administration staff is not readily evident. PHC team research is mainly confined to the interprofessional relationships of GPs and practice nurses (Chan, Proudfoot, Zwar, Davies, \& Harris, 2011; Finlayson \& Raymont; Pullon, 2008a; Pullon, McKinlay, Stubbe, Todd, \& Badenhorst, 2011). Finlayson and Raymont's study analysed data collected from GP and practice nurse questionnaires, as well as questioning practice managers about their perspectives of the GP/practice nurse team. They found that doctors and nurses in general practice in New Zealand consider themselves a team, and that the nature of the work and the business context most often leads to a multidisciplinary style of teamwork. However, 
this process could be seen to continue the notion of a general practice team being limited to health care professionals excluding administration staff, who may be perceived as having their own team. Taggart et al. (2009) stress that effective teamwork in general practice requires opportunities for clinical and non-clinical staff members, each with clearly defined roles, to provide feedback and input into how the practice is managed. They emphasise the distinct position within the practice of each team member, but patients rely on receptionists to assist them with decision-making, not only around timing of appointments, but often with choice of health professional. A study by Pullon et al. (2011) challenges these perceptions of team members. These authors show that while GPs view patients as recipients of the health professional teams' care, practice nurses and patients believe that patients are included in the team. One patient participant described his role as team leader with ultimate responsibility for his care.

Tarrant, Windbridge, Boulton, Baker and Freeman (2003) studied 40 adult patients, 13 GPs, 10 practice and community nurses, and six administrative staffs' perceptions of the meaning of personal care in an English general practice setting. They found that despite their different roles, patients, GPs, primary care nurses and administration staff held similar views of the meaning of personal care. Patients described personal care as the experience of receiving personal care, including the importance of human communication that integrates empathy, time to listen, social chat, and humour. Personal care was demonstrated even in brief encounters, when the GP or nurse communicated well with them. Health professionals and administrative staff described how they tailored treatment, attempting to care for the whole person, and placing value on continuity of care. Reception staff focused on being friendly and communicating well with both patients and health professionals in the practice. The organisation and culture of the practice also influenced personal care (Tarrant et al.). The detailed information supporting their findings indicates that their conclusions might be applicable in similar primary health contexts such as general practice in NZ.

\subsubsection{Medical receptionists' role}

In general practice, receptionists are usually the first point of contact for patients (Patterson, Del Mar, \& Najman, 2000). Investigating the role of Australian medical receptionists, these authors surveyed 84 GPs to determine the extent to which receptionists undertook tasks that were traditionally the domain of nursing. They found that although 
primarily employed for reception and clerical duties, some receptionists were performing tasks that involved direct patient assessment, monitoring and therapy. Similar to Finlayson et al. (2009), Patterson et al. established that while a small percentage of receptionists may have had previous nursing experience, they were not employed as practice nurses and did not maintain their professional competencies and registration. Because GPs believed they could teach receptionists any nursing work they required, they did not perceive the need to employ more highly paid nurses. These findings were confirmed in a follow-up qualitative study (Patterson, Forrester, Price, \& Hegney, 2004). Patterson et al.'s conclusions also indicate that receptionists in these studies had time to undertake traditional nursing procedures such as wound care, electrocardiograms and injections. These activities may be more difficult in larger practices. Not addressed in their study was the receptionist-patient relationship, nor how it might differ from the practice nurse-patient relationship. Also unknown are patients' experiences and views of receptionists acting in a nursing role.

Receptionists' roles and receptionist-patient relationships were described in three studies. Arber and Sawyer (1985) investigated the public's experiences of English general practice receptionists as gatekeepers to the GP. Drawing on the interviews of a sample of 1000 patients from their 1977 study, they argued that the structural position of receptionists in general practice, and the nature of PHC, gave receptionists choices about which, and when, patients may access the GP. Receptionists were constrained by the availability of appointments, the demands of the GP to lessen the appointment load, and hostility from patients who felt that receptionists were not meeting their expectations or needs. Arber and Sawyer showed that receptionists sometimes imparted unsolicited medical advice to patients, and while no class differences were demonstrated, younger people were more likely to criticise receptionists' medical decisions. The authors suggested that this was because young people were less deferential and knew their rights, which resulted in receptionists' hostility towards them.

Hewitt, McCloughan and McKinstry (2009) applied ethnographic discourse analysis to examine receptionists' communicative styles and to identify the difference in perceptions between patients and receptionists. They interviewed 283 patients and 16 receptionists from three Scottish general practices and found that most receptionists repeated established verbal routines, described as task-centeredness, conventional politeness, and rapport 
building. While all three routines enabled completion of tasks, a habitual approach became problematic when patients with complex needs presented at the practice.

From two Australian rural and coastal community health centres, Duncombe (2011) examined the experiences of three receptionists in relation to their occupational health and safety, and the "Intake System." Duncombe established that while these receptionists did not undertake a clinical role, they were the first point-of-contact for patients, and had the potential to influence whether patients became engaged or alienated from the service. While health professionals received ongoing education, she showed that receptionists also needed situational and formal education, controls and support. Duncombe demonstrated the complexities of the receptionists' role in the community health setting highlighting the receptionists' expressed care and concern to patients. Without being intrusive, receptionists balanced the necessity to make decisions about appointments with the need to obtain accurate information. Given that general practices in New Zealand, Australia, Canada and the UK have similar PHC systems, it is likely that the experiences of general practice receptionists are comparable.

\subsubsection{Practice nurse-doctor relationship}

Historically, there has been little research into the practice nurse-doctor relationship (Blue \& Fitzgerald, 2002; Pullon, 2008). These professional relationships have often been perceived as challenging and an impediment to collaborative practice (Pullon). Although the histories and philosophies of nursing and medicine are different, international literature relating to the nurse-doctor relationship is mainly of interest to nurses (Blue \& Fitzgerald, 2002).

The relationship between 10 registered nurses and six GPs in four rural Australian Health Services was the focus of Blue and Fitzgerald's (2002) research. Populations of these health services ranged from towns of 200 people covered by full-time nursing services, with twice-weekly GP visits, to a town of 14,000 people with full-time nursing and GP services, as well as hospital access. Findings from their case study showed that in these rural settings, especially where nurses worked without GP cover, nurses were less dependent on doctors, demonstrated confidence, and did not act as subordinate to the doctor. They also found a "symbiotic" relationship that increased interprofessional collaboration occurred when nurses were both assertive and co-operative in their 
relationships. Participants experienced their relationship as "harmonious, friendly and as a co-operative "mateship" (p. 317). Nurses were "increasingly prepared to negotiate with doctors and communicate their clinical knowledge and experience and the doctors are listening and responding to this" (Blue \& Fitzgerald, p. 321). Professional boundaries blurred when nurses and doctors were familiar with each other's families, interacted socially as well as professionally, and nurses might be patients of the doctor.

Blue and Fitzgerald (2002) clearly portrayed the remoteness of Australian Rural Health Services and the symbiotic manner in which health care was provided by nurses and GPs. These authors illustrated not only the evolution of the nurses' roles in rural settings but also nurses' gate-keeping activities, with nurses mindful of the doctors' well-being. Nevertheless, although GPs appreciated nurses' protective, nurturing behaviours when they were tired and stressed, there was no indication of GPs' reciprocation. Although nurses were described as being experienced and usually older than the doctors, the ethnicity of the participants was not disclosed suggesting that participants were Australian Europeans. It is not known from this study how, or if, the inclusion of other cultures and ethnicities, including Aboriginal, might affect the results. While the study included one male nurse, the gender of GPs was not given.

From a New Zealand perspective, Pullon (2008a) explored the roles and relationships of nine female nurses, and nine doctors of both sexes, in primary care settings in the Wellington region. Her mixed method inquiry included participants from rural and urban practices, private and community-led practices, and one participant employed by a nurseled and owned practice. Pullon showed that the development of trust, confidence and mutual respect of each other's professional competency, led to collaborative practice. Factors that may affect the relationship were "organisational and funding structures of the health system, organisational and employment issues at practice level and training and education issues particularly to do with on-going professional and workforce development" (p. 138). Pullon noted that interviewing only female nurses created gender imbalance between professions. Whether nurses (or GPs) believed the 'team' included administrative staff, or how the practice organisational structure affected the ability of nurses and doctors to form collaborative and collegial relationships was not described. While teamwork was identified by nurses as "fostering functional working relationships" (p. 138), there was no indication that GPs were of the same opinion. By restricting her study to nurses and 
doctors, it is uncertain if the professional collaborative relationships included the administrative staff. Pullon did not explain whether nurses' roles were solely nursing or included administrative work.

In this review, I have shown that we know nurse-patient relationships are closely associated with patients' health and well-being, and patients' engagements with medical receptionists are a significant factor in patients' perceptions of personal care. Continuing to address literature relevant to practice nurses and PHC, the following section reviews writings relating to the nature of well-being and implications for patient health and wellbeing outcomes. While there is ample literature relating to well-being and quality of life generally, what is less well understood, is how the quality of the nurse-patient relationships may contribute to patients' perceptions of well-being.

\subsection{Overview of well-being literature}

Definitions of well-being appear dependent on the authors' frame of reference, and have diverse meanings and understandings that are context specific. The WHO (2012) definition of health as "a state of complete physical, mental, and social well-being and not merely the absence of disease or infirmity", does not define well-being (Schickler, 2005), and has not been adapted since 1946 to accommodate criticism of the concept of 'complete' well-being (Huber, et al., 2011). Health and well-being are interrelated, with health usually associated with both the physical and mental well-being domains (Schickler). Major aspects of health can include an "inner and outer state of wellness, integrity and wholeness" (Jarrin, 2007, p. 87). The inner state reveals how an individual, society or culture, views their level of wellness and how well people fulfil their function in society, their lives and occupations. The outer state reflects the individual's physical appearance, how well the person is looking, or physical measures of the bodily function such as blood pressure or weight measurement. Jarrin emphasises that health may also encompass illness and dis-ease from both an individual and collective, population based standpoint.

Well-being relates to an individual's positive functioning and feeling good about their lives; ill-being is perceived as "pervasive negative feelings and poor function in life" (Boehm, Kivimaki, Peterson, \& Kubzansky, 2011, p. 259). People might be physically healthy or physically unhealthy; or they might be psychologically unwell or psychologically well. The terms well-being, wellness and health are often used 
interchangeably by the general public and by health professionals and researchers (HealeyOgden \& Austin, 2010). However, definitions of well-being are not restricted to those terms and may be described by terminology that is more diverse. The concept of wellbeing can be found in academia, in policy decisions, self-help psychology, and in interior design (White, 2010). Studies of well-being are established in "the fields of 'subjective well-being', 'quality of life', and 'life satisfaction' in psychology and social-indicators research and the "economics of happiness"” (p. 160). The 'economics of happiness' centres around economic localisation that enhances well-being (International Society for Ecology and Culture, 2011). Well-being is often associated with life satisfaction where an individual's subjective experience of well-being is influenced by their present perceptions of how they are feeling and how they view their quality of life (Mehlsen, Thomsen, Viidik, Olesen, \& Zachariae, 2005). An inherent holistic outlook connecting the individual's mind, body and spirit is fundamental to well-being (Mehlsen et al.; White, 2010).

Well-being is expressed in positive terms; that is, it requires a holistic outlook, is personcentred and focused on priorities and perspectives. "Well-being may be assessed at individual and collective levels, but at base, it is something that happens in relationships between individual and collective; between local and global; between people and state" (White, 2010, p. 158). Drawing on the work of the Economic and Social Research Council (ESRC) Research Group into Well-being in Developing Countries (WeD), White created a framework for assessing well-being. From the analysis of the $2007 \mathrm{WeD}$ study of Ethiopian, Bangladeshi, Thai and Peruvian villagers, she defines well-being as "Doing well - feeling good; Doing good - feeling well" (p. 160). Although the study and results are primarily designed for political, social and development policy, they are transferable to the work of health professionals.

Well-being can be viewed as a social process with material, relational and subjective dimensions (White, 2010), which are illustrated in the form of a pyramid (Figure 2). The triangular shape expressed interdependence and no dimension can exist without the other. Well-being is found in the interplay of 'objective' or the externally observable and independently verifiable, and 'subjective' or the perceptions and assessments of these. Commencing from the pyramid's base, the Material dimension concerns practical welfare and standards of living and income, including, but not limited to, physical health and access to services. The Relational dimension is connected to personal and social 
relationships that also included love and care, support and obligations, social, political and cultural identities and inequalities, as well as scope for personal and collective action and influence. The Subjective, human dimension is used to underpin the concept of well-being and is linked with cultural values, beliefs, perceptions and experiences, the hopes, fears and aspirations, levels of meaning, trust and confidence, personal relationships and satisfaction that people perceive as influencing their well-being. White places the Subjective dimension at the apex in order to keep the model together.

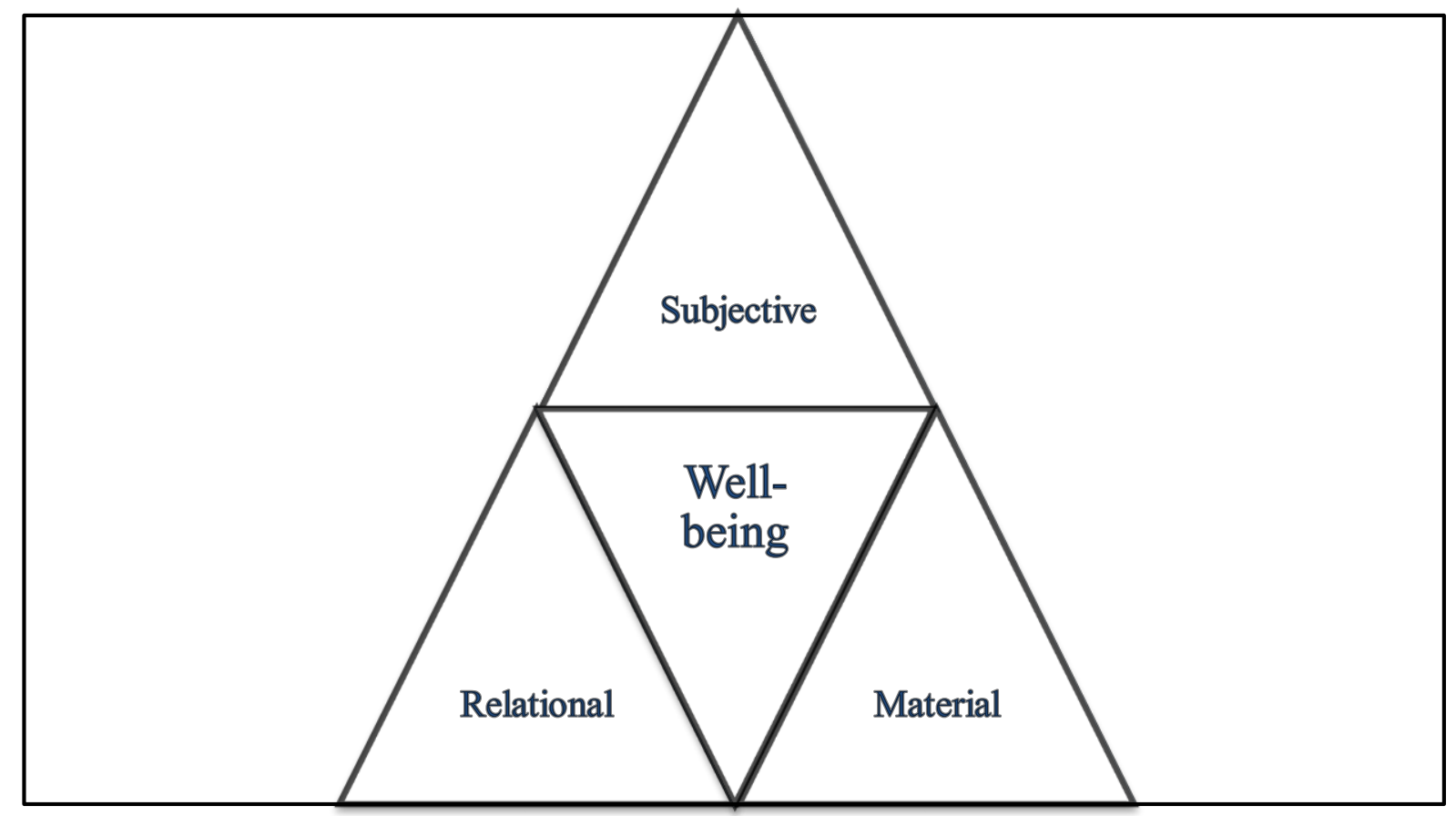

Figure 2. Well-being triangle illustrating the three dimensions

Note: White, S. (2010). "Analysing well-being: A framework for development practice," Journal of Development in Practice, 20(2). Routledge Publishing. University of Bath, UK. Adapted with permission of the author.

Much of the large volume of literature relating to health and well-being is directed towards the psychological aspect of well-being in mental health. Most research has focused on psychological ill-being with fewer studies examining well-being and physical health outcomes (Boehm, et al., 2011). While health and well-being are closely aligned in health promotion studies and ill health research, there is little literature pertaining to PHC and general practice. I found none that related to practice nurse-patient relationships and how these relationships might contribute to patients' well-being. However, I did find relationship well-being literature from other settings. 


\subsubsection{Well-being from a community health research perspective}

A study of 18 Caucasian participants aged between 45-60 years from the British community, found that being well and healthy might not necessarily be aligned with wellbeing (Schickler, 2005). Well-being is a subjective, contextual 'feeling' state that is in opposition to feeling ill, and was perceived by participants as being made up of "higher feelings of enjoyment and vitality, being in control of one's life and ethical congruity" (p. 221). Well-being can be experienced momentarily, as a feeling of euphoria or happiness, and also as a feeling of satisfaction with life that lasted longer. Although feelings of wellbeing may be diminished by stressful experiences, including negative engagements with health professionals and unexpected health challenges, physical health is not necessary for people to experience well-being. People may be unwell but can achieve well-being independently from physical or ill health. When people became acutely ill or stressed, Schickler suggests that suffering might be the antonym of well-being. Personal work and interpersonal relationships with close others or professionals are also significant factors in achieving well-being. Although the inclusion of black and mixed ethnic origin participants in Schickler's three validation focus groups assisted credibility in that setting, all these participants were middle-aged women. It is unknown whether these findings are applicable to the general practice context where patients may sometimes not have chronic conditions, or are ill. It is also not clear if these results would be similar if a greater range of ages were considered, if men were consulted, and whether the nurse-patient relationship influenced patients' perceptions of well-being.

A Danish study investigated whether evaluations of previous decades in life and cognitive processes involved in these evaluations were related to the experience of well-being and life satisfaction in old age and mental health (Mehlsen, et al., 2005). Patients between 7085 years from nine general practices were recruited for structured interviews by trained interviewers, with follow-up interviews conducted 12 months later. Results showed that, individuals who evaluated their old age as the best part of life experienced increased wellbeing. Negative aspects of life satisfaction indicated by increased depression, resulted in decreased well-being. What was not described in this study, were the experiences and evaluations of people in different life-stages. Further research using un-structured or semistructured interviews where participants could tell their stories would augment these findings. 
From the 1991-1994 phase 3 Whitehall 11 cohort longitudinal studies, Boehm et al. (2011) examined the association between two aspects of well-being - emotional vitality and optimism - and coronary heart disease in a sample of 7,942 middle-aged men and women. These authors defined emotional vitality as the "active engagement with the world, effective emotional regulation, and an overall sense of well-being" (p. 260). Optimism was perceived as the individual expecting to have more positive than negative experiences. Taken from a much larger study, Boehm et al. like Guerette and Smedema (2011) and Mehlsen et al. (2005), found that a person's sense of well-being was expressed through optimism and emotional vitality. The more optimistic patients were about their life and health, the less likely they were to experience coronary heart disease, and this positively influenced any negative coronary heart disease outcomes. This subjective perspective of well-being is also found in other health related disciplines.

\subsubsection{Subjective well-being}

Well-being is further defined by the domains of physical, psychological, economic, family and social well-being, and medical well-being. In positive psychology, subjective wellbeing is a measure of people's thoughts and feelings about their lives and level of happiness (Diener, 2000). From their literature review of the subjective well-being of patients with schizophrenia, Vothknecht, Schoevers and de Hann (2010) found that subjective well-being was also a measure of how patients' illness was managed. To demonstrate people's perceptions of life satisfaction in the relationship between perceived social support and multiple indicators of well-being, Guerette and Smedema (2011) investigated 199 visually impaired American adult participants from diverse ethnicities and ages. Objective measures for quality of life included physical or material indicators, such as marital and employment status, and physical functioning. Subjective quality of life measures indicated the individual's sense of well-being, depressive symptoms and satisfaction with life. Online questionnaires and scales showing social networks, depression, satisfaction with life, and sense of well-being were also used for data collection. Results from Gurette and Smedema's computer-based social science statistical package indicated a correlation between social support and depressive symptoms, satisfaction with life, as well as the multifaceted domains of well-being. However, this online method for data collection did not capture people who were not computer literate, those who would have preferred to hand-write their answers, or talk face-to face. 
Moreover, although Guerette and Smedema did not find significant connections in medical well-being, they did not indicate what questions were asked in this domain.

When measuring psychological well-being the focus is on psychological illness, including "anxiety, depression, coping, positive well-being and adjustment, and a sense of control and self-esteem" (Meadows, 2011, p. 147). He maintains that while psychological wellbeing is associated with an individual's quality of life, it is not synonymous with it. With greater emphasis on patient involvement in their care, researchers are examining different ways of measuring how patients view their health outcomes and quality of life (Meadows), including spiritual well-being.

The influence of spirituality on well-being is demonstrated in many studies. However, spirituality has a completely different literature and it is only briefly covered here. Green, Emery Kozora, Dias and Make's (2011) longitudinal study examined the religious and spiritual coping of 40 American patients with emphysema found that patients used both negative and positive religious and spiritual coping mechanisms. Negative mechanisms included questioning God, while positive mechanisms entailed prayer. Research applying diverse meanings of well-being was found in other spirituality studies such as AbdelKhalek and Eid's (2011) investigation into the happiness (well-being) and depression among Kuwaiti and Palestinian Muslim children and adolescents. A mixed method study explored the impact of religious and psychosocial factors of hospice patients (Neimeyer, Currier, Coleman, Tomer, \& Samuel, 2011), while Taliafero, Rienzo, Pigg, Miller and Dodd (2009) applied a linear regression model to assess the religious and spiritual correlation into suicidal ideation. Although, some participants talked of Christian church associations, and others of their Māori spiritual connections with their whakapapa (ancestors), it was not my intention to address spirituality in this research.

This review has discussed definitions of well-being that may be viewed through multiple lenses and included life satisfaction, physical, psychological and spiritual aspects of quality of life. Well-being may be experienced not only when physically well, but also when experiencing 'illnesses'. Well-being is usually viewed in positive terms and has a holistic and person-centred focus. White's (2010) simple well-being definition and framework not only clearly indicates a pathway to explore patients' experiences of well-being, but her three dimensions closely align with life course principles. People's well-being and being 
well may be experienced differently at distinct times and phases over their life-course, and the following section assesses life course literature in the context of health care with emphasis on PHC and general practice settings.

\subsection{Life course literature overview}

Life course is a theoretical orientation of great significance to human development and ageing scholarship (Elder \& Kirkpatrick Johnson, 2000). Life course studies have a social science orientation that views the process of change and development from a broad perspective (Giele \& Elder, 1998). By using age cohorts to study changing lives over time, life course theory describes a sequence of socially defined events and roles that an individual enacts over time. To assist understanding, Giele and Elders' four-part paradigm is adapted (Table 2). Implicit in these four elements are trajectories or path of life, transitions that shifts the focus of an individual's life course, and turning points, which are events that cause an individual to take a different path and demonstrate human agency (Giele \& Elder, 1998).

\section{Table 2. Life course four-part paradigm}

\begin{tabular}{|l|l|}
\hline Location in time and place & $\begin{array}{l}\text { Observing the history, social structure and cultural background of } \\
\text { the person or group being studied. }\end{array}$ \\
\hline Linked lives & $\begin{array}{l}\text { Demonstrating the results of interactions individuals have with } \\
\text { societal institutions and social groups leading to social integrity. }\end{array}$ \\
\hline Human agency & $\begin{array}{l}\text { Embodying a person's sense of self, the active pursuit of personal } \\
\text { goals, and making decisions and organising their lives. }\end{array}$ \\
\hline Timing & $\begin{array}{l}\text { The chronologically ordered events of life that simultaneously } \\
\text { combine personal, group and historical markers leading to } \\
\text { strategic adaptation. }\end{array}$ \\
\hline
\end{tabular}

Note. Adapted from Giele, J., \& Elder, G. (Eds.). (1998). "Methods of life course research: Qualitative and quantitative approaches." Thousand Oaks, London, New Delhi: Sage Publications.

Evolving from early critical longitudinal studies of the 1920s, the advancement of life course theory influenced adult development studies, becoming a significant component in social and behavioural sciences (Elder \& Kirkpatrick Johnson, 2000). While these studies demonstrate that valuable insights can be gained from following people's lives over time, the sociology of age shifted from the old age and youth stages of life, to perceiving ageing as a continuous process. This became more difficult to classify in terms of expected societal roles as each life-stage has its characteristic tasks, challenges and opportunities. Much of the past regularity has dissolved and it became unclear what people of a given age or life period share. Over a period of 20 years, what 'old people' have in common, when 
middle age begins and ends, and old age commences, has changed (Settersten, 2008). This dissolution of stable patterns of social life is consistent with Brockmeier's (2000) fragmentary model of time, which is explained in Section 4.2.1.

The developmental, social and historical meanings of age represent key elements and depict lives in terms of aging, career and historical setting. Age places a person's position in history as well as social structure. This means that where and when a person is born, and how they live, influences what career and pathway they choose in later life (Elder \& Rockwell, 1979). Any change in the way people live their lives affects their development, and both are subject to change in established pathways (Elder \& Kirkpatrick Johnson). The many advances that have been made in methods of studying changing lives over time, include disciplines such as anthropology, history, psychology, sociology and medicine (Giele \& Elder, 1998). Therefore, life course provides an interdisciplinary framework for descriptive and explanatory research that is embedded in age-graded life patterns that are enmeshed in social structures and historical change (Daaleman \& Elder, 2007; Elder \& Kirkpatrick Johnson, 2000). Daaleman and Elder adapted the original framework to encompass five core principles (Table 3).

\section{Table 3. Five core principles of life course}

\begin{tabular}{|l|l|}
\hline $\begin{array}{c}\text { 1. Human development } \\
\text { and ageing as lifelong } \\
\text { processes }\end{array}$ & $\begin{array}{l}\text { Life is longitudinal and often intergenerational. Links early life } \\
\text { influences such as culture, society, economics and family with events } \\
\text { and outcomes in later years. }\end{array}$ \\
\hline 2. Human agency & $\begin{array}{l}\text { People are envisaged as active participants who, given the opportunities } \\
\text { and constraints of history and social circumstances, construct their own } \\
\text { life course through the choices and actions they take. }\end{array}$ \\
\hline $\begin{array}{l}\text { 3. Historical time and } \\
\text { place }\end{array}$ & $\begin{array}{l}\text { Links the individual's previous developmental processes and } \\
\text { consequences of behaviour patterns, life events and transitions. These } \\
\text { elements vary according to their timing in an individual's life. }\end{array}$ \\
\hline 4. Timing & $\begin{array}{l}\text { Connects the developmental antecedents and consequences of behaviour } \\
\text { patterns, life events and transitions that also vary according to their } \\
\text { timing in a person's life. }\end{array}$ \\
\hline 5. Linked lives & $\begin{array}{l}\text { Refers to the interdependence and network of shared relationships that } \\
\text { surround individual lives. }\end{array}$ \\
\hline
\end{tabular}

Note. Adapted from Daaleman, T. \& Elder, J. (2007). "Family medicine and the life course paradigm." Journal of American Board of Family Medicine, 20(1), 85-92.

The social factors of any particular time and place form individual pathways or trajectories, and become elements of human development and ageing as lifelong processes. In an individual's life course, human agency is influenced by the integration of these elements. "The capacity to exercise control over the nature and quality of one's life, is the essence of 
humanness, and human agency is characterized by a number of core features that operate through phenomenal and functional consciousness" (Bandura, 2001, p. 1).

Two further factors influence life course theory. An extended view of the life course includes the concept of social trajectories encompassing sequences of family and work roles. The short perspective focuses on life transitions representing change, such as when a child leaves home. However, Elder and Kirkpatrick Johnson (2000) contend that during a life transition, any substantial change represents a turning point. Concepts such as lifereview and autobiographical memory that emphasise the importance of storytelling within people's lives are applied to life course research.

\subsubsection{Life course from a community perspective}

Daaleman and Elder (2007) maintain that the life course framework can be applied not only to the individual patient and their families, examining how they lived their lives, but also at the health care system level. This population perspective of health is consistent with the New Zealand's PHCS (King, 2001). Several such studies were loosely connected with general practice with authors using practice enrolment data to gain information and/or recruit participants, rather than direct engagement with patient participants (Farrimond, Saukko, Qureshi, \& Evans, 2010; Watt, Carson, Lawlor, Patel, \& Ebrahim, 2009). Hughes (2003) reviewed the summary of findings and recommendations from 14 projects of the British Nutrition Research Initiative (1997-2000). With the aim of reducing adult obesity, cardiovascular disease and some cancers, this project added to the scientific evidence used to devise dietary targets and inform policy.

From a community perspective, King et al. (2003) used "turning points" as a tool, to investigate the nature of resilience of Canadians with diverse physical disabilities. Factors that hindered or helped 15 people of both sexes between the ages of 30-50, at turning points in their lives were examined in this qualitative study. Although previous studies described various supports and strengths that operate in people's lives to protect them from risk and lead to new directions in life (Rutter, 1979, 1987, 1990), King et al. identified three new protective processes: transcending or replacing a loss with a gain; selfunderstanding and recognising new things about oneself; and, accommodating and making decisions about relinquishing something in life. These authors found that life-span perspectives and retrospective factors contained in the stories that affected a person's life 
and health, were important considerations and had implications for service delivery. Given that their research was undertaken in a community health context, it has implications for general practice, where people with diverse disabilities engage with practice nurses, GPs and reception staff. Consistent with Devine, Connors Bisogni and Sobal (1998) and Hays (2002), King et al. described significant findings such as knowledge of transitions, turning points and the resilience of individuals and families that have been shown to be applicable to general practice and practice nurses.

A number of literature reviews have focused on experiences of older people and life course. Hays (2002) examined the living arrangements and health status in later life from a public health nurse perspective. A theoretical model of the antecedents and sequelae of living arrangements in late life was adapted to demonstrate by flow-chart, the sequence of determining an individual's ability to remain in the community. Hays contends that by using the flow-chart, nurses in primary care, discharge planning, and home care, are strategically positioned to influence the living environment of older people and therefore improve their health and well-being. The applicability of her model to people in other contexts, such as people with physical or psychological disabilities, and younger people in assisted living homes, was not addressed in this study. Patients' experiences of practice nurses' assessments of their living environment was also not explored.

A grounded theory multi-ethnic study of 86 American adults looked at a model of food choice trajectory including personal and environmental factors (Devine, et al., 1998). This model was developed to reflect how past events and experiences were used to shape food choices. Devine et al. showed diverse trajectories in the development of personal food systems and choices. Life course trajectories and transitions were clearly revealed in this study, and while not specifically designed for the general practice context, the food choice trajectory model is easily transferable to the health promotion work of practice nurses.

Other life-course studies observed the influence of antecedents in an individual's life that affected their food choices (Ferraro, Farmer, \& Wybraniec, 1997; Van De Mheen, Stronks, Van Den Bos, \& Mackenbach, 1997; Wandel, 1995). Applying a life course approach to nutrition studies provided a framework for understanding how food choices develop in changing temporal, social, and historical contexts (Devine, 2005). She found that due to the ways in which individual choices and environments changed over the life-span, using a 
life course analysis including trajectories, turning points, linked lives, and timing of events in lives, was a useful research and practice tool.

Given the nature of general practice, life course "provides an ecological understanding of individual people by examining phenomena at the nexus of social pathways, developmental or health trajectories, and social change. It provides a way of thinking about patients in both proximal (e.g., lived lives and family) and distal (e.g., health care system) contexts over a life span" (Daaleman \& Elder, 2007, p. 85). From a proximal perspective, as life-course physicians, doctors would use their contextual knowledge of patients to help devise care plans and facilitate decision-making. From a distal standpoint, doctors would seek to improve the health of a defined population over the entire life course. Daaleman and Elder suggest that the life course paradigm might help individuals at different stages of their lives by emphasising health and illness trajectories, and then linking health and other service organisations. Although these authors describe the transferability of life course paradigm and the advantages of GPs applying life course principles, they appear to assume a quality of patient trust in the doctor-patient relationship that would result in patients telling the doctor what she or he needed to know, and to carry out the doctor's instructions. Moreover, that up-to-date Practice Management Systems with comprehensive patient data from which to gain information would be available for the doctor.

The evolution of life course theory described by Elder and Rockwell (1979) and others, and its significance in generating knowledge in human studies over time, demonstrates its value in, and applicability to, health care. Of note, are the links between the principles, and that one principle does not have pre-eminence over another. All the elements within the principles affect choices people make over their life course.

\subsection{Summary}

Although there is a large volume of nurse-patient relationship literature, gaps have been identified regarding practice nurse-patient relationships and understanding about these relationships from patients' perspectives. Patients' stories of how their relationships with practice nurses contribute to their health and well-being are not described in the literature. In PHC, research mainly relates to the doctor-nurse relationship, leaving the broader general practice team perspective and the kinds of relationships found within the team largely unexplored. Research into patients' interpretations of their place within those 
relationships is also not well understood. The notions of emotional labour, emotional management and emotional intelligence have not been researched in the field of general practice, and there remains a contextual gap in the understanding of the life course perspective in general practice research.

Practice nurse-patient engagements and relationships can be influenced by the many life stories patients relate to explain their health and well-being. Therefore, a narrative methodology that focuses on these stories, and informed by life course theory, became the methodology of choice. The following chapter examines Narrative Inquiry methodology, along with the analytical model I adapted to understand how the relationships contribute to patients' health and well-being. 


\section{Chapter 4 Methodology}

\subsection{Introduction}

Research methodology enquires how we know the world or gain knowledge of it (Crotty, 1998). It is a "strategy or plan of action, process, or design lying behind the choice and use of particular methods linking the choice and use of methods to the desired outcomes" (p. 3). In the previous chapter, I argued that there was a gap in the research literature concerning the awareness of practice nurse-patient engagements and relationships particularly from a patient perspective. This chapter details my chosen research approach of Narrative Inquiry informed by life course methodology and includes a particular focus on PHC and practice nurses. In discussing the approach, I refer to particular ways in which narrative has been used, as well as how I used it in my research that involved interviewing 15 general practice patients about their engagements with practice nurses. My constructionist epistemology and McCormack's (2001) multiple lens approach to storytelling analysis are detailed. I conclude with positioning my research argument and decisions.

Over several decades, the proliferation of qualitative research has advanced the science of nursing, as well as the collective understanding of the human health experience (Whittemore, Chase, \& Mandle, 2001). Qualitative research embraces several disciplines and subject matters, including a complex, interconnected family of terms, concepts and assumptions (Denzin \& Lincoln, 2005). It became an important tool in studying human group life during the 1920s (about the time life course theory was being developed [Giele \& Elder, 1998]), placing emphasis on the qualities of the individual, and processes and meanings that are not empirically analysed or measured, as in positive, quantitative research. Denzin and Lincoln's generic definition recognises its complex historical area of interest and diverse interpretations. Qualitative research is "a situated activity that locates the observer in the world; it consists of a set of interpretive, material practices that make the world visible" (p. 3).

\subsubsection{Qualitative research}

Qualitative researchers combine beliefs about ontology, epistemology and methodology. Ontology refers to the nature of reality and the kind of human beings people are (Denzin $\&$ Lincoln, 2005). It is concerned with the 'what is', with the nature of existence, with the structure of reality, and sits alongside epistemology informing the theoretical perspective 
(Crotty, 1998). Epistemology is the exploration of the relationship between the person asking the questions, and what is known (Denzin \& Lincoln). Because epistemology and ontology direct researchers' selection and use of methods, both are essential in qualitative research methodology. Each theoretical perspective symbolises a precise approach to understanding 'what is' as well as a certain way of appreciation of 'what it means to know' (Crotty). By separating narratives into ontological and epistemological categories, the researcher and reader come to form a more comprehensive and contextualised understanding of the categories (Harling Stalker, 2009). Ontological narratives set the scene, and epistemological narratives ask the questions and theorise interpretations. Both types can be used in the analysis and presentation of findings. In this research, the ontological realities of 'what is', the nature of the social reality of the participants, is articulated through narration of their stories in time and place, their socio-cultural understandings and their realities experienced through their engagement with practice nurses and general practice. Epistemology is found in the co-construction of stories (Harling Stalker; McCormack, 2001) and, as a researcher, my reflexive interpretation of the stories that describe the participants' social worlds.

Qualitative researchers' participants are generally drawn from a small sample of the population. The interview transcripts are usually used to understand how participants organised their talk (McCormack, 2001; Miller \& Glassner, 1997). In line with my chosen method of analysis, the importance of "understanding how and where the stories are produced, which stories they are, and how we can put them to honest and intelligent use in theorising about social life" (Miller \& Glassner, p. 111) was crucial. A life course theoretical orientation to my methodology was also essential to facilitate interpretation of participants' experiences with practice nurses, their culture, history, and the time of their life the stories were told.

\subsection{Life course in health care}

In the main, life course is applied as a research tool for longitudinal comparative studies such as the US Panel Study of Income Dynamics that began in 1968. This study continuously collects data from individuals and their descendants, covering employment, income, wealth, expenditures, health, marriage, childbearing, child development, philanthropy, education, and numerous other topics. Similarly, the British Household Panel Survey (1990-2002) examined change in self-rated health from one discrete state to 
another. These health trajectories were linked to socio-economic measures at the beginning and at the end of the study period. Using these studies, Sacker, Wiggins, Bartley and McDonough (2007) reviewed the US and UK literature on comparative social policy and life course research, comparing links between health and socio-economic circumstances over an 11-year period. They found that both good and poor health remained stable over time, but when change occurred, people were more likely to experience ill-health. Using Norwegian censuses, tax and death registries Naess, Hernes and Blane (2006) investigated life course influences on social inequality in mortality in early old age. These authors followed the trajectories of people aged 68-72 years through their adult working life into retirement examining pathways that may increase the risk of mortality. Most of the increased risk of mortality related to an individual's social conditions (Naess et al.).

\subsubsection{Life course, Primary Health Care and practice nurses}

In order to address health disparities, the life course approach became increasingly significant to scientists and health planners to understanding population health and wellbeing (Yu, 2006). The life course perspective views health as the product of risk behaviours and protective and environmental factors that we encounter throughout our lifetime (Daaleman \& Elder, 2007). It provides a structure for interpreting how people's experiences when young, influences their later health and ability to function. In New Zealand general practices, these disparities are addressed by the government directive that all patients be included in the Deprivation Index (GeoStan) (Ministry of Health, 2011b). This Index is used in health funding decisions to address health disparities. It enables services that cater for those who live in the most deprived areas, such as many Māori and Pacific peoples, and those of lower socio-economic groupings, to have additional targeted funding to address the health need. Gaining some understanding and insight into each participant's life history, culture and experience, facilitated my analysis of their experiences of engagements with practice nurses at specific times in their lives.

The sociological concepts of 'time' include a macro or abstract perspective, a micro or functional perspective, historical time such as looking at the Depression years or the World Wars, and the time or timing of events in an individual's life (Giele \& Elder, 1998). Ricoeur (1981) believed there were two concepts of 'human time;' time as linear succession as we experience the passing of hours and days and the progression of life from birth to death, and phenomenological time that is experienced in terms of past, present and 
future. However, Brockmeier (2000) argues that we not only deal with "classical time modalities of past, present and future, but also with different temporal orders of natural, cultural and individual processes" (p. 51). He describes six different narrative models of 'autobiographical time' (the time of one's life) as the time of autobiographical processes. Linear time perceives life as a continuous line of chronological marks, circular and cyclical time follows the linear pattern with variations, spiral time views life as a forward-moving process, static time is found in stories of catastrophe, and fragmentary time emphasises the unpredictable nature of life (Brockmeier). Given that the participants' experiences of times in their lives and where they were in their life course varied, an appreciation of the models of time added depth to my comprehension of participants' stories of their relationships with practice nurses.

Practice nurses' work necessitates engagement with people of all ages and life-stages over their life-span; from a woman who is pregnant, to the young child, adolescent, young adult, mid adult, older adult and those who are dying. Their knowledge of the patients' histories is often dependent on the amount of time available with patients or their families in directed questioning, or social chat and how long they have known them. For example, some patients may have been enrolled with the practice for a significant length of time, but because they are generally healthy, they have not required regular medical or nursing input. Therefore, the practice nurse has limited knowledge of their lives. Conversely, through many intensive consultations for childhood immunisations or chronic health conditions for example, the nurse might have a comprehensive knowledge of a person or family.

\subsubsection{Interface between life course and story}

Life course and narrative are usually about time, and change or transformation over time. In narrative research, time takes on diverse meanings depending on the content, context and construction of the narrative. Observing and listening to patients narrating stories, even those that are not necessarily health related, enhanced my awareness of a patient's life course trajectories, turning points, and transitions within it. By building on the knowledge, understanding and insight gained from this course of action, I created an intuitive connection between the 'now' story, the story that was being told at that moment, and the patient's history, culture, the time in his or her life and the links between them. These knowledge-transforming processes demonstrate the close relationship, between not only 
patients' life course trajectories and their story or stories of their lives, but also, how the kinds of relationships patients had with practice nurses influenced their health and wellbeing. I integrated people's social realities of how patients experienced their interactions and relationships with practice nurses with the knowledge I co-constructed with them from the stories. This constructionist approach aligned with my life course theoretical perspective and is addressed in more detail in Section 4.3.2.

\subsubsection{Life course and storytelling in practice}

Although practice nurses document necessary medical and social information, recording a patient's life-history is neither appropriate nor practicable. Nevertheless, people often do tell stories to describe how they arrived at a particular point of their lives. Working with these life course stories is important when engaging with patients. The following example taken from my experience as a practice nurse in a rural practice in Motueka, describes the connectedness and intersections of life course's historical time, culture, links with society, family, between generations, human agency, and timing of events in people's lives. In the past, tobacco was a significant crop grown in the Motueka area, providing employment for generations of families, people from the Pacific Islands, as well as for students wishing to save money for their studies. Although tobacco has not been commercially grown in New Zealand for about 25 years, hop gardens, and apple and pear orchards, kiwifruit orchards and other horticultural enterprises which replaced tobacco, continue to play a significant social and economic role in people's lives. While some people are financially secure in strong economic times, other people, who are seasonally employed, can be economically and educationally disadvantaged. The fishing industry also employs significant numbers of people who can be either out at sea, sometimes for weeks at a time, or in land-based fish factories. Although a number of people choose this way of life, for others it is a necessity. Moreover, for tertiary education and other career prospects, young people often need to leave their families and the region. These reorganisations demonstrate not only the trajectories, transitions and turning points in people's lives but the influence of these on human agency and the choices people make.

Practice nurses who gain knowledge and understanding of such historical, social and economic backgrounds of their patients are in an advantageous position to meet their health and well-being needs. As a practice nurse, I understood the value of listening to 
their stories and how the timing of events in their life course had influenced their choices, which in turn contributed to their health and well-being.

\subsection{Narrative in qualitative research}

Unlike other qualitative methods such as grounded theory or phenomenology, the definition of narrative is often disputed as it does not offer a framework with automatic starting and finishing points (Andrews, 2008; Riessman, 2008). However, for Ricoeur (1984), the development of narrative theory moved, via interpretative, temporal and actionorientated view-points, from a linguistic standpoint to an ethical perspective (Frid, Ohlen, \& Bergbom, 2000). From Ricoeur's standpoint, it was the activity which produced the plot, rather than the plot itself. By viewing reality as a dynamic process, narration reformulates reality and its difficulties, casting new light on familiar experiences. Narrating involves a creative process changing both the narrator and reality, therefore, every act of narration is a new one (Frid et al.). Narrative is seen as retrospective meaning making (Chase, 2005), and is a means by which people connect past and present, self and other, within the context of the cultural fabric of their social world (Lawler, 2002). People tell or write stories of past events or experiences, finding sense in these memories that produce a social reality and personal identity. Lawler perceives narratives as "accounts which contain transformation (change over time) some kind of 'action,' and characters, all of which are brought together within an overall "plot"' (p. 242). The process of creating a plot, or emplotment, is a technical process by which unrelated events, actions, characters and situations are brought together and formed into one coherent whole. It is this synthesis of emplotment that makes an account a narrative (Lawler). The linking of ideas or order, from random happenings, is often called a plot and constituted the life-blood of a narrative, with the players in the plot taking second place (Riessman, 2008).

Narratives can be material, method, or route to understanding psychological or social phenomena, or all of these, but there is considerable variability in how narrative is conceptualised, what narrative is, how to study it, and why it is important (Andrews et al., 2008). The most obvious difference amidst the concepts is between a narrator (the person telling the story) relating an event that had happened to them, and experience centred work that explores stories from segments of interviews to complete life-histories. Both event and experience narratives share the assumption that events, thoughts and feelings gave narrative expression and meaning (Andrews et al.), especially in the social sciences where 
narratives told during interviews have become a central tool of qualitative research (de Fina, 2009).

Researchers frequently call the narrative they work on 'accounts', but often fail to explain what they mean by the term (De Fina, 2009). Accounts can be descriptions, linguistic strategies, statements, justifications, excuses or explanations. Nevertheless, because they are produced in response to an enquiry, all accounts involve an explanatory (narrative) component. Paley and Eva (2005) have suggested that the use of the term 'narrative' is inconsistent and various assumptions have been made about the nature and function of narrative. Narrative may be a simple account of events; a source of 'subjective truth'; a fiction, and a way of explanation. There is also a difference between narrative and story, and misconceptions continue when the difference is not recognised. Narrativity is a continuum, with 'story' sitting at the upper end of the spectrum (Paley \& Eva). These authors distinguish between 'story,' that is an interweaving of plot and character and whose organisation is designed to elicit a certain emotional response from the reader, and 'narrative', which they refer to as the sequence of events and the claimed causal connections between them. It is proposed that all talk and text are not narratives, and storytelling is only one type of communicative exchange that is used to gain certain effects (Frank 2000; Paley \& Eva 2005; Riessman, 2008).

The terms narrative and story are used interchangeably in many texts (Bingley, Thomas, Brown, Reeve, \& Payne, 2008; Bleakley, 2005; Fairbairn \& Carson, 2002; Frank, 2000; Hinchman \& Hinchman, 1997), however, people do not tell narratives, they tell stories (Frank), and stories are narratives (Wolf, 2008). Aristotle also used these terms synonymously (Greenhalgh, Russell, \& Swinglehurst, 2005). He defined 'story' (narrative) as having three characteristics - an unfolding of events and actions over time; emplotment, identified here as the "rhetorical juxtaposition of those events and actions to evoke meaning, motive and causality" (p. 443); and trouble - the unexpected in the form of a surprise. Greenhalgh et al. add embeddedness, which is the personal story that nests within a particular social, historical, and organisational context. Narrative has a clear sequential order that connects events in a meaningful way, for a definite audience, and provides insights into people's experiences (Hinchman \& Hinchman, 1997; Paley \& Eva, 2005). It is a form of expression recognisable as a story comprising a clear, sequential order that connects events that make sense (Bingley, et al., 2008). Based on time, it has a plot, a 
beginning, middle and end. Although there are many ways to speak and write, narratives require a longer turn at talk, than accounts do, to consequentially link events or ideas, or eventuality (Riessman, 2008). In text, narrative and story do not exist independently from one another. Narrative is a linguistic construct, and story a cognitive construct, but the way that story is understood can vary between both versions (Patterson, 2008). Early academic narratives focused on the story content, the 'what' of narrative, that effectively reduced stories to a set of formal rules and typical structures, but, in contemporary narrative, the mechanistic methods of gaining knowledge has been challenged (Bleakley, 2005). Like the previous authors in this paragraph, Bleakley describes narrative as a root organising principle of human activity, with a plot structuring the narrative by sequencing events. The study of narrative has been associated with literary texts that usually focused on the technical components of the narratives (Lawler, 2002). However, more recently, the use of narrative has been applied in social-scientific work to draw attention to the significance of narratives in studying the social world, how it was interpreted, and the place of the people in it (Lawler).

Telling stories is considered a natural human impulse and a way of making sense of experience, and storytelling is relational (Frank, 2000; Mishler, 1986; Riessman, 2008). The act of telling a story is not only a relationship where one person may be speaking and another listening, but listeners are part of the storytelling process (Frank). Stories are about shared memories brought into the present, with shared futures being expressed in 'one day when' stories. Stories affirm what people mean to each other, and who they are in respect to each other (Frank). Storytelling also happens collaboratively in a cultural context where at least some meaning and conventions are shared (Riessman). However, to be able to understand what is being told, listeners or readers need some ordering to make sense of the story, as well as to evaluate it. Some researchers use the term personal narrative to indicate that they are not referring to literary narratives or folklore, but describing, in a more generic sense, the use of diaries, journals and letters, as well as autobiographical stories (Chase, 2005).

My belief that stories gain a particular relevance at times of life transitions or change, dovetails with my life course theoretical orientation and constructionist epistemology. However, tension exists between the type of narrative that comprises a clear sequential order with an explicit beginning, middle and end, with the kinds of narratives presented by 
patients to practice nurses. While some stories follow this process, I have found that in many situations, the organisation of patients' stories unfolds in fragments during the consultation, or even episodically over a number of consultations. Patients' stories may be brought together by a theme rather than time (Riessman, 1993), but the sequence of stories is revealed over time.

To resolve the tensions I experienced within the many descriptions of narrative research, I returned to my research question. All the participants in the study uniquely experienced their lives, histories and cultures and expressed their engagements with practice nurses in the context of that uniqueness. Therefore, the explanation of narrative that sat most comfortably with me was that of Lawler (2002). She describes narrative as a means by which people connect past and present, self and other, within the context of their cultural fabric of their social world. The integration of people's social realities linked well with my life course theoretical orientation, signalling a way of co-constructing and analysing patients' stories. Following deliberation of the many descriptions of narrative and story, I chose to use the terms narrative and story interchangeably.

\subsubsection{Narrative Inquiry}

Narrative Inquiry is often identified with the social sciences and has substantively developed in the fields of history, anthropology, psychology, education, and sociology. Life-story narrative was used as early as the 1900s when Freud undertook case-study analysis using the stories of his patients (McEldowney, 2002). Later theorists preferred to explore how stories were used rhetorically in social contexts. The antecedents of contemporary narrative social research occurred post-war (after 1945) offering two parallel lines of academic inquiry (Andrews, 2008). The first line encompassed anti-positivist, empirical rise of humanistic person-centred approaches within western sociology and psychology. These often included individual case studies, biographies and life-histories. The second line encapsulated the structuralist, post-structuralist, post-modern, psychoanalytic, or de-constructionist theories. Writers such as Foucault (1972), Lacan (1977) and Derrida (1977) were concerned with the post-structuralist stream using approaches that were often focused on story structure and content, and the "narrative fluidity and contradictions, with conscious and unconscious meanings, as well as the power relations within which narratives become possible" (Andrews, p. 3). Storytelling sought to better understand the "why" behind the human action. 
Narrative Inquiry is a method that uses data sources such as stories, autobiography, journals, field notes, letters, conversations, interviews, family stories, photos and other artefacts, and life experience (Clandinin \& Connolly, 2000; Miller \& Glassner, 1997; Silverman, 1993, 1997). Each experience is perceived as being on a continuum of the imagined present, some imagined past and some imagined future. "In explanatory narrative research, the researcher seeks to render an accounting via narrative of why something happened" (Sandelowski, 1991, p. 163). For Chase (2005), Narrative Inquiry is an "amalgam of interdisciplinary lenses, diverse disciplinary approaches, with both traditional and innovative methods - all revolving around an interest in biographical particulars as narrated by the one who lives them" (p. 651).

Narratives are not an individual's personal impression, feelings and opinions, they are always composed jointly, and are essentially co-constructions, with the seen or unseen audience exerting their influence on what is said or explained and what is left out (Riessman, 2008). Narratives of personal experience are pivotal to a rich and nuanced understanding of social phenomena and Narrative Inquiry allows participants to speak without interruption and to tell what happened (de Fina). There is no perfect interview that can provide the whole story or the real 'truth,' therefore, the interview method "necessarily depends on people's varying abilities to recall the past, comprehend the present and consider the future" (Gerson \& Horowitz, 2002, p. 211).

My review of the authors' assessments of narrative and Narrative Inquiry covered in this section, informed my decision to utilise this methodology. Guided by Groleau, Zelkowits and Cabral (2009) and in line with my definition of narrative, one of the strengths of Narrative Inquiry in healthcare research is its appositeness to patients' experiences and comprehension of their health and well-being within their social and cultural contexts. Through participant interviews, my co-constructed stories of their engagements and experiences with practice nurses enabled me to explore these relationships by a method that revealed features of interactions that had not previously been acknowledged in the literature. These stories had their foundation in participants' cultures, socio-economic and health histories, and the timing of events and experiences in their lives. The construction of the stories was influenced by the context of their experiences as well as the context of their interpretations of their experiences in the interviews (McCormack, 2001). 


\subsubsection{Construction in Narrative Inquiry}

My chosen epistemology is constructionist rather than constructivist. Although constructivism and constructionism are closely associated (Bryman, 2004; Crotty, 1998; Mason, 1996), the constructionist approach strongly links with my life course theoretical orientation (Daaleman \& Elder, 2007; Elder \& Kirkpatrick Johnson, 2000; Holstein \& Gubrium, 2000). From a life course constructionist perspective, how "facts" are collected and the meaning and use of them in everyday life, is examined (Holstein \& Grubrium). Constructivism centres on participants' individual accounts which contain some "meaningmaking activity of the individual mind" (Crotty, p. 58), reflecting the unique experience of each of us. Constructivism suggests that while each individual's approach to making sense of the world is as valid and worthy of respect as another's standpoint, it denies any critical expression. Constructionism emphasises the influence our culture shapes the way in which we perceive and feel things, providing "a definite view of the world" (p. 58). In constructionism, the experiences of the narrators, their stories told and knowledge acquired, are the consequence of the shared generation and communication of meaning. Without denying each person's unique experiences and approaches to meaning making, this collective construction (Crotty; McCormack, 2001), better reflected the experiences of the participants' relationships and engagements with practice nurses through expression of their social, historical, cultural and contextual knowledge. Through these ontological and epistemological lenses (Harling Stalker, 2009), I perceived the interviews to be sites for knowledge construction (Mason, 2002). The stories, grounded in the relevant contexts are a co-production through which participants' thoughts and actions are interpreted. The coconstructed stories were the product of an interaction between the participant-storyteller and myself, the researcher-listener. The researcher-listener describes who the people are, and expresses transformation or change across times and places (Harling Stalker; Lawler, 2002; Squire, 2008). To address the tension of how to analyse the stories within stories that drew out the participants' meanings of their stories, I required a method of analysis that viewed the transcripts from a number of different perspectives.

\subsubsection{Narrative and nursing practice}

Narratives have been viewed not only as a means of improving knowledge about nursing care, but also as a method of nursing research (Frid, et al., 2000). Compared to social science research, narrative in nursing research is relatively new. Narrative and storytelling 
are depicted independently, with narrative first being established in the Cumulated Index of Nursing and Allied Health Literature (CINAHL) in 1997 (Frid et al). Narrative is defined as an account of events experienced by the narrator, while storytelling is the reiterated telling or reading of a story by a person other than the narrator (Frid et al.), and even though narrative was beginning to be significant in theory development within nursing science (Benner \& Wrubel, 1989), it was not then perceived as a concept (Frid et al.). Despite the origin of narrative research being unclear, the narrative researcher is exposed to many influences and Narrative Inquiry is found in diverse nursing contexts (Emden, 1998). For example, to evaluate the effectiveness of a nursing doctorate (Howell \& Coates, 1997), in the context of community health care nursing (SmithBattle, Diekemper, \& Drake, 1999), in mental health nursing (McAllister, 2001), and in lifestories of nurse educators (McEldowney, 2002). Storytelling research is established in palliative care studies (Bingley, et al., 2008), and in stories of people in residential care facilities (Ervin, Cross, \& Koschel, 2013; Thompson, 2011), in wound care studies (Morgan \& Moffatt, 2008a) and in PHC practice nurse context (Fyers, 2008).

Narrative is utilised by nurse researchers as a way of understanding the lived experience of patients, with researchers taking a reflexive approach to understanding narratives in nursing care (Koch, 1998). Stories, and research on stories, complemented nursing practice helping nurses reveal what they do (Carson \& Fairbairn, 2002). Narrative research facilitates the development of nursing knowledge by emphasising nursing practice, and, by taking nurses' stories seriously, narrative research methodology is also respectful of nursing practice (Carson \& Fairbairn). Nurses are becoming actively involved in practicecentred inquiry to better understand patients' experiences in ways that developed their nursing role (Frost, 2004). For example, Wolf (2008) explored clinical work that included descriptions of unique and essential nursing practice, uncovering accounts that used nurses' stories to interpret and enhance understanding of their lives at work. Narrative methodology is organised around the key concepts of listening, learning and leadership (Carson \& Fairbairn). Listening to, and learning from stories generates new knowledge in authoritative and authentic ways (Carson \& Fairbairn; Frank, 2000). There is also value in analysing the concepts and language of stories. No matter what approach, nursing research should be presented in such a way that the maximum number of people - nurses, policymakers and colleagues - are able to understand what was found (Carson \& Fairbairn). For 
Carson and Fairbairn, analysing stories is more about ways of listening to, and learning from others than the researcher's single interpretation of the stories.

Conversant with life course principles, I explored how the principles could be positioned within the story research context. This examination culminated in my choice of a humanistic approach using storytelling as a method that would highlight not only the human agency of participants, but also how their choices were influenced by their relationship with practice nurses. This method drew on participants' individualised descriptions of their engagements and relationships with practice nurses and is congruent with Bruner (1990) and Squire (2008) who reminded me that stories play a significant role in building personal identity and agency. Particularly pertinent to my research and consistent with Bruner and Squire, is Clausen's (1998) assertion that a person's identity and sense of self is closely linked to human agency and the life choices they make. Given these links with personal identity, a method of analysis that views participants' stories from different perspectives and retaining an accountable and ethical focus, I looked to McCormack (2001) for guidance.

\subsubsection{McCormack's multiple lens model}

McCormack's (2001) model "From interview transcript to interpretative story" methodology inspired me, and is a novel method of presenting life-story data that informed my data analysis. Her study explores how the experience of being a post-graduate research student changed the way women constructed and experienced leisure in their every-day lives. This lens model was also used by Dibley (2011) in her study of experiences of lesbian parents in the healthcare system. McCormack (2000) begins the process by viewing the transcript through the narrative process lens, listing the titles of small stories she found within the larger story. The story titles summarise each small story's evaluation. Story titles represent the point of the story, such as "There is an overlap between leisure and study: Going camping with friends" (p. 109). McCormack reflected on these titles noting how the story came together. To test her initial theory, she then viewed these small stories from each lens of language, context and moments, which added to the overall theme of the story "This was a real holiday" (p. 289). Taking each lens as an analysis heading McCormack completed the stories which were returned to participants for comment prior to the follow-up interviews. Further interpretation of the stories were included in the final 
draft. McCormack does not stipulate that her model be meticulously followed, but offers it as a guide for analysing transcripts.

\subsection{Positioning my research argument and decisions}

In practice nurse-patient engagements, stories can play a significant part in determining the outcome of the consultation and therefore the patient's health and well-being. Without stories, the depth of meaning and understanding in the what, why, how and who, can be unheard, unobserved and unrecorded. Occasions where this unheard story may be found is when time constraints limit the engagement, or in those brief consultations where a patient might 'pop in' for a blood pressure check and, without further clinical enquiry into the reason the patient wanted a check, the story behind the concern can be lost. The consequence of this 'lost' story has the potential to change the outcome of the consultation. For example, further enquiry might reveal the patient had experienced unusual headaches, or that close family members have died of cardiovascular disease raising concerns about their own risk of illness. The result of listening to the patient's story and holistically observing the storyteller can indicate to the nurse that further assessment and follow-up care are required and should be offered. For people who have built up a relationship and rapport with the nurse over time, stories of life events and experience can lead to growing trust between them, allowing patient and nurse to work in partnership.

This patient-centred approach is consistent with my research objective of describing patients' engagements and relationships with practice nurses. How individuals narrate their experiences is as important to the meanings they communicate, as is what they say (Chase, 2005). Through my interpretation of McCormack's (2001) multiple lens analytical method, and the contextual, subjective relational and reflexive nature of contemporary narrative research, this study will uncover how these engagements contribute to patients' health and well-being.

\subsection{Summary}

Described in this chapter were the diversity of meanings and approaches in qualitative research and Narrative Inquiry. Issues relating to the study's constructionist epistemology were addressed as was the interface between life course theoretical orientation and storytelling in practice. McCormack's multiple lens approach to analysing narratives was 
also introduced. The methods used to carry out the study are outlined in the following chapter. 


\section{Chapter 5 Methods}

\section{$5.1 \quad$ Introduction}

This chapter describes the study setting, access to sites, recruitment and sample selection. The data collection process using narrative interviews informed by life course theory, and the analysis that applied McCormack's (2001) multiple lens approach are presented. Because of my role as a practice nurse, the section on reflexivity addresses my thinking around the challenges of the insider/outsider conundrum, and this thread runs throughout the chapter. Other issues relating to my position as a nurse researcher are also addressed. Caring for research participants requires the researcher to be ethical and accountable, and I discuss ethical implications relating to participants and their stories, as well as issues of trustworthiness, power and control, the Treaty of Waitangi, and professional boundaries. The chapter finishes with a discussion of research rigour and the methodological issues I experienced.

\subsection{Setting}

Fifteen participants were recruited from three rural and five urban general practices in the Nelson and Motueka regions of the South Island of New Zealand. Urban practices were located in a small city of about 46,000 people, and the rural practice in a town of approximately 7,500 people that also drew patients from the densely populated surrounding area. All practices were members of the Nelson Bays PHO.

\subsubsection{Site access issues}

Gaining consent to begin recruiting participants, proved challenging. I had understood that permission for Common Site Access to general practices from the local PHO only, was required. However, after discussion with the Chief Executive Officer and the General Practice Regional Facilitator regarding the political nature and independence of general practices in New Zealand, my request was declined. Consequently, I needed permission from each practice principal. This was a daunting prospect as I was well aware how difficult it was for non-patients to arrange appointments with GPs. Furthermore, as some practices were large, with a number of principals, numerous meetings would be required. However, following discussion with the General Practice Regional Facilitator, I organised meetings with each practice manager who then discussed the study with the principals at their practice meetings and obtained approval for the study. To achieve as broad a mix of 
practices as possible, I approached eight practice managers, and seven practices agreed to participate (Appendix 1).

Invitation flyers targeting patients were placed in waiting-rooms by practice managers who also requested their receptionists to advise patients of the study (Appendix 2). The invitation set out the intent of the research, stating that the Upper South B Regional Ethics Committee had approved the study (Appendix 3). Information sheets describing the research and interview process were also placed on reception desks, either to be given to prospective participants, or for people to take with them (Appendix 4). In some larger practices, the waiting rooms were expansive and, by comparison, notice boards very small. In most instances, practice managers placed the flyers and information sheets as I requested, but when I questioned people known to me, they reported that they had not observed the posters or the information sheets when they had been to a practice. Because many receptionists and practice nurses worked part-time, practice managers might have found it difficult to remember to prompt staff about the study which may have been a factor constraining the recruitment process.

\subsection{Selection of participants}

The study inclusion criteria stated that participants were to be 20 years or older, speak and understand the English language, and have the time to take part in the two interview process. To obtain diverse experiences of patients' engagements and relationships with practice nurses, I wanted participants of both sexes, a range of ages, different ethnicities, and a cross-section of health issues. Excluded, were friends, relatives, neighbours, colleagues, and, initially, patients who were enrolled with the practice where I worked. These criteria were designed to reduce the possibility of coercion involved in the research process (Karnieli-Miller, Strier, \& Pessach, 2009). Because adults under the age of 20 were less likely to access practice nurse services during the recruitment time-frame, they were excluded from the study. The possibility that some participants might withdraw was also a consideration in the number of participants recruited.

Although I expected each of the seven Locality Organisations to contribute between one and five participants, this did not happen. While seven people replied to my initial invitation, all were from the larger Nelson urban area. Three participants were from two larger practices, and one participant was from a small practice. Participants from the larger 
practices had experiences of smaller practices, as described in Section 2.3. To obtain participants from a rural practice, with the support of my practice manager and practice nurse colleagues, I applied to the Ethics Committee for approval to amend the study (Appendix 5). Following the placement of the study invitations in the waiting room, eight people requested to take part. Even though patients who were familiar to me may also respond, I was one of three practice nurses at the practice, which provided a broader foundation for my study. The ethical implications of interviewing the seven participants from other practices and eight from my practice are discussed later in Section 5.8. Eleven of the 15 participants were interviewed in their own homes at their request; one participant asked to meet at my home, which I agreed to do. Three participants chose to be interviewed in their offices during working hours, with one of those participants not taking part in the second interview.

\subsection{Preparation of the researcher}

Practice or pilot interviews are a means by which qualitative researchers gain skills in interviewing techniques and data collection and test potential questions. They also provide the opportunity for a researcher to explore their use of language and active listening skills (Banner, 2011). In planning the research, I was aware that, as a researcher the questions I asked would influence the outcome of the research (Reflective journal, 10/06/09). My pilot interview was especially significant, not only for my listening and responding skills in an unfamiliar situation, but for learning to manage two unfamiliar audio-recorders. I chose to use two recorders to cover instances where I might inadvertently lose part of the interview through high noise interference or other technical disruptions (Banner). In my reflective journal (14/10/09), I noted that "I did not need to ask many questions beyond 'can you tell me?' as the pilot participant told me five stories of her engagements with practice nurses that all revolved around the kind of relationship she had with nurses. I also observed I had difficulty in keeping my practice nurse self separate from my position as a researcher. When I reflected my understanding of her experiences with practice nurses back to the participant, she said she felt I was 'leading or channelling' her responses as what I had recorded was not what she thought she had said." Initially, during the pilot interview I found note-taking and checking my prompt questions very distracting. It affected my ability to be attentive and to actively listen, blocking the flow of the participant's story. Therefore, I stopped writing notes until after the interviews. Audio-recording allowed for repeated listening, freeing me to be 'present' with participants in a reflexive relationship, 
and while transcription of the interviews did indicate pauses, laughter, false starts, talking over each other and interruptions, I did not focus on them as part of my analysis. Although I recognised that these factors were possibly significant in my research, my emphasis was on the interpretation of the participants' overall story. Following the pilot interview, I reflected that the way the participant told her stories was different to my initial expectation that they would be similar to the way nurses told stories, but that of course they were not (Reflective journal, 14/10/09), as they were a patient's account.

\subsection{Interviewing for a Narrative Inquiry methodology}

Three forms of interviewing generate patients' stories about their experiences: standardised or structured interviews that apply the same format for each participant; semi-standard or semi-structured interviews, where the interviewer has the same major questions but can vary the timing and ask further questions; and non-standard or un-structured interviews, where the researcher has a list of topics (Fielding \& Thomas, 1993; Riessman, 2008; Roulston, 2010). Un-structured or semi-structured interviews are valuable strategies for discovery, allowing insight into participants' experiences and what these experiences mean for them (Fielding \& Thomas; Riessman, 1993). I used an un-structured interview approach and asked open-ended questions such as "tell me what happened," that allowed participants to tell their stories (Riessman, Silverman 1993). In un-structured interviews, researchers collect individual narratives which are then analysed for structure, coherence and meaning in the particular social context (Greenhalgh, et al., 2005). Un-structured interviews also use key structuring devices, such as metaphors, imagery and rhetorical devices to imply causality and agency (emplotment), and linking events in time (chronology) (Greenhalgh, et al.). Roulston describes how, during interview-talk, sensemaking is found in participants' explanations, ascribing, justifying, praising and disagreeing (McCormack, 2001; Rosenthal, 1993).

The research interview is an interpersonal conversation between two people discussing themes of mutual interest (Kvale, 1996). One-to-one, face-to-face interviews are a commonly used data collection method in qualitative research (Banner, 2011; Ryan, Coughlan, \& Cronin, 2009). Qualitative researchers use four major methods that are often combined, and include observation, analysing texts and documents, and recording and transcribing open-ended interviews (Silverman, 1993). Observation is fundamental to understanding another culture, and textual analysis provides understanding of participants' 
categories (Silverman). It was essential that during the interview, I thought about the participants as social and cultural narrators of the stories that they chose to tell. To be truly ethical, in the analysis I needed to be inclusive and not edit out the less interesting stories (Mason, 1996; McKenzie, 2007). However, as a researcher, if I took interviews at face value without searching for what was not apparent, I risked being taken in by participants who might want to portray themselves in a certain light (Sandelowski, 2002).

\subsection{The interviews}

My reading and interpretation of narrative research methods for obtaining stories from text, audio-recorded or videotaped interviews, directed me to choose a face-to-face audiorecorded interview process that was congruent with the research question and aims of the study (Roulston, 2010; Ryan, et al., 2009). This form of data gathering preserves the stories and prevents possible memory failure or misinterpretation of the participant's meaning. While this method of data collection could not portray visual or body language such as facial expressions, hand and arm movements or posture, the recordings did capture language nuances used by the participants and by me (McCormack, 2001). Interpreting the story and gaining meaning, language and para-language, such as tone of voice, pauses, laughter, as well as visual elements such as eye movements, facial expression, body posture and gestures and emotions, is difficult to define and measure (Andrews, 2008). Nevertheless, participants' emotional inflections of happiness, sadness, anger, frustration, fear and uncertainty were apparent in the recordings and recorded in my notes written following the interviews. For example, a participant with the spinal injury firmly and politely reframed his identity as a "wheelchair user' rather than someone who was 'confined to a wheelchair"” (Reflective journal, 07/04/10). When participants were uncertain how to proceed, or needed encouragement to elaborate on what they had said, or to tell another story, I invited stories by using prompts.

My objective as a researcher was to have the storyteller elaborate, with feeling, what had happened to them in their life; to get the "insider's" voice (Atkinson, 2002). (Insider/outsider research is discussed in Section 5.7.1). For Roulston (2010), like Atkinson and Sandelowski (2002), although some researchers assume they can access the authentic selves of participants via interview talk, problems arise if participants tell researchers something they think the researcher wants to hear, rather than using their authentic voice. While I accepted this might be a possibility, I was unsure if I would 
recognise a non-authentic story. If inconsistencies did arise, I asked for clarification and the participants' own interpretation of the story either at the time, or at the second interview. This was my approach even for participants whom I knew from my own practice.

During the storytelling research interview, the gender of the participant is a factor in how they respond to questions (Overcash, 2004). Female participants might bring many concepts into the central topic, such as the shock experienced at a diagnosis, how their sense of self was affected, and how their families reacted, while the response of males might be more linear (Overcash). I had found this distinction in my every-day working experience, and it was also apparent during the interviews. Women were more likely to elaborate on their story without the need for prompt questions, whereas men were more likely to need encouragement, and specific questions to answer.

Each of the participants told their own stories, the way they happened, in their own language, in the best way they knew how (Frank, 2000; McCormack, 2001). The relationship between myself, as both nurse and researcher, and the participant, particularly the relationship with my own patients, had the potential to affect the outcome of the interview (Gubrium \& Holstein, 2002). I was careful to explain that, although I was a practice nurse, I was not there in a nursing role, and that, as I was interviewing them as a researcher, my interest lay in their stories (Asselin, 2003; McConnell-Henry, James, Chapman, \& Francis, 2009). Nevertheless, it was because I was a nurse that I was asking for their stories to uncover what it was in their relationship with practice nurses that contributed to their health and well-being. It was in that sense that being a practice nurse who understood the situational context of their stories (McCormack, 2001; Theodosius, 2008) was important for the research. Drawing on my reflections from the practice interview where the participant felt "channelled," the initial interviews began using a conversational, un-structured approach to draw out participants' lives, their work, or retirement, and their hobbies. The follow-up questions and prompts did have some structure to uncover further stories of their engagements with practice nurses.

\subsubsection{Initial interviews}

From my experience as a practice nurse, I was familiar with patients' body language that often indicated when their concentration or time limit was reached. Although I planned for 
the two interviews to take approximately one hour each, I did not expect participants to continue beyond the time they felt they could manage, or my prompts failed to elicit new information. I asked participants preliminary questions such as, "Tell me about yourself, have you always lived here?" and, "Tell me in what way a practice nurse has, or has not, made a difference to your health and well-being?" But to keep the flow of the story, the interviews tended to be 'conversational' while at the same time, as uninterrupted as possible (Ryan et al., 2009). Prompts, such as "Has your experience with a practice nurse always made a difference?" "Why is that?" "How did you feel at that point?" "So that created a change for you?" and "What happened next?" were included. While I was mindful that finding understanding from their own stories was empowering for participants, I remained aware that, although the interviews included an informal aspect, there was always a power imbalance in the interviewer/interviewee relationship (Grubrium \& Holstein, 2002; Ryan et al.). However, as researcher I could empower participants to find and speak in their own 'voice;' to tell their own story in their own words.

In my initial discussion with all participants, I emphasised the importance of them telling their story in their own words because it was they who owned their experience and what meanings they learnt from it. As researcher and operator of the audio-recorders, I could stop recording or remove any comment that participants did not wish to be transcribed or used for analysis. My awareness of my place in the research process and the context of my relationship with participants were constantly present (McCormack, 2001). Further information relating to how professional boundaries were managed in the interviews is provided in Section 5.9. During the interviews and writing up the findings, my voice was reflective and reflexive as I did not want my voice to override that of the participant and the participant's experience. Despite some participants beginning the interview with a statement or an account of their experiences, my interview prompts brought forth elaborations that produced stories (Frank, 2000). A journal entry (25/08/10) describes me being aware of letting the conversation flow without interruption except for prompts. It is noted I was aware of not asking participants questions, such as "do you feel supported by the nurse, or do you feel you are treated like a number?" that could direct their response. This meant these kinds of stories had to arise from the participants themselves.

An independent qualified transcriber who had signed a confidentiality agreement (Appendix 6) transcribed the interviews, following which I reviewed each transcript for 
accuracy. I then wrote the interviews up as individual stories, which I returned to the participant for "respondent validation" or "member checking" (Lincoln \& Guba, 1985; Sandelowski, 2002; Silverman, 1993) and "member reflections" (Tracy, 2010). While member checking is a common method of validating interview data, as a measure of trustworthiness it cannot be taken at face value. Participants may forget, or regret what they have said (Kvale, 1996), feel compelled to agree with the researcher, or present themselves in a different light at different times (Sandelowski). Tetley, Grant and Davies (2009) found that although returning the full interview transcripts back to participants contained too much information and participants were more likely to focus on grammar and syntax, writing up participant interviews as a story was a way of managing the interpretation process. To ensure that any question of misrepresentation could be directly addressed I took the original transcripts to the second interview with me. However, none of the participants accepted my offer for them to read these full transcripts.

\subsubsection{Second interviews}

The second interviews provided space and time for participants to discuss their thoughts as well as responding to any further questions I had. A journal entry noted that "participants seemed to greet me like someone they know" (19/04/10); they welcomed me with genuine friendliness, with their written stories placed in front of them. While the stories were well received by all the participants and the content and context of the stories were not an issue, grammar and sentence structure errors and the frequent use of idioms (Tetley, et al., 2009), especially in the verbatim accounts, were highlighted by some. Misspelling of place names and misinterpreting the participants' meanings were also underlined. Some of these issues might have arisen due to the way I linked verbatim sections to construct the story.

The second interviews were critical for my interpretation of participants' meanings as they were a way in which to review the initial story. Supported by the prompt questions and reflexive journaling, the follow-up interviews allowed me to address some of the questions raised by the initial interviews and aid continuing interpretation (McCormack, 2001). They were also a further opportunity for participants to engage with their story, morally, emotionally, aesthetically and intellectually (Ellis \& Bochner, 2000), and share any other observations they may have. During the second interview, I took a more purposeful approach to enable further construction of their stories. Any reinterpretations or additions to the original story were included in the over-all story. Even though these augmented 
stories were not returned to the participants for a third time, the process did allow for coconstruction of the stories (Sandelowski, 2002; Silverman, 2001). Constructivism suggests returning several times to participants for further information (Bryman, 2004; Mason, 2002; Patton, 2002; Silverman, 2010), however, time constraints and ethical concerns relating to third parties, prevented repeated returning to participants, for example, how husbands or wives talk about each other. In these second interviews, I also requested clarification of their understanding of the practice nurse role, and if there was anything else that they would like the practice nurse to do, or do differently. The responses to these and other questions relating to the practice as a whole were integrated into their story.

\subsection{Reflexivity}

Reflexivity is the process by which the researcher is constantly self-critical of their actions and role in the research process (Mason, 2002). Reflexivity involves researchers scrutinising their conduct throughout the research process by means of a research diary and critical reflection. Taking this approach, I found the stories participants related to me were event as well as experience centred (Labov, 1972; Ricoeur, 1981). For example, I wrote in my journal (16/3/10) that even though I had known the participant as a patient, I felt "uncomfortable when interviewing him in his own home but unsure why" and I needed to separate my researcher self from my personal self. However, the more I listened to participants' stories, the more I appreciated Frank's (2000) tenet that listening is about the willing acceptance of different beliefs, and of lives in which these beliefs make sense. Working in general practice and PHC for many years, I have listened to numerous stories and I was comfortable working with people from diverse backgrounds, experiences and histories. However, I became increasingly sensitive to the positioning of the context, culture and language used by participants when telling their story (McCormack 2001). Drawing on my own experience, this understanding was replicated when I detected a tension between actively listening to patients and recognising my own prejudices, beliefs and attitudes. I did consider that, in a research context, my Pakeha/European, middle-class culture might subconsciously influence my engagement with participants, and that people I did not know may have been reluctant to talk to me because of their perception of my cultural and social traditions. Acknowledgment of this tension is crucial in maintaining relationships with people who might describe accounts of their life experiences or events that reflect their history, culture and beliefs, but conflicted with my history, culture and beliefs. For example, my history, training experience, culture and beliefs led me to 
appreciate the necessity and availability of vaccines, while others might have opposing experiences or beliefs they have gained from their histories and cultures. This challenge was managed by journaling my reflections immediately leaving the participant, adding to the study's accountable and ethical approach. I was aware of my apprehension when interviewing Maori participants and inadvertently causing offence, and how reluctant one participant was to answer questions from a practice nurse without building a relationship first (Reflective journal, 14/05/10).

It was essential for me to explore the philosophical foundation of my research study to identify the choices, challenges, and philosophies from my standpoint as a researcher (Banner, 2011). I used my research diary to scrutinise factors that might influence the collection and analysis of data, such as preconceived ideas about particular phenomena, especially about participants from my practice. For example, journal entries (04/11/09; 21/10/10) note my continuing pondering over the meaning of story and how each participant's small stories fitted into their whole story. However, by returning to Lawler's (2000) definition of story I gained clarity. Labov (1972/2006) also did not seem to fit with what I was doing nor help me address "if the participant [had] perceived me as a 'friend' rather than a researcher or [practice] nurse" (Reflective journal, 05/12/10). I was also cognisant (Reflective journal, 10/10/09, 2/11/09, 30/11/09) that some questions might be perceived as invasive which had the potential to limit the analysis if I did not ask them. I was unsure how much my culture and way of being as a person and a nurse would influence my interactions with participants both known and unknown. Journaling meant I could track my thoughts and ensure I remained engaged with the research data and process.

Writing my observations in a research diary immediately following each interview allowed me to set out my feelings and reflections of how the interview had progressed. Any concerns I encountered, and comments of interest for possible inclusion in the second interview were documented. For example, following the first formal interview (Reflective journal, 30/11/09), I wrote that I had observed from the participant's demeanour and talk, that she was apprehensive about the research and unsure of what it was for (Ryan, et al., 2009). I also noted my anxiety relating to asking questions I thought might have been intrusive for the participant, as well as my inefficient management of two different types of audio-recorders. I recorded that, prior to the interview, the participant reported a health related event she thought would not be relevant. At the second interview, I gained her 
consent to include this experience into the story. On a number of occasions these 'getting to know you' social chats prior to the interview or post interview, revealed aspects of the participant's life course, or engagements with practice nurses that might not have otherwise arisen in the formal interview. Another journal entry noted that "I did not find reading my part of the transcripts difficult, exactly, but I wonder why I found asking some questions and getting more than one word answers like pulling teeth" (Reflective journal, 20/20/10).

The use of a reflective diary of the interviewer's experience and observations during the interview process enhances trustworthiness (Ryan, et al., 2009). Throughout the interview process, I continued to journal my thoughts, feelings and responses to my observations and the interviews, returning to them at regular intervals to ensure I was not confusing my role as a practice nurse researcher with my position as a practice nurse (Asselin, 2003; Manderson, Bennett, \& Andajani-Sutjahjo, 2006). For example, a participant who was unwell and still in her night attire, had forgotten about the interview but insisted on continuing, asked for personal health advice (Reflective journal, 20/04/10). At the followup interview, the contrast in her demeanour was significant; it had changed from one of vulnerability and in need of care, to being a person in charge of the interview process. After thanking me for listening to her on the previous occasion, she firmly pointed out my grammatical errors, stating that (like the pre-test participant) she appeared different from her perception of herself (Reflective journal, 09/06/10). This method of reflection and reflexivity increased the trustworthiness of the research. Two further concerns emerged from this reflective practice. Firstly, there was a possibility that participants, especially those known to me as patients, might not be as open about their experiences as they might be if I were unknown to them, and secondly as a practice nurse, I might take certain things for granted and make assumptions that the participant did not intend. Nevertheless, throughout the interview process, I did not detect participants' reluctance to be open about their relationships and engagements with practice nurses. On the contrary, participants appeared to tell freely stories of both positive and negative engagements with nurses. Even participants whom I knew well from my own practice appeared to go out of their way to tell both favourable and unfavourable stories of their experiences. My feeling was that they were doing their best for the research. I also felt that due to the new, shared knowledge, the relationship between the participants and me deepened (McConnell-Henry, et al., 2009). 


\subsubsection{Insider/outsider research}

The nomenclature 'native,' indigenous' or 'insider' research was coined in the field of anthropology, with the researcher choosing an emic, "subjective, informed and influential standpoint" (Kanuha, 2000, p. 441) rather than an etic perspective that was more objective and distanced from the research. In studying participants in my own setting, one of the challenges of insider research was for me to retain a researcher distance between the participants and me and not become involved as a practice nurse during the interviews while at the same time, remaining connected. Moreover, being an insider to a culture or group did not necessarily mean that I, as an insider researcher, had intimate knowledge of the participants' situated experiences (Kanuha). Due to my understanding of ethnicity, training and my biography, inside knowledge brought "authenticity to the research that is impossible to reach from the outside" (Griffith, 1998, p. 375).

Because I was a practice nurse researcher interviewing general practice patients, some of whom were patients from my workplace, I had given considerable thought to whether I was an insider or outsider researcher, or both. Insider research is conducted by a person who is also a member of the researched community (Asselin, 2003). Reflection and journaling (22/06/10) led me to understand that in the context of the research community, I was not a patient researcher and was not interviewing patients from that perspective, so I was not an insider in that sense. I was a patient enrolled with a general practice that informed my thinking of being a patient, so in that sense I was an insider. I was a practice nurse who engaged with patients and had some insight into how patients and nurses thought, but I was interviewing people from other practices as well as my own. Therefore, I was both inside and outside the setting. I knew how general practices commonly worked, and the work of practice nurses in other practices, so in that context I saw myself as an outsider/insider, (italics emphasis) but as a practice nurse and researcher interviewing my own patients I viewed myself as an insider/outsider. Furthermore, apart from one participant who chose to be interviewed at my private address, because I interviewed participants in their own homes or offices rather than in my (home) practice, the study settings were unfamiliar territory to me, which positively weighted the outsider perspective. Nevertheless, I perceived a difference in the rapport building process. People who knew me prior to the interview communicated with a degree of familiarity that was not apparent in people who had not known me in that way (Asselin, 2003). Conversely, I was also aware that others told me things because they did not know me preceding the 
interview. While there remains debate in the literature about who is an insider or an outsider, researchers are rarely either insiders or outsiders as "research is constructed in a relationship with many others" (Griffith, 1998, p. 361). Therefore, because I have experience as a patient, and at the time of data gathering, was a practice nurse and a researcher, I became both an insider and outsider researcher. This interactive, going backwards and forwards, speaker-listener relational concept, linked well with the aim of my study to explore patients' perspectives of how their relationships and engagements with practice nurses contribute to their health and well-being.

\subsection{Analysis}

For the purposes of research, there is a difference between qualitative analysis applied to narratives, and narrative analysis as a method (Bingley, et al., 2008). In the former, general analysis uses themes, discourse and conversation, and may be applied in the interpretation of narratives as well as other sources of data. The latter specifies analytic techniques that have been developed to exclusively focus on narratives. Following reflection of the purpose of interpretative and meaning-making research, I applied both a qualitative constructionist (Bryman, 2004; Crotty, 1998; Holstein \& Gubrium, 2000) and multiple lens (McCormack, 2001) analytical approach to the participants' stories.

There is also a tension between science and narrative (Bleakley, 2005). Narrative is a form of qualitative research that takes 'story' as either its raw data or its product. For Bleakley, there are two types of knowing that are shown by the distinction between evidence-based medicine derived from population studies, and narrative-based medicine that focuses on the single case to do with experience and meaning. Bleakley argues that researchers can make sense of narrative inquiry by addressing this tension between two qualitative approaches. The first approach is 'thinking about' stories, with the researcher analysing the structure of the narrative, inductively deriving classifications from it. The second, holistic, integrative method 'thinks with stories'. Here, the researcher either empathetically enters a given narrative, or creates a story as the research product. In this way, elements that otherwise may be missing from a structural approach are captured. Because I mindfully engaged with participants who told their stories, I chose to 'think with' my raw (interview) story data by applying a holistic participant-centred method of analysis. 
To discover what influenced peoples' health care choices, I was interested in both event and experience approaches. Two seminal writers of narrative provided me with some direction. Ricouer's (1981) concept of time and agency in narrative that applied a personal experience-centred, phenomenological approach, and Labov's (2006/1972) event-centred, personal experience narrative, constructivist approach. Labov viewed personal stories as text that represented past events in the form of a chronologically ordered story that recapitulated events, and took little account of context (Patterson, 2008). Present tense narratives, such as the Labovian approach, have an "inherent tendency to decontextualise narratives by treating them as self-contained monologues which have an autonomous existence" (Patterson, p. 35). This method can exclude talk that is not about the events, such as thoughts and feelings that might be significant for the story. Not only do thoughts and feelings give substance and identity to the narrator clarifying their sense of self, but also, if they are absent, the individual's identity is not apparent in the analysis (Patterson). Given my interviews were interactional; they went backwards and forwards, observing the past, present and future, and to draw out participants' stories, I chose to inform my analysis from both a Labovian event approach and Ricoeur's experience-centred method, as well as McCormack's (2001) multiple lens method for analysing text. Appendix 8 provides an example of how I co-constructed the stories and a reflective analytical mind map. Figure 3 summarises the audit trail used.

\subsubsection{Multiple lens analysis}

McCormack's (2001) multiple lens approach to data analysis is one in which participants' individuality and life experiences are captured in an ethical and accountable process. It is a way of effectively managing the different kinds of stories, unveiling meaning in and across stories, and culminates in an overall interpretative story. McCormack also used a recursive process of returning the stories to participants for comment and follow-up interviews that added further discussion or explanation to the overall story. A schematic representation of the development of the individual interpretative stories is shown in Figure 4. 
1. Descriptive writing of first interviews formed individual co-constructed stories

2. Returned stories to participants

3. Second interviews

4. Integrated second interviews into each story

5. Stories analysed for commonalities and differences

6. Mind-maps to search for topics and themes

7. Re-examined transcripts and mind-maps

8. Themes analysed using multiple lens approach

9. Findings' headings identified

\section{Figure 3. Audit trail of analysis process}

Although the task of constructing an interpretative story is "daunting" (McCormack, 2000, p. 282) the movement from transcript to interpretative story occurs in two phases: viewing the transcript through multiple lenses, and developing the stories using the views highlighted by the lenses (McCormack). By viewing transcripts by this method, I drew meaning from the 'active listening,' 'narrative processes,' 'language,' 'context' and 'moments' that re-presented the stories. I actively listened by becoming immersed in the transcripts and identified the narrative processes used by the storytellers. Narrative processes encompass four "styles of presentation" (Rosenthal, 1993, p. 69): stories, description, argumentation and theorising. After the initial analysis of the interview text, participants often added or expanded information to the story in a process of augmentation (McCormack). 


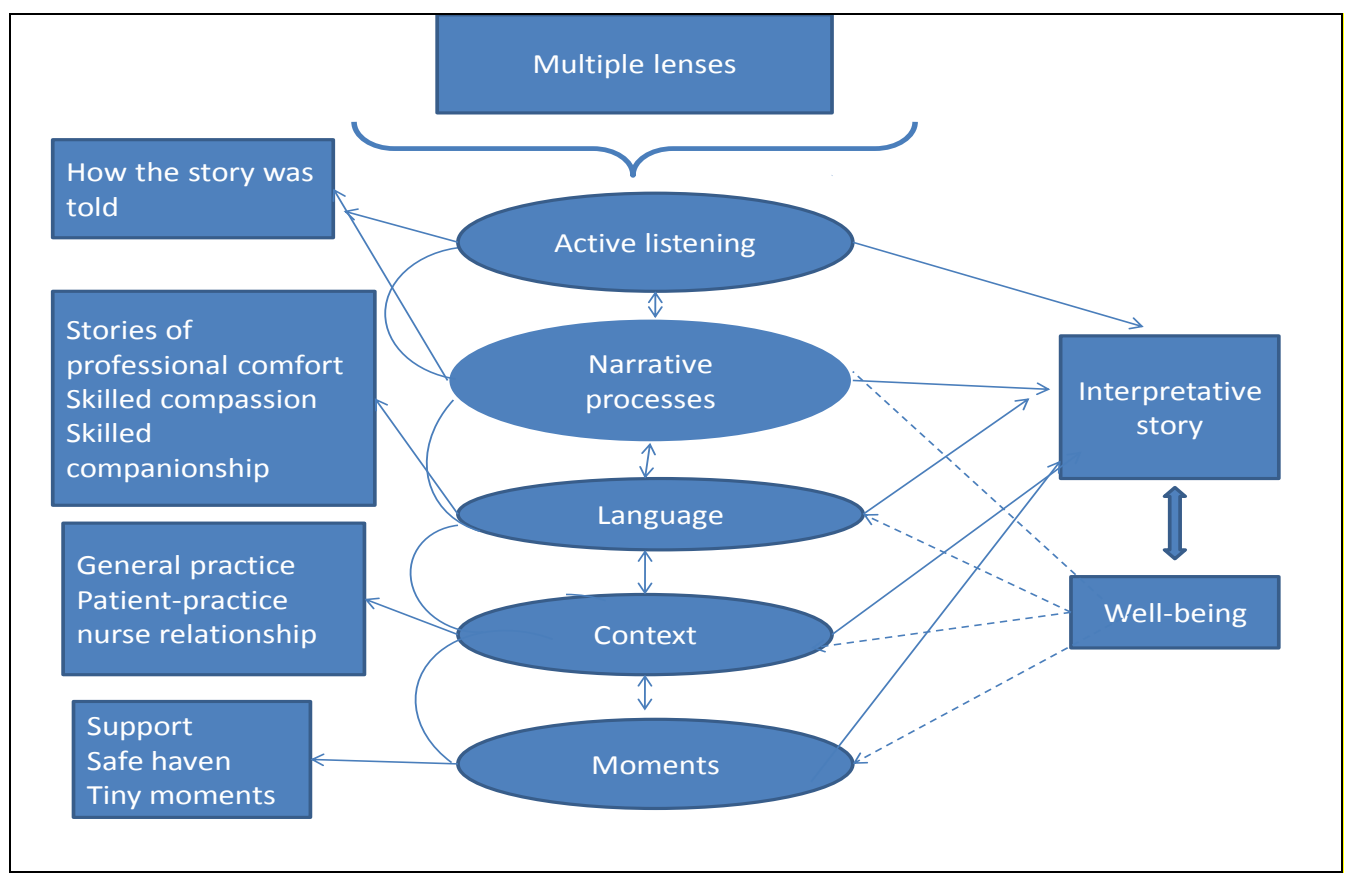

Figure 4. Schematic representation of the development of individual interpretive stories and the emergence of shared themes across stories

I began the narrative process by locating stories within the text, attending closely to, and attaching significance to what the person was saying. I paid attention to the language of the text, acknowledging the context in which the text was produced, identifying any moments in the text when something unexpected happened. During the storytelling process, I noted when participants became reflective, trying to work out the 'why', and theorise their experiences. Participants added information to the stories, making detailed descriptions of people, places or things throughout the interviews. Through this narrative process lens, one perspective of how participants created and gave meaning to their life is given. The lens of language constructs a sense of who the participants are. As text, language is a means of communication concerned with content, with "people, situations, and ideas that speakers mean their words to convey (Riessman, 1993, p. 21). Language functions to create a person's individual identity and social relationships between people. It helps to portray how the storytellers speak about themselves, relationships, and the environment in which they live (McCormack). By observing participants' stories through the lens of context, I found the participants' experiences that produced the told and retold stories, were simultaneously situated in a comprehensive wider environment that included the social, political, cultural, and historical circumstances of their lives (McCormack, 2001; White, 2010). I was able to identify the immediate social situation of participants, as well as myself as researcher, bringing a personal and interactional context to the interview 
(McCormack). The lens of moments is congruent with life course principles (Giele \& Elder, 1998; Elder \& Kirkpatrick Johnson, 2000), and White's dimensions of well-being, as recalled stories can represent significant moments or turning points leading to other stories that alter the shape and meanings people give them. Throughout the analysis process, I was attentive to the particular meanings and reasons the participants wished to convey (Frank, 2000; Mason, 2002; McCormack, 2001; Riessman, 1993, 2008). Informed by these authors, the adaptation of these methods revealed who participants were as individuals and added depth to the stories and analysis.

My analysis began immediately following the first interview by repeatedly and actively listening to the recordings and, following the transcriber's return of the transcripts, reading and re-reading of the transcripts, and personal journaling (McCormack, 2001). There is no one way to analyse narrative data (Bailey \& Tilley, 2002), but listening to participants' coconstructed stories (McCormack) and acknowledging the value of those stories in the context of the nurse-patient interactions provided access to the person's subjective reality, that is, their truth and their meanings of their experiences (Bailey \& Tilley; McCormack). For both Labov $(1972,2006)$ and Ricoeur (1981), understanding necessitated re-living the event that produced the story, but, for Ricoeur, little in the story was predetermined. Although these authors agree that human action and experience, like human symbols, all have a narrative structure, for Ricoeur, narratives are not autonomous. I concur with Squire (2008) who found that, like Ricoeur, understanding occurred after the worlds of readers and texts, speaker and listeners were brought together. The stories were also changeable; they could be removed from the happenings that were described, have many meanings, and were never the same when told twice, which without member reflections (Tracy, 2010) could lead to me misrepresenting what participants meant. Management of this variability included drawing on verbatim extracts of the participant's conversation to reveal their experiences of their engagements with the practice nurse, their lives, and the general practice as a whole. I then crafted my interpretation of these engagements into a story (McCormack, 2001). These first descriptive, biographical stories were returned to participants as an account of their lives and relationships with practice nurses. This recursive process allowed for augmentation of the story by adding any embellishments, elaborations or new information provided by the participants to be merged into the story. By this method the biographical accounts were co-constructed and participants had given permission to generate the biographies. This process allowed not only for the genesis of 
further discussion, but for the participants' personal experience stories to be viewed as a means for me to enable participants to feel the authenticity of their story and give them meaning (Tetley, et al., 2009).

By reading the transcripts, listening to the recordings and visualising not only the context of the stories, but also of the interviews, I became aware of further questions and discussion points (McCormack, 2001). These were more extensive than the initial prompt questions, and they allowed me to explore concepts or new knowledge found in the second interview I might otherwise have missed. I believed it was ethically unacceptable and methodologically inappropriate to edit out unflattering stories which would have resulted in incomplete data. I suspected I might have unconsciously looked for optimistic or 'good' stories (Andrews, 2008) to describe a constructive, trusting nurse-patient relationship. However, I found I also placed value on identifying deviant or atypical stories (Bryman, 2004; Silverman, 2000) that presented nurses in a less favourable light (McKenzie, 2007). These opposing stories provided an illuminative learning perspective to my project.

Seeking themes from stories is a common approach to analysing interview data (Overcash, 2004). Using this approach and from a constructionist, shared generation and communication of meaning perspective (Crotty, 1998; McCormack, 2001), at the beginning of the analysis I noted commonalities and idiosyncrasies in the participants' stories. These I placed under headings such as 'emotional aspects', 'perceptions of trust,' 'assessment of the practice nurse,' 'reason they saw the practice nurse,' 'choice and access,' and their life stage, and social and cultural aspects of their life course (Elder \& Kirkpatrick Johnson, 2000). However, I discovered that there were numerous topics and events that could be located under different headings, without a precise theme apparent. For example, topics that related to 'what participants valued the nurse for' such as reassurance and 'being genuine' and 'fills a gap,' are also found under the headings of 'assessment of the practice nurse,' 'the reason participants saw the practice nurse,' 'practice nurse role' and the participants' identity in the relationship.' To manage this challenge and to facilitate organisation of the data, I created a series of "mind-maps" (Burgess-Allen \& Owen-Smith, 2011; Buzan, 2010; Eppler, 2006; Tattersall, Watts, \& Vernon, 2007) for each participant, using different coloured pens, highlighting words and phrases I found significant. Informed by McCormack, mind-maps were a significant step in helping crystallise and direct my thinking, and explore possible themes. Further mind- 
maps were drawn that captured life course orientations of trajectories, transitions and turning points, implications for not only participants' human agency and health and wellbeing, but also their engagements with practice nurses. These helped me taking care to not push or force the analysis (Reflective journal, 1/3/11), and to clearly show my findings (Reflective journal, 10/5/11). Each cycle of analysis revealed different aspects of the stories as well as refinement of themes. By this method, my interpretation of participants' stories uncovered meaning for the participants and for myself. That is, including the two stories of unprofessional practice, in the context of participants' lives, and the content of stories they told, participants achieved a sense of meaning and understanding in their lives.

Following repeated active listening to the audio-recordings and reading the transcripts, I developed another analysis plan to uncover the influence of practice nurses such as what comfort, skilled compassion and companionship meant for participants (Reflective journal, 18/5/11). I substituted the mind-map findings into lists, initially with 11 themes. Using verbatim extracts from participants' stories to describe headings such as 'General Practice Activity,' and 'Professional Comforting,' I examined these accounts applying McCormack's (2001) multiple lens approach. Using participant Kay’s stories (Section 6.2) as an example, under the 'Health Focused Practice' heading, stories about Kay's relationship with the practice nurse she had developed a rapport with, described her assessment: "She's an important part of the surgery....She was treating me in a situation where she could see I needed help, and pointed me in the right direction." Beneath the Professional Comforting heading, describing the narrative process of stories, description, argumentation and theorising (Rosenthal, 1993) and augmentation (McCormack), Kay related her decision to consult a naturopath "I felt that the fact she'd [naturopath] helped the practice nurse, obviously there was something she could do for me too." Through the use of the multiple lenses of narrative processes and language, the context in which the stories were told were revealed, and the moments or turning points when something significant happened became apparent. Also described in Kay's stories were the wider cultural and general practice contexts. All participants' stories were viewed through McCormack's multiple lenses.

The manner in which participants used words, language flow, or pauses (Labov, 1972, 2006; McCormack, 2001; Dibley 2011) was never intended to be analysed in this study. However, there were occasions where participants' language was pertinent to the analysis, 
for example, during discussion of cultural differences. In qualitative interpretative research, it is the meaning, and not the truth of what is narrated that researchers seek to understand, and story is one method of constructing meaning (Bailey \& Tilley, 2002). The historical truth of an individual's story of an event is not the primary issue; it is that the researcher recognises that the storyteller chooses which piece of the story is told in order to convey the meaning that they wish the listener to hear (Riessman, 1993). The job of the narrator is to choose among all the things that could be included in a story, what things will be included, and how they will be included (Martin, 1998; Ricoeur, 1981). While there are many ways to tell the same story, although they will be different, they are still true, just differently true. Informed by Sandelowski (1991) I believe that it is not how to know the truth, but how the experience of the participants was given meaning which was important. In this sense, White's (2010) three dimensions of well-being became significant. Distinguishing what participants' understood by well-being and how participants experienced it, was revealed in our joint interpretation of their stories.

Narratives are a means of making sense of individual lives. The process of constructing their stories created contradictory layers, with meaning perceived as an act of negotiation between narrator and listener (Andrews, 2008). "Making sense of a life involves exploring the complex interactions between self and society constructed through language and mediated by the particular material conditions of our lives over time" (McCormack, 2001, p. 286). Meaning is continually constructed and reconstructed (Andrews; McCormack; Riessman, 1993). I interpreted 'meaning' as human sense-making, which is experienced by an individual at any given time or context. Over time, and throughout the narrative, transformation or interpretation of meaning may occur. This interpretation of meaning was reflected in my own experience where I found that individuals made sense of events in their lives in diverse ways. In the context of the participants' stories, I found meaning by asking myself whether the content of what participants' conveyed made sense rather than non-sense. By deliberately hyphenating non-sense I accentuated the notion that, rather than in a humorous or condemnatory sense, the experience or narrative did not make sense in the context it was offered to me.

\subsection{Ethical considerations}

Saturated with ethical and moral decisions, narrative research has its own rigour (McKenzie, 2007). Ethical decisions are dependent upon the personal comportment and 
highly developed literary and analytical skills of the researcher (McKenzie; Frank, 2000). Research relationships are not static but change over time (Frank). People do not act on principles that are set, but act as best they can at a particular time and place in their history.

When contemplating the ethical implications of the research, I was careful not to limit them to the stage of data collection (interviews) where the relationship between myself as researcher and the participants was closest (Redwood, 2008). I also gave thought to the quality of the questions I asked myself about my own practice, the participants, my assumptions about how knowledge can be produced, the method of collecting the data, and the language and style of the completed product (Redwood). I became aware that limiting ethical concerns to those posed during the process of gaining ethical approval did not allow for the possibility of shifting ethical concerns during the emotional engagement when participants told their stories (Redwood). These ethical issues included not only the possibility that participants from my own practice may relate personal stories unrelated to the study that may affect our ongoing professional relationship, but that in the rapport building process I may disclose information about myself I may later regret (McConnellHenry, et al., 2009). Therefore, prior to the interview process I gave careful consideration to possible boundary conflicts.

The protection of the rights of all people to life, self esteem, self determination, privacy and harm minimisation (Guillemin \& Heggen, 2009; Karnieli-Miller, et al., 2009; New Zealand Nurses Organisation, 1995; Shaw, 2008) directed me to discuss with participants how they wished to proceed. In the context of nursing research, it is not only the overtly vulnerable populations, such as the very old, very young, or mentally ill, who need protection, but also participants who are vulnerable in other ways (New Zealand Nurses Organisation, 1998). While physical harm resulting from nursing research is slight, the potential for psychological injury is clear, and researchers need to be cognisant of the risk to participants. In this context, my concern that I might recognise practice nurses, doctors or general practice administrative staff from participants' stories was noted in my research journal. I pondered the management of a situation where I considered a nurse's behaviour placed the participant at risk. I also reflected on the likelihood that a nurse might disagree with my interpretation and findings. 


\subsubsection{Consent and confidentiality}

Narrative Inquiry necessitates building rapport with participants, who trust that their information will be treated with respect (Guillemin \& Heggen, 2009), and participants needed to believe that, as the researcher, I could safely manage their stories and the audiorecording procedure. What is recorded, the interpretation of the story, and the dissemination of the findings should be acceptable to participants (Guillemin \& Heggen). In qualitative research, gaining consent is hazardous as it implies that the researcher knows before the event, what is going to happen (Shaw, 2008). In the course of collecting stories, participants may involuntary or deliberately impart confidential or sensitive information (Shaw), or tell stories which disturb them. Consequently, confidentiality and consent issues must be addressed as an ongoing process (Guillemin \& Heggen). When these challenges occurred prior to, during, or following the interview, even if I found the information instructive, I discussed the revelation's possible inclusion or exclusion with the participant.

Prior to the interview, and before signing the consent form (Appendix 7) I discussed issues of confidentiality and identifiability with participants, especially those participants with high community profiles. Even though participants mainly chose their own pseudonyms, the risk that they might be identifiable to some who read the thesis was considered minimal and acceptable by the affected participants. Participants were made aware that I may recognise practice nurses from their descriptions, and at times, participants used a practice nurse or doctor's name. Any names referred to by participants have been changed or removed from the transcripts. Through the Locality Organisation consent procedure, general practice principals and practice nurses were aware of the research question and possible conversations with patients. I clarified my position as researcher in the interview process and the purpose of the research. I was transparent about how the research would be used and I explained who might have access to it. As a researcher, I was 'ethically mindful' when addressing ethically important moments in the research process (Guillemin \& Heggen, 2009), and clear on whether I would either gain consent, or discard the information. Notwithstanding the ethical imperatives of beneficence and non-maleficence, I was also aware of times when something did not feel right, when I experienced mild discomfort about either the research process or my relationship with the participant, and the need to explore this feeling further. While participants were invited to bring a support person to the interview, I ensured that everyone was aware that it was the participant's story and meaning that was the focus of the interview. The possibility of parallel or 
conflicting stories and the different interpretations and emphasis that the second person might place on the participant's story, would not be part of the process. Even though the interviews included one couple, the person not being interviewed positioned him or herself away from the person being interviewed and did not take part in the interview. Other participants attended the interviews alone.

Additional ethical considerations related to practice nurses' possible expectations that I recount participants' stories to them, especially if they were aware that one of their patients had accepted my invitation to take part in the research. In the first instance, I decided I would raise the ethical imperatives of confidentiality, privacy, and non-maleficence of which all nurses are cognisant. In the second circumstance, given that the stories would be as non-identifiable as possible, and the length of time between when the story was told, to publication, would be long, it was doubtful that anyone would accurately remember the context and content of the story. Therefore, any disparity in the understanding of any part of my research and the possibility of harm to participants, or our relationship, declined.

\subsubsection{Power and control}

Other ethical considerations for this research involved the interpretation of the data, who had control over which part, and who 'owned' the stories. Some researchers allows interviewees to comment and even rewrite their own analyses, thereby engaging in many conversations with participants and generating additional material for analysis (Andrews, 2008; Karnieli-Miller, et al., 2009; McCormack, 2001). Nevertheless, partnership with participants cannot replace research rigour. Following the transfer of data to the research sphere and the data becoming research property, it committed me as the researcher, to use strict ethical guidelines (Karnieili-Miller et al.). The unique contribution of researchers and participants to a project makes them inseparable as both partners have significant levels of involvement (Karnieli-Miller, et al.). These authors compare the democratisation of the research process, the promise of control sharing, and the discrepancy between the informal talk of the early stages of the research process, with the later, more formal structured public use of the data. There are many ethical questions about power and control over the research process and ownership of knowledge. Karnieli-Miller et al. emphasise that the relationship between researcher and participant can be affected by the motivations of the participant, such as the need to tell their story, their willingness to help the researcher, financial gain, or the outcome of the research. Conversely, the researcher might be 
motivated by the desire to gain a degree, or receive study funding. In this study, I was motivated to gain insight and understanding into the practice nurse-patient engagement and relationship from the patients' perspective and how it influenced their health and wellbeing. The notion that the DHBs and PHOs would consider the results of this research when making decisions about the role and education of practice nurses, and PHC was also a factor. Although I did not undertake this research for any 'research boxes' to tick for academic purposes, glorification, or desire for power, I did recognise my wish that the results of the analysis could positively impact on the nurse-patient relationship, and patient outcomes.

Each stage of the research process creates different roles for the participants and the researcher that could change or influence the balance of power within the relationships. Five stages identified by Karnieli-Miller et al. (2009) include recruitment, data collection, data analysis and production of the report, validation, and additional publications from the same source material. All the stages rely on the type of relationship and understanding between the researcher and participant and the degree of responsibility the researcher has towards the participant:

There is a need to find a way to create power relations that balance the building of a respectful relationship between researcher and the participants, based on mutual trust and the use of theoretical and clinical knowledge that has been gained in professional training. This balance is affected by the stages of the research process. (Karnieli-Miller et al., p. 286)

Because this research involved people telling stories of their experiences with practice nurses, it was essential I balance the requirement for information with my obligation towards the participants. There was the potential for me, as a nurse researcher to become involved as a nurse and also to attempt to perform nursing interventions (Asselin, 2003; Overcash, 2004; Wilkes \& Beale, 2005). This predicament was especially relevant to my research when a participant known to me in the nursing role, during the interview, requested some nursing care. I was cognisant not only of the participant's emotional vulnerability, but also my own psychological susceptibility. To prevent being drawn into acting as nurse while conducting research, I advised the participant that my role was a researcher and not a nurse in that instance. I suggested that I could either address the participant's concerns at another time, or that the participant arrange an appointment with 
me, a different nurse, or a doctor. This self-awareness and responsiveness to another's emotional well-being is described as an emotional intelligence competency (Goleman, 1995; Kooker, et al., 2007) and was addressed in Section 3.3.3. Further concerns arose when participants from my practice had differing recollections of consultations, to my own, or had expectations that I would remember previous conversations. As a researcher I could not be drawn into the discussion, also, given that the research was about patients' experiences and I may have recalled the conversations differently, I did not challenge participants, and at no time did I check their clinical records. A journal entry (19/04/10) noted that one participant known to me had not remembered a discussion of the Care Plus programme even though the consultation with me had been a few days earlier.

In respecting and protecting the participants' rights and human agency, and acknowledging ethical concerns (Asselin, 2003; Hudson \& Russell, 2009; Karnieli-Miller, et al., 2009; Overcash, 2004; Reinshaiz \& Chase, 2002; Wilkes \& Beale, 2005), throughout the research process, being open and honest with myself and the participants about the nature of the partnership was essential. Engaging with the participants with respect and sensitivity, ensuring that they were aware of the changing dimensions and aspects of the research, such as what had been said, how it was said, and when it was said (KarnieliMiller et al.), demonstrated this respectful partnership. The "primary moral research obligation is the participants and their welfare, which can only be achieved through nonjudgmental analysis and writing" (Karnieli-Miller et al., p. 286). This ethical nonmaleficence, the avoidance and minimisation of harm, and beneficence, doing good, is reflected in the expectation in research involving Māori (Hudson \& Russell).

\subsubsection{Treaty of Waitangi}

To be ethically responsible to Māori participants, it was important for me to be sensitive to cultural differences and relationships based on trust and integrity (Hudson \& Russell, 2009). This approach ensured the opportunity for Māori participants to assess and negotiate the respective risks and benefits of participating in the research and determine whether it contributed towards reducing or increasing inequalities. Therefore, the three broad but encompassing principles of the Treaty of Waitangi (1840) of 'partnership', 'protection' and 'participation' were inherent in my ethical approach to this project. 
Taking care to promote maximum benefit and minimise the risk of cultural harm, I consulted with Māori prior to beginning the research. This ensured that my proposal acknowledged that Māori participation would provide mutual benefits, and confirmed that my research respected their culture and was beneficence orientated. For example, the participatory storytelling approach could benefit Māori if the results led to change in the way in which Māori were related to, not only in general practices, but also on other health care environments, leading to possible improvement in health care for Māori.

\subsubsection{Professional boundaries}

I was aware of the ethical implications surrounding possible psychological and practical benefits to the participants of the 'told' story conflicting with the benefit of my research agenda (Gubrium \& Holstein, 2002). While the aim of the research was explained to participants prior to the first interview, the outcome of the analysis might not be what they expected from the study. It was my responsibility as the researcher, to inform participants, as clearly as possible, the expectations and boundaries of our research relationship. However, I also understood that both the participants and my expectations and boundaries remained unpredictable (Reinshaiz \& Chase, 2002). Stories are more than data for collection and analysis; storytelling is relationship building and this relationship includes the person who is to analyse the stories (Frank, 2000; McCormack, 2001). Good story analysts have an ethical and intellectual responsibility to enter relations of storytelling so I, as the analyst, needed to step back from first-person testimony and allow those who testify to speak for themselves (Frank). Narrative research also seeks to be respectful of the researcher and participant (Carson \& Fairbairn, 2002; McCormack, 2001), and it was essential that I understood that the methods might not only influence the participants, but also the outcome of the inquiry (Mason, 2002).

Being a practice nurse researcher can generate professional boundary dilemmas (DicksonSwift, James, Kippen, \& Liamputtong, 2006; Duncan, Drew, Hodgson, \& Sawyer, 2009; Overcash, 2004). I was aware how these dilemmas could occur if participants discussed practice nurses I knew, or divulged health problems not disclosed to their nurse or doctor. If a participant revealed a problem, there could be a conflict between my researcher role and that of me as the nurse being an active listener (Overcash). Being aware of these challenges, I addressed them in the information sheet which I reviewed with each participant prior to beginning the interview. Because I live in a small town and 'everybody 
knows everybody,' I journaled (11/7/09) my “initial concerns about occasions when I may meet research participants in the street, and how I would manage the event if they wanted to discuss the research". If this occurred, I would advise them that if either of us wished further consultation about the research we needed to choose an appropriate method of contact to make a time and place to do so.

Rapport is not only necessary for methodological rigour, but is an indispensable attribute of ethical rigour (Guillemin \& Heggen, 2009). An overriding ethical concern in qualitative research is the need to balance establishing rapport and developing rich relationships with participants while maintaining distance and respecting their privacy. 'Pseudo intimacy' in the researcher-participant relationship is where the researcher builds rapport to meet the needs of the study (Shaw, 2008). The possibility of participants perceiving me as a 'friend,' especially participants from my practice, rather than a researcher (Reinshaiz \& Chase, 2002) added to the ethical milieu. Consequently, I was mindful of participants' vulnerability in the interview process, negotiating these boundaries balancing tact with the need for information.

\subsection{Rigour}

Telling stories is a responsive and reflexive process, and participants are more likely to maintain their power and control when it is their story that is being told, in their own voice and in their own way (Atkinson, 2002; Holloway, Freshwater, \& McKenzie, 2007). These responsive and reflexive processes add credibility to the authenticity of the research. To distinguish narrative truth from other kinds of formal science truths, narrative truth places emphasis on life-like, intelligible and plausible stories (Sandelowski, 1991). Coherence is found by the narrator of a story, striving for a story that makes sense (narrative probability), a story that is consistent with past experiences or other stories (narrative fidelity), and a story that has a satisfactory end and representational appeal (aesthetic finality). Written and told stories can be changed when read or heard however, the understandings of composition and configuration of the stories are completed by the reader (Ricoeur, 1981). A narrative approach to the study of lives prioritises internal coherence that is experienced subjectively, rather than the external criteria of truth or validity (Atkinson, 2002). Internal consistency is the person's understanding of their past experiences, their present experiences and their anticipated future. Although there are always inconsistencies in people's stories when told at different times, the stories 
themselves should remain constant, with one part of the story not contradicting another (Atkinson). Internal consistency can be used by both storyteller and listener to clarify earlier comments if they appear different. External consistency is "what the storyteller says conforms to what one may already know, or think one knows, about the person telling the story" (p. 135).

The value of truth is found in the "plausibility of the connoisseur's interpretations, or the extent to which the interpretations resonate as plausible meanings of human experience" (Pellico \& Chinn, 2007, p. 63). Moreover, there is no need for formal rules or standardised technical procedures for validation in qualitative research (Riessman, 2008). The trustworthiness of the research should be assessed from within the situated perspective and traditions that frame it. Narratives are interpretative and in turn require interpretation, and truth or trustworthiness is always partial, committed and incomplete. Personal narratives are not meant to be an exact record of what happened; as a result, trustworthiness is found in the coherence of the narrative, and the researcher's interpretative work with the participant. A story should 'hang together' and be consistent (Atkinson, 2002; Riessman), and understanding occurs when the worlds of readers and texts, speakers and listeners are brought together (Andrews, 2008).

It was the joint meaning-making of the participants' stories that was significant for this research (Tracy, 2010). In my professional experience, patients may inform me that they related an event or experience exactly as it occurred; what happened, how it happened and the outcome of what happened. However, with reiteration, although the general story was the same, other aspects were disclosed in the re-telling. I found that when listening to a story, it was often challenging for the narrator of the story to follow a coherent sequence and it commonly took several repetitions before the story became meaningful to the patient and myself. In this research, I acknowledge that the participants' stories were always situated in the cultural and political context of the participant telling the story (Atkinson, 2002; Riessman, 2008; Sandelowski, 1991). The co-construction, recursive process of the stories, enhanced the truthfulness and ensured authenticity of the understanding of what the participants intended. Moreover, to increase the credibility of the study, the three practice nurses who read my draft thesis commented that they identified with my findings and that I had portrayed their own understanding of the patient experience within general practice. Returning the initial stories to participants for comment, suggestions, changes or 
elaborations of their meaning, was a significant factor in addressing possible interpretation issues. This added trustworthiness to the study. My research diary, reflection, and discussion with experienced researchers, as well as presenting the research to practice nurse colleagues, my $\mathrm{PhD}$ peers and other academics, added to the rigour of the research.

\subsection{Issues with method}

I envisaged that the inclusion of participants from my own practice would become a significant issue with my research and as these interviews occurred following the interviews with participants who were not 'my' patients, I was prepared for a different type of interview engagement. However, I found that while I was familiar with the participants in my general practice setting, I was not conversant with them in their own environments. Although this created an objective 'outsider' distance for me, and while the prompts and follow-up questions were similar, unexpectedly, the rapport between the participants and myself, although different appeared to be already in place. Other challenges associated with participants who were both known and unknown to me, included the raising of health related concerns outside the research boundaries, those who wished to discuss previous professional consultations, or those wanting professional advice. Disturbances during the interviews such as telephone calls, low flying aeroplanes, dogs, children or other family members, or caregivers was assessed and appropriate action taken.

\subsection{Introduction to participants}

All general practices discussed by participants employed more than one practice nurse, but participants talked mainly of the rapport they experienced with one specific nurse. Participants' engagements, not only with practice nurses, but also with GPs and receptionists are presented. Table 4 provides an overview of the participants with pseudonyms chosen either by participants, or if the participant requested, by me. 
Table 4. Introduction to participants

\begin{tabular}{|l|l|l|l|l|}
\hline $\begin{array}{l}\text { Participant } \\
\text { pseudonym }\end{array}$ & Gender & Age & Ethnicity & Occupation \\
\hline Kay & Female & Mid 70s & Pakeha & Retired \\
\hline Peggy & Female & Mid 60s & American & Retired \\
\hline Bert & Male & Mid 50s & Pakeha & Maintenance engineer \\
\hline Katriona & Female & Early 50s & Pakeha & Self-employed accounts \\
\hline Tui & Female & Mid 50s & Māori & $\begin{array}{l}\text { Self-employed dance teacher/employed } \\
\text { teacher }\end{array}$ \\
\hline Mere & Female & Mid 50s & Māori & Administration \\
\hline Jack & Male & Early 70s & Pakeha & Retired Volunteer Service Abroad \\
\hline Jo & Female & Mid 60s & Pakeha & Retired nanny \\
\hline Pango & Female & Mid 50s & Māori & Manager \\
\hline Sam & Male & Early 80s & Pakeha & Retired pharmacist \\
\hline Nikki & Female & Early 60s & Pakeha & Self-employed accounts \\
\hline Billie & Female & Early 20s & Australian & Care-giver student \\
\hline Miles & Male & Mid 20s & Pakeha & Student \\
\hline Helen & Female & Early 80s & Pakeha & Retired doctor \\
\hline Roni & Female & Mid 30s & Pakeha & Volunteer \\
\hline
\end{tabular}

\subsection{Summary}

In this chapter, I have described the setting from which participants were recruited. I addressed sampling and recruitment issues, and illustrated how they were overcome. Ethical tensions I experienced when interviewing participants from my own practice including my insider/outsider status were addressed in detail. The complexity of data collection directed me to approach my analysis informed by McCormack's (2001) method of interpreting narrative analysis through multiple lenses. The recursive nature of my method was a significant factor in the trustworthiness of my study. Participants were described in Table 4. The following chapter introduces the participants to the reader. 


\section{Chapter 6 Participants and their stories of their relationships with practice nurses and general practice}

\subsection{Introduction}

This is the first of two findings chapters. This chapter continues to introduce participants to the reader and describes the social, cultural and historical circumstances of their life course in the form of stories. Further analysis is addressed in the following chapter. Captured from the original individual transcripts, the initial stories were considerably longer and included more detail. However, to reduce the necessity of repeated quotations, and for the purposes of analysis, some portions of the stories are presented in both chapters. Even though the individual stories may give the appearance of a selection of participants' accounts of their engagements with practice nurses, each story title draws them together, creating a meaningful account of how practice nurses contributed to participants' health and wellbeing.

\subsection{Kay's story: Doctors are good, but I would rather talk to the practice nurse}

Following the retirement of Kay's husband, the couple relocated from a rural area to their present home in Nelson city to be closer to medical and shopping facilities. Kay took pleasure in home crafts, regularly walked, and enjoyed a close relationship with her extended family.

Kay was generally well, and consulted the doctor for "really routine stuff now." She perceived the practice nurse and doctor working as a team, with the nurse an "important part of the surgery" who took the time to listen to her. Kay described feeling more comfortable engaging with the nurse who is "nice, but good" rather than the doctor because:

I feel I can talk to a practice nurse... and tell her more of what I need....she takes an interest and she will talk about any problems I've got.... We'll have a friendly talk; it's helpful.... I always feel the doctor hasn't got the time [to listen]...where you could ask the practice nurse.

Many years ago, Kay experienced a medical misadventure event resulting in continuing shoulder pain that became "just something I have to live with." Kay theorised that the practice nurse at that time, was "constrained from helping me," either by her employment relationship with the doctor, or, because she was a nurse rather than a doctor, she "couldn't 
give me any advice that I would need." Nevertheless, Kay's recent interactions with a practice nurse were very different. When she believed she did not need to see the doctor, she mainly consulted the one practice nurse with whom she had built a relationship. This nurse was "very capable...and points me in the right direction.... There's more help now because of what the practice nurse provides." Although she occasionally consulted another practice nurse, "who is probably equally as good," continuity of carer and feeling comfortable with the one practice nurse she knew well, was important to Kay. Should her preferred nurse leave the practice, she found the prospect of getting to know another nurse, daunting.

Contemplating an injury to her leg that culminated in several hospital admissions, Kay talked of being "on... a type of morphine tablet for about a month because of the pain, which was a quite dramatic part of my life." Despite her requests for an x-ray to help explain her continuing symptoms, she felt her doctor did not take her complaints seriously. However, he did enrol her in the nurse-led Care Plus programme where Kay regularly consulted the practice nurse independently from the doctor. This arrangement pleased Kay because "I knew there was a problem...this is where the help comes in from the practice nurse.... I find the practice nurses are far more outspoken than they used to be...they give...you confidence to query the doctor." Even though the nurse advocated for Kay with the doctor, it was "six months later, I was x-rayed and the lower part of the leg had been a break, which at the time hadn't been detected. I was so ill I thought I was dying.... I get a bit angry now at why couldn't I get in there [hospital] earlier. I was not listened to. Now that Kay shared a bond with the practice nurse, she contended that "if the practice nurse I know had been there, she would have known that I needed to get into hospital.

During a Care Plus consultation, Kay described a time when the nurse not only explained the Green Prescription physical activity programme (see Glossary), but also chose to share something of her own health issues and the benefit she gained from consulting a naturopath. "I felt that the fact she'd [naturopath] helped the practice nurse, obviously there was something she could do for me too." Kay appreciated the practice nurse communicating something of her private life, as it added weight to her advice, but "she didn't pressure me in any way, it was my choice." Kay talked of the significant relief she gained from the care of the practice nurse which she experienced through increased energy and a "good feeling." 


\subsection{Peggy's story: She saw something in me}

Twelve years ago, Peggy, her husband, and three children immigrated to New Zealand from the United States of America. Peggy enjoyed creating and selling handcrafts at a city gallery, growing vegetables, and walking the tracks along the river. Peggy valued the organisation of PHC in New Zealand, as "they do know pretty much the whole picture of what health care...people need at different stages of life."

Due to the collegial, collaborative professional practice Peggy sees existing between the nurse and the doctor, she has remained enrolled with the one general practice. This unified approach to health care, strengthened her feeling of being cared for, as "I trust them; I feel I get good care from them" and she sent cards of appreciation to the whole practice. Nevertheless, the possibility of the nurse's retirement and "having to start a new relationship" with another nurse, was an uncomfortable notion for Peggy.

Engaging in social talk with the practice nurse in which they shared aspects of their lives, significantly augmented the development of the trustful relationship between Peggy and the practice nurse. "She is so capable and has been there so long...building up trust with her over time...I have every reason to trust her and I have never been failed by her and her abilities." This confidence continued even through a communication misunderstanding. The confusion arose when the nurse rang Peggy with her blood test results, and Peggy became concerned that there was something wrong. "I was a little worried about going in [to see the nurse] because there sounded like some hesitation in her voice when she called me...after I hung up I thought, 'gosh, what didn't she want to say on the phone." However, her anxiety was resolved through face-to-face discussion with the nurse who was “mortified. She said 'there's nothing at all...I wouldn't do that to you that way.' So we decided that maybe she was looking at her computer screen at the same time she was talking on the phone."

During another consultation, as the nurse was taking her blood pressure, she became aware of a change in Peggy's usual demeanour. "She saw something in me and said something that allowed me to open up to her [about a very upsetting domestic problem]. I was blurting out what was so raw on my mind." The nurse's non-judgemental approach, taking Peggy's concerns seriously, and the confident manner with which the nurse presented 
herself, created such a sense of safety for Peggy, that when a similar situation occurred, she did not hesitate to seek counselling from the nurse. "I went back to her specifically to talk to her and she was everything I had hoped," and more than Peggy expected.

\subsection{Bert's story: They all seem to be the same; it's like seeing a second doctor}

Bert lived with his wife in their own home in the city. He had a varied career including working as a taxi driver. Even though he enjoyed this job, it involved long periods of inactivity which he realised was not good for his health. His most recent occupation was as a "maintenance person" which he also liked, and where he was more active. "No two jobs...are normally ever the same." Bert took pleasure in interacting with people, using his handy-man skills, fishing for whitebait and riding his mountain bike.

Bert's sole GP and one practice nurse general practice had amalgamated with another practice. Consequently, he needed to become accustomed to engaging with several practice nurses with whom he was unfamiliar. Even though "it's always nicer to see the one you've always seen; it's the familiarity...you get used to the same one," when Bert required an appointment on a particular day, and his preferred nurse was unavailable, he also valued the option of consulting other nurses. "You've got to take who is available on that day....They all seem to be the same, and they'll discuss anything with you...and she [a different nurse] may ask you a different question." Bert's answers to the questions provided the nurse with additional information about his health, and placed the nurse in a better position to support him with appropriate health care. Bert also gained comfort from knowing all his consultations were recorded on the computer and available for other nurses and doctors to view.

As a taxi driver, Bert regularly consulted the practice nurse and doctor for his routine taxi licence medical certificates. Since changing his occupation, his visits to the practice were less frequent, and he declared "they'll [the practice] never get rich out of me." However, Bert's three urgent admissions to hospital within three years followed a similar pattern. Initially he would engage with the nurse for an aural toilet ${ }^{5}$ and the nurse would opportunistically "check everything" while he was there. As a consequence of one of these professional clinical assessments, the nurse "noticed that there was something else" (cardiac irregularity). The nurse promptly arranged a medical assessment by the doctor,

\footnotetext{
${ }^{5}$ Aural toilet is the medical term for ear syringing
} 
organised the ambulance and Bert was transferred to hospital. On the second occasion, Bert became:

a bit annoyed...I didn't really mind because they're doing their job...trying to...look after your health...But, I couldn't understand how I could drive in there [the practice] and the next minute, have to go in the ambulance to the hospital...They reassured me that it wasn't because I was sick, it's just that they were concerned for my health.

Despite Bert previously being advised to make lifestyle changes, he "didn't really want to listen to it [the advice] too much," and although he did have a mountain-bike, he did not use it. However, the third episode caused Bert to become "a bit scared...I thought, 'I've got to make a change." "Following his third admission to hospital, and at the time the nurse was attending to his ears, she proactively offered him a Vascular Risk Assessment. The findings of this assessment helped Bert change his perception of his health and motivated him to alter his lifestyle.

Bert contended that practice nurses "do a good job...it's like seeing a second doctor." They are "only too willing to oblige" and provided explanations for why they suggested Bert make lifestyle changes, or for the necessity of returning to hospital. "If you say to her 'what do you think I should be doing, what have I done wrong?' You'll get told. I think honesty and being told something goes a long way" in building relationships.

Bert continued regular consultations with the practice nurses, independently from the doctor. Through these engagements, he was encouraged and motivated to make the essential modifications to his lifestyle. "It was mainly the nurses telling me that I was overweight...Now, we have cereal every morning with yoghurt and fruit." Not only did Bert transform his own lifestyle, his wife also made significant changes, and they "get a lot of pleasure" out of cycling together.

\subsection{Katriona's story: She's really support for the doctor}

Katriona and her husband relocated to Nelson city to raise their, now adult, three children. She enjoyed outdoor activities and was a keen kayaker. Working mainly from home assisting businesses with their accounts, allowed her flexibility to choose her working and recreational times. 
When the children were young, Katriona engaged with a practice nurse more frequently. Now, she regularly consulted both the nurse and doctor for "ageing problems like blood pressure." However, it was unexpected cardiac symptoms that led Katriona and one practice nurse to meet again after many years. "She didn't realise who she was seeing and I didn't realise who I was seeing." Although the nurse offered the option for another nurse to take the electrocardiograph the doctor had referred her for, Katriona "was quite happy for her to do it." This reconnected relationship was the basis for the growing rapport between Katriona and the nurse, and when she had sensitive issues to discuss, she chose to consult only with her, describing her as "good support." Even though she had consulted other nurses, when she could, "I do choose...the nurse...I find very easy to talk to...because I know her" [through their young children's mutual activities]. When Katriona believed she did not need to see the GP, she would consult the practice nurse. She preferred to talk to the nurse because "it's so hard to talk to the doctors," and the nurse she usually consulted was "very relaxed and puts me at ease." Katriona would also ask the nurse if it were she, or doctor, she needed to consult. The professional knowledge and competency demonstrated by the nurse's explanations of medications based on "research evidence" emphasised Katriona's sense of well-being, comfort and confidence, not only in herself, but also her faith in the practice nurse.

Katriona observed the expansion of the practice nurse role over time, and had noticed the increasing collegiality between nurses and doctors. Previously "they were separate” but now the nurse has more of a supportive role rather than assistant role and they "work a lot closer...She's really support for the doctor." Katriona also found that the distinct areas of expertise led to two-way referrals for second opinions, further assessment, and advice about wound care. Maintaining a healthy lifestyle was important for Katriona who appreciated the doctor's referral to the practice nurse for a Vascular Risk Assessment. The nurse, who shared some aspects of her own healthy lifestyle, reassured Katriona, as she was maintaining a similar way of life. The rapport Katriona experienced with the one nurse, and the nurse's professional competency, were factors that positively contributed to Katriona's resourcefulness in managing her health. 


\subsection{Tui's story: I don't feel the need to see the doctor}

Tui had lived in the Nelson district with her husband and large extended family for many years. She enjoyed being with people, and was a busy "community based person" which included engaging with young Māori.

Tui had been enrolled in the sole practitioner and one practice nurse medical centre in the city for many years, until it amalgamated with another medical centre. Although Tui experienced chronic health problems, and was enrolled in the Care Plus programme, she chose mainly to consult with practice nurses because she "doesn't need to see the doctor...and the nurses are really good....Incredibly caring, and go that little bit further, with interest." Nevertheless, on one occasion, an unknown practice nurse who spoke English as her second language, attended to Tui's toe wound using a dressing material that neither the nurse nor Tui, were familiar with. Even though she found the nurse "very pleasant," she was concerned that the nurse had not listened to her attempts to explain which dressing material other nurses customarily used. Despite this nurse's advice not to disturb the dressing, the following day Tui removed the dressing revealing a wound she found disturbing. Returning to the practice, she selected a different nurse for follow-up care. "That's the only complaint ever I've had with a nurse that could have been avoided by her ability to go and ask somebody...I hold the surgery responsible for that." Tui chose not to raise this issue with the first nurse, but she did attempt, unsuccessfully, to have the matter resolved through discussion with other staff.

Openness and professional competency were important to Tui, who appreciated her relationship with "holistic" practice nurses, and the ease of access to their care. The developing role of practice nurses, as well as the increasing collegiality between nurses and doctors, was noted by Tui, who stated, "I think that doctors work more easily with nurses now." She also found that the receptionists actively facilitated her choice of doctor or nurse.

In 2000, Tui took part in a general practice survey to ascertain how reception staff treated young people when they attempted to make an appointment with the doctor without advising receptionists the reason for the consultation. While the receptionists at some practices "were brilliant," at other practices they were not, and "they didn't need to treat people like that [ignored, spoken to impolitely]." Following the survey, most practices 
received further staff education to reduce the instances of discrimination against young people.

\subsection{Mere's story: We're so very different; chit-chat allays my fears}

Many years ago, as a young person Mere moved to the Motueka region. "I came to see a friend and stayed here...I came from a city background and thought I'd get a job in the tobacco. Well, that opened my eyes because I didn't have gumboots or long pants [necessary clothing when working on the tobacco farms].” After marriage, and the birth of her son, Mere became interested in early childhood education, observing that she was the only Māori mother at kindergarten at that time. Interested in education and health, she worked as a volunteer for a number of charitable organisations before gaining an administrative position with a Māori Health provider. Her interests included gardening and floral art, contending that flowers were like people, "all different colours, all got our little bents." Mere valued her Māori and non-Māori whakapapa (heritage), easily walking in both worlds. Although she recognised that "the Pakeha world and the Mãori world, for me, are so very different," she applied this knowledge and skill to advance the cultural, and health and well-being understandings of both entities.

The compromised health of Mere's extended family was an ongoing concern for her. Her father, mother, two sisters, brother and nephew died at relatively young ages, and she "ended up with all these death certificates." Even though smoking was a habit she enjoyed, about 10 years ago, following the death of her nephew, she chose to stop. She realised that, although she could not change her family's health behaviour, she could, and did change her own. More recently, working at the health centre helped her "understand what health is." This insight led to her consulting the practice nurse for assistance in making further lifestyle changes. The practice nurse's person-centred approach was instrumental in empowering and motivating Mere to consider lifestyle changes, and to make informed choices about her own health.

Mere maintained that the practice nurse was as necessary to a person's health care as the doctor, and she appreciated the autonomy of the nurse. Mere remembered that, in the past, the nurse acted as receptionist, as well as a practice nurse who placed each patient's clinical records opened and prepared for the doctor, and "rolling bandages." Now, while working alongside the doctor, the practice nurse was also independent from the doctor, and 
in a position to talk to Mere about "womanly things... and go through things together with you" rather than discussing them with a male doctor. "How they work is different for me...they [practice nurses] practise the stuff that's in these books and break it down" into everyday language.

For many years, Mere enjoyed a warm relationship with her long-time GP. However, more recently, and now a widow, the continuity of medical care had been disrupted through the employment of locum doctors, and she "doesn't like the changes of doctors all the time." Nevertheless, she had built a rapport with one practice nurse who "is good. You can sit there and have a talk, and watch what she is doing, and she will tell you what she is doing, and I can see what she is writing on the computer about me." Mere and the practice nurse also shared social talk, the "little chit-chat that allays my fears." She gained comfort from the practice nurse's compassionate presence, especially when "I broke my leg and the practice nurse was very kind even though I was very disgruntled." Mere's trust in the practice nurse grew over time, but "it wouldn't have occurred with just anybody...I felt I was free to speak my mind, with manners." Mere contended that her healthy lifestyle engagements with the one practice nurse had been "empowering... and it was a good time for me to take stock again." Conversely, there were times at another practice when her engagement with the nurse could have been more attuned to Mere's needs:

She wanted to get the job done, but sometimes it doesn't work like that. It's very hard to go into a surgery and someone says 'this is what we are going to do' and I'm sitting there thinking 'is that all there is to it?' There is something I'd like to say but I feel I can't.

Mere had also experienced occasions when the manner of a receptionist caused her to walk away from one practice, and another instance when she considered that a receptionist's demeanour and conduct was belittling to a young Māori man she was supporting, who could not pay his medical account. As "fronts people" for the practice, Mere emphasised that the receptionists demeanour, and how they interact with the public, gave people an indication of how they will be treated by the health professionals in that practice. On another occasion, during an incident involving a foreign locum doctor at her own practice, Mere informed the doctor that she did not appreciate the doctor's health assumptions about her ethnicity. Telling the doctor to return to where she had come from, Mere walked out of the consultation. 


\subsection{Jack's story: She gave me confidence that I was going to last}

Jack and his wife had lived in the Motueka district for many years. Now retired, his varied occupational life included farming, the police force, and a number of years with Volunteer Service Abroad (VSA). From the age of 12, his main hobby had been malacology that had led to collaboration with other snail-studying scientists. Although Jack had been enrolled with the one practice for about 20 years, until more recently his rare consultations with the practice nurse were for updating his travel vaccinations. The professional attitude of the nurse contributed to his perception of being cared for as an individual rather than a number.

Jack usually received general health check-ups from the doctor, but, recently, it was the practice nurse who invited him to come for a nurse-led Well-man check "that was the first time I saw the practice nurse in a stand-alone capacity." This was unlike his past experiences of health checks with the doctor. The unexpected comprehensiveness of the practice nurse's well-health assessment inspired confidence in Jack, giving him confidence that he "was going to last...I am pleased, at my age particularly, to be included in any screening...the practice might have." He was also reassured that any untoward consequences would be followed-up and addressed. As a consequence, he felt sufficient trust and confidence in the nurse to discuss a sensitive issue with her. His experience with this nurse was in contrast to his engagements with a locum doctor following his return from a VSA assignment. In that consultation, the doctor did not display any interest in Jack's health concerns that fell outside the VSA form that the doctor was completing, and "he just wanted to tick the boxes. Whereas, you see the practice nurse you have had continuity with, and you'd feel that she would just do a little bit extra than the form."

\subsection{Jo's story: I'm not falling through the gaps}

Following Jo's husband's retirement, they relocated from a large city to a rural property near Motueka. While her husband enjoyed many hours working on his boat, Jo's interest lay in her garden and church activities. Choosing a general practice in a new town was " $a$ pig in a poke" for Jo. She telephoned the one practice she hoped to join, only to find that the doctors were not accepting new patients; the atmosphere of another practice discouraged her from enrolling there. The feeling was not something Jo could clearly identify, but she thought it might have been the manner of the receptionist. At the third 
practice, she found the attitude of the receptionist "delightful and helpful" and chose to enrol there. Because of the distance from town, Jo arranged her shopping, doctor and practice nurse's appointments to fit a weekly schedule. Although this was not an issue for her, it meant that apart from the nurse she consulted, she "didn't know the other practice nurses."

At her previous practice, Jo had received regular ear care, and it was for this reason her new doctor referred her to the practice nurse. Strategically, and with knowledge of Jo's multiple health issues, the nurse discussed the Care Plus programme, with Jo deciding to enrol. Jo valued the nurse's non-judgmental approach as she "made it [losing weight and increasing exercise] really feel quite easy...I am hoping for positive results." On another occasion and following the nurse's referral to the doctor for assessment of three health concerns, Jo informed the nurse that she was "disappointed...because she [GP] never even...looked at my shoulder, and there was nothing she could do for my balance. The only thing I got any joy with was the tummy medication." However, she did appreciate the nurse's concern and "valid" referral. She also found the nurse's "advice and counsel very helpful... and she made sensible suggestions" which were in line with Jo's own thinking.

Noting the development of the practice nurse role, Jo described the nurse previously doing "menial things" the doctor did not want to do. Now, Jo had confidence in the professional knowledge and skill of the nurse who worked independently, but in collaboration with the doctor. She felt cared for and confident she was not "falling through the gaps."

The use of Jo's first name by the nurse indicated to Jo that the nurse perceived her as a person, and not a number. With the continuity of consultations with the one nurse, Jo believed that she was being cared for, and that her health concerns were genuinely important to the nurse. These factors contributed to Jo's confidence in the nurse. The nurse also reminded her when her next Care Plus appointment was due. This connection augmented Jo's rapport with the nurse, and she felt she could be more open, and tell her about aspects of her life and health she was concerned about. 


\subsection{Pango's story: I'm coming for that risk assessment you have been chasing me}

for

Pango's family (whanau) “have lived here [Nelson] for generations. My people are here, my bones very much so." Pango was a registered nurse who had lived and worked overseas, but several years ago, she, with her Pakeha husband and teenage daughter, returned home to be nearer her extended whanau. Pango's formal education included degrees in social work, biculturalism and practice, and Māori and administration. Pango walked and worked in both the Māori and non-Māori worlds, noting "you wouldn't last in this role [senior management position overseeing Māori patient cultural service] if you didn't have a depth of awareness." Pango's interests included gardening, walking, fishing, and addressing health inequalities between Māori and non-Māori. This inequality directly affected her, as she "didn't have grandparents from the age of 12. They'd all passed away at 53 and 36...A lot of it was around access to health services and being able to articulate need in a way that was understood." To address some of these issues, Pango became a member of the Human Ethics Committee which she found "quite challenging at times because of the deficit of knowledge in relation to Màori cultural practice."

Prior to its amalgamation with several other practices, Pango had been enrolled with her sole practitioner general practice for a number of years. However, at this larger practice, she experienced a loss of familiarity and intimacy with staff and her surroundings as "I went from three seats in the waiting room to 15...different receptionists and they all have their own phones...It doesn't allow for an exchange of niceties." Until recently, Pango seldom consulted practice nurses, and she did not know the practice nurse who had contacted her several times, suggesting she make an appointment for a Cardiovascular Risk Assessment. Pango postponed approaching the nurse until she had become better acquainted with her, by observing her around the practice. Pango believed the nurse demonstrated respect by delaying further contact until she was ready to engage with her. Consequently, she did not feel pressured into making an appointment with the nurse. Eventually, she called the nurse saying "I'm coming in for that risk assessment you have been chasing me for." Pango contended that this reluctance to engage with people, whom they did not know well, was the way of many Māori. Because they were contributing personal information to an unknown person, a sense of connection and respect between people was important, but often: 
In many ways it's disempowering...because I am in a position of giving, and getting nothing back from the practice nurse...She's trying to look at you and busy doing the computer work...it doesn't feel that there is equal reciprocity; it's a one way street.

Pango talked freely of her culture, ethnicity and feelings of respect and reciprocity. Even though she appreciated the waiting room with its culturally appropriate posters and health information, she would like the reception and nursing staff to use some Te reo (Māori language) such as "Kia ora" [Hi], when engaging with her. However, she did not want it forced "because I'd feel it," but for it to become a natural extension of the welcoming atmosphere of the practice. The clinically clean "antiseptic smell they use tells me that the bugs will be in the bin...It smells as it should," added to Pango's sense of the practice's respect for people. She also welcomed knowing that the nurse was there for her, and not for any statistical measurement that must be met by the practice. By turning the computer screen toward Pango, the nurse ensured she could read what was being entered, that indicated that the information belonged to Pango. Full explanations of any procedures and outcomes, and the autonomy to make her own decisions about her health, further contributed to Pango's sense of respect in this nurse-patient relationship.

Pango described the contrasting styles of practice nurses over time. Her previous practice nurse was "task-focused...old school," whereas her present practice nurse worked independently from, but collegially, with the doctor. The doctor demonstrated his faith in the nurse's professional competency by referring Pango to the nurse for health care.

\subsection{Sam's story: They will hold my hand if necessary}

Sam was a retired pharmacist and widower living alone in a small flat in a rural setting. His family lived in a distant city. Sam and his wife spent several years as missionaries, and his church activities continued to be a significant feature in his life. He occasionally assisted at a local primary produce shop, was active in his garden, enjoyed reading, and "pottering around."

Sam had been enrolled in the one rural general practice for many years. His choice of practice was influenced by his acquaintance with the receptionist through church activities, and he had come to know the nurses who had worked at the practice for many years. The 
nurses' shared social talk was "another point of contact" allowing nurses to know him as a person and build rapport. These established relationships with practice nurses were important to Sam as they ensured continuity of care and carer in a practice that had employed many locum doctors over an extended period:

I am happy with any doctor I have seen, but if the practice nurse had changed as often as the doctor, then I would be more concerned. There's always someone I know and who knows me, whereas the doctors don't have a clue until they look at my case notes.

Sam made regular appointments with the practice nurse and doctor to monitor his chronic health condition, and to renew his vehicle driver's licence. Other consultations with the practice nurse included annual influenza immunisations, and opportunistic blood pressure checks. Over the years, Sam had noticed the increasing contribution practice nurses made to the practice. For some time after he first enrolled, he was unaware that the person often at the reception desk was more than a receptionist, and that she was also the practice nurse. When he required minor surgery, this same person assisted the doctor and "cleaned up after him," but was "left behind the desk" when the receptionist was unavailable. Now, Sam engaged with the nurse, not only independently from the doctor, but also in association with the doctor, and he was confident that the practice nurse would refer him to the doctor if necessary. Such an event occurred when he was in the town and experienced an unexpected health issue. He opportunistically approached the receptionist to enquire if the practice nurse would take his blood pressure. Following the nurse's clinical assessment, "I was very happy with that," she arranged further evaluation from the doctor which occurred between the doctor's arranged appointments.

On another occasion, and in the process of giving Sam his influenza vaccination, the practice nurse observed that he looked unwell and his skin was moist. Being cognisant of his diabetic status, she tested his blood sugar finding it to be too low. However, it returned to normal following Sam's ingestion of jellybean sweets provided by the practice nurse. Sam, who had recently changed his medication, had not previously experienced hypoglycaemia. He emphasised that the nurse's prompt actions and information helped his understanding of diabetes and he now carried jellybean sweets with him at all times "jellybeans are good." 
In addition to valuing the practice nurses' professional clinical competency, during his wife's illness and following her death, Sam found comfort in the nurses' companionable and nurturing approach. "They knew my situation and kept an eye on me a bit closer than [usual]. It's worse for a male, because you're not used to doing all the things that you have to do." He had confidence that the nurses also knew him well enough to be sensitive to any subtle changes that may indicate that he was unwell or distressed. Even though he consulted different locum doctors, he gained comfort from the knowledge that there was always someone at the practice who knew him and could "hold my hand if necessary."

As a pharmacist, Sam had always appreciated efficiency, finding the same attributes in the practice nurses, "they look efficient." His cognisance of their professional competency and his awareness of the continuing education and study that some nurses had undertaken increased the confidence and comfort he experienced.

\subsection{Nikki's story: That's where the practice nurse came in}

Nikki and her husband had resided in the Nelson/Motueka region for many years. Their now adult children, also live locally. Nikki worked from her rural home helping small businesses with their accounting needs. Her interests included researching her family's genealogy, and more recently, increasing her physical exercise.

Nikki had previously mainly engaged with the doctor for regular repeat prescriptions, and occasionally, with the practice nurse for blood pressure checks. However, following blood tests results, demonstrating raised lipids, the doctor referred her to the practice nurse to assess Nikki's lifestyle. "That's where the practice nurse came in...I have had a good time with the practice nurse." However, her feelings prior to her initial engagement with the nurse were of "fear and trembling...because I am apprehensive of any nurse anyway." She had assumed the nurse would list Nikki's lifestyle errors and be prescriptive with her advice. In spite of this early anxiety, the nurse's sensitivity to how she was feeling, and her skill and understanding of the difficulty of changing lifelong habits, quickly put Nikki at ease:

It was about what I was comfortable doing, and it was important that I related to her on a one-to-one basis...It was great; there was a good understanding of where I was at...and that provided me with an incentive to start working on those 
lifestyle changes...I walked out of that first appointment feeling good; feeling I could achieve something.

The nurse respected Nikki's human agency by scheduling appointments to suit her lifestyle, rather than the nurse setting dates and times. Nikki gained confidence in her ability to "make that milestone," and the period between appointments increased. The practical, small steps and changes in her lifestyle and sensitive support from the nurse empowered and motivated Nikki to continue with her changes, as "the consultations with the nurse were about helping me get that power to deal with it myself."

Continuity of care from the same nurse was important for Nikki. However, on one occasion when her usual nurse was absent, she consulted another nurse who "was not on the same wavelength and her approach was totally different." It was this nurse's authoritative approach, rather than being mistaken about her clinical advice, that Nikki found difficult, and she left the consultation “disappointed." However, she was also aware that "I have to take responsibility for what's happening. The practice nurse can help...but my target was to get me doing what needed to be done, not having someone else telling me what to do."

Computerised clinical records were a significant factor in Nikki's progress. She appreciated the nurse discussing what she was writing on the computer and "I could see what she was typing and that it was right" This resolved two issues for her:

I didn't have to explain myself again because the practice nurse remembered what stage we were at...and as a carrot and stick. I knew what we'd discussed...and I knew we would discuss how the plan went....I did use it [clinical records] as motivation...to make sure I did try...She knew...that last week or fortnight we'd discussed trying whatever it was.

Building rapport and trust in the practice nurse who was sensitive to Nikki's personality and her need to begin "where I was at" and "being alongside" were influential in empowering Nikki to make the changes she wanted. She valued the independence of the practice nurse who was:

More about, 'here's the problem you're dealing with, how can I help you work with it'...encouraging the patient to do what they need to do... whereas the doctor 
is...this ailment, this medication you need to take...She [nurse] is the first port of call if I have a concern that I am not sure how to address with the doctor.... She is more accessible than the doctor.

\subsection{Billie's story: She explained everything}

Billie immigrated to New Zealand from Australia to be her wheelchair-user partner's primary caregiver. While relocation from a large city to a rural area and a new occupation in a different country were significant transitions in her life course, she enjoyed taking advantage of the opportunities she found here. Studying for a certificate in horticulture, Billie's hobbies included gardening and "crafty things."

Billie enrolled with the same general practice as her partner, as he had already "established a relationship with a doctor at the practice." However, she retained her enrolment because of her rapport with one practice nurse and reception staff. The practice also had a "sterile feel, and is lovely and bright, and makes me think that I am going to a good place; that I am not going to catch 'flu from a previous person... and there is hand sanitizer."

Following a letter from her Australian general practice reminding her that her cervical smear was due, Billie contacted the practice for an appointment. For this consultation " $I$ was just assigned the nurse" by the receptionist. However, this was acceptable to her, as she "preferred to engage with a female" for this kind of situation. Although Billie recognised that a male doctor would have the relevant medical knowledge, she would not have been as open with him about her health issues as she was with the practice nurse.

In contrast to her previous practice, where Billie had not observed a practice nurse being present, and she had "never had my vitals taken before," she appreciated the nurse's proactive approach to health. The nurse's compassion and sensitivity in warming the speculum prior to use was comforting for Billie because "I had never had them warmed before." The nurse not only explained the procedure, but, as Billie did not understand the medical terminology, she also interpreted the results of her previous test. Being able to observe what the nurse was typing into the computer and "that I can always look at that if need be" also comforted Billie. Confidence in continuity of care and the nurse, is reflected in Billie's statement "it's nice to have that continuity with the nurse. She knows my history and every time we go back...get to know her better and feel more comfortable around her." 
Given that Billie was her partner's caregiver, and there were care issues she needed to be informed of, Billie often attended his doctor's appointments. "We are very open with each other...sometimes he comes with me to my appointments as well." These joint nurse consultations added to their confidence in the nurse.

Billie found that the practice nurse or receptionists sharing some personal, social information assisted her feeling of connecting with the community, and to building the relationship with practice staff. Getting to know them as people and not just by their occupations was a significant element in Billie's sense of comfort.

\subsection{Miles' story: She worked on that bond between us}

Miles had experienced significant tragedy in his life. When he was 18 his 15 -year-old brother drowned while swimming, and at aged 22, and on an overseas holiday, Miles sustained a severe spinal injury in a diving accident, and was now a wheelchair-user. Following months of rehabilitation, Miles lived on the West Coast with his parents, but because he found this to be so socially isolating, about 12 months ago, the family relocated to this rural area where he had made new friends. His partner relocated from Australia to become his primary caregiver. Miles interests included completing a degree in psychology with a "rehabilitation theme" that he hopes will lead to employment opportunities, and "going out for dinner."

Acknowledgement of his specific health needs was important for Miles, and prior to relocating, he chose a doctor he considered would meet his complex requirements. Using the Internet to find a list of doctors in the area, he chose one practice contacting the receptionist to ensure the health professionals were competent in spinal injury care.

Over the past three years, Miles had mainly engaged with the doctor, and while he was aware of practice nurses, he had not previously consulted a nurse. However, on one occasion when he had expected to see the locum doctor, he met with the nurse whose interest in him as an individual, and her professional competency created a sense of comfort and companionship in Miles:

I'm quite aware if people sort of ignore me because of my injury and I am in a wheel chair. I've had a few experiences of it in the past with various 
professionals. It's quite offensive...but I've found at this practice I've never had anything of that sort which is great.

Although apprehensive about an influenza immunisation she was about to give him, he found "it was good because she explained things." $\mathrm{He}$ described the nurse opportunistically engaging with him in a "health orientated discussion," and she also "worked on that bond between us" by including social chat during the consultation, Miles gained comfort from the nurse taking his concerns, such as communication between health professionals, seriously, and working to resolve any issues he might have. Since transport was problematic for Miles, other engagements with the practice nurse included telephone consultations to organise repeat laboratory tests and prescriptions. This type of contact added to the value Miles placed in the professional competency, knowledge and skill of the practice nurse.

\subsection{Helen's story: She is almost like a doctor}

Helen was in her 80s and was a retired medical practitioner. She continued to maintain an active community and social life in the city. Her large family and many grandchildren also kept her busy. Even though one of her daughters lived close by, she did not see her every day "but we're there if we want to see each other." Several years ago, the retirement of Helen's doctor and an "excellent...and empathetic" practice nurse, necessitated her enrolment with another general practice. This larger practice changed the way in which she related to the doctors and practice nurses, and she missed the feeling of companionship she had enjoyed with her former nurse.

Helen talked of a time at her previous practice when she needed her blood pressure taken more frequently, and how during these engagements she shared her "troubles" with the nurse. Helen did not discuss these concerns with her family and friends as she assumed that they would think she was complaining. The bond with the practice nurse influenced her sense of well-being as she "found it very helpful to have a supportive person there." The perception that the nurse has the "opportunity to sit and listen... and doctors do not have time to listen to what your real troubles are" also contributed to Helen's preference to discuss her problems with the nurse rather than the doctor. 
Helen consulted her doctor at the new practice "quite often" but found that the practice nurse could be very helpful "without me having to...see the doctor." The nurse is "very good and can point me in the right direction." On one occasion, Helen felt very unwell with an infection she had previously had treatment for. Believing it would be easier for her, and she "did not want to worry the doctor," she telephoned the practice nurse whom she expected would organise the necessary laboratory form for her. The practice nurse not only discussed suitable options with Helen, she arranged an appointment with her the same day, without the need to consult the doctor:

She did test it and I had a nasty infection... She was so efficient; she sent some to the lab, looked up [on the computer] what I was allergic to...it was recorded there, so she ordered something else and went...to get the prescription signed by the doctor...After two days I was much better...I was most grateful.

Comparing the role of practice nurses at the time her husband practiced medicine, with the nurses she now consulted, Helen commented "I'm impressed with them...They do all the smaller things" that used to be undertaken only by the doctor, such as ear syringing and wound care. The professional competency of the practice nurse she consulted was also noted by Helen, who contended that they had equality with doctors and "I often think she would make a good doctor....They have degrees."

\subsection{Roni's story: She fills the gap}

Roni had been living by herself in a large city, but she had resigned from her job due to health issues. Subsequently, she and her partner relocated to Motueka to be closer to her partner's children. Her interests included volunteering for St John Ambulance and craftwork, both of which provided the freedom to work from home, and to accommodate her illnesses.

Roni had high health needs that required frequent medical consultations. Given that some of her previous experiences with health professionals were traumatic, choosing a new general practice and doctor with whom she could relate, was of paramount importance. Her choice of practice was influenced by two factors; the psychological discomfort she experienced in one practice, and unpleasant rumours about the GP at another practice. Even though these reports increased her trepidation about approaching this practice, as this doctor was on leave, she consulted a locum doctor with whom she related well. Roni 
developed a rapport with the receptionist, and also "built up a level of trust" with the practice nurse that contributed to Roni's decision to remain with the practice. Being able to trust her carers was of critical significance to her as she had been:

Let down in the past...Just the fact that I wasn't let down by her, [nurse] ever. It means being honest, it means speaking in confidence...getting the information, or talking to the doctor; doing your job, and doing whatever you can for your patient; being an advocate.

Consultations with the practice nurse included well-woman checks, Care Plus follow-ups, pain relief injections, and smoking cessation advice. However, it was the time the nurse spent listening to Roni talking about her health, which she found particularly helpful. She also valued the practice nurse proactively offering further health checks as "it makes sense to check other things while I am there." Roni appreciated the nurse advocating with the doctor for her and arranging for her to be "seen between patients." She also valued the nurse's sensitivity in raising the issue of historical events that may have affected Roni's mental health during an intimate examination. This was especially relevant to Roni who, at a previous practice, experienced one practice nurse's diminished level of professional competency when, during one such examination, left the room without first ensuring Roni's privacy.

Although "I can ring my mum," [a nurse] Roni preferred to engage with the one nurse she perceived as trustworthy to ensure "that level of care." Notwithstanding, Roni would appreciate dedicated time for her Care Plus programme:

I generally get shuffled into whoever's there...It feels like 'better do this while you're here...we'll squeeze you in between other people' rather than an actual appointment. It's easier if I see the one person on a continuous basis because they know me, as well as what they see on the computer screen.

Although she found being squeezed in between patients for Care Plus reviews problematic, she did appreciate this same process when she was acutely unwell. The nurse "fills the gap" until Roni could be assessed by the doctor. The practice nurse who shared some personal information with Roni, further contributed to her sense of well-being. "You know that they're not just someone who is a practice nurse...You want someone human dealing with you, because you're human and you want to know that they are as well." 


\subsection{Summary}

In this, the first of two findings chapters, I have presented each participant's life-story to illustrate who they were as people, and their time in their life course. Given that the research was about participant's relationships with practice nurses, these stories were a critical factor, in understanding participants' historical, cultural, and structural backgrounds. The stories also described how participants viewed their engagements and relationships with practice nurses. In the context of general practice, the stories also presented insight into participants' relationships with receptionists and GPs. The following chapter provides further analysis of participants' stories describing their perspectives of their consultation and relationships with, not only practice nurses, but with general practice as a whole. 


\section{Chapter 7 Participants' relationships and engagements with practice nurses}

\subsection{Introduction}

This second findings chapter is informed by McCormack's (2001) multiple lens approach. White's (2010) three dimensions of well-being, the overarching presence of the doctor, and the concept of practice nurses "filling the gap" in care are central to the concepts presented in this chapter. Three symbiotic themes of "General Practice Activity," "Health Focused Practice" and "Professional Comforting" emerged from the analysis, and are presented diagrammatically (Figure 5). Each theme demonstrates the symbiotic relationship; that is, the close, mutually benefiting relationship between participants and all members of the general practice team.

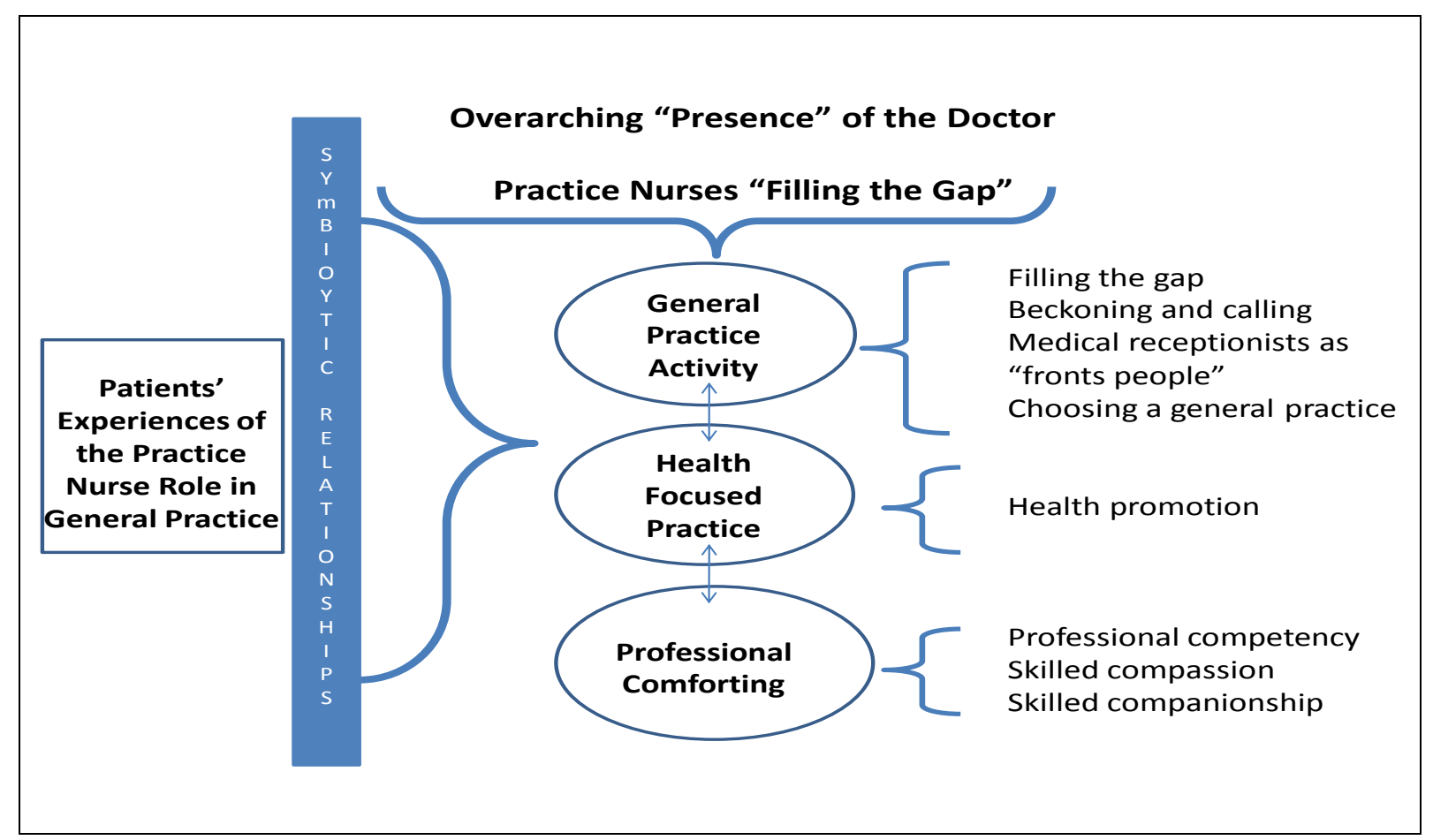

Figure 5. Schematic representation of the themes and well-being

\subsection{General practice activity}

General practice team members included doctors, practice nurses and receptionists. Participants talked of each person as individuals, and as a group, portraying symbiosis in the relationship between all the members of the practice. By this, it is meant that not only did the nurse and doctor have a close and usually obligatory working association that was often to their common advantage in providing health care to participants, thus linking participants to the symbiotic relationship, but also the receptionist's role, meant that she, 
likewise, was symbiotically linked with the doctor, nurse and participant. No practice team member was positioned in isolation from the other, as they all relied on each other for their mutual benefit. (Symbiotic relationships are discussed in more detail in Section 8.3.1). Although participants/patients were symbiotically linked with practice team members, they did not indicate that they viewed themselves as part of the health care team.

Participants saw doctors as team leaders; the person to whom other team members referred and deferred. Doctors were viewed as an overarching 'higher power' that was perceived in all interactions between patients, nurses and receptionists. Participants' perceptions emanated from the physical presence of the doctor in the room, as well as from his or her unseen presence, where the doctor's authority was assumed. Practice nurses were observed as an essential component of the general practice team 'filling the gap' in care provided by the doctor. Receptionists were found to wield considerable influence in many engagements with participants. The sense of the overarching presence of the doctor, and of practice nurses filling the gap was implicit throughout the data.

\subsubsection{Filling the gap}

Symbiotic connections between the practice nurse and the doctor were manifested in Roni's story when the practice nurse, whom she trusted, filled the gap until she could consult the doctor:

She will go in and see the GP and ask questions...for me... When I was very low [mood] and I wasn't able to get in to see the GP...I came down and spoke to the practice nurse, who got me in to see the GP between the patients...it fills the gap until I can be seen properly...I built up... a level of trust [with the nurse who is] honest; [I can] speak in confidence, so I feel comfortable talking about my depression and my illness and just general problems that I might have.

Roni described a subjective dimension of well-being in this exemplar. The symbiotic link between the nurse, doctor and patient, and Roni's augmentation of the story were also illustrated. Not only did the nurse make clinical decisions independently of the doctor, she was aware of Roni's feeling of powerlessness and reluctance when talking to the doctor, undertaking this advocacy role herself. By protecting Roni's confidences, the nurse's sensitivity contributed to Roni's certainty of the nurse's professional, ethical competence. 
Symbiotic relationship and the subjective dimension of well-being were also revealed in Bert's descriptions and reflections of his engagement with the practice nurse:

They know what they're doing, so I just find them pretty good...Each time they tell me to make sure that I do the right things...I'm grateful, because sometimes people don't get the opportunity to get checked out....If she thinks it's necessary, she will call the doctor in ... he'll just check you... while he's going to get the next patient; he'll pop his head in the door...he said 'I need to see you then.' I think it was pretty good because you had the satisfaction that if the nurse...wanted a second opinion...he was right there....I was a bit annoyed [about another hospital admission] but they were doing their job.

The nurse had been so concerned by Bert's cardiac symptoms, she interrupted the doctor's scheduled appointments to request further assessment. While being reassured by the doctor's immediate availability, Bert was also comforted by the nurse's professional competency when she identified his symptoms being of sufficient concern to her, that a second opinion from the doctor was necessary. However, he also deeply appreciated the care he received, and was reassured by the knowledge that the nurses were acting as he expected them to. By looking after his psychological and physical comfort, they were caring for him in a manner that reflected their education and professionalism.

Preserving the sense of symbiosis, the following sub-theme portrays the subjective and relational dimensions of well-being through the increasing diversity of the practice nurse role. It embodies not only cultural identities, obligation and political and personal inequalities, but also the caring and support provided to the participants by practice nurses.

\subsubsection{From beck and call, to beckoning and calling}

In their encounters with practice nurses, seven participants referred to the "how it was before" and "how it is now." While the evolutionary nature of the practice nurse role had increased the visibility of practice nurses, the following example uncovers the historical nature of the work of practice nurses:

I had a little thing removed from my neck... she [practice nurse] started preparing things, and I thought 'she's more than a receptionist'...she put a plaster on.... She was assisting the doctor. He did the incision and removed it, but...she...cleaned up 
afterwards....[However] if the receptionist wasn't there, it was over lunchtime or...afternoon off for her, she [nurse] would have been left behind the desk. (Sam)

The past invisibility of the practice nurse and the hierarchical nature of the doctor and nurse's roles were evident in this passage. Also apparent was the confusing nature of the nurse's position in the practice. The person Sam understood to be the receptionist, was also the nurse who assisted the doctor, acting as his hand-maiden when "she cleaned up after him," and then "left behind the desk" when the receptionist was unavailable.

Jo bluntly depicted the historical role of the practice nurse "just doing the menial things really, to relieve the doctor from having to spend his time doing them." She perceived the nurse's function was to act as the doctor's assistant, while at the same time, divesting him of the tedious, "menial" tasks that did not command his higher-powered attention. This suggests that the doctor's medical knowledge and time were perceived as being of greater value than that of the practice nurse.

Illustrated in the following account are both the past and contemporary symbiotic relationship between the nurse and doctor:

It used to be the receptionist who was a nurse, and the doctor....at some surgeries that...role is very clear; the doctor and the nurse...the doctors' respect and work more easily with nurses now...the way they speak to each other suggests a mutual respect of authority. (Tui)

The diminishing professional distance between the nurse and the doctor was described in this excerpt. It also demonstrated acknowledgement by the doctor, of the practice nurse's professional status within the practice authority. Their apparent amicable and symbiotic relationship was evident when the doctor chose to engage with the nurse in a collaborative and mutually respectful manner. This new environment allowed for an exchange of information that had not previously been evident to Tui.

As a retired medical doctor, Helen was familiar with the historical, hierarchical doctorpractice nurse separation. Noting that doctors had progressively passed on minor tasks to practice nurses, she supported the advancement of the practice nursing role and took advantage of their professional competence and autonomy: 
We used to syringe out ears and all those sort of minor jobs that now they hand over to the nurses...they do [them] very efficiently....They are given more responsibility than they used to. They see patients and communicate with the doctor if there was anything that [they need medical input for]. They almost have their own practice in a way, which wouldn't have been the case years ago.

Helen's description traced the historically 'higher-powered' doctor now bestowing more responsibility on to the 'lower powered' practice nurse. She also illustrated her growing admiration of the nurses' expertise, taking advantage of their autonomy to meet her health needs.

Mere painted a similar picture of the practice nurse as 'doctor's assistant' or 'handmaiden.' Her story (Section 6.7) described the evolutionary activities of the nurse, as well as the professional distinctiveness of the nurses and doctors' roles:

Now practice nurses can do smears...they couldn't do that back then and it was more or less like bring the bandage....They'd get out the record books and have those all ready....They weren't doing what they can do now....Even taking your blood pressure; back then it wasn't the practice nurses....They do have a connection [with the doctor]...You can either have the practice nurse or a doctor...everyone in that setting has got their...own rules; their own structure....The practice nurses I know can do your Well-Woman...Men can't tell you about those sorts of things....The practice nurse...is just as important as a doctor. They may not be a doctor, but they also have got knowledge. The practice nurse will spend more time talking with you.... Not all doctors can...they need to talk in every-day language...but our practice nurse can tell you.

Clearly shown in this exemplar, is the historical perception of the nurse as doctor's assistant and hand-maiden. The importance Mere placed on the independent engagements and relationship she now has with the practice nurse, was also apparent. The nurse was perceived as not only possessing professionally distinct knowledge from the doctor, but that her gender was a significant factor in her discussions about her needs as a woman. It was the nurse's empathetic, womanly knowledge, rather than a male perspective, that Mere described as significant when discussing female concerns. Also expressed, was the 
importance Mere placed on the every-day language used by the practice nurse, and the time she spent interpreting the doctor's medical terminology.

Although the participant's needs were met in that account, in another broader cultural context, Mere talked of a culturally significant moment of disconnection with a locum doctor who made assumptions about the health of Māori:

She said 'so, about your blood pressure'... what did you have to eat?' I told her, and she said 'that's no good for you, and that's no good for you'.... I was getting upset [about what the doctor was saying about Māori]. I said 'where do you come from?' She said 'I'm from the UK'...I could feel my blood pressure was up. She said 'your blood pressure's up' I said 'yes, thanks to you...I'm going to tell you here and now, you're not taking my blood pressure ever again...You have no idea about Māori. Don't try and tell me about my race of people....As far as I'm concerned you can return to the UK, ' and I walked out.

Mere's excerpt portrayed the UK doctor's cultural bewilderment. Even though the UK doctor was working in New Zealand, she did not show any apparent understanding of culturally competent practice. The doctor's general negative assumptions about the Māori "race of people" made to a Māori woman, incensed Mere to the extent where she confronted the doctor about her attitude, and left the consultation. Cultural dissonance in general practice was noted by two Māori participants who described altering their behaviour to correspond with the dominant non-Māori or Pakeha culture of practice staff.

Similarly portraying the significant repositioning and responsibilities of practice nurses in a contemporary practice, Katriona identified the symbiotic synergy between the nurse she usually consulted and doctor:

I'd check with her [nurse] about it first and see whether I needed to see the doctor...I know the nurse is doing all the things, and that they might have been able to deal with it or tell me.... I was seeing the nurse because I didn't need to see the doctor [and] she said 'I think we'll get him to come and check that what I'm saying is right'. So, he did pop in between patients, he...reconfirmed what she had said. [Historically] The doctor was here and the nurse was there...Now I feel they're support...like backup to him. I have been there when...he said 'we'll go 
into the nurses' area... and we'll just check what she thinks'...she's not there as a doctor's helper.

This account demonstrated Katriona's belief in her ability to make decisions about her own health status and her choice of health professional. She was confident the practice nurse would appropriately advise her to consult the doctor should it become necessary. The symbiotic nature of the doctor and nurse relationship was disclosed when Katriona talked of the nurse beckoning the doctor, who interrupted his appointment schedule to give his opinion. It was further shown by the doctor's reciprocity when he asked the nurse for her assessment of a situation he was unclear about. This description portrayed professional colleagues who accepted and respected each other's expertise, rather than the nurse as 'doctor's assistant' or doctor as 'higher power.'

The autonomous practice of the nurse as well as the interconnectedness of the practice team members is conveyed in the following example:

She's very much part of the team...I see her as being complementary...she's well able to provide good information and do the hands on as well....You see the GP for such a short period of time... and that's just the business end of things. The doc's just one piece of the jigsaw....it's the receptionist that you go in and see, and you get the appointment or you ring....it's a team effort, and they've all got their own set of skills....sometimes the practice nurse does [reception] if they're really stretched...At one stage...everybody was sick and she had the baby on the hip and the phone...she was multitasking....I'd go to the practice nurse...for follow-up. (Pango)

Pango's perception of the practice nurse was one of the nurse not only as a support for the doctor, but also complementary to the doctor, filling a gap in the delivery of health care. Pango augmented her story by describing how the nurse not only filled a health professional gap, but also she filled an administrative gap by acting as receptionist, and as a baby-sitter. These multitasking qualities of practice nurses demonstrated the role confusion sometimes experienced by patients, such as Sam described, especially if staff members did not display name and status labels. It also demonstrated the historical expectation of GP employers that nurses would undertake non-nursing duties. 
Clearly portrayed was the sense of symbiosis in the general practice team; the doctor, practice nurse and the receptionist, all dissimilar, but mutually reliant on each other for the benefit of the dependent participant. Pango's account emphasised the perceptions of six participants who talked of the doctor not having time to engage with them in a holistic sense, and she gave this as the reason for consulting the nurse.

The relational dimension of well-being continues in the following section on participants' relationships with medical receptionists. Also highlighted is the material dimension when participants accessed health care services.

\subsubsection{Medical receptionist as 'fronts people'}

Receptionists were usually the first point of contact in the practice, with participants engaging with them either by telephone or face-to-face. Participants portrayed the receptionist as a person with significant influence within the practice; it was the receptionist who often decided whether participants would engage with the nurse or doctor. This finding indicated that participants not only conferred with receptionists about appointment times, but also sometimes discussed their health issues. It was the receptionist's opinion participants asked when they were unsure whom they should see, and it was the receptionist who sometimes decided the urgency of their health issues and timing of appointments. Although the following accounts describe the authority of the receptionist in the receptionist-patient relationship, they continue to depict the symbiotic nature of the general practice team:

I might say to the receptionist, do I need to see the doctor or can I just see the practice nurse. (Kay)

Bert spoke of 'the receptionist checking to say 'what would you like to have done?' and I say 'I want to have my ears done,' or 'I'm coming in to have this done', [the receptionist advised that] 'you just go and see the nurse' and they just make the appointment for you.

Receptionists gave Tui the option of seeing the nurse. "They didn't used to, but now they say, 'would you like to see the nurse?' 
Three different approaches are found in these citations. Kay asked the receptionist for advice about whom she should consult, with the receptionist making the decision for her. Bert's receptionist asked him the reason for the appointment request, and chose which health professional to allocate him. However, while both these quotations signified that participants discussed their health issues with receptionists who made health professional appointment decisions, without prompting, Tui's receptionist offered her the option of consulting a practice nurse without first seeking health information, leaving Tui to make the decision.

How receptionists might demonstrate their management of people's time in addressing participants' health issues, irrespective of whether they had a booked appointment or not was described by Sam. He was concerned about a "blackout" and wanted his blood pressure checked:

I popped into the surgery and saw [receptionist]. 'I've come for a blood pressure check', she said...[nurse] 'will be with you in a few minutes, '...I saw [nurse]... she was very good...she said 'I think you should see the doctor...I'll just check' and she...saw [receptionist] and she said... 'he will be free in a few minutes'... and she fitted me in...I appreciate that so much.

In the context of Sam's story, the opportunistic nature of his approach to the receptionist was described. It also depicted the skill of the receptionist and nurse in taking advantage of a gap between scheduled patients, ensuring Sam's prompt medical assessment. Moreover, it demonstrated the nurse's professional clinical decision-making competency.

Receptionists' demeanour and manner of engagement influenced participants' perceptions of how they might be received in the practice. One participant (Mere) talked about an engagement with a receptionist that so distressed her, she left the practice without her mother's health needs being met. The irritated performance of the receptionist as an authoritarian "fronts person," influenced the environmental character of the practice for Mere. The language used by Mere conveys her continuing anxiety about the encounter:

I was accompanying someone else... she [receptionist] said 'you know you're very late. To hell with the doctor and you've put all the other patients out of their timing '....I apologised and I explained why, but that wasn't good enough. She says 'this is not a place for grandstanding.' I said to my mother... 'you don't deserve 
this. We're going,' and I took her out; never went back again.... But the way they behave...They are the fronts people, and it's to them that you will get a guide as to how the place feels...if you have...those who smile...you can actually feel the atmosphere.

Similar "power-play" by the receptionist was illustrated by Tui, who took part in a survey relating to young peoples' confidential access to a health professional:

This girl walked in into the surgery; and this lady [receptionist]...was immaculate. She stood up and looked down her nose... and this kid said 'it's confidential' and this woman said 'really' and started hounding her; she was just really awful. I walked in [from outside the open door but where she could hear and observe the discussion] and she said 'Hello [Tui] how are you?' Just this huge change...she left this kid, and I said to her 'are you dealing [with young person]' and she said 'no.' [Then] she leant over and said 'yes'...I said 'she's with me'. She said 'oh really?' She was so grumpy with me. But she was power and control stuff and it was really horrible....All she'd done was walk in and ask, and she [receptionist] grilled her; 'what did she want? Did her parent's know she was there?' She was an older woman...There's no need to treat people like that, and they [receptionists in the survey] were awful to the girls; not so much to the boys...It's about how you want to sell your practice

The commanding position and authoritative demeanour of the receptionist was depicted in this narrative. Also shown was the transformation of the projected 'front' of the receptionist. Her initial expression of dominance, judgemental attitude and dismissiveness, changed to one of amicability and openness when Tui, whom the receptionist knew, entered the practice. The sudden alteration in demeanour, suggests that the receptionist wanted to make a favourable impression with Tui. However, this open attitude changed again when the receptionist learnt that Tui was supporting the young person, becoming "grumpy". Further revealed, was Tui's theorising and understanding of receptionists as the forefront of the practice, and that the first impression of the practice was often a deciding factor in whether a patient felt welcomed or rejected. Tui's perception of receptionists' softer attitude when engaging with teenage males compared to teenage females, may indicate that young men could remind receptionists of their own sons, and assume a nurturing response. 


\subsubsection{Choosing a general practice}

The environmental "feel" of a practice was a factor in Jo and Roni's stories (Sections 6.9 $\&$ 6.16). Being new to the area and searching for a medical centre, both participants found contrasting practice "atmospheres" that contributed to their decisions about which practice to choose:

That was a pig-in-a-poke, I got the phone book out and I rang around and the one I originally wanted...weren't taking any more patients. Another one we had been to once...didn't quite gel with me. I couldn't put my finger on it. Maybe it was the person on reception; it didn't feel right...I tried the third one and the lady on the reception was so delightful and so helpful, I thought 'yes, this will do me.' (Jo)

At each practice, Jo's decision was influenced by the receptionist's 'way of being'. While she was prevented from enrolling with the practice of her first choice, the adverse ambience at the second practice caused her some emotional discomfort, a feeling of disconnection, she could not identify. This altered when she encountered the receptionist at the third practice who was "delightful and helpful." The welcoming demeanour and disposition of this receptionist created feelings of comfort and well-being in Jo.

For Roni, although it was the environment that discouraged her in one practice, at another it was the poor opinion she had of the regular doctor (who was on leave), and the high regard she held of the locum doctor, which influenced her decision. However, her bond with the receptionist also impacted on her feelings about the practice:

I went to one medical centre...I didn't like the surgery at all...I went to another one...the [regular] doctor wasn't there...and the really neat locum was really fantastic.... I didn't want to see [the regular] doctor because I had heard about him....I managed to get away with not seeing him for quite some time, and then I finally saw him and went 'mm.'... He sold the practice and I was really happy....I have built a rapport with the receptionist now so they know who I am, because I go there so often.

The degree to which outside agencies may contribute to participants' choices of health professionals was uncovered in Roni's story. The negative comments from community members led to her forming a bias against one doctor. While her impression of this doctor's reputation was initially based on hearsay, but later confirmed by her own 
experience, she found she could "get away with" not consulting him. However, it was the positive engagement with the "really neat" locum doctor that facilitated her continued enrolment with the practice. Although the disposition of the receptionist was not raised by Roni, the rapport she developed with this receptionist also helped to maintain her choice of medical practitioner and medical practice. Nevertheless, it was the actions of that receptionist, who did not make full scheduled appointments for her Care Plus consultations with the nurse of her choice, that discomforted Roni. "I just get shuffled into whoever's there...squeezed between other people." Continuity of carer was important for Roni, who contended that it was more beneficial to her to engage with the one nurse with whom she was familiar, and "who knew her background and her personality."

Despite Sam being familiar with the town's GPs, and a receptionist, it was his church affiliations, rather than professional connections, that drew retired pharmacist Sam and his wife to enrol with one practice. "I knew all the GPs... We knew [receptionist]...through church."

To become subjectively familiar with receptionists, the importance of social talk was emphasised by participants, and is reflected in Billie's comment:

I find that even with talking to the ladies at the desk, getting to know them more; even just small chat, like, where did you get that skirt from? You understand that they have a life outside there and being in a small community helps with that as well. You get to know the person as well, rather than just the face in the crowd.

As a wheelchair-user, the prerequisite for Miles was ensuring the availability of medical care that was appropriate for his unique needs. Utilising the Internet to locate a list of medical practices, he telephoned the practice of his choice, with the receptionist confirming that the doctors were experienced in tetraplegic care:

I...went on the Internet...I liked the look of the one I'm with, and just rang them up and explained my situation and asked if there was a doctor available and they [receptionist] said 'yes. '... Once I moved up here, I got back in touch.

In the following theme of Health Focused Practice, although all three dimensions of wellbeing are present in the data, the 'material' dimension of well-being is dominant. The overarching presence of the GP continues to be apparent. 


\subsection{Health focused practice}

Demonstrated in this theme are participants' experiences and perceptions of the practice nurse role. They describe the symbiotic nature of medical and nursing responsibilities, as well as the doctors' overarching presence in any engagement with the practice nurse. Health Focused Practice conveys participants' experiences with practice nurses in health promotional and functional terms. These activities are carried out by practice nurses and are directed towards health promotion, health maintenance and Chronic Conditions Management. Healthy Lifestyle, Care Plus, Vascular Risk Assessment, immunisation programmes, diabetic assessments, smoking cessation programmes and cervical screening fall into this category. Through this professional practice, and engaging with participants independently from the doctor, the nurse could "point people in the right direction," "keep on top of things," or provide "counselling." The function of the nurse was also observed as being "support for doctor" and as someone who "takes the pressure off the doctor." They were viewed as professionals who filled the gap by their professional competency, and through their personal and professional comforting praxis of "skilled compassion" and "skilled companionship."

\subsubsection{Health promotion}

Participants consulted practice nurses because they believed their health concern was something that the practice nurse could manage, that she would "point them in the right direction" without needing a doctors consultation. Although the nurse engaged with them independently from the doctor, the sense of the doctor's presence was immutable. Even though the professional roles of the doctor and nurse are explicit in the following passage, Helen was clear about expressing her agency and the reasons behind her choices. It also demonstrated her perception of the doctor's higher status:

I do see my doctor quite often but I find that practice nurse can be very helpful without me having to see the doctor...Instead of worrying the doctor, I think the nurse would organise a specimen jar, and she would get the doctor to sign a form which would be easier for him and me, without bothering him, and they're [nurses] always very pleasant and they find the out the right thing to do.

The overarching presence of the doctor and the hierarchal and discriminatory nature of Helen's understanding of the roles and responsibilities of the doctor and nurse were 
displayed in this account. How the nurse filled the gap in care for her was also demonstrated. Although unwell, Helen was reluctant to "worry the doctor" or cause him any inconvenience. Consequently, to make life easier for the doctor, Helen anticipated that the amicable practice nurse would "find the right thing to do," organise her specimen jar and laboratory form, and obtain the doctor's necessary signature, without her seeing him.

Other autonomous consultations with practice nurses also disclosed the overarching presence of the referring doctor. 'I'd been to the doctor...he looked at my age...and because of my blood pressure he said to make an appointment with the nurse...I was seeing the nurse because I didn't need to see the doctor (Katriona). Sometimes such engagements were influenced by what needed to happen. "There will be times where I don't need to see the GP, I'm quite happy to see a practice nurse [such as] the regular cervical smear" (Pango).

Despite being aware of the presence of the doctor, Katriona and Pango chose to consult the nurse independently from the doctor because of her particular knowledge and skills. The passing over of a task, and GP referral, and an awareness that the nurse could effectively manage their particular health concerns, were perceived by participants as something to be valued.

Although the following exemplar has similarities with the previous examples, the overlying sense of the doctor's presence, as well as the independence of the nurse is discerned:

When I went to the doctor I had my 'flu injection; normally the nurse does that. It just happened that I had to get prescriptions...I don't always see the doctor...The nurse does my prescriptions if it's six months. It was the practice nurse that suggested that I get a Green Prescription after I'd had the back and leg...I went to the gym and did light exercises and also started walking a lot...She was treating me in a situation where she could see I needed help and pointed me in the right direction. (Kay)

The symbiotic relationship between the doctor, nurse and participant, as well as the health focused practise of both health professionals were shown in Kay's discussion around obtaining her pharmaceutical prescriptions. While not a physical presence, when she 
engaged with the practice nurse, the doctor's overarching proximity was discernable. The collaboration, or sharing of roles between the doctor and the nurse was displayed when the doctor not only prescribed her medication, he gave her influenza vaccination, which the nurse usually did. Conversely, when there was no change to her medication, the nurse independently co-ordinated Kay's prescriptions. She was also cognisant of Kay's health concerns, suggesting a course of action that would help her.

Tui talked of choosing to engage independently with the practice nurse only to discover that, in some instances, the doctor's medical expertise was required. Her excerpt also demonstrates the development of the practice nurse role over time:

I've ended up seeing both...I just said 'no, the nurse will be fine; I just want my toe dressed,' but then because it was infected they had to get the doctor....[Another time] He said' who are you here to see?'...that's been fine. I can just get away with seeing the nurse. You never used to be able to...I never considered myself sick enough to be needing the doctor...I've always found them [nurses] satisfactory and helpful and I think they have a lot more dealings with the sorts of things that may go wrong than the doctors.

Recognising the distinctiveness of their professional roles in the practice, Tui made her own decisions about whom she consulted. She pointedly commented, "I never consider myself sick enough" to consult the doctor and can "get away with seeing the nurse." This suggests that she would rather consult the practice nurse. By asking Tui whom she was at the practice to see, the doctor or the nurse, the doctor's cognisance of the nurses' professional autonomy and skill was portrayed.

Human agency and gender preference featured in the following exemplar showed the nurse's health focused practise in undertaking the task the participant requested. It also demonstrated the nurse proactively offering a health promotional baseline well-health check:

The first time...I was just assigned the nurse....The ladies [receptionists] did say the nurse here is a female is that okay with you...that's certainly great because I do feel more comfortable talking to a female about those issues....Male would have been alright but I wouldn't have been as open as I was with the female nurse....discussing any changes in my body which she asked me...she knows 
what's going on, even though a male has the education...She [nurse] offered it [health check]...I quite liked that just to get an idea of where I was with my health. They...get a baseline record of it [on computer] and look at that in the future. (Billie)

An emotional connection with the nurse of the same gender empowered Billie to discuss intimate health issues with her. She felt that the nurse would have better insight and understanding of her particular health concerns. This openness was more difficult for her when consulting male health professionals. Further, not only did the practice nurse autonomously engage with Billie for a cervical screening check, she opportunistically offered a broader well-health check, recording Billie's baseline data for future use. Such checks had not been offered at her previous practice and this new experience increased Billie's sense of confidence in managing her health.

Despite the doctor's presence again being evident in the following excerpt, the practice nurses' self-governing, health promoting and health maintaining actions are distinct:

They send me a letter and tell me I have to ring the nurse and I've got to make an appointment for one of my health checks, and if there's anything comes out of that, then I'm referred to the doctor....[Nurses advised him to] change your lifestyle, what you eat; how you eat and stuff like that...I think it was more pushing me in the right direction by saying...you've got to get some exercise. You've sat for years and years, [as a taxi driver] you haven't had any exercise. (Bert)

Disclosed in this exemplar were the proactive and opportunistic health promoting activities and motivational interviewing techniques of the practice nurses. Bert's language indicated that he felt impelled to follow the letter's instructions to consult the nurse for his health review. Explaining how his previous sedentary occupation as a taxi driver had impacted on his health over time, the nurses motivated and sustained Bert through changes to his lifestyle. Bert experienced the consistent and persistent practice nurses' advice as 'pushing me in the right direction." These nurse-led health-focused engagements occurred not only at scheduled intervals, but the nurses took advantage of his ear problems to explore other means of motivation, such as through analysis of his cardiovascular risk factors. This indicated that a gap in his care was filled by the nurses' multifaceted approach and showed 
that Bert's engagement with the practice nurse was sufficient in itself and he did not need to consult the doctor unless referred by the nurse.

Even though the following account describes the health promoting, health maintaining direction and independence of the practice nurse, the doctor's presence is perceptible:

It's usually for an injection or for a cervical smear or for a referral for giving up smoking...or for Care Plus....It makes sense...while you're there check other things...It helps me see where I am in the whole process...It's just the time spent talking and listening because...doctors don't have enough time to...sit there and listen.... One time when my depression was particularly bad, it was just having that chance to talk; it was very helpful. (Roni)

Access to an independent practice nurse consultation was a significant factor in Roni's approach to managing her health issues. The practice nurse provided space for her to talk about her mental health and related clinical concerns. Roni found further meaning in the engagement when the nurse capitalised on the time available to address other compelling health related subjects, such as smoking and lifestyle.

Similarly, this following example portrays the nurse's professional competency in helping Jo find meaning in the advice the nurse offered her. The practice nurse's proficiency is shown by the completion of health practices in an accepting and accommodating manner that contributed to her well-being:

I saw the practice nurse because of constant wax build-up in my ears.... Now the latest...is for weekly weigh-ins....I found the practice nurse very helpful and obliging and non-condemning and she's made it really feel quite easy.... found out about [Care Plus] through my practice nurse....She rings me and says it's time I came in for a Care Plus appointment, so she's quite proactive...I know that I'm not falling through the gaps. [The advice]... are just very sensible suggestions and Ifeel they are the right suggestions because they're sensible and because they just gel with what I'm thinking anyway.

Jo's main concern related to her uneasiness about aspects of her health that may not be adequately addressed; that she might 'fall through the gaps'. However, the nurse not only discussed and offered to enrol Jo in the Care Plus programme, she recalled her when her 
next appointment was due. This comforted Jo, who realised that the nurse took her concerns seriously. The nurse's suggestions and advice were conveyed in a way that were not only sensitive and appropriate, they were expressed in a language and manner that Jo found congruous with her own thinking and how she felt about her lifestyle.

The practice nurse's independent clinical competency is further described in this following example. Although the nurse was focused on giving of the vaccine, she "noticed I didn't look too hot and my skin was sweaty. She knew I was a diabetic and tested my blood sugar and said 'it's pretty low' then she fed me some jellybeans." (Sam)

Despite the doctor's physical proximity not being apparent in this account, his symbiotic and overall presence remained, as the nurse relied on his nearness in the event Sam required further assessment. However, although not evident in the quotation, the nurse's auspicious clinical assessment and treatment of his hypoglycaemia resulted in Sam learning to assess his own health and blood sugar levels and carry jellybeans with him at all times (Sam’s story, Section 6.11).

From the standpoint of nurses 'filling the gap,' and consistent with the previous exemplars, the doctor's presence is evident in Mere and Jack's accounts of the practice nurses' initiative. Although Mere was already enrolled in the Care Plus programme, during a Healthy Lifestyle consultation, the nurse introduced alternative choices and ways of viewing her health and well-being:

For a long time I mainly saw the doctor...rather than the practice nurse...I had a consultation with the practice nurse that was initiated by the practice nurse....this opened up other ways of doing physical activity...It caught me at that time. It was a good time for me, but it was about me making choices again...But, for me it's about empowering a person like me to go further. So once a person becomes empowered...your confidence, your competency, rises even higher to a different level. I've always had motivation but having learnt more things, I have...the need to motivate others. Well, empower, self-empowering. (Mere)

Overlaying Mere's story, were the symbiotic links between her, the nurse and doctor. Nevertheless, what her story showed was the nurse's knowledge and skill filling the vacuum in health promoting care. By choosing to adapt her usual routine and engage with 
the practice nurse independently from the doctor, Mere illustrated the progression of the practice nurse role. Moments when her engagements with the practice nurse contributed to her human agency and her resulting empowerment were also portrayed. The motivational and empowering modelling of the nurse enabled Mere to use these skills in motivating other people.

The next account also describes the practice nurse's initiative and independent practice and also, highlights the nurse and doctor's contrasting approaches to patient care:

I first heard of this wellness check...from [the nurse]....And that was when [she] saw me in a stand-alone capacity as a practice nurse, and that was to do a wellness check...It inspired confidence by reason of its apparent thoroughness and by reason of the practice nurse being relatively conversant with my health history so that when she was going through that [health check] item by item, Ifelt that this was a considered check....It was certainly more thorough than any other check that I can recall from any practice or practitioner.... any consequences of my answers would be followed up, so that gave some confidence... He [the doctor] said blood [laboratory form]...tick, tick, tick, and away he went. Just competent; but pretty lacking in information coming to me as to what was going on; nothing inviting me to make any suggestions as to what I want. (Jack)

Jack's story exhibited the autonomous role of the practice nurse, while, at the same time, acknowledged the presence of the doctor. It also conveyed the nurse's professional competency and Jack's resulting satisfaction. For Jack, there was a schism; a dissonance, between the care he received from the nurse and from the doctor. Although the nurse was familiar with his health history, Jack considered that she was systematic and careful in her assessments and questions, and she asked him for his contribution and suggestions. The very nature of the engagement and its outcome inspired an assurance of, and reassurance about his health, and therefore his well-being. However, while accepting the doctor's medical competency, his engagement with him left him feeling voiceless. Without Jack's involvement or informing him of which tests he was requesting, the doctor ticked the laboratory form. Jack was not consulted about any possible health concerns, or encouraged to take part in the discussion about his own health. 
Another perspective of the doctor's overall presence, as well as the participant's mixed feelings about engaging with the nurse for the first time was expressed by Miles who had expected to see the locum doctor:

The first time I had anything to do with the practice nurse...was getting the flu shot that went really well....that was the first flu shot I had so I was a little bit apprehensive, but we went in there and she explained what to look out for...and had a bit of a chat....it was good... We were expecting to see the doctor, and we saw the nurse...it was almost better because I didn't know the doctor I was quite pleased to see the nurse.

This account reflected the importance participants placed on social talk, and appropriately communicated health information. Even though they had not previously met, and consulting the nurse was unexpected, Miles's initial anxiety about his vaccination and side effects was relieved by a combination of the nurse's clinical explanations and social talk. Despite not having met the doctor either, and supporting Mere, Jack and Kay's contention that nurses were easier to talk to than doctors, Miles reported that he was pleased to see the nurse rather than the doctor.

While participants talked of practice nurses in positive terms, in the context of two anomalous events, Tui and Roni described significant experiences that adversely affected their well-being and their opinions of the nurse:

I had a split under my big toe which caused a major problem....This nurse...was new. She spoke English...she was really nice. She couldn't find the dressings and she said to me... 'some of the things are different...I don't recognise them.' I said to her 'the dressings are in there'...she went somewhere else and she came back with this plaster. I've not seen them before...I know that the girls [nurses] have said a dry dressing....Anyway she put that dressing on and I thought... 'this is not right' and by the next morning I peeled it off and it took all the skin out of my toe...I was absolutely furious because...I should have said that's the wrong dressing. But for me she should have gone and asked somebody to show her which dressings were the correct ones...I did say to one of the nurses 'that's just bloody not good enough'... she's really nice, but...if that had cost me that toe, I would have been spewing...I didn't want to be the first legless, toeless dance teacher in town. I got over it, but I don't want to have her again.' (Tui) 
Even though Tui informed the nurse which dressing material the practice nurses usually used, her 'patient' voice went unheard. Moreover, the nurse being amicable and "really nice," did not alleviate Tui's concern about her care. The following day she removed the dressing, returning to the practice to consult a different practice nurse. Tui chose to remove the dressing material, not address the issue with the particular nurse and not see the nurse again. Instead, she selected to talk to another nurse, but held the practice accountable for the first nurse's actions.

In the second event, Roni details an invalidating engagement with a practice nurse during a cervical screening procedure:

I had gone for a cervical smear and had my feet in the stirrups and my sheet for my modesty that... went up to my knees, and my bottom half was facing the door and she left the room and left the door open.... had a nice breeze. I thought 'at least they can't see my face because I've got my sheet for my modesty. But they could see everything else....No, I didn't [talk to the nurse about it]. I don't know why I didn't; I just wanted to get out of there.... I never went back there. (Roni)

By not protecting Roni's privacy, the nurse demonstrated professionally incompetent practice that disabled and disempowered the participant. Roni's reluctance to address the issue at the time of the incident further emphasised the impact that regrettable and distressing events had on participants. For different reasons, neither Tui nor Roni felt able to talk directly to the nurses about the incidents.

The Health Focused Practice theme described participants' engagements with practice nurses to be, in the main, beneficial. Underpinned by the overarching presence of the doctor and by the symbiotic relationships this theme illustrated nurses' professional competency and how they filled a gap in care.

\subsection{Professional comforting}

Three components of comfort encountered during consultations with practice nurses that contributed to participants' health and well-being were identified. These elements composed of practice nurses' professional expertise, their skilled compassionate presence, and their skilled companionship. Nurses' professional competency was demonstrated by 
their skill and knowledge, and by protecting participants' privacy and confidences. Most participants talked of their sense of emotional comfort in terms of feeling cared for and of being listened to. Nurses portrayed a supportive presence by being "alongside" participants. Conspicuous in the stories were descriptions of practice nurses showing kindness, concern, and compassion, and creating a feeling of calmness. Congruent with the merging of skilled compassion and skilled companionship found in the stories, so to, did participants' perceptions of practice nurses' professional competency blend with their compassion and companionship.

\subsubsection{Professional competency}

Although the doctor was not usually present in a physical capacity, he or she was a significant, felt presence, during consultations with practice nurses, that is, he or she was present in a symbiotic sense. Further, while the doctor overlooked from above, as a parent might, or as a 'higher power,' it was clear that he or she supported the nurses' clinical judgements. Despite participants' descriptions of their confidence in practice nurses' professional competency, the proximity and overarching presence of the doctor were shown to be comforting. Participants talked of knowing that the nurse would contact a doctor for further assessment should her clinical judgement deem it necessary. Conversely, they described times when they felt they "did not need to see the doctor," or they "were not sick enough to see the doctor." Participants were secure in the knowledge of the nurses' competency in managing their concerns.

Professional comforting was also shown in the participants' perceptions of the nurse's demeanour. The following exemplar describes Nikki's experience of nurses' professional competency and comforting practices when she enrolled in the nurse-led Healthy Lifestyle programme. The referral into the programme occurred following a consultation with the doctor and blood tests for lipid and glucose levels. The outcome of the tests resulted in a series of independent practice nurse consultations:

I was in fear and trembling a wee bit, because it was my first experience of that kind of appointment...I'm always apprehensive of any nurse anyway, and I had in my mind that there was going to be 'you should do this, and you're doing this, and this all wrong'. That wasn't the case and I was pretty quickly at my ease.... One of the things that I struggled with, and I needed from the practice nurse and got, was some kind of pats on the back...I'm not very good at acknowledging my own 
achievements, and for someone else to be on that wavelength and saying 'you did that really well, that's great, I'm glad you did that, what shall we do now?'...that was the value of it, because it was something that I'd struggled with on my own.... So it was really important that we did do it together and it was very, very good. I walked out of that those appointments feeling good; feeling I could achieve something...It's important to have continuity... seeing the same person.

The growing trust and rapport with the practice nurse was crucial to Nikki's sense of achievement, no matter how small. The nurse appeared to be sensitive to Nikki's anxiety around engaging with her for this type of consultation, and to intuitively understand that issuing bald statements about healthy eating and exercise would be unacceptable to Nikki. The nurse used inclusive and nurturing language to lessen her "fear and trembling" indicating she understood Nikki's need for support. She joined Nikki in an equitable, companionable interaction, and validated any progress Nikki made, encouraging recognition of her own achievements. While the communicative and perceptive competencies of the nurse were significant contributory factors in Nikki's "feeling good," she also augmented her story by describing an engagement with a practice nurse where the synergy she had experienced with the first practice nurse was absent:

Her approach was totally different. I felt that she wasn't quite on my wavelength and I walked out of it disappointed. Not that she was wrong.... She may not have been the one that I would have related to as well. (Nikki)

Historically, when engaging with a doctor, Kay experienced disempowerment and voicelessness. More recently, self-belief was heightened by the nurse's directness in her communications with Kay, as well as with the doctor:

I find the practice nurses are far more outspoken [now] which is good because they give...you confidence....Give me the confidence to query a GP now...Also makes you feel better in yourself...I found out that there had been a break in my leg and it had never been $x$-rayed. The practice nurse did say to the GP 'should we have it $x$-rayed?' The GP said 'it wouldn't prove anything now.' Well, to me...it would prove what the problem was....If there's anything that I don't need to see the doctor for, I've got enough faith in the practice nurse to see her. I find her very easy to talk to, more so than the doctor...I prefer to talk to the practice nurse 
unless I had to go to the doctor because I knew the practice nurse couldn't help me with it. But, don't get me wrong, the doctors are good.

The active listening and advocacy competencies of the nurse were described in this exemplar. It also demonstrated the doctor (higher power) overriding the nurse's request for an x-ray. Through listening, talking, and helping the participant with her health issues, the nurse expressed ways by which Kay might gain the confidence she needed to question the doctor's decisions. This moment of transition and turning point is reflected not only by the degree of faith Kay had in the nurse's professional competency, it culminated in her preference to engage with the nurse unless it was specifically an issue that only a doctor could answer.

Likewise, Peggy talked of the development of trust in the practice nurse's professional competence giving her comfort. Trust that grew over repeated engagements with the nurse:

Time after time of seeing the nurse...It was a kind of natural evolution to trust her because of how she always spoke to me and handled any issues that our family had....She always took us seriously.... She is willing to listen to what your reason is for being there, and then help you figure out what she can do for you, or who else is better to take care of whatever the issue is....She doesn't prejudge why I'm there.... She's always been very able.

Comfort lay in the nurse's professional competence and abilities that Peggy found trustworthy, as well as in her personal 'way of being'. The tone of voice and language the nurse used indicated to Peggy that her issues were taken seriously. The nurse's behaviour indicated that the nurse did not harbour any preconceived notions about the reason Peggy was there. Even if it meant referrals to other health professionals, Peggy believed that she could rely on the nurse to find ways of helping her.

Unlike the previous participants who found comfort in the practice nurses' manner and sensitivity, the main focus for Katriona was the confidence and comfort she gained from the practice nurse's professional knowledge and understanding of researched best-practice:

She did go into some depth about some of the research that has come out regarding the aspirin side of it and she explained the results of research they've done....She's had medical evidence to back up what she was saying....[It's] 
reassuring to go over a diet and exercise and all that sort of thing....It just confirmed everything we are doing is right; it was quite good to hear it from the medical side of it....You feel you're in capable hands; you feel if you have got any concerns she will take them seriously and give good service.... She's got a good manner that's relaxed; reassuring.... Comfortable that you don't need to get too wound up about thing.

The nurse endorsed Katriona's healthy lifestyle choices, and she provided evidence-based information for her medication. The certainty of knowing that the practice nurse was cognisant of current practices regarding medication and healthy lifestyle advice, were significant factors in Katriona's trust in nurse.

Similarly, Bert found reassurance in his belief that the practice nurses would be clinically competent, monitor his health, and keep him motivated. Bert's confidence in the practice nurses' skills increased following the opportunistic checks of his blood pressure, and diagnosis of heart rhythm disturbances necessitating urgent ambulance trips to hospital:

Nice to see that they're actually doing something for you....I think it was pretty good. I've gone in with my ear and they said my cholesterol had come down, but it's still up...I'll need to see the doctor [for possible medication]. It was good that they keep an eye on you and keep onto you.... That's one of the benefits of a larger practice, if you can't see one nurse, there are other nurses there as back-up and all your notes are on the computer. They have always been obliging and explained things to me.

Although he would have preferred to consult with the nurse he had become familiar with, Bert also felt "they all seem to be the same" (Bert's story, 6.4). He also found peace of mind in knowing the nurses wrote comprehensive clinical computer records.

The following exemplar similarly focuses on the practice nurse's professional competence. The symbiotic association between the doctor and practice nurse are again apparent establishing juxtaposition between the nurse, the doctor, and trust:

Our relationship is so much stronger and I know that if I was struggling with anything I could give her a call and she would give me good advice.... I really respect her as a professional and I know she'll maintain confidentiality....the 
judgements she makes...I'm sure that the GP has that same level of faith in her as well....I think she's just a general all-round expert in her field and knows that the offer [of a chaperone] is worth its weight in gold because it reaffirms that you do have a relationship that is reciprocal. (Pango)

Pango talked of respecting the nurse as a professional who had exemplary skills and clinical wisdom, upholding ethical standards. In a symbiotic parallel, she was convinced the GP accorded the nurse similar status. The respectful mutuality between Pango and the nurse, and the unspoken sharing of values, created a sense of partnership in which Pango could turn to the nurse for competent, professional guidance. However, despite speaking positively about the reciprocal relationship and feeling respected by the nurse, in her story (Section 6.10), in a broader cultural context, she also spoke of her desire for her ethnicity and culture to be acknowledged by the general practice staff:

The waiting room does have more of a welcoming environment than a lot of other practices, and it's becoming more inclusive. It would be nice if the nurses or the receptionist felt comfortable enough to say 'kia ora' I'd welcome it, but I wouldn't want it if it was forced because I'd feel it...it's lovely to hear....the more people hear it the less daunting it becomes and it starts to blend in as normal every day [language].

These comments suggested an inconsistency with her observations of feeling respected, and being in an equal, two-way relationship with the nurse. While she described the practice waiting room becoming more inclusive with its Māori oriented pamphlets and artwork, she also remarked "it would be nice" if the nurses and receptionists (who are of the dominant non-Māori culture) were comfortable enough to greet her by saying "Kia ora." Consistent with Mere's story (Section 6.7), Pango showed, that when in the Pakeha world, such as her general practice, she engaged in that way, but when in the Māori world, she adhered to Māori cultural practice. Nevertheless, she theorised that changing the habits and culture of the dominant group take time and dedication.

Helen found comfort not only in the professional competence of the practice nurse, but also in her demeanour. The nurse's accessibility and independence from the doctor, as well as the symbiotic link with the doctor, were factors in Helen's confidence in the nurse. 
She is almost like a doctor; what I would expect a good doctor to be. She seems to get to the bottom of what is wrong and knows what to do about it....they're equal to doctors. But I just feel she is dignified and cheerful....Even when they're busy they seem to focus very well... and communicate to the doctor if there was anything that they [were concerned about]....almost have their own practice in a way.

Similarly, Sam gained reassurance from the professional competence and self-presentation of the practice nurses by:

Their demeanour and smile, and acknowledgment....they all knew my name which is good....I'm used to things being done in an orderly fashion; I don't like it when they're not....They all seem to be fairly knowledgeable; obviously done a lot of study.... just feel comfortable with them, and knowing that they obviously know what they're doing....It's their demeanour as much as anything, not so much by what they do....they just look efficient.

The personal presentation of the practice nurses was a significant consideration in his experience of emotional ease. As a pharmacist, he respected preciseness and accuracy, valuing similar characteristics in practice nurses. Although he had experienced their professional competence, he recognised that his perception of their expertise was coloured by the manner in which practice nurses engaged with him, such as their welcoming facial expressions, being well-organised, resourceful and well informed.

\subsubsection{Skilled compassion}

Skilled compassion refers to engagements between participants and practice nurses whom they liked, who responded to their needs, and who showed empathy and compassion. It was also found in situations where participants sensed they could talk to the nurse about other issues at the same time they were consulting her for a clinical, medical purpose:

I went to her was because of...just tiny moments of other visits...she and I have this rapport we will talk about things in our life, and on one occasion she was checking my blood pressure...I mentioned something about my unhappiness...She took that in and just made a few appropriate comments to me....this same issue came up again.... So I went to her because of her warm response to me...taking it seriously and doing what she could with words when I hadn't actually asked her to do anything.... She went that extra mile and got a little deeper...showing true 
care and concern for me. I thought it was wonderful... she made me feel like I was okay...choosing her as a person to talk to....I felt it was a safe haven. (Peggy)

The bond Peggy shared with the nurse was created over many engagements, "tiny moments" in time, and through sharing aspects of their lives. Through this rapport, the nurse became familiar with Peggy's usual way of being, and mindful when she intuited a change in Peggy's demeanour. Not only did the nurse observe a variation in Peggy's projected attitude, it occurred at the same time she was performing a clinical task that required her full attention. The nurse skilfully and compassionately responded, calming her distress and "doing what she could with words" even though Peggy had not requested her help (Peggy's story, 6.3). This initial response exceeded Peggy's expectations of the nurse, creating a feeling of security; of the nurse being a "safe haven." She felt she received compassionate, emotional support, and her concerns taken seriously. This feeling of comfort encouraged Peggy to return to the nurse for further counselling.

The practice nurse's skilled compassion and kindness in the following exemplar is also linked to the observations and knowledge the nurse imparted to the participant:

Compassionate, kindness, and you know they always ask me 'what do you think of that' and so you know it's about they're giving feedback too....they give you information. They can also give you comfort...that's my personal view. That's compassion too. I broke my leg some years ago; that practice nurse was very kind. Trying to help me even though I was quite disgruntled with everything. It was quite good. It was comfort; comfort at a time when I was feeling not good, comfort at a time when I was feeling unwell, not just physically; emotionally and mentally. (Mere)

Despite Mere's irritability, the practice nurse remained patient-centred not disclosing any dissenting feelings she may have felt. She heard the participant's story of the pain of her broken leg, and the effect that it was having on her quality of life. The memory of this nurse's compassion and kindness, and the comfort Mere gained from that experience were still fresh in her memory.

Kay described a practice nurse's skilled compassion when the nurse shared her personal experience of an alternative health provider: 
I knew that I needed help to sort it out, and the practice nurse...told me about a naturopath that she'd been to....how a naturopath had helped her....I said to her 'do you think it's a good idea if I was to go to her' and she said 'yes'. And so between her [naturopath] and the practice nurse I think that it was of great benefit....She [nurse] is prepared to listen.... Over a matter of about a year I started feeling better...that was wonderful to have a better quality of life.

Skilled compassion is demonstrated in the practice nurse's sensitivity to Kay's distress. The nurse was not only open and ready to listen, but she was "prepared to listen," and to share part of her own health story with Kay. This decision to subjectively share, rather than objectively distancing herself from Kay's distress, created a sense of comfort and wellbeing in Kay, filling the gap in her care. Consequently, rather than consulting the doctor, she would confer with the nurse (Kay's story, Section story, 6.2).

Instances of skilled compassion did not always manifest as counselling type engagements with the practice nurse. They occurred in health promoting consultations such as a wellman check:

My interaction with the practice nurse has...always been exceptionally positive and professional, tinged with a degree of appreciation of me as a person rather than just a number...I appreciate that in somebody that you consult with...this is a very personal thing, and I do remember mentioning it to the nurse....It certainly gave me a sense that this is a thorough examination...thorough coverage of the issues that may or may not arise. It inspired confidence and I felt that I was going to last. (Jack)

By her appreciation of him as a human being, with his own hopes and fears, and not an anonymous number, the practice nurse's professional competence intensified Jack's sense of comfort. This approach became a significant factor in his decision to discuss an intimate and delicate issue with her. Not only did she professionally acknowledge his concern by including related health topics and providing options in the discussion, she responded with compassion to the man who was asking a woman, a nurse, a sensitive question. Jack was also reassured by the inclusiveness and comprehensiveness of the health assessment, inspiring his assurance he was going to continue to live for some time yet. 
The practice nurse's acknowledgement of the participant as a person, and continuity of carer were significant considerations for Jo. Even as a new patient to the practice, her sense of being treated as important, engendered a sense of well-being for her:

She spotted me [in the waiting room] and...she actually called me by [first] name, and that always makes me feel cared for....Just knowing that she was, or feeling that she was, genuinely committed and concerned about my welfare....It's always nice to feel that you're having contact with [people] that think of you as a person and not just a number...The longer you have the contact with the same nurse is important. The more rapport you build with her, you're more likely to be more open with her...I've found her advice and counsel very helpful. (Jo)

Jo perceived that the practice nurse was genuinely interested in her well-being. When the nurse used her first name, she described feeling that she mattered as a person, and that she was being cared about and cared for. Skilled compassion was indicated by the nurse's sensitivity and creation of a continuing relationship with Jo, who, over time, became more open in her discussions with her.

This skill was also shown in the compassionate manner with which the practice nurse explored the participant's psychological sensitivity around the cervical screening process:

The only person to ask me was the practice nurse at my practice....it's very beneficial because if people don't know that you have a history of sexual abuse and if you're doing a smear or an internal exam on someone who has a history of sexual abuse they need to know that because it can be important. It depends on each individual as to how much they're prepared to disclose. (Roni)

Skilled compassion was identified in the practice nurse's sensitive discussion of the cervical screening process. It was further found in Roni's statement that the nurse was the only health professional who had asked her about any relevant history that might impact on her emotional health. The nurse's perceptivity facilitated Roni's decision to share some of her history of abuse and its ongoing effects.

Although skilled compassion and skilled companionship was closely interrelated, and both are essential to the professional comforting practices of nurses, the dominant theme in the following exemplar is skilled compassion: 
One of the big things was feeling...respected. That the nurse is there for you, you're not there for the nurse to achieve her outcomes.... it was a good encounter. We were able to have a little joke about how long has it taken to get me here...it's just being open and the [nurse's] body language...'come in, great to see you, you're looking well, have a seat, catch your breath'....I didn't feel as though I was being herded and drenched and out....She'd say something that would ease my apprehension.... I needed to feel that safety. I wanted to be in control of what happened with my health. I wanted to make the call; I didn't want to feel like, number 245, you're up....She's a gem. (Pango)

Even though Pango described both skilled compassion and skilled companionship, the nurse's sympathetic verbal and non-verbal expressions highlighted skilled compassion as the leading concept. Pango's feelings of safety and comfort were found in the nurse's recognition, sensitivity and compassionate understanding of Pango's need for time to make her own health decisions. When she did engage with the nurse, she felt that there was a synergy, a harmony and reciprocity between them. This was established by the nurse adopting humour and moderating her voice and language to relieve Pango's anxiety. At the same time the nurse joked with Pango, she skilfully portrayed a respectful presence; one where Pango felt that she was the priority for the nurse, and not any health outcomes the practice might need to achieve.

Participants" not only described nurses as "genuine", and "sharing" in their relationships, but they also used similar language to illustrate their experiences of skilled compassion and skilled companionship. The skilled companionship sub-theme continued to be underpinned by the subjective dimension of well-being.

\subsubsection{Skilled companionship}

Skilled companionship was found in the welcoming, responsive, sociable and nurturing, or parenting behaviours of practice nurses. The behaviours took the form of "being there" or "being alongside" the participant; being friendly, sharing, encouraging an amicable affinity, and projecting comfort:

I became very friendly with the practice nurse and she was excellent.... My doctor had her taking my blood pressure for about a week...She was very helpful....I was able to talk to her and she was very empathic; a lovely person.... She was so 
friendly, and it's nice to have someone you know. You don't like to tell people you're not well and you try to keep cheerful.... they are understanding enough to know that you don't really complain...it is just being honest and saying this is how it is for me....you don't do that with your friends or anybody....To be able to do that with an empathic person is wonderful.... We didn't spend a lot of time....just chatting while she did my blood pressure...I found it very helpful to have the supportive person there. (Helen)

The nurse not only performed the clinical task of taking Helen's blood pressure, at the same time she conveyed an understanding, comforting and friendly presence. This presence portrayed insight and an understanding that Helen was not really grumbling, but needed someone to whom she could unburden herself in a safe, non-judgemental, nurturing, environment.

Skilled companionship included feelings of affinity and a friendly relationship with practice nurses:

We have a very warm friendly relationship where there's more that we're interested in each other than just what I'm going to see her for. She's genuinely interested in my family and I'm interested in hers...I felt like a rapport has grown....she made me feel like I was okay with coming to her and choosing her as a person to talk to....I went to her the second time specifically to seek some counselling from her and because of that previous time and her kind comments and insights that helped. I didn't have to go looking for some psychologist or therapist who doesn't know anything about me...I thought she really was probably the most appropriate person I could approach. (Peggy)

Peggy's experience of connection and intimacy with the practice nurse developed over time. This affinity was created not only from clinical, functional engagements, but also from shared stories of their families and their lives. At her time of emotional distress, it was her confidence in this bond that drew Peggy to seek counselling from the practice nurse. Although the nurse's professional competency shaped Peggy's perspective, it was who the nurse was as a person; her demeanour and her way of being, that evoked feelings of safety and of being protected. Even though the nurse's considered observations were those such as a close friend or parent might make, at the same time, the advice she offered 
was related to her expertise. Peggy perceived the nurse as a skilled companion and a trusted mentor who "filled the gap" between her and an unknown professional psychological counsellor.

Roni described the sense of the practice nurse as a 'surrogate' mother, as well as a companion:

Especially with my mother being a distance away it just made a difference....I ring my mum ...But sometimes there are some things that you don't really want to talk to your mum about, that you still need that level of care and you want someone that you're familiar with so... I go to the practice nurse.... you want to know they are human...You have feelings and you want to know that they have as well.

The nurse choosing to professionally nurture her by sharing in social chat and general personal information, fostered Roni's sense of well-being. This bond was not only shaped by providing information for the nurse, but also, the nurse's way of interacting with her reinforced the human connection that was so important to Roni.

Knowledge of nurses' activities outside the practice also contributed to the professional companionship experienced by participants:

We're not buddies you know, we've met through our children, and so it's nice to catch up with what her children are doing and she takes and interest in what my kids are up to.... She tries to give you options what to look for or what you could be doing to improve things. We're a similar age, and when she was doing that $V R A$, just sharing things that she does with exercise and things, which is what we're doing. (Katriona)

Sharing of family related experiences increased Katriona's confidence in the nurse. Moreover, the nurse relating her own health maintenance strategies affirmed Kationa's own health plans and contributed to her health and well-being.

The creation of a bond between the participant and practice nurse was also significant for Miles:

We were talking about the flu shot, which was good, and then as the conversation progressed...more personal....talking about where we live and how long we'd been together and things like that which was great for... working on that bond 
between us and her. Just developing that relationship....just asking how I was in general.... [She is] somebody who will listen to you; feel like your concerns are being taken seriously and resolve the issue that you've come in with. It's quite nice that the practice nurse knows about those specific considerations I have....She appreciates how effective communication benefits my experience with the medical system.

By showing interest in him as a person with unique health needs, the nurse created an environment in which Miles became aware of a companionable affiliation with her. Skilled companionship was demonstrated in the practice nurse's attentiveness and her sincere approach to his concerns, which conveyed her understanding and cognisance of his frustrations. The nurse's efficient transmission of health information also benefited Miles's emotional and physical heath.

Descriptions of friendliness, of being "alongside," and "being there," such as when Nikki and Sam were beginning to take steps on their own, were identified. Sam described the practice nurses' nurturing behaviour following his wife's death:

They were very sympathetic and knew my situation....Just by being friendly and saying 'are you okay? Is there anything that we can do? Are you looking after yourself?'...they're just concerned, and showed that concern..... I felt comfortable. I was never apprehensive of the fact that I might be seeing a different doctor; it didn't worry me at all. Somebody's [nurse] there that will hold my hand if necessary.

Skilled companionship was shown by the practice nurses' consistent, supportive presence. By enquiring about his changed circumstances and management, and offering their support, the nurses' sensitive responsiveness and continued attention increased Sam's feelings of comfort. Their familiar presence relieved his anxiety about continuity of care and carer in a practice where there were many changes of doctors. He felt that there was always someone whom he could rely on to help him, who knew his position, and who could advocate for him. The nurse was someone who could nurture him by maintaining regular contact. Sam augmented his story by adding that the nurses would provide a metaphorical and physical hand he could hold if he needed support. 
Nikki talked of taking first steps such as a child might, and the skilled companionable way in which the practice nurse raised her confidence in her ability to make lifestyle changes:

The question to me was, what could I do to improve things a little bit? It was a step-by-step process of gradually me building confidence that I could do something. Encouraging, and getting to a point where I felt confident to take the steps on my own and recognise the steps I was taking and feeling confident enough to keep on that path....it is about empowering me to deal with my problem myself, but I had to start with lots of help. I feel like I have achieved something...because that empowers me to keep going...that's what changed....it was about the practice nurse being alongside as the work was done or the progress was made. That's very important...It was steps along the way, support.

To enable Nikki to take control of her health choices, the practice nurse adopted a nurturing, supportive approach. By remaining close by, such as a parent might with a child, the nurse's presence sustained her throughout her journey. This skilled companionship method was empowering for Nikki.

\subsection{Summary}

Described in this chapter were the three main themes of General Practice Activity, Health Focused Practice, and Professional Comforting. In their engagements and relationships with practice nurses, and viewed through multiple lenses, participants' descriptions of the subjective, relational and material dimensions of well-being were identified. Nurses, doctors and receptionists were shown to have distinct roles within the practice, while at the same time, they were all symbiotically linked to each other and to the participants. Despite the overarching presence of the GP, it was the stories of practice nurses who filled the gap in care through their professional competency and comforting practises that was significant.

In the following chapter, I discuss my findings drawing out aspects of the symbiotic relationships within general practice. I also examine compelling aspects of well-being, such as "skilled compassion" and "skilled companionship," and how these concepts "filled the gap" in participants' health care. 


\section{Chapter 8 Discussion}

\subsection{Introduction}

Set in the context of general practice, this study aimed to describe, from patients' perspectives, how their relationships with practice nurses contributed to their health and well-being. From this patient perspective, these findings bring important new insights into what patients saw and valued about general practice services. Permeating all the themes throughout the discussion are the participants' sense of the overarching presence of the GP and of practice nurses filling the gap in care.

This chapter commences with a presentation of the key findings of general practice activity, practice nurses' health focused practice, and the professional comforting practice nurses provide. Guided by White's (2010) dimensions of well-being (Figure 2), particularly the subjective and relational dimensions, and McCormack's (2001) interpretative lens method of analysing narrative transcripts, this discussion draws on the literature to examine the meaning and significance of the findings.

The general practice activity theme described the 'symbiotic relationships' observed and experienced by participants. Within the cell of general practice, symbiotic relationships were identified as existing between not only practice nurses and GPs, but also drawing in receptionists and participants. The evolution of the practice nurse role, from being at the beck and call of the GP, to initiating the beckoning and calling, influenced participants' perspectives of their experiences in general practice. Far from being perceived as the GP's assistant, practice nurses were people to whom participants turned to fill a gap in their care. Reasons participants chose a particular general practice were shown to include environmental and relational factors, as well as location. The position of the family doctor, and the role of receptionists, whom participants viewed as the 'fronts people' of the practice, helped illustrate the symbiotic nature of those working in general practice. Receptionists questioned participants about their health concerns, formed judgements about whom they should consult, and were observed to engage in triaging activities. Health focused practice described practice nurses filling the gap through their health promotional activities, as well as factors that facilitated or hindered participants' experiences of enablement. Professional comforting demonstrated the expertise of nurses, highlighting participants' experiences of nurses' skilled compassion, and skilled companionship, and the influence that these had on participants' health and well-being. 


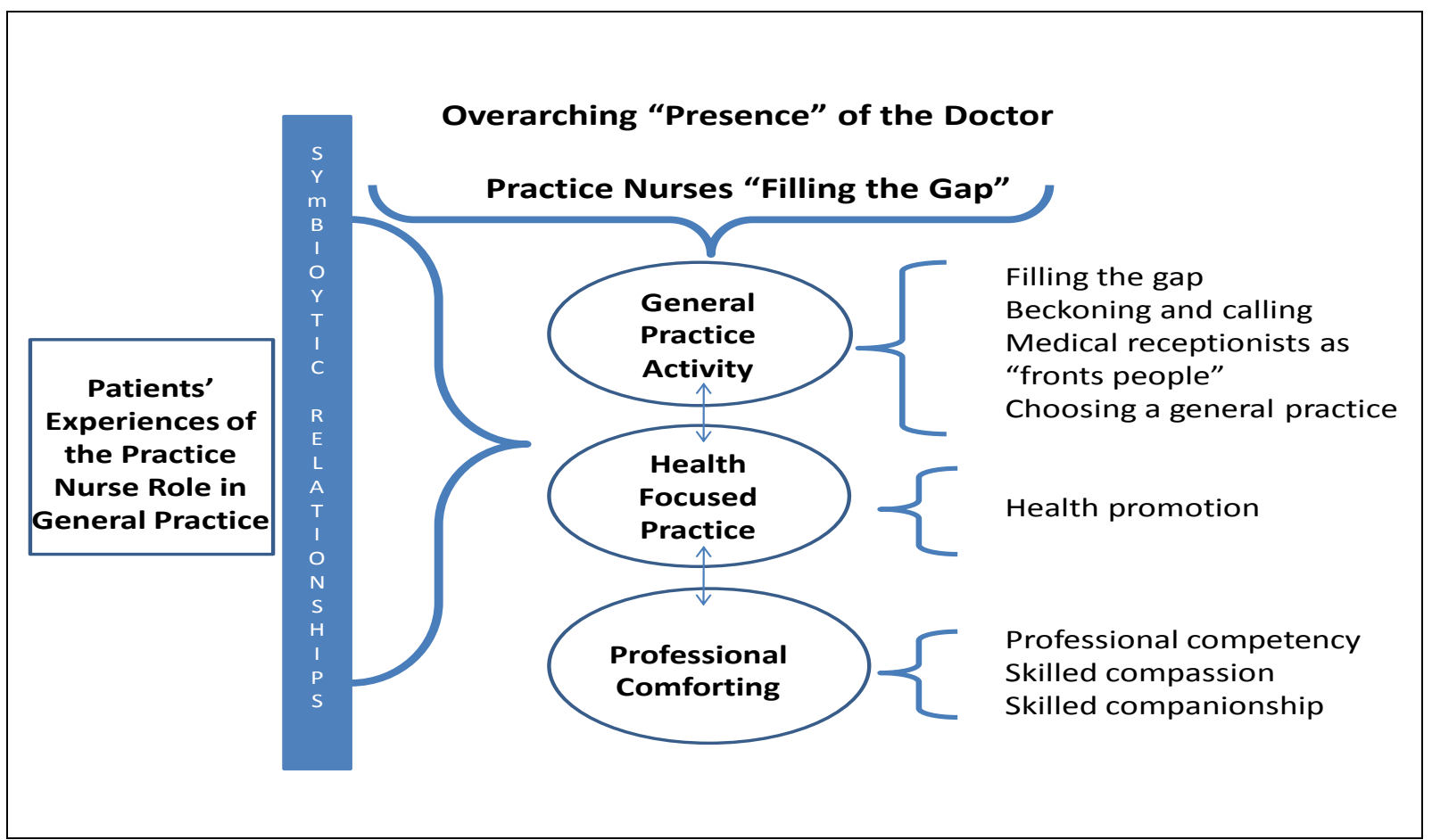

Figure 6. Schematic representation of findings

\subsection{Overarching GP presence and practice nurses filling the gap}

Generally, patients know there is usually a GP on the practice premises. In some practices, such as rural or small practices, there are times when the GP is not present, for example, they may be visiting patients at home, on an emergency call, or lunch break. Nevertheless, participants' stories revealed that the unseen presence of the GP permeated the practice. This was especially apparent when participants engaged with nurses independently from the GP. Some of these independent nurse activities were neither substitute, supplementary, nor complementary to the doctor, with participants describing the trusting, nurturing relationships with the nurse that filled a gap in their care. Consistent with the concept of 'nurse as mother' (Campbell, 1984), participants described the art of nursing including caring, compassionate concern (Peplau, 1992, 1997), and humanistic caring (Kleiman, 2009). Participants welcomed the warm, trustworthy "safe haven" presence of the nurse. They were aware of her genuine interest in them, not only in a professional, clinical sense, but also in a human connectedness sense, as a friend. The subjective, relational need for nurturing actions of practice nurses enabled and supported participants' own coping strategies. Differing from Coyle (1999) and McDonald et al. (2008) who reported the nurturing control of nurses over patients, these were the actions of Campbell's notion of a competent nurse. 
The finding that it was the professional skill and the relational availability of nurses that drew participants to engage with practice nurses, is significant. Participants described practice nurses filling the gap emotionally through their personal and professional comforting praxis of skilled compassion and skilled companionship. These subjective and relational concepts were important determinants in participants' expressions of health and well-being.

In the general practice context of business hours, waiting-rooms and private consultation rooms, participants described practice nurse consultations that resembled Christensen's (1990) three-phase partnership theory of patients transition from old to new and new to old (Section 3.2.1). Although patients are often well, the three phases were evident when participants entered the practice, leaving the 'old life' and embarking on a 'new life.' They expressed their human agency by making choices around the time, duration and frequency of consultations, whom they consulted and how their engagement was managed. During this process, the practice nurse negotiated with the participant. At the completion of the consultation, the procedure was reversed with the participant's transition from new to old life, when they left the practice. Although participants were familiar with the practice and regularly engaged with practice nurses, each visit was essentially new.

\subsection{General practice activity}

\subsubsection{Symbiotic relationships}

The definition of symbiosis applied in this study is not a synonym for collaboration. Symbiosis symbolises a mutual dependence or reliance on another, where collaboration does not. Collaboration is the act of working with another or others, on a joint project. For example, following the GP referral, the practice nurse provides care for a patient with acute asthma.

Relationships between practice nurses and GPs have been described as a clinical symbiotic relationship between two organisms (Blue \& Fitzgerald, 2002). Symbiosis is the "association of two different organisms living attached to each other, or one within the other to their mutual advantage" ( $\mathrm{Li}, 2002$, p. 158). For $\mathrm{Li}$, symbiotic relationships were those that connected palliative care nurses, and those linking nurses and patients. However, Blue and Fitzgerald and Li's descriptions differed from the symbiotic relationships (relationships of mutual benefit or dependence) found in the 
relationships in general practice in this study. This research showed that symbiosis also encompassed non-clinical team members such as receptionists, and notably, that patients were drawn into this relationship. Interactions occurring between participants and practice nurses, participants and GPs, participants and receptionists, and between GPs and nurses, are consistent with this concept of symbiotic relationships. Each individual relied on others in the practice to meet their needs, with all benefiting from the role of the other. In response to patient need, GPs relied on receptionists to acknowledge patients' enquiries, schedule appointments and to collect appropriate fees. They depended on practice nurses to supplement and to 'round out' (complement) their role, and to work autonomously with patients. Practice nurses were dependent not only on patients with whom they often engaged following receptionist arranged appointments, but also on the GP, from whom they received and referred patients. Given their employment status, receptionists and practice nurses depended on the (usually) GP employer, both for work, and remuneration. The consequence of including patients in this symbiotic relationship indicated that they were also a component in the general practice team.

Good leadership, shared values, and a common vision amongst members are indicators of effective teamwork, and to be successful, the general practice team should include clinical and non-clinical members (Taggart, et al., 2009). However, a more inclusive concept of a general practice team, one encompassing nurses, doctors, administrators, receptionists, and patients was demonstrated. This finding was more in line with Pullon et al.'s (2011) New Zealand study of patients' and health professionals' perceptions of teamwork in primary care showing different viewpoints between team members. Even though the two GPs interviewed in Pullon et al.'s research perceived patients as recipients of their care, the two practice nurses and four patients considered patients also to be members of the health care team.

Finlayson and Raymont (2012) found that team-leader GPs were delegating an increasing proportion of general practice work to practice nurses. Nevertheless, based on this research, participants' perceptions were of a collegial, two-way relationship between nurses and doctors, with each referring and deferring to the other. This collegial relationship was very different from that which has been historically reported about practice nurses (Docherty, et al., 2008; Minto, 2006) where the independence of nursing as a profession with its own theoretical underpinning and professional competency 
governance structure, may be obscured. While collegial symbiosis infers equality and partnership within the relationship, participants' perceptions were of the overarching higher-powered doctors' presence, and they were reassured by this distinct, but symbiotic presence. This presence was sensed in the often, lofty, dignified company of the unseen, but felt existence of the GP, with participants describing feeling comforted by the knowledge that, in critical situations, the doctor was always nearby for the nurse to call on.

Examples of mutual dependence could imply equality and partnership; however these were mitigated by the hierarchical nature of general practice. Contributing to each individual's perceptions of their place or task in the symbiotic relationship, the GP/employer defined not only much of the nurses and receptionists' roles, but also that of the patients. While this can lead to power differentials of hierarchy and dependence, indicating an unequal partnership (Armstrong, 1983; May, 1992; McDonald, et al., 2008), when it came to patient care, each person in this symbiotic relationship was seen to be equally dependent on the other.

\subsubsection{From beck and call to beckoning and calling}

Participants spoke of their experiences of, historically, practice nurses simultaneously being employed as doctors' assistants and as receptionists, and how the role had significantly changed over time. Now, nurses were taking on responsibilities previously not expected of them. The consequence of this development meant that nurses' work not only substituted but also supplemented the role of the GP. Participants described care that was both supplementary to, and a substitute for, the doctor. Supplementation occurred when nurses extended or supplemented the care of the doctor by providing a new service, such as Care Plus. Substitution happened where tasks formerly performed by doctors, for example, cervical screening, were transferred to practice nurses (Hefford, et al., 2010; Laurant, et al., 2007). However, neither of these terms fully captured participants' descriptions of their experiences of how practice nurses filled the gap in their care, nor did they encapsulate the choices participants made when they were not sick enough to see the doctor, nor need medical advice. Nevertheless, practice nurses were viewed as both independent from the doctor and as support for the doctor; a position that may be understood as complementing or rounding out the GP role (Keleher, Parker, Abdulwadud, \& Francis, 2009). Although this finding suggests that participants were unclear about nurses' professional role, it also implies that their perspectives of nurses were context and 
content specific. Notwithstanding, there remained an awareness of the doctor as an overarching higher power. Participants indicated that the autonomous role of the practice nurse was crucial in their decision-making processes, and although many of the engagements focused on health promotion activities, others were for more mental health and well-being reasons. All these engagements with nurses were independent from the doctor.

The Practice Nurse Cost-Benefit Analysis report to the New Zealand MOH estimated the financial impact of task substitution between GPs and practice nurses (Hefford, et al., 2010). Similar to Finlayson et al. (2009) and Keleher et al. (2009), this report noted that actual nursing roles in primary care varied markedly between practices and that practice costs and patient outcomes varied depending on the context of the situation (Laurant, et al., 2007). However, in this current research from participants' perspectives, although there was some inconsistency in nursing competency, there was no noticeable role variation between practice nurses or between rural and urban practices. In fact, there was uniformity in the nursing roles, with participants reporting a high level of nursing autonomy, but at the same time, nurses were described as working in collegial and symbiotic relationships with the doctor.

Participants described the mutuality and respect shared by nurses and doctors, who, at the same time, honoured their own professional knowledge boundaries. This symbiotic and collegial two-way relationship evolved over many years. Participants did not describe nurses and doctors attempting to 'take over' each other's role, but congruent with Finlayson et al. (2009), illustrated occasions where nurses beckoned the doctor for a second opinion, or to authorise a prescription, as well as situations in which doctors sought nurses' expertise.

From my experience as a practice nurse, and corresponding with practice nurse colleagues from both rural and urban practices, over time, and with advances in practice nurse education, encouragement from the PHCS and PHO funding, collegiality between GPs and practice nurses has progressed (D. Auld \& M. McElhinney, personal communication, August 8,2010 ). Nurses were moving from being a medical substitute to working as a collaborative practitioner (Patterson \& McMurray, 2003). GPs referred participants to practice nurses for follow-up care, chronic conditions management and wound care, and 
passed on things they don't want (Charles-Jones, et al., 2003) freeing up doctors' time (Finlayson et al., 2009). Practice nurses referred participants to the doctor when they were concerned about symptoms or situations that required medical expertise. There were times when participants were asked to wait while the nurse beckoned the doctor for a second opinion, or to assess them between patients: that is, the time after the doctor has completed one patient consultation, but prior to the next appointment.

Although the descriptions and claims of the invisibility of practice nurse activities of practice nurses has been described (Fyers, 2008; Keleher, et al., 2007; Minto, 2004, 2006), this study established that much of the work of practice nurses was evident to participants. Their experiences with nurses were consistent with the Ministry of Health's (2003a) definition of practice nurse activity. The past perception of nursing's subordination to medicine and of nurses as handmaiden of the doctor (Campbell, 1984; Jack, 2002) has metamorphosed to one where participants chose to engage with the nurse independently from the doctor. This freedom to engage with practice nurses is in line with Blue and Fitzgerald's (2002) findings that patients in Australian rural practices freely engaged with increasingly autonomous practice nurses and that GPs relied on nurses' professional and personal knowledge of patients to provide appropriate care.

\subsubsection{Determinants in general practice selection}

Literature indicates that most patients changed practices because they had relocated, were not enrolled with a general practice, were unwell and needed to see a GP (Bornstein, Marcus, \& Cassidy, 2000; Ministry of Health, 2008b; Salisbury, 1989). However, a significantly important finding in this current research was that participants' choice of general practice was also influenced by feeling welcomed and comfortable. Participants did not raise the cost of GP and practice nurse consultations as something they considered when choosing a practice (Salisbury; Anderson, Barbara \& Feldman, 2007). Informal hearsay also helped participants choose a GP (Anderson, Barbara, \& Feldman, 2007; Pruskus, 2009). One participant described a situation where her reliance on rumour and social comment led her to believe that the reported characteristics of one particular doctor were unpalatable to her, and influenced her decision when she did consult him. Participants described changing their minds about their choice of practice following negative encounters with GPs, receptionists and practice nurses. However, they also chose to continue at the same practice because of their relationship with the practice nurse. 
Bornstein et al.'s (2000) finding that doctors' personal characteristics, and the kind of care they provided, played a negligible role in choosing a practice, was refuted. Personal characteristics and the quality of care GPs provided were important to the participants' health and well-being decisions. Demeaning cultural attitudes from GPs and reception staff also influenced participants' impressions of the kind of care the practice may offer. In the example where one patient changed practices due to a nurse's inadequate practice, but remained at another practice because of the high quality of the nurse's competency and professional comforting practise, highlighted the crucial position of the practice nurse. Although the personal attributes of GPs was not a significant factor for another participant, their qualifications and experience were.

Even though the process of changing practices or GPs is technically, relatively simple, being able to make such changes is only possible if there are options (The Commonwealth Fund, 2012). One participant described a situation where she was prevented from enrolling with the doctor of her choice due to that practice's closure of further enrolments. While this may not be an issue in larger centres, in small communities it can be problematic for prospective patients with fewer alternatives.

Continuity of care was a significant factor in participants' relationships with nurses. While this has been described by practice nurses (Fyers, 2008) and physicians (Freeman, 2008; Turner, et al., 2007), participants also emphasised that continuity of carer was important to them. They not only engaged with nurses they liked, and who were responsive to their needs, they preferred to maintain the relational contact and rapport they had built with a specific practice nurse. This close association became especially important in practices where there were frequent changes of GPs. One practice experienced a number of years with mostly foreign locum doctors, some for whom English was a second language. Because of the changing face of policy (discussed in Chapter 2), the relationship patients had developed with a practice nurse, rather than the GPs, was crucial in their continuing enrolment at that practice, indicating that practice nurses were seen as a linchpin in the practice.

\subsubsection{Receptionists as 'fronts people'}

Consistent with previous research, as they are the first point of contact for people seeking an appointment, receptionists were shown to perform a pivotal role in general practice. 
Participants talked of receptionists' demeanour and manner of engagement influencing their perceptions of how they would be received in the practice (Arber \& Sawyer, 1985; Goffman, 1976; Jacobson, Richardson, Parry-Langdon, \& Donovan, 2001; Tarrant, et al., 2003). People in positions where they engaged with the public put on a "performance" (Goffman). The person portrayed a certain "front" for the consumer, giving the appearance of maintaining certain standards. This personal front, or decorum, took the form of showing respect, not only for the role, but also for the "desire to impress the audience favourably and avoid sanctions" (p. 111). Given that receptionists projected the 'front' or 'region' of the practice, the way in which they presented themselves was an important indicator for participants, and intersects with the notion of performance and the concepts of emotional work and emotional labour (Hochschild, 1979, 1983; Theodosius, 2008). However, the atmosphere or 'feel' of a practice also shaped participants' thinking. This feel caused such discomfort for three participants, they refused to return. Some participants" descriptions of receptionists resembled "the old battle axe" and "dragon behind the desk" styles (Arber \& Sawyer, 1985; Jacobson et al., 2001), and of receptionists being impersonal, officious, rude and insensitive (Hewitt, et al., 2009). Participants viewed their engagements with general practice as a highly personal experience where they bonded with people with whom they felt comfortable. They talked of their rapport and positive relationships with receptionists who endeavoured to portray a friendly front through social talk, to build rapport and personalise care (Tarrant, et al., 2003). Although receptionists were the intermediaries through whom contact with the medical practitioners was made (Arber \& Sawyer; Patterson et al., 2004), participants indicated that receptionists were also the main means by which they engaged with practice nurses.

Patients have been shown to perceive belonging to a practice as a relationship with a GP with whom they experienced sincere, warm interactions (Anderson, et al., 2007). Participants also valued these same kinds of relationships with practice nurses and reception staff, and described receptionists' continuing relationships with them (Tarrant et al., 2003). However, in an atypical case, the officious 'gate-keeping' stance of the receptionist (Arber \& Sawyer, 1985; Patterson, et al., 2004) in deciding who may or may not see the doctor at any given time, impacted on at least one patient's attempt to see the GP. The swift transformation in tone of voice and facial expression (Goffman, 1976; Jacobson et al., 2001) of the receptionist, when the "audience" switched from the young person to an older person (participant Tui), was shown to occur. This implied not only 
youth culture discrimination, but also dissimilarity in approaches of older receptionists to young males and young females. Although there is abundant youth health research (Dutton, 2006, 2009; Mathias, 2002) this kind of discrimination raises questions, particularly relating to practice policy and front-line staff training.

At times of uncertainty about consulting a doctor, patients sought advice from receptionists (Arber \& Sawyer, 1985; Patterson et al., 2004). In contrast to these authors, some participants spoke of asking receptionists whether they should consult the practice nurse or the doctor. They described situations where receptionists made clinical assessments based on only a brief verbal exchange (McKinstry, Watson, Pinnock, Heaney, \& Sheikh, 2009). However, while some participants in the above study were unhappy at being asked to provide information, most participants in this study appeared to unreservedly discuss their personal health information with receptionists, valuing and acting on their opinion. Receptionists were not reported to be undertaking direct patient care such as wound care or taking electrocardiographs (Patterson et al.; Taggart et al., 2009).

Receptionists mainly garnered health information for triage purposes to enable them to direct participants to the relevant health professional at the appropriate time (McKinstry, et al., 2009). Although participants talked of historically engaging with non-practising practice nurses working as receptionists (Finlayson et al., 2009; Patterson et al., 2004), they did not describe current receptionists having nursing qualifications. Apart from the event described by one participant, evidence of receptionists' gate-keeping activities preventing patients from accessing the GP was not described. On the contrary, receptionists were shown to promptly address participants' immediate concerns including contacting the practice nurse for further assessment.

Despite receptionists' triaging activities raising possible breaches of privacy and confidentiality issues, only one participant talked of her disquiet about whom may have inadvertently over-heard her conversation with receptionists. The reception area is a particularly difficult one in which to protect confidentiality, not only for patients, but also for clinical and administrative staff (McKinstry, et al., 2009). Telephone conversations where patients' personal details are discussed can be overheard by other people near the desk or in waiting areas, and GPs and nurses discussions with receptionists may also be heard by others. Because of the complexity of the receptionist role, there are guidelines and 
protocols for receptionists to follow, and staff can attend training courses (Eisner \& Britten, 1999). In New Zealand, most general practices have gained Cornerstone Accreditation which is a combined quality improvement and quality assurance process allowing practices to measure themselves against a set of standards including privacy and confidentiality (Royal New Zealand College of General Practitioners, 2009).

\subsection{Health focused practice}

\subsubsection{Health promotion}

Health promotion activities are carried out by, and with people, rather than for, or to people (Jadelhack, 2012). They provide strategies enabling people to improve their ability to make health choices. In New Zealand health promotion programmes such as Healthy Lifestyle, Care Plus, VRA, immunisation, diabetic assessments, well-health checks, cervical screening, and smoking cessation fall into this category. Differing from Patterson, Price and Hegney (2005) who described Australian practice nurses' health promotional activities being mainly opportunistic and focused on existing medically defined diseases, participants talked of both planned and opportunistic health-promoting activities being carried out by nurses independently from the GP. Three participants described the comprehensiveness of their well health checks, and of nurses taking advantage of consultations to address other health issues. Participants talked of practice nurses enhancing their knowledge (Keleher, et al., 2009), informing them of health promoting programmes such as the Green Prescription programme (Ministry of Health, 2011a), and inviting them to take part. Nurses encouraged them in their attempts to cease smoking, and have influenza immunisations to help prevent severe illness or exacerbate existing health conditions. Nurses also recalled participants when their health checks were due.

\subsubsection{Enablement: Facilitation and impediments}

Enablement and empowerment have often been used interchangeably in the literature. They have been described in many contexts including sociology, psychology, political science, economics, nursing and social work. The many interpretations of these terms are often easier to define when absent, as in disempowerment (Aldridge, 2006). Aujoulat, d'Hoore and Deccahe (2006) were unable to draw out a unified, well-articulated theory of empowerment in health care, while Funk, Stajduhar and Purkis (2011) portrayed empowerment as an abstract ideal with diverse interpretations, but with specific interventions and delivery approaches. Associated with good outcomes, empowerment is 
an intervention by which the health care provider recognises, promotes and enhances patients' ability to control their health and life (Hudon, et al., 2010). Aligned with the concepts of Emotional Intelligence (Goleman, 1995), participants in this research experienced enablement through nurses' ability to sense their needs and bolster their ability to make health care choices.

Enabling practises by practice nurses were not limited to health promotion advice, explanations of procedures, or by professional ethical practice. They included practice nurses responding with authentic sensitivity to who participants were as individual human beings. They described feeling that they mattered to the nurses. Consistent with Coyle's (1999) finding that participants sought to be informed, especially about alternative therapies, this study established that practice nurses' communicated information enabling participants to manage their life course turning points and transitions. Enabled participants challenged doctors' cultural assumptions, questioned doctors' advice and walked away from interactions with nurses, doctors and receptionists they found disturbing. These findings differed from Sheridan et al. (2012) who described older ethnic minority groups with chronic conditions reporting helplessness when engaging with GPs or practice nurses. The difference in the studies pertaining to ethnic groups, may relate to the character of the three Māori participants all of whom were working in occupations which required selfsufficiency and assertiveness.

From a hospital nursing perspective, distance or clinical objectivity, constrained nurses' ability to meaningfully and authentically respond to patients' concerns (Hartrick Doane \& Varcoe, 2005). Similarly, even though some participants described practice nurses remaining at a relational distance and not connecting with them on a subjective level, these reports did not extend to the detachment and depersonalisation described by Kralik, Kock and Wotton (1997). On the contrary, most practice nurses were reported to appropriately choose the time and context to disclose a small but relevant part of their own health choices in order to help patients (Aranda \& Street, 1999).

Disablement in practice nurse-patient relationships was mainly related to power inequality or negative feelings participants experienced with a particular nurse, rather than the profession as a whole. Turning point disabling practices from practice nurses, GPs and receptionists, occurred not merely from insufficient explanation and information, but also 
from unsatisfactory professional and cultural competence. Disabling activities by practice nurses were those where participants perceived that their concerns remained unheard and unresolved. Nurses' attitudes or behaviours at the time of the incident, contributed to participants feelings of constraint about discussing an untoward event. Nevertheless, for one participant, even the 'nice' manner of the nurse was viewed as a disincentive to personally address the issue with the nurse. These findings showed that participants' disagreements with nurses and GPs often lacked resolution for the patient (Annandale \& Hunt, 1998) and supports Coyle's (1999) conclusion that practitioners need to be sensitive to how their manner and work may undermine a patient's self-worth through objectifying experiences. The significance of feeling enabled in their relationships in general practice, and its influence on their health and well-being was emphasised throughout participants' stories.

The description of the 'niceness' of the practice nurse leading to the patients disablement, differed from the "symbiotic niceness" described by ( $\mathrm{Li}, 2002)$. This " "niceness" of nurses simultaneously requires, feeds on and 'grows' from the 'niceness' of nurses themselves, and of patients and nurses. It is mutually benefiting and sustaining" (p. 158). However, there were similarities. One participant described the nurse as "really nice", indicating a subjective and relational "clinical friendship" (Walker, Wilkes, \& White, 2000) and the participant responded by being 'nice' and uncomplaining. This was consistent with the portrayal of niceness that included not making a fuss and not complaining (Street, 1995). At the same time, the nurse's niceness discouraged more assertive behaviour from the participant. Conversely, she may also have been showing conventional politeness to a stranger.

Being symbiotically nice to the nurse in return for the nurse's niceness supports Shattell's (2005) study of the strategies hospitalised patients used to attract nurses' attention. Patients encouraged a personal, subjective connection with nursing staff, so when they needed care and attention, the nurse was more likely to attend to them than if there was not a subjective, connecting relationship. While this symbiotic bond has similarities with Li's (2002) symbiotic niceness, participants in this study, experienced nurses' genuineness, compassion and companionship, indicating authenticity in the relationship. They did not describe situations where they were nice to nurses to ensure niceness in return, but instead 
showed how nurses practised the subjective, relational and material dimensions of wellbeing (White, 2010).

\subsubsection{Well-being translation}

Theorising about White's (2010) holistically inclusive three dimensions of well-being led me to adapt her concepts of well-being for this study. The subjectivity of the patients' perspective encompassed not only the relational, personal, social and cultural identities and inequalities, it included material concerns of practical welfare and access to health services. These are critical factors affecting the health and well-being of patients in general practice. To more clearly explain patients' subjective perspective, I reversed White's hierarchy by commencing at the apex with the subjective dimension (Figure 7).

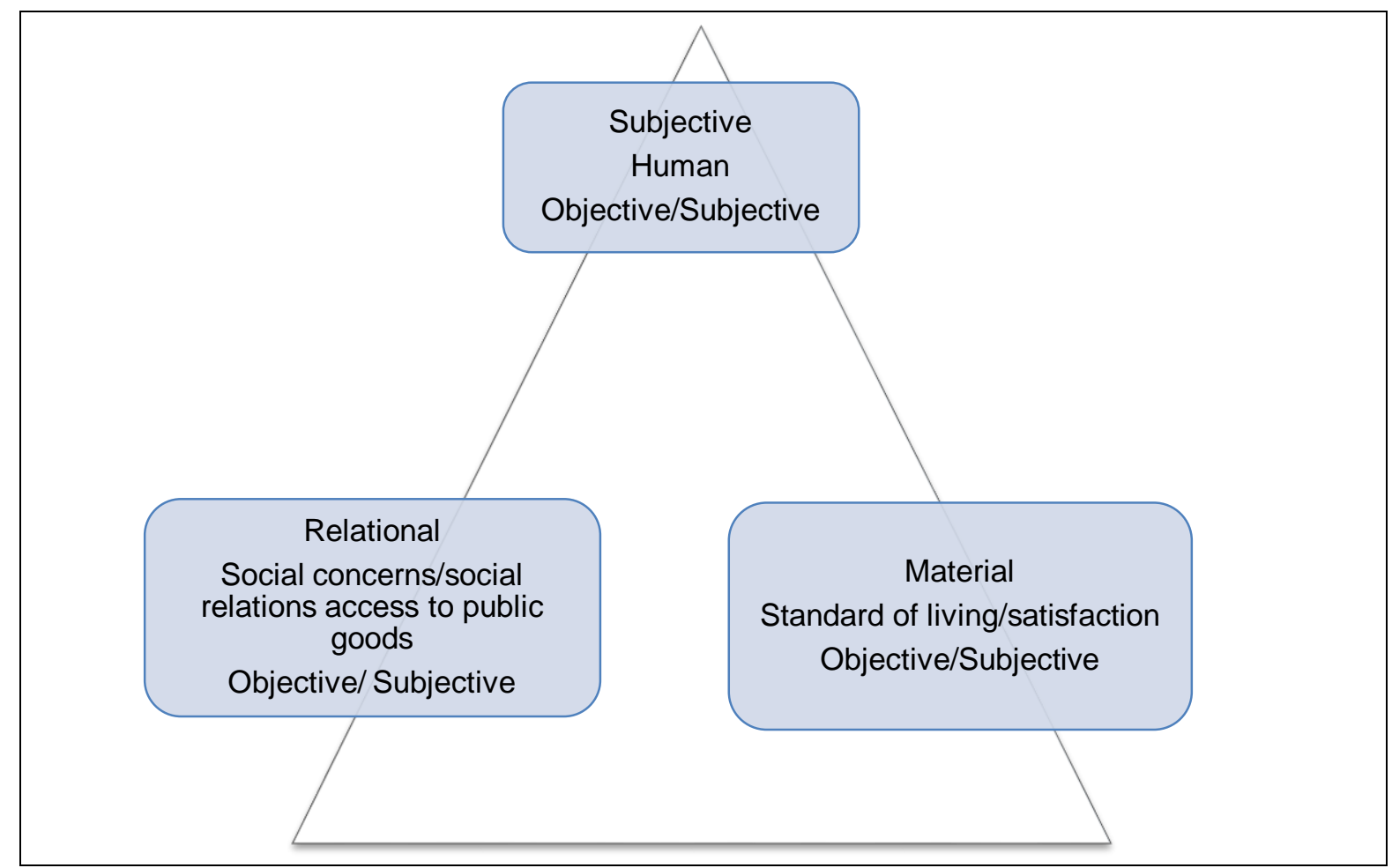

Figure 7. Three dimensions of Well-being

Note. Adapted with permission of White, S. (2010). Analysing wellbeing: A framework for development practice. Development in Practice, 20(2).

I deliberately hyphenated well-being to emphasise not only the distinction between 'well' and 'being' as two unique words with diverse meanings in our language, but also the distinctiveness of the words even when used in conjunction with each other. One cannot be alienated from the other. For participants, being well was more than enjoying physical health, as people with chronic ill-health or disabilities may feel well when compared to 
feeling ill, it also encompassed the spiritual, psychological and sociological health of the individual. Table 5 depicts my understanding of well-being that illustrates, not only the connectedness of the term, but also its unique dichotomy, with each element (well and being) able to stand alone. This representation was derived from the writings of Boehm et al. (2011), Schickler (2005) and White (2010), and is highlighted in the professional comforting theme exploring skilled compassion and skilled companionship.

\section{Table 5. Representation of well and being}

\begin{tabular}{|l|l|}
\hline Well & Being \\
\hline Physically well & Being:- human (physical) \\
\hline Individually well & Being:- authentic \\
\hline Psychologically/emotionally well & Being:- psychological/emotional \\
\hline Spiritually well & Being:- spiritual \\
\hline Sociologically well & Being:- - social \\
\hline
\end{tabular}

\subsection{Professional comforting}

Nurse-patient relationships are often developed over time, and practice nurses may have the opportunity to become aware of events in an individual's life that result in transitions to altered ways of being and living. For example, changes patients make following a diagnosis of a heart attack or diabetes or adapting to physical or mental disabilities, or an unexpected change in patients' relationships. This understanding was found in the practice nurses' portrayal of their skilled compassion and skilled companionship.

\subsubsection{Skilled compassion}

The significance of feeling comforted by their relationships with practice nurses was emphasised through the skilled compassion and skilled companionship participants encountered during each engagement. Acknowledged as the essence of nursing and its effective strength, compassion is aroused when nurses recognise suffering in others and impelling and enabling them "not only to acknowledge the suffering, but to act towards alleviating it" (Schantz, 2007, p. 51). Schantz indicates a major issue with terminology. "Nursing research that uses the terms such as caring, empathy, sympathy, compassionate care, and compassion interchangeably, implying that these words are synonymous, not only promotes erroneous assumptions, but also compromises the validity of the research findings" (p. 49). However, there is a volume of literature relating to empathy across the health arts and nursing that does apply empathy and compassion interchangeably. Määttä’s 
(2006) review of the tension between distance and closeness in nurse-patient relationships emanated from the concept of German philosopher Edith Stein (1916/1989), who contends that empathy is about recognising an individual's lived experience. She maintains that, while it is possible to see and understand another person's feelings of joy or grief by remembering how we personally felt at those times, it was not possible to experience the pain or joy as experienced by that person. Stein perceives empathy as analogous to memory and imagination, and as such are also experienced as second-hand emotions.

In contrast to Peplau's (1997) assertion that empathy is "to feel in oneself the emotions of another in the same situation" (p. 163), the definitions of empathy I chose, fit closely with Stein (1916/1989), and with Kleiman's (2009) humanistic nursing practice. Here, empathy is demonstrated by nurses applying open responses, accepting people as they are, coming to know the 'whole' person, and entering into an understanding of the world of the patient. Coming to know the whole person and understanding the person's world is also congruent with life course principles and White's (2010) subjective and relational dimensions of well-being.

Even though these descriptions of empathy are meaningful, they do not entirely correspond with the concept of compassion as an enabling response towards alleviating patients' concerns, promoting their human agency and influencing their health and well-being. Similarly, authors who define compassion as "suffering alongside" (Golberg, 1998, p. 838) can imply pity in the sense that the nurse 'feels sorry for,' or demonstrates condescension towards the participants. However, while practice nurses may have felt sympathy for distressed participants and acknowledged a desire to alleviate or solve their problems, this meaning does not completely capture participants' descriptions of nurses' compassion. Nor does it illustrate participants' experiences of nurses altering their personal and professional boundaries to share something of their personal life story in order to help them.

Despite differing world views, and consistent with Tarlier's (2004) concept of responsive relationships, movement of nurses' professional boundaries were shown to fluctuate, not only from participant to participant, but also at different times within the same relationship and same engagement. Moreover, these responsive relationships occurred during nonpersonal clinical engagements as well as in highly personal clinical engagements. This is consistent with Golberg's (1998) sense of nurses remaining open to patients "without a 
shell, vulnerable, but paradoxically strong; it is this strength that patients draw on for healing” (p. 838). Golberg's professional understanding of flexible boundaries supports Schantz's (2007) meaning of motion in compassion. However, skilled compassion was more than movement to mitigate the situation; participants described the professional skill of practice nurses dictating what the process would entail. It took sensitivity and genuine concern for the whole person to recognise what any movement would demand. The skilled responsiveness of nurses not only demonstrated compassion in its narrow sense of suffering alongside (Golberg) it also illustrated the professional, relational subjective and human-centred skill of nurses and the domain of social awareness described by Goleman (1995).

Reflecting Buddhist philosophy with its awareness of connection with others (Golberg, 1998; Schmidt, 2004; Tarlier, 2004), participants' described practice nurses' compassionate actions that encompassed love, affection, gentleness, generosity of spirit and warm-heartedness. In this professional, relational context, participants experienced a love that was expressed as agape; an "altruistic love, in which an individual can care for a complete stranger as if that stranger were family" (Stickley \& Freshwater, 2002, p. 251). Participants were also aware of a 'neighbour-love,' relationship with practice nurses, who showed equal regard for all human beings (Campbell, 1984). Compassion was found in nurses' "vocal and visual non-verbal, behaviours of warmth, positivity, energy and capability including competence and interpersonal care" (Haskard, DiMatteo, \& Heritage, 2009, p. 28). Nurses creating a safe haven, somewhere participants could confidentially disclose their thoughts, further highlighted the skill in compassion. Nurses' compassionate skill was demonstrated in the participants' descriptions of nurses not separating their personhood from that of the participant, but choosing to embrace it in their relationship. In specific situations, participants talked of nurses deliberately electing to engage on a personal level, where both individuals shared things in their lives. Participants experienced this involvement as the nurse being genuinely interested in them and identified that this kind of skilled compassion contributed to their health and well-being.

While rapport and mutual sharing have been described in hospitalised patients (Halldorsdottir, 2008; Kleiman, 2009), in the general practice setting, this study showed that the subjective, mutual, personal sharing and bonding was created during many encounters and in tiny moments in time within those engagements. The quality of the bond 
between one nurse and participant was critical in alleviating at least one participant's distress. The nurse comforted her by being fully present, actively listening and responding to her concerns, soothing her discomfort. Extending the findings of Christensen (1990) and Jonsdottir et al. (2004) who described the nurse and patient working together in a dialogic process throughout the encounter, the skilled compassion and comfort the nurse brought to the engagement demonstrated the extent of authenticity and partnership between the nurse and patient. The discretionary mutual sharing and flexible boundaries expressed by participants (Fosbinder, 1994), is in contrast to the views of Armstrong (1983) and McDonald et al. (2008). These authors described nurses' professional surveillance of the body and mind, asserting that nurses engaged in various practices to distance themselves from patients. This patient objectification is in opposition to the concept of love in a therapeutic relationship that automatically provides for the needs of the whole person (Stickley \& Freshwater, 2002). These authors promote a balance between discipline, concentration, patience, concern and activity. Nurses need discipline to understand professional and personal boundaries, to concentrate on the best method to express therapeutic love, patience when engaging with people, a genuine concern for the whole person, and to actively practise the art of loving (Stickley \& Freshwater), all of which were described by participants.

Participants preferred to discuss health and personal issues with their selected practice nurse. Although this may have been due to the continuity of care and carer, they also indicated a sense of aloneness, an alienation from friends, relatives, other practice nurses and GPs who might not understand, or have time to listen to their problems. Feeling a solidarity in the relationship (Halldorsdottir, 2008), participants often elected to heal this existential loneliness (Nystrom, 2007) by engaging with a particular trusted, practice nurse they felt was on their side.

Descriptions of effective nurse-patient relationships showed participants felt that practice nurses were skilled in compassionate care, were self-aware, able to cope with selfdisclosure, and authentic and genuine in their engagements (Aldridge, 2006; Aranda \& Street, 1999) and with emotional intelligence (Goleman, 1995). They felt that the nurses not only related to them as their real selves, they engaged with intimacy and empathy. Intimacy and empathy were revealed by participants' stories of how nurses understood their needs, actively listening to them by being reflective and reflexive, and 
communicating with them in a non-patronising manner. These behaviours differed from the assertion of nurses' patronisation of patients, and reliance on their dependency to maintain nurses' professional identity (McDonald, et al., 2008). This also conflicts with Peplau's (1977) concept of 'illness maintenance' where nurses may indulge patients' illness behaviours rather than encourage movement toward health.

Examples where nurses remained at an objective distance rather than at an inter-subjective person-centred level were not found. Peplau (1997) contends that sharing personal experiences created patients as audiences for the nurses' benefit, and by not listening to patients, nurses missed teaching opportunities. Unlike Peplau' theory, it was practice nurses' skilled compassionate decisions, to not only be prepared to listen, but also to share something of their real selves, creating teaching opportunities that benefited participants. Being prepared to listen indicated that nurses were ready in body and mind to listen; they approached the engagement openly and compassionately, genuinely seeking ways in which they could help. In contrast to participants' experiences of GPs, practice nurses were perceived to have time to listen, they were easier to talk to, and explained things more clearly than doctors did (Laurant, et al., 2007).

Although these active listening skills were consistent with the contention that doctors provided care for medical issues, whereas practice nurses focused on the emotional and social needs of patients (Walsh, Roe, \& Huntington, 2003), it raises issues around GPs work-load, scheduling, and length of appointment times, as well as funding mechanisms (Hefford, et al., 2010). Literature confirms that GPs are cognisant of the need to meaningfully listen to patients and develop rapport, but time constraints often dictate the focus and priority of the consultation, leaving little time for storytelling discussion (Daaleman \& Elder, 2007; Dugdale, Epstein, \& Pantilat, 1999; Frederiksen, Kragstrup, \& Dehlholm-Lambertsen, 2009; Goedhuys \& Jan-Joost, 2001; Kenten, Bowling, Lambert, Howe, \& Rowe, 2010; Little, Everitt, Williamson, Warner, \& et al., 2001; Mercer, Jani, Maxwell, Wong, \& Watt, 2012).

Practice nurses intuitively becoming aware of, and acting on, subtle changes in participants' demeanours, and taking their concerns seriously and professionally, were described. Participants spoke of practice nurses sensitively doing what they could with words, going that extra mile, pointing them in the right direction, and being accessible and 
available to participants. Participants' stories showed that it was the professional skilled action, not merely the desire to alleviate the problem, that illustrated the skilled compassion of nurses. These qualities were comparable with the understanding of intimacy described by Williams (2001), engagement in relationships portrayed by Kralik et al. (1997) and the creation of safe environments for patients to share information with the nurse establishing connections (Staudt, Lodato, \& Hickman, 2012). They were also consistent with Fosbinder's (1994) interpersonal competence of 'going the extra mile.'

From the participants' perspectives, even though some consultations could have been better managed, nurses' emotion work, emotion management and deep acting (Hochshild, 1979) and surface acting (Goffman, 1976) were not demonstrated. Similar to de Raeve's (2002) sense of reflectivity and reflexivity, and Theodosius's (2008) concept of Therapeutic Emotional Labour that is "integrally linked, and flows from personal identity" (p. 218), when communicating with participants, nurses showed skill and sensitivity. Unlike Smith (1991) and Li (2002), participants did not describe nurses 'doing' emotion work, or withdrawing their emotional labour, but talked of nurses being compassionate and kind. Nevertheless, Li's notion of symbiotic niceness could be construed from participants' stories of practice nurses sharing with them some details of their personal lives, such as families or hobbies, which positively contributed to their feelings of safety and being cared for. These findings demonstrated not only the expertise of nurses in managing their emotions but, like Theodosius, they also indicated that the nurses were being their real selves.

Examples of nurses' skilled compassion were consistent with human centred nursing where there was "an awareness of the uniqueness of the individual, and the affirmation of the "I-Thou" mode of being with others" (Kleiman, 2009, p. vi), and being in a therapeutic relationship (Stickley \& Freshwater, 2002). Therapeutic relationships imply partnership, where there is sharing of information, power and decision-making. Objectifying the patient (Aldridge, 2006; Armstrong, 1983; McDonald et al., 2008), to restrict questions to those relating to their ill health, and not responding to their social talk, differs from the findings of this study. However, the data do reflect Peplau's (1997) idea of the science of nursing that applies "knowledge to understand a broad range of human problems and psychosocial difficulties as well as for health restoration and maintenance" (p. 163). The appreciation of practice nurses sharing something of their real selves and assisting the development of a 
therapeutic bond with participants was also in direct contrast to Peplau (1997) who cautioned that while patients might attempt to engage with the nurse as a family member, the nurse should remain distanced. Despite Peplau's contention correlating with Shattell's (2005) description of patients engaging with nurses in a friendly way to get their needs met, and Theodosius's (2008) concept of patients' emotional labour, this point of view was not found in the data. However, some engagements did resonate with "clinical friendship" (Walker, et al., 2000) with participants describing feeling psychologically and physically safe, receiving person-to-person support, appreciating the nurses' friendly humour in offering information and comfort. The implication from these examples of nurses' use of flexible professional boundaries indicated that nurses applied this knowledge for a purpose. That is, to contribute to participants' health and well-being, they appeared to use social talk to build rapport.

\subsubsection{Skilled companionship}

A companion is someone with whom you might be with for a short time, or someone who might be a life-long companion (Campbell, 1984). Companionship denotes warmth, a feeling of friendship, conviviality and an alliance, even if for a brief time. It is not a deep personal friendship, but a "bodily presence that accompanies another for a while" (p. 49). A 'good' companion is someone who freely shares "without imposing, allowing others to make their own journey" (Campbell, p. 49). In nurse patient-relationships, Campbell described companionship as "loving as caring," with the nurse a "skilled companion." Skilled in the sense, not only of the nurse's commitment to 'being with' and helping the patient onwards (movement), but also with an awareness of professional boundaries, including the relationship's limitations of time and space. However, this definition suggests that patients may be perceived as unskilled companions in the relationship. Bayntum-Lees (1992) added the critical qualities of closeness and mutual commitment to Campbell's meaning of skilled companionship. While Campbell's statements indicate a power imbalance between nurse and patient, this was not present in study participants' stories. Even though nurses had medical knowledge and (generally) participants did not, what participants described was the equality between them. Nurses were shown to be friendly, and easy to talk with, explaining things using language comprehensible to participants. Contrary to Campbell's concept of companionship and Christensen's (1990) nurse-patient partnership theory, companionship between the participants and practice nurses did not end at the completion of the consultation, but was sustained through each 
engagement over time, building rapport and contributing to their well-being. Even though power differentials prevented such partnerships (Armstrong, 1983; McDonald et al., 2008), the closeness and mutualism described by participants implied equality in the nurse-patient partnership (Bayntum-Lees).

Skilled companionship was also found in participants' accounts of the welcoming, responsive, sociable and nurturing behaviours of practice nurses. There was no evidence of nurses attempting to be their personal friends or act as a parent (Paterson \& Zderad, 1976; Peplau, 1997). Instead, participants described nurses' skilful and intuitive knowing; knowing when to come emotionally close in a nurturing and companionable sense, and when to stand back, providing space for them to move at their own pace. Participants spoke of the skilled familiarity, ongoing concern and supportive structures that nurses placed around them, sustaining their physical, social and cultural human agency (Elder \& Kirkpatrick Johnson, 2000; White, 2010). Merging skilled companionship with skilled compassion, these behaviours took the form of being there or being alongside the participant, being friendly, sharing, encouraging an amicable affinity, and projecting comfort, and being soothed by the mutuality and closeness of the nurses comforting practises (Bayntum-Lees, 1992). Participants felt at ease and were confident about expressing their stories of distress in a confidential, supportive, and companionable environment (Christensen, 1990) that was a non-judgmental atmosphere, and awareness that they would receive skilled, mindful assistance from a skilled companion.

Skilled companionship was influential in participants' transition to improved health and well-being. Nurses worked with them in a person-centred therapeutic relationship that involved acting in partnership with them in a manner that was appropriate for that person (Aldridge, 2006; Christensen 1990). This inclusivity of skilled compassion and skilled companionship in providing professional comfort, far from being a myth (Armstrong, 1993), was experienced by participants as authentic care, that is, care that was given and received in mutual partnership. This attention was provided by a nurse who was not merely a listener, not giving of herself, but someone who was 'being with' participants (Paterson \& Zderad, 1976) in the sense of being available to them. 


\subsection{Summary}

Drawing on the literature, this chapter discussed the key findings of general practice activity, practice nurses' health focused practice, and nurses' professional comforting practises. It was shown that nurses' actions supported patients though their life course transitions. The overarching presence of the GP infused the general practice even when participants engaged with practice nurses independently from the GP. The nature of general practice, demonstrated that symbiosis included relationships between the GP and practice nurse, receptionists and patients, with each relying on the other to meet their needs. A significant factor in this symbiotic relationship was the concept of a team inclusive of patients. The practice nurses' comprehensive role enabled participants to develop rapport with practice nurses through the nurses' autonomous practice. Contributing to participants' health and well-being were their experiences of practice nurses' skilled compassion and skilled companionship.

Viewed from my role as a practice nurse, the process of researching practice nurse-patient engagements and relationships from a patient perspective raised a number of issues. In the next chapter, I reflect on the research process, provide a critique of the methodology, data collection and data analysis, and make recommendations for practice, policy and future research. 


\section{Chapter 9 Study critique and conclusion}

\section{$9.1 \quad$ Introduction}

This new and original research into the work of the practice nurse in general practice demonstrated that the kind of engagements patients experience with practice nurses influences patients' health and well-being. The research brought to the fore the importance patients place on the time practice nurses put into building relationships with them. The research demonstrated an important new understanding of what occurs in general practice by describing a symbiotic relationship existing between practice nurses, GPs, receptionists and patients. It showed that patients value their relationships with most practice nurses, recognising that nurses are skilled compassionate, companions to whom they could turn for comfort and expert advice, independently from the doctor. The findings also challenge previous assumptions in the literature by establishing that patients embrace the discretionary, responsive, mutual sharing and flexible boundaries of nurses. Practice nurses do not distance themselves from patients, but bond with them over time. The study established that, while historically, there had been little collaboration between GPs and nurses, the increasing development and independence of the nurses' role had significantly filled a gap in patients' care and augmented teamwork within the general practice.

\subsubsection{Reflections on the study}

The research arose from my desire to explore the practice nurse-patient engagement and relationship, and what it was about the relationship that patients' considered contributed to their health and well-being. Narrative Inquiry and storytelling methodology informed by life course and underpinned by White's (2010) dimensions of well-being, led to an understanding and insight into how patients' history, culture and the time in their life course influenced their decisions. Patients share many stories with practice nurses about facets of their health and lives over time. Through its shared interaction, the person who is talking and the listener, this interpretative storytelling methodological approach accentuated the relational aspects of connections with people, revealing a great deal about participants' engagements and relationships with practice nurses.

When writing up their accounts and stories, being respectful to what participants' shared was at the forefront of my mind. Therefore, to capture their 'way of being' and hear their voice, using their language, tone of voice and sentence structure, the stories were coconstructed with the participants. In this way, the context of their narrative processes and 
moments within the stories were reflected (McCormack, 2001). However, this manner of writing required significant editing for inclusion in this thesis.

Conducting this study has been a significant learning experience for me. Not only did I discover more about the value and emphasis patients placed on the role of the practice nurse, but also, their assumptions and expectations of nurses' role in general practice. I became increasingly aware of the participants' experiences of the compassionate and companionable skill of practice nurses, and the significance of their understanding of nurses' professional comforting. I also came to understand the influence that peoples' life course trajectories, transitions and turning points play in their health and well-being. From my standpoint as a practice nurse, a strength of this study lies in my knowledge about patients, practice nursing and general practice. For example, even though the triaging activities of receptionists were familiar to me, the study findings highlighted their influence in patients' choices of practitioner by directing patients to the doctor or nurse. The receptionists' demeanours, communication manner, and 'feel' of a practice also contributed to patients' choice of practice and doctor.

Carrying out this study led me to reflect on my own practice, creating deeper insights into relational aspects about my own engagement and relationships with patients. I acquired greater understanding of the delicate balance between relational distance and closeness; of the implications of sharing and revealing something of myself that made me human to patients. It was this humanity that patients responded to, and, as a practice nurse I was reminded, once again, of the significance patients placed in my ability to understand them as human beings with eventful lives lived over many years.

Some participants, including those from my practice, talked of their uncertainty of my expectations of them as research participants during data collection (McConnell-Henry, et al., 2009). However, free of the constraints of a consultation, and over ice-breaking cups of tea in their own homes, participants talked freely of their social, cultural and economic histories. Reflecting life course principles, these initial conversations often revealed hidden health concerns. Interviewing Māori participants in their own environment achieved greater depth of the meaning of cultural difference and how small behaviour changes of nurses, GPs and receptionists could contribute to the quality of Māori and other patients' health and well-being. 
While returning the final stories to the participants was never intended, two participants' interviews brought a particular ethical lens to interviewing and of returning transcripts or stories to participants for member checking. In the interests of confidentiality, some revelations from these interviews were not reported in the thesis. My disquiet arose from ethical non-maleficence and any adverse reaction that may result if either participant's family members had seen these comments. A consequence of working in general practice where a number of family members attend, had increased my mindfulness of how inadvertent comments from one family member can be misunderstood or interpreted by others, resulting in distress for all concerned. Patients' relatives may also be concerned by imprudent comments from health professionals who may assume that patients discuss their general health with each other.

My insider/outsider status initially provoked much deliberation as it influenced the type of questions and assumptions made by me. A non-nurse researcher, or one who was unfamiliar with general practice, would bring a different outsider perspective to the study. However, because of the relational, constructionist nature of this study, and because most participants drew on my professional knowledge at some point prior to, during, or following the interview, my insider/outsider status worked well. I could take both roles at different points of the study. Participants asked about specific health advice, about contacting practice nurses, how to gain access to test results, and how nurses could help. There was also the expectation from participants familiar to me that I would remember engagements and conversations from long past consultations. Conversely, there were times when I remembered details of recent consultations that participants' stories indicated they did not recall. However, as an ethical and accountable researcher, and especially as I was interviewing my own patients, I needed to remain objective and chose not to probe for more information with patients whose memory of past consultations differed from my own.

Of significance to me, was the finding that by interviewing my own patients, people I had known for a number of years in some instances, I gained life course knowledge and understanding that I would have found useful as a practice nurse, in building relationships and providing a broader, more thoughtful care. This new knowledge included how people lived their lives in their own homes. Aspects of their lives not observed or revealed in 
consultations. (At the time of interview collection, I was working as a practice nurse, but later during the analysis period, I retired). Although I was aware I could not know all there was to know about everybody and I could not be all things to all people, knowledge about life course, turning points, transitions and transformations and their implications for their health pathways would have provided me with another medium for communication and rapport.

\subsection{Contribution to knowledge}

This study makes an important contribution to nursing knowledge by providing a new perspective in understanding of nurse-patient relationships within general practice. Even though the significance of these relationships is well understood, less clear was how general practice patients viewed that relationship and how it contributed to the patients' health and well-being. The notable new and original finding of the symbiotic relationship between practice nurses, GPs, receptionists and patients identified in this study, has implications not only for building collegiality and communication within the general practice team, but also for other health professionals in related disciplines.

The research illustrates how the practice nurse role has changed and extended over time. Historically, nurses were employed to assist the doctor, undertake nursing tasks and reception work. The symbiotic nature of general practice, with no engagement between any team member or patient, taking place in isolation, but each relying on the other to perform their individual and collective roles, became apparent. Contemporary practice nurses, however, also do some work independently of the doctor, and performing few or no reception duties. Participants built relationships with nurses over time, choosing to engage with the nurse without the knowledge of, or input from the GP. Participants described this autonomy as nurses filling a gap in their care. However, nurses were also perceived as support for the doctor. Even though both professions engaged in collegial activities such as two-way referrals, and participants valued consulting nurses independently from the doctor, generally, participants' perceptions of the nurses' role was of one that complemented the more important overarching medical role.

The degree to which cultural misunderstandings influenced participants' decisions was a critical factor in their general practice and GP selection. The personal characteristics of the GP were a minor factor in patients' reasons for choosing a particular practice. Not only 
who the GP was, but also the receptionists' demeanour, the aura of the practice, and the professional competency of practice nurses contributed to the participants' choices of enrolling or staying with a general practice. Despite some participants citing the disabling behaviours of GPs, practice nurses and receptionists as reasons for not returning to a practice, for others it was these players' responsive behaviours that drew participants to a practice. In practices where there were many changes of GPs, the quality of the practice nurse-patient relationship fortified participants' decisions to remain at the practice. Adding to what is already known about continuity of care and carer, this study demonstrates the importance participants placed, not only on care continuity, but also on the continuity of a familiar carer with whom they felt safe and comfortable; someone who they felt was on their side.

Although the literature described some receptionists in pejorative language, participants more often talked of receptionists in terms that suggested rapport rather than friction in the relationship. Instead of being 'an old battle-axe' and 'gatekeeper,' receptionists were perceived as facilitators who assisted patients' decision-making processes. Participants appreciated talking with these fronts people with whom they had some personal connection through social talk, or had built a rapport over time.

The finding that receptionists triaged patients' urgency and appointment times for GPs has previously been described in the literature. However, the finding that they also allotted practice nurse appointments has not been made apparent. There is also limited information of receptionists' decision-making processes based on health information provided by patients determining their access to a particular health professional. Nevertheless, without prompting, participants report that receptionists regularly offered GP or practice nurse consultation options. Although some health information requested of patients may be necessary, it was evident that the types of questions receptionists ask, and the amount of information patients provide raises issues of confidentiality. In face-to-face-interactions at the reception desk, or telephone conversations, instances of identifiable confidential information being overheard increases the risk of breaches in patient privacy.

The practice nurses' professional comfort, skilled compassion and skilled companionship expressed by participants, augments previous understandings describing compassion and companionship in nursing practice. Significantly, participants highlighted the skilled, 
responsive comportment and know-how of practice nurses. The skill of practice nurses knowing when to come close and when to stand back; intuitively knowing when patients were not their usual selves; skilfully supporting participants' 'movement' and knowing what that movement entailed and interpreting the process for participants; and when to implement actions. Sharing was perceived as particularly important in providing skilled companionship and professional comfort. Over tiny moments in time, sharing brought forth stories of events in participants' life course that directly contributed to their health and well-being. Practice nurses sharing appropriate personal information was also found to help participants in their decision-making and to build rapport. Differing from some previous literature that discourages sharing, this finding adds to other interpersonal nursing models that encourage nurses' use of appropriate personal sharing to help patients.

\subsection{Contribution to methodology and method}

The findings contribute to Narrative Inquiry methodology, and methods of data collection and analysis. Although the concepts of linear, circular, cyclical, spiral static and fragmentary autobiographical time described by Brockmeier (2000) were found in participants' stories, linked with McCormack's (2001) lenses of narrative processes, language, context and moments, there were also other concepts of time described in my research. Participants talked of tiny moments in time during engagements with practice nurses, of practice nurses having time to talk; time that was less about life and events and more about access to the nurse. Time with, and the availability of the nurse, even in a busy practice where time is often not available for extended consultations, or when people are fitted in between patients creating pressure on the nurse to keep to time. Participants also described episodic time, where they returned to the engage with the nurse over time in their life course. In every-day nurse-patient relationships, the principles of life course were present in participants' descriptions of fragments of their life events and experiences in one or two interviews, while still providing a clear picture of the timing of events and outcomes, in their social, historical and cultural sentient beings. Although life course theory is often applied to longitudinal and lifestyle studies, this study highlighted its versatility and value in other research disciplines such as Narrative Inquiry, and in episodic contexts, for example, general practice.

Participants' stories included different historical and social times, cultures and contexts, and to interpret them in a more complete and meaningful way, I adapted McCormack's 
(2001) approach of analysing the data through different lenses. Recognising my place in the interview and the analytical process as a practice nurse researcher, viewing transcripts and listening to the audio-recordings through the lenses of Active Listening, Narrative Processes, Language, Context, and Moments, allowed me to interpret the whole and part of each narrative from more than one perspective. However, because I needed to facilitate my intuitive awareness over all the lenses, I extended the Active Listening lens used by McCormack and Dibley (2011) beyond interview transcripts, to become an overarching process throughout the analysis. Through this augmentation, viewing each presentation of the story with overarching active listening has brought new understanding, not only to the different parts of each story, and the meaning of each participants' story but the over-all story of the participants' experiences of practice nurses and general practice. Applying this process, active listening intensified the view from each lens, how each participant reflected on what was told in the context of the time and place of the event. It enhanced the moments in the stories when there were times of uncertainty or a when a turning point was reached. This combined method strengthened the credibility of the findings. Both McCormack and Dibley took similar short story approaches to their interpretative stories, and both authors noted the participants' tone of voice, pauses and body language during the analysis. Dibley also applies an alternative definition of language to draw meaning from the narratives. However, to capture the varied directions of participants' accounts and stories within their narratives, but not analysing voice influences, I modified both authors' interpretative methods by taking a global narrative process approach to the analysis which began with searching for commonalities and differences within and over the stories, developing four main themes, which I then analysed through the multiple lenses.

\subsection{Methodological and method critique and study limitations}

\subsubsection{Sampling}

The gender imbalance of only $27 \%(\mathrm{n}=4)$ men may have been addressed through an informal approach from people unrelated to the study, such as other family members or friends who were aware of the study. If receptionists or GPs had discussed the study with men, I might have recruited more. However, I now realise that the receptionists and GPs were connected to the study and therefore, ineligible. However, at the time of recruitment this connection was unknown. Efforts to include more Māori involved informally talking with staff from a Māori Health Provider, as well formal consultation with Māori prior to recruitment. However, there remained an ethnic imbalance with no other cultures 
represented. A more proactive approach to a number of other cultural groups from different backgrounds and in their own environment may have supplied greater numbers of participants and added depth to analysis. As only two young people were recruited, a higher number of young people would have provided a broader understanding of their relationships with practice nurses and general practice. However, the perspective of a person with spinal injury added to the study. Because one participant did not take part in the second interview, her story was unable to be co-constructed. Although the study included urban and rural areas, it involved only one PHO region. A study which included PHOs from other regions and larger cities would have strengthened the research.

\subsubsection{Trustworthiness}

Throughout the co-construction of the stories and analysis, I strived to be both ethical and accountable in my approach (McCormack, 2001). I was aware that as the researcher, I was exposing participants' stories to a wider public arena and care was needed to protect participants and third parties from harm. The subjective stories were situated within the cultural and political context of the person telling the story which contributed to the truthfulness of participants' reporting (Atkinson, 2002; Riessman, 2008; Sandelowski, 1991). Obtaining patients' perspectives of their relationships with practice nurses, rather than from the standpoint of practice nurses increased trustworthiness of the study. This approach not only revealed patients' judgments of their engagements and relationships with practice nurses, but also how these relationships contributed to their health and wellbeing. The recursive process of returning the stories to participants for review, then integrating the stories from the second interview into the whole, assisted in the validation of my interpretation of their narratives. Providing further credibility for the study, three practice nurses, and an independent patient who read my thesis, identified with my findings. What is not clear from the interviews is what, if any difference did the participants' relationship with me as the researcher who was also known to them as one of their practice nurses have on their participation, candour and what they shared. However, the stories of participants who were not from my practice did not differ in substance and interpretation from those of my practice.

\subsection{Implications for education and practice}

Even though the education and practice requirements of practice nurses who episodically care for people over a life course may differ from those working in other domains and 
disciplines, my findings have implications for practice nurses generally, and for other health professionals.

- Despite consultation time constraints, nurses new to general practice could benefit from the knowledge that actively listening to patients' stories, and social chat are not only important in building rapport, but also meaningfully contributes to patients' health and well-being. Health issues that might not be addressed via other forums may be raised through stories and social talk. New nurses may value being aware that patients might appreciate a nurse sharing some appropriate personal information to help them in their decision-making process. Continuing professional development programmes such as chronic conditions management, including Care Plus, smoking cessation and Healthy Lifestyle, could also feature professional information relating to the comforting practices of skilled compassion and skilled companionship.

- Although undergraduate nursing schools may include emotional intelligence studies (Wilson \& Carryer, 2008), a curriculum review could establish a gap in knowledge in patient-centred care. Guidance and modelling of professional comforting, skilled compassion and skilled companionship would further contribute to nurses' understanding of nurse-patient relationships.

- The training of medical receptionists was not examined in the study, however, patients placed emphasis on the welcoming demeanours and good communication practises. Continuing awareness of cultural safety and the importance of selfawareness when engaging with patients may reduce instances of practises unacceptable to patients.

- Examples of cultural insensitivity raised questions relating to the educational needs of foreign-trained practice nurses and locum doctors. These issues could be addressed by the general practice principles and through peer review and professional development programmes. 


\subsection{Implications for policy}

Participants' descriptions of their experiences of general practice have implications for policy makers not only in general practice but also for PHOs and DHBs.

- There are constraining factors related to patients choosing a general practitioner and general practice. While doctors' personal characteristics shaped some patients' preferences in choosing, or not choosing a particular doctor, the availability of a doctor also restricted their options. This is significant not only for patients, but also for future PHC planning. Given the importance of doctor-patient relationships, the impact on patients' health and well-being may be considerable if patients are required to consult GPs who are not of their choosing.

- Although time allocation for each funded or non-funded consultation is organised by practice management, the consultation time practice nurses were allocated for each patient was an issue for some patients. Some patients felt they were squeezed into a truncated consultation slot, while others would have appreciated extra time with the nurse. A patient's sense of feeling compressed into a brief time-slot with a busy nurse may result in that patient feeling devalued as a person, inhibiting his or her ability to connect meaningfully with a nurse and to express their health and well-being needs. Dedicated longer consultation times would allow patients and nurses to build the rapport necessary for patients to gain and maintain confidence in the nurse, and for the nurse to acquire a deeper understanding of the patient's health and well-being needs.

\section{$9.7 \quad$ Future research}

A number of key areas where further research into patients' relationships and engagements in general practice, arise from this study:

- An observational or ethnographic research approach could be undertaken to provide additional insight into practice nurses' comforting practices of skilled compassion and skilled companionship, and which skills contribute to patients' improved wellbeing. 
- A survey of patients' attending practices where continuity of health professional (practice nurses or GP) who are not a patient's preferred practitioner is likely to reveal insights and understandings of how this factor contributes to their health and well-being outcomes. It would also extend the idea of well-being measurements in quality of life studies. The fresh insights gained from such studies would add to existing knowledge of the reasons patients choose a practice or GP.

- An exploratory research approach would provide further understanding of the receptionist's influence in general practice. It would also reveal how triage is managed at the reception desk and how receptionists make decisions when directing patients to the practitioner (nurse or GP). Research is also required into how receptionists balance what they need to share with patients to build rapport, with information gathering to make appropriate appointments. Using a case study approach for example, research to find to what extent receptionists are constrained by scheduling difficulties that they recommend patients consult the practice nurse knowing the nurse will contact the doctor between patients if needed, is required.

- Like general practice patients, practice nurses lives include different histories, social times, and cultures over their life course. Taking a life course approach, further research would help determine the extent the age and culture of practice nurses contributes to their relationships with patients.

- Two-way referrals between practice nurses and GPs were described by participants. Further research applying a survey or observational study would establish the reasons for these referrals, leading to possible extension of the practice nurse role.

- The finding that two participants chose not to address their concerns about the care they received directly with either the practice nurses or the practice management raises questions of patients' emotional work, and of empowerment and control. Despite some studies noting that hospitalised patients are nice to nurses to get their needs met (Shattell, 2005; Smith, 1991: Theodosius, 2008), a Narrative Inquiry research model into why, how, and when patients use emotional work and the reasons they choose not to resolve problems, would provide more depth in understanding their perspective. 


\subsection{Conclusion}

This research has established that patients valued their rapport with practice nurses and that the humanistic skilfulness of nurses positively contributed to their health and well-being. The conceptualisation of symbiotic relationships between practice nurses, GPs, receptionists and patients described in this study shows how these relationships work in practice. Although each person was independent and capable of working autonomously, for their mutual benefit they developed a close association with which to meet their needs. The study also established that while there has been significant increase in collaboration between nurses and GPs over time, this collaboration was distinct from the symbiotic relationships described. This symbiotic relationship reflects an aspect of new ways that doctors and nurses practice together.

The findings of general practice activity, health focused practice and professional comforting, and their sub-themes, revealed the hidden, subjective, relational and material work of practice nurses. Within these humanistic engagements and relationships, participants emphasised the skilled compassion and skilled companionship that facilitated the professional comforting practises of nurses and contributed to their health and wellbeing. General practice activity illustrated the symbiotic nature of general practice relationships encompassing patients, nurses, GPs and receptionists. Although participants perceived the GP as the higher power with an overarching presence, practice nurses worked both collegially with, and independently from them. At the same time, participants remained cognisant of their professional identities of the GPs and nurses. The evolvement of the practice nurse role was illustrated by descriptions of the nurse being at the beck and call of the GP who passed on tasks he did not want, or need to do, to a position where participants chose to engage with an autonomous nurse. However, there was ambiguity in participants descriptions of the nurse being both independent from, and support for, the doctor.

As patients, the participants' decisions around which practice or doctor to enrol with was essentially gained through social talk, the sentiment of others, and their interactions with receptionists. Despite doctors' personal characteristics shaping participants' choices, the doctor's availability was also a constraining factor. The demeanour of receptionists influenced participants' perceptions of connection with the practice, of how they may be 
cared for, as well as how a practice might be organised. Although the atypical case drew out one aspect of a fronts persons' performance, generally, receptionists were valued members of the team. Participants appreciated receptionists' advice about whom they needed to see. Perceptions of an unwelcoming gatekeeper may be the consequence of receptionists trying to manage patients' needs and expectations with too few available appointments, and the GPs' needs and expectations.

Filling the gap activities were those tasks undertaken by practice nurses that were at times supplementary to and a substitute for the doctors' role. However, they may also be perceived as complementary to the GP, rounding out the role. Nurses were often independent from the doctor, with participants choosing to consult them when they did not need to see the doctor. A strong nurse-patient relationship enabled participants to return to the nurse for care, without judgement. Nurses enabling practices were those processes that allowed participants to move at their own pace, respectful of their human agency and culture, and sharing their real selves to help participants. Disablement arose from cultural misunderstandings and nurses' inexpert behaviours.

Descriptions of participants' engagements and relationships with practice nurses were further captured in the concepts of skilled compassion and skilled companionship. While they were often inherent in the data and discussion, they were also shown independently. Skilled compassion was revealed in participants' experiences of nurses being responsive to their needs, sharing something of their real selves, and knowing subjectively, relationally and materially which skilled professional action to take to move the patient forward. Skilled companionship was described in relationships between the participants and practice nurses where participants felt a sense of peace, and mutual closeness with the nurse, such as the nurse being alongside, nurturing, and being responsive. Participants became, and remained enabled to move forward, while at the same time, preserving their human agency.

In response to government policy, general practices are endeavouring to fulfil the directives of the Primary Health Care Strategy (King, 2001) by harnessing the skill and knowledge of practice nurses to provide affordable and accessible health care to their enrolled patients. The generous contribution of the patients I interviewed enabled this research to fill a gap in knowledge relating to the practice nurse-patient relationship from the patients' perspective. Practice nurses have a pivotal and unique role in providing safe 
and effective care for patients throughout their life course. This work of practice nurses is not invisible to patients; rather patients have good knowledge and understanding of how the practice nurse contributes to addressing their health concerns. Although the functional and health promoting work of nurses is recorded, nurses professional comforting, skilled compassion and companionship work remains unrecorded and invisible to employers and policy makers. It is important that nurses have dedicated time with patients to enable them to build the type of relationship that positively contributes to patients' health and wellbeing. 


\section{Appendices}

\section{Appendix 1 Locality Organisation Consent}

\section{Locality Assessment by Locality Organisation}

Refer to pages 13-15 of Guidelines for Completion of the National Application Form for Ethical Approval of a Research Project (NAFG-2009-v1).

\section{Locality organisation sign off}

Ethics committees review whether investigators have ensured their studies would meet established ethical standards if conducted at appropriate localities. Each locality organisation is asked to use the locality assessment form to check that the investigator has also made the appropriate local study arrangements.

Ethics approval for study conduct at each site is conditional on favourable locality assessment at that locality.

Please note that the locality organisation may have additional requirements to be met before a study may commence at that locality.

\section{Part One: General}

To be completed by the principal investigator for this locality.

Full project title:

Short project title:

Locality to be assessed:

Brief outline of study:

Principal investigator (for this locality):

Contact details:

Other local investigators (list all at this site):

Contact details:
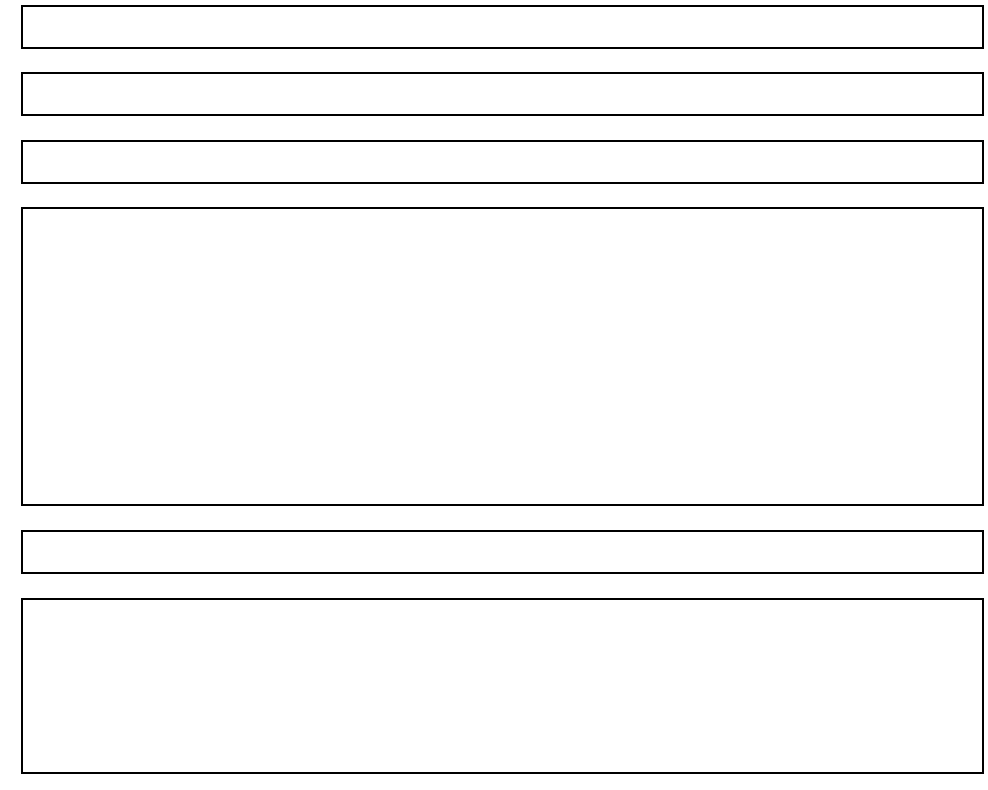


\section{Part Two: Locality Issues}

To be completed by the principal investigator for this locality and signed by the authorised locality representative. (See the Guidelines (NAFG-2009-v1) (pages 13-15) for more information and examples.) Identify any local issues and specify how these issues will be addressed.

\section{Suitability of local researcher}

For example, are all roles for the investigator(s) at the local site appropriate (for example, has any conflict the investigator might have between her or his local roles in research and in patient care been adequately resolved)?

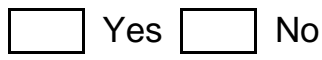

2. Suitability of the local research environment

a) Are all the resources (other than funding that is conditional on ethical approval) and/or facilities that the study requires appropriate and available (for example, is staffing adequate? Is this site accessible for mobility-impaired people where necessary)?

b) Have all potentially affected managers of resources such as patient records or laboratory managers been notified?

3. Have issues such as cultural issues specific to this locality or to people being recruited at this locality been addressed?

4. Have the local investigator contact details and other important contact details been provided to the locality organisation for

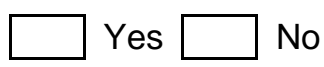
checking?

\section{Part Three: Declaration by locality organisation}

I confirm the organisation has sufficient indemnity insurance to compensate participants for harm that does not qualify for compensation under the Injury Prevention, Rehabilitation and Compensation Act 2001.

I am authorised to complete locality approval on behalf of this locality organisation. I understand that I may withdraw locality approval if any significant local concerns arise. I agree to advise the principal investigator and then the relevant ethics committee should this occur.

(Questions 1-4 at Part Two above must be completed prior to signing.)

Signature:

Name:

Contact details:
Date:

Position: 
Appendix 2 Invitation Flyer

\section{INVITATION TO PARTICIPATE}

\section{IN AN \\ INTERESTING RESEARCH PROJECT}

I am a PhD student who is researching what it is in the patient-practice nurse relationship that can make a difference to patients' health and wellbeing, and what else the practice nurse could do to help patients.

This study has been approved by the Upper South B Ethics Committee

I want to interview people over the age of 20 years who speak English and have consultations with practice nurses. If you are interested in taking part in my project or would like more information, please take the information sheet or contact:

Elsa Lally

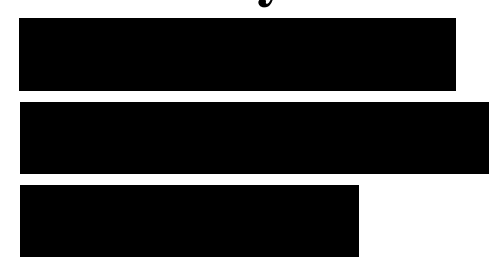

PLEASE HELP YOURSELF TO ONE OF THE TAGS BELOW 


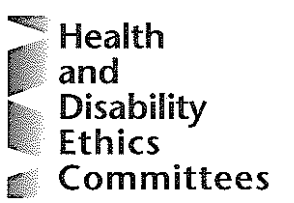

4 November 2009

Ms Elsa Lallv

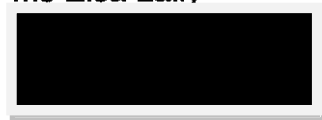

Dear Ms Lally

Ethics Reference Number: URB/09/10/046

An exploration of the Practice Nurse consultation and engagement with patients

Investigator: Ms Elsa Lallv

Localities:

\author{
Upper South B Regional Ethics Committee \\ Ministry of Health \\ 4th Floor, 250 Oxford Tce \\ PO Box 3877 \\ Christchurch \\ Phone (03) 3723018 \\ Fax (03) 3721015 \\ Email: uppersouth_ethicscommittee@moh.govt.nz
}

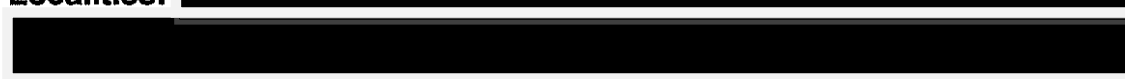

The above study has been given ethical approval by the Upper South B Regional Ethics Committee.

\section{Approved Documents}

Information Sheet version 2 dated 9 October 2009

Consent Form version 2 dated 9 October 2009

Confidentiality Agreement for Transcriber version 1

Prompts Interview Guide version 1 dated 10 August 2009

\section{Accreditation}

The Committee involved in the approval of this study is accredited by the Health Research Council and is constituted and operates in accordance with the Operational Standard for Ethics Committees, April 2006.

\section{Progress Reports}

The study is approved until $\mathbf{3 0}$ June 2011. The Committee will review the approved application annually and notify the Principal Investigator if it withdraws approval. It is the Principal Investigator's responsibility to forward a progress report covering all sites prior to ethical review of the project in November 2010. The report form is available at http://www.ethicscommittees.health.govt.nz. Please note that failure to provide a progress report may result in the withdrawal of ethical approval. A final report is also required at the conclusion of the study. 


\title{
Amendments
}

It is also a condition of approval that the Committee is advised of any adverse events, if the study does not commence, or the study is altered in any way, including all documentation eg advertisements, letters to prospective participants.

Please quote the above ethics committee reference number in all correspondence.

It should be noted that Ethics Committee approval does not imply any resource commitment or administrative facilitation by any healthcare provider within whose facility the research is to be carried out. Where applicable, authority for this must be obtained separately from the appropriate manager within the organisation.

The committee would like to take this opportunity to wish you all the best with your study.

Yours sincerely

$$
\text { Diana T. Whipp }
$$

\author{
Mrs Diana Whipp \\ Upper South B Regional Ethics Committee Administrator
}

Email: diana_whipp@moh.govt.nz 


\title{
Appendix 4 Information Sheet
}

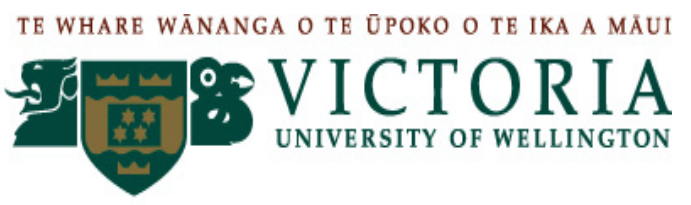

\section{Information Sheet}

\section{The contribution Practice Nurses make to the health and wellbeing of patients.}

\section{Introduction}

Patients of Practice Nurses are invited to take part in this study that looks at what it is in their relationship with the practice nurse that they see as making a difference to their health and wellbeing. The study is being undertaken by Elsa Lally, a practice nurse, as a part of a $\mathrm{PhD}$ degree in nursing through the Graduate School of Nursing, Midwifery and Health, Victoria University of Wellington.

\begin{abstract}
About the study
While there is evidence from nurses that the quality of the relationship between nurses and patients influences people's health choices, there is little evidence of this from the viewpoint of the patient. By interviewing 10-15 patients who have seen a practice nurse, this study intends to identify what it was about practice nurse consultations that patients considered made a difference to their health and wellbeing. The interviews will take the form of story telling.
\end{abstract}

\section{Participation}

Your participation is entirely voluntary (your choice). You do not have to take part in this study and if you choose not to take part, this will not affect any future care or treatment. If you do agree to take part, you are free to withdraw from the study up to two weeks after the second interview. No reason for withdrawal needs to be given and all data given by you will be destroyed at this point. You may stop the interview at any time or request that the tape recorder be turned off.

During the first interview you will be asked to tell stories of how the practice nurse has helped, or could have helped you with your health. After the first interview, you will be sent a summary of you story/s. During the second interview, you will be asked to provide comments on the summary and to share any other observations you may have about the work of the practice nurse. Each interview will take approximately one hour.

People can participate if they are over the age of 20, speak English and are interested in being interviewed. People involved in this study cannot be patients of the principal researcher. 
Each person will be interviewed up to two times. With your permission, I will audiotape the interview and it will be transcribed by a qualified transcriber. The interviews will be at a time and place that is convenient for you. These arrangements will be made with you by telephone.

Your doctor or practice nurse does not need to know of your involvement in the study, and no conversations with your doctor or practice nurse about your involvement will be held.

\section{What will happen to my interview data?}

Once all the interviews are complete, they will be examined for their similarities, differences and revelations in how practice nurses work with patients to assist patients manage their health needs. This appraisal will also look for how practice nurses could change how they work. Extracts from parts, or of whole stories will be presented in the thesis. Particular care will be taken to ensure you, your family, whanau or friends, practice nurse or surgery, will not be identifiable in the presentation of the findings.

You may take a consent form, and you may have a friend, family or whanau support to help you understand the benefits and risks of this study and any other explanation you may require.

I will return a summary of the interview to you so that you can see if the meaning I take from your stories are correct, and you can make changes or additions that you need to.

There will be no cost to you if you decide to take part in the study, and there will be no payment for taking part.

No material which could personally identify you or your practice will be used in any reports on this study.

If you need an interpreter one can be provided.

\section{Benefits of the study}

The results of the study will help Practice Nurses and other people who work in the health care industry understand the significance of listening to the stories of patients; that an awareness of the meaning of the stories and how events in people's lives shape their health and wellbeing choices will help nurses work in partnership with people to decide their care and lifestyle choices that are right for them.

\section{Risks of the study}

During the story telling process it is possible that sensitive issues about their health or about an interaction with a nurse might be revealed causing the participant emotional distress. I will talk to each participant before beginning the interviews and explain that support will be provided should they need it. 


\section{What will happen at the end of the study?}

Once completed, all participants will be sent a copy of the study. The overall results of the research will be written up as a thesis lodged at the Victoria University of Wellington library. It will also be presented at conferences and written up in a journal, and be available electronically via the Thesis Repository. Please note there will be a delay of up to 12 months between information collection and the final written report.

Your consent form and transcripts will be filed in a secure filing cabinet at the Graduate School of Nursing Midwifery and Health for 10 years after the research is completed, at which point they will be destroyed. Tapes will be destroyed following successful examination.

If you have any queries or concerns regarding your rights as a participant in this study, you may wish to contact an independent health and disability advocate:

Free phone: 0800555050

Free fax”0800 2 SUPPORT (0800 2787 7678)

Email: advocacy@hdc.org.nz

\section{Statement of approval}

This study has received ethical approval from the Upper South (B) Regional Ethics

Committee, ethics reference number URB/09/10/046

Please feel free to contact the researcher or her supervisors if you have any questions or need more information about this study.

\section{Principal investigator}

\section{Elsa Lally}

Practice Nurse

\section{Study supervisors and contact details}

Dr Katherine Nelson - Primary research supervisor

Graduate School of Nursing, Midwifery and Health

Victoria University of Wellington

Wellington

kathy.nelson@vuw.ac.nz Telephone (04) 4636138

Dr Margaret Martin - Research supervisor

Graduate School of Nursing, Midwifery and Health

Victoria University of Wellington

Wellington

margi.martin@vuw.ac.nz 
Appendix 5 Ethics Committee approval to interview patients from my practice

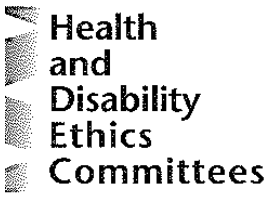

10 March 2010

Ms Elsa Lally

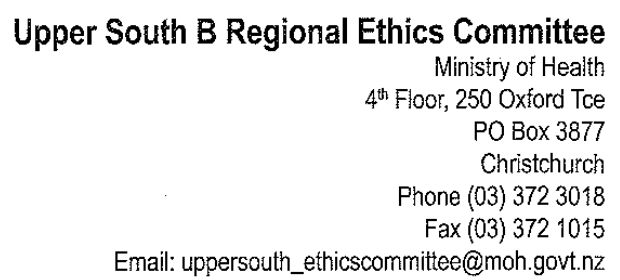

Upper South B Regional Ethics Committee

Ministry of Health

PO Box 3877

Phone (03) 3723018

mittee@moh.govt.nz

Dear Ms Lally

Ethics ref: URB/09/10/046

Study title: An exploration of the Practice Nurse consultation and engagement with patients

Amendment(s): to include patients from the researcher's workplace

Thank you for submitting the above amendment(s) to this study. This has now been approved by the Chairperson of the Upper South B Regional Ethics Committee under delegated authority.

Yours sincerely

Diana r. Whipp

\section{Diana Whipp}

Administrator

Upper South B Regional Ethics Committee 


\section{Appendix 6 Transcriber Confidentiality Form}

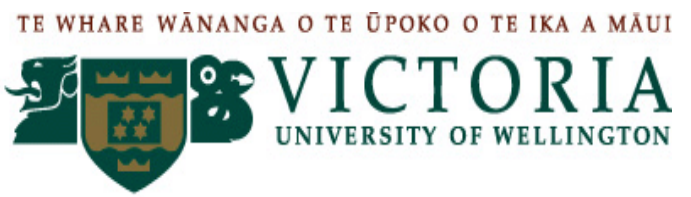

\section{Confidentiality Agreement for Transcriber of a Research study titled: \\ An exploration of the Practice Nurse consultation and engagement with patients}

Researcher: Elsa Lally

I have read the information sheet outlining this study. I have discussed with the researcher the nature of the research and have had any questions that I have had answered to my satisfaction. My role as the research transcriber has been outlined to me by the researcher.

At all times the research information (tapes and transcripts) will be inaccessible to other persons. The researcher has assured me that she will debrief me following transcribing to address any issues that transcribing bring up for me.

Most importantly, I understand and agree to keep the information I hear and type in the course of transcribing confidential to the researcher and myself.

Full Name:

Signature:

Date:

Researcher's Signature:

Date: 


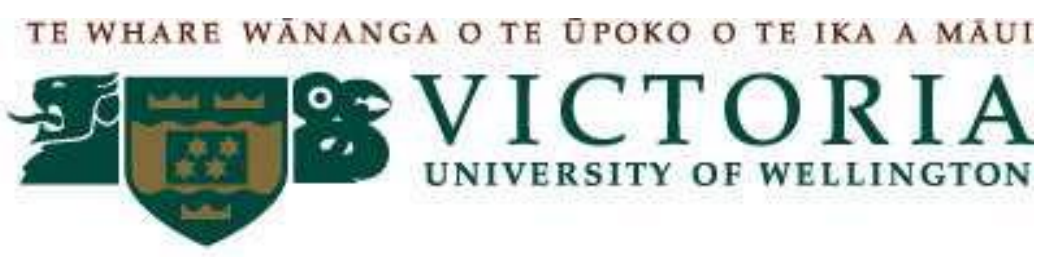

\section{CONSENT TO PARTICIPATE IN RESEARCH}

An exploration of the Practice Nurse consultation and engagement with patients

\section{Researcher: Elsa Lally}

\begin{tabular}{|l|l|l|l|}
\hline English & I wish to have an interpreter & Yes & No \\
\hline Māori & E hiahia ana ahau ki tetahi kaiwhaka Māori/kaiwhaka pakeha korero & Ae & Kao \\
\hline $\begin{array}{l}\text { Cook Island } \\
\text { Māori }\end{array}$ & Ka inangaro au i tetai tangata uri reo & Ae & Kare \\
\hline Fijian & Au gadreva me dua e vakadewa vosa vei au & lo & Sega \\
\hline Niuean & Fia manako au ke fakaaoga e taha tagata fakahokohoko kupu & E & Nakai \\
\hline Sāmoan & Ou te mana'o ia i ai se fa'amatala upu & loe & Leai \\
\hline Tokelaun & $\begin{array}{l}\text { Ko au e fofou ki he tino ke fakaliliu te gagana Peletania ki na gagana o } \\
\text { na motu o te Pahefika }\end{array}$ & loe & Leai \\
\hline Tongan & Oku ou fiema'u ha fakatonulea & lo & Ikai \\
\hline & $\begin{array}{l}\text { Other languages to be added following consultation with relevant } \\
\text { communities. }\end{array}$ & & \\
\hline
\end{tabular}

I have been given and understand an explanation of the research project. I have had an opportunity to ask questions and have them answered to my satisfaction.

I understand that I may withdraw myself and any information provided by me from this research project up to two weeks after the second interview.

I understand that I can bring a family member or friend to the interview.

I understand that I will receive a summary of my first interview and will be able to comment and make changes to this.

I understand that the recordings, notes and transcripts of my interview will be kept in a 
secure place, that no one other than the researcher, her supervisors and a confidential typist who will assist with transcribing, will have access to them.

I understand that the tapes will be electronically wiped at the end of the research and the transcripts destroyed after 10 years.

I understand that any information provided by me will be unidentifiable and that my name will be kept confidential to the researcher.

I would like to receive a summary of the research findings when the research is completed. Yes No

I agree to take part in this research.

Name:

Signed:

Date:

Address for summary or report: 


\section{Appendix 8 Sample of Story Co-construction and Reflective Analytical Mind Map}

Below is an example of one part of one story that when I returned to participants for second interview, was included in the overall story. It was the inclusion of this second story (in bold type) that allowed the analysis process to begin. An example of reflective journaling and a mind map that portrays a part of my analysis process are included.

\section{Example:}

Being taken seriously is important to Peggy. In this context, being taken seriously means that I like to think that in this world if a person approaches someone else, lets that other person know they have something to say, that the other person will at least listen; they won't prejudge you; know that I can listen to what she has to say. It's the same with the nurse and doctor. It you come in here it's for a reason and they are willing to listen to what your reason is and then figure out what they can do for you or who else is better to take care of whatever the issue is. That is what I mean, they won't prejudge.

Because of the relationship that Peggy had with the practice nurse, she trusted the knowledge and skill of the nurse instead of "looking for a psychologist or therapist who doesn't know anything about me; I thought she was the most appropriate person I could approach." The confident manner with which the practice nurse presented herself increased Peggy's faith in her nurse. "I have no reason over time, you know, building up trust with her. I have every reason to trust her and I have never been failed by her and her abilities." This trust "has been earned" by the practice nurse and doctor and also means that Peggy has faith in consulting "someone who knows that thing well."

So for my health care I want a doctor who know his or her stuff, keeps current, and the same with the practice nurse, and I want, I've gotten used to the service they've given here in New Zealand, where I guess I've not really come to expect, but I guess part of that trust is, I believe, that they do know pretty much the whole picture of what health care, of health attention people need at different stages of life, and I don't feel I need to do reading at home where, you know, to do my own medicine, I want a professional. 
Furthermore, Peggy's trust in the doctor and the practice nurse includes confidence that "they can do most of my care. It's only when there is something, you know, outside that normal realm that they would refer out. I like that; I don't want to go to specialists all the time." Peggy has a warm relationship with her doctor and has shown her appreciation of the care provided by the doctor, practice nurse and receptionist by sending them a card to thank them for the care they have provided. "Just having that rapport, and doctors and nurses who know us, to me, makes huge difference. It's worth telling them how good they are."

As a patient, Peggy takes her responsibilities seriously as she knows it's a busy practice and she has a 15 minute appointment time and

I try to respect that; I know we are not going to sit and chat; that there is a reason, and we take care of business and I try to do my part to keep things short and not keep him from other patients.

However, Peggy knows that if she needed more time she would be granted it if she asked when she made the appointment, or she would be invited back. "They are very kind, they aren't in the business of hustling people in and out for health care; they are very personable." In addition, Peggy is confident that she would feel she could address any cultural or other issues that might arise if she needed to.

Sure. If I, yep, if I had a specific thing that I felt was important in my life that, you know, that they would somehow show their respect for it. I would ask them, I would point it out to them. Yes, I'd feel comfortable in talking to them about anything.

The possibility of the retirement of the practice nurse and the doctor were of concern to Peggy as she would lose the rapport and trust she enjoyed over the years.

I trust them; I feel I get good care from them, so anybody else it would just be someone that I didn't know. I don't have experience with any other GPs in town. I guess it's just having to start a new relationship

Peggy has experienced referrals from the practice nurse to the doctor and from the doctor to the practice nurse, such as the doctor referring Peggy to the practice nurse for travel vaccines and the nurse referring Peggy to the doctor for possible surgical attention to a wound. 
Overall, Peggy is very satisfied with her care from the practice nurse. However, there was one occasion when the nurse rang Peggy with her results and from her hesitant tone of voice Peggy became concerned that there was something wrong with her results.

I had to tell her when I went in there that I was a little worried about going in just because there sounded like some hesitation in her voice when she called me and I thought, you know, after I hung up I thought 'gosh, what didn't she want to say on the phone,' so I had a little bit of a worry there, and when I told her that, she was mortified. She said 'Oh' she said 'there's nothing at all, you know, I wouldn't do that to you that way. I wouldn't break news or'-so we decided that maybe she was looking at her computer screen at the same time she was talking on the phone; you know how you get a bit of lag there sometimes in thought and speech when you're trying to do too many things at once. So she apologised for that, but it did put a little bit of a worry in there at first.

While Peggy and her husband are managing their health and are well, Peggy would appreciate any additional care such as Care Plus when she required it.

Yes, I would say that, initially said 'no' because I'd never had a need for that sort of thing, but I know as I age, the things that I see, you know, possibly becoming health issues, I would like, I would love to have support now at those times, you know, and it's mainly this arthritis business that hangs in the back of my mind. So, I'd say my day is coming where I will look for extra.

Reflecting on the Peggy's second interview and its insertion into the whole story (Reflective journal, 31/3/10), I noted again the importance of pre and post interview social talk. Prior to the second interview, I was not aware that her family was Jewish until I saw her dinner table set for many people. She informed me it was Passover, a religious festival observed by Jews. This knowledge directed me to raise questions about any experiences of cultural difference in her relationships with general practice and practice nurses. Peggy found this a "very interesting, thoughtful question" and one I may not have addressed as she did not appear to be culturally or ethnically different from other non-Māori participants.

A scanned mindmap of Peggy's interviews that was generated as part of the analysis follows. The mindmaps were initially drawn on A3 paper so were considerably larger. 


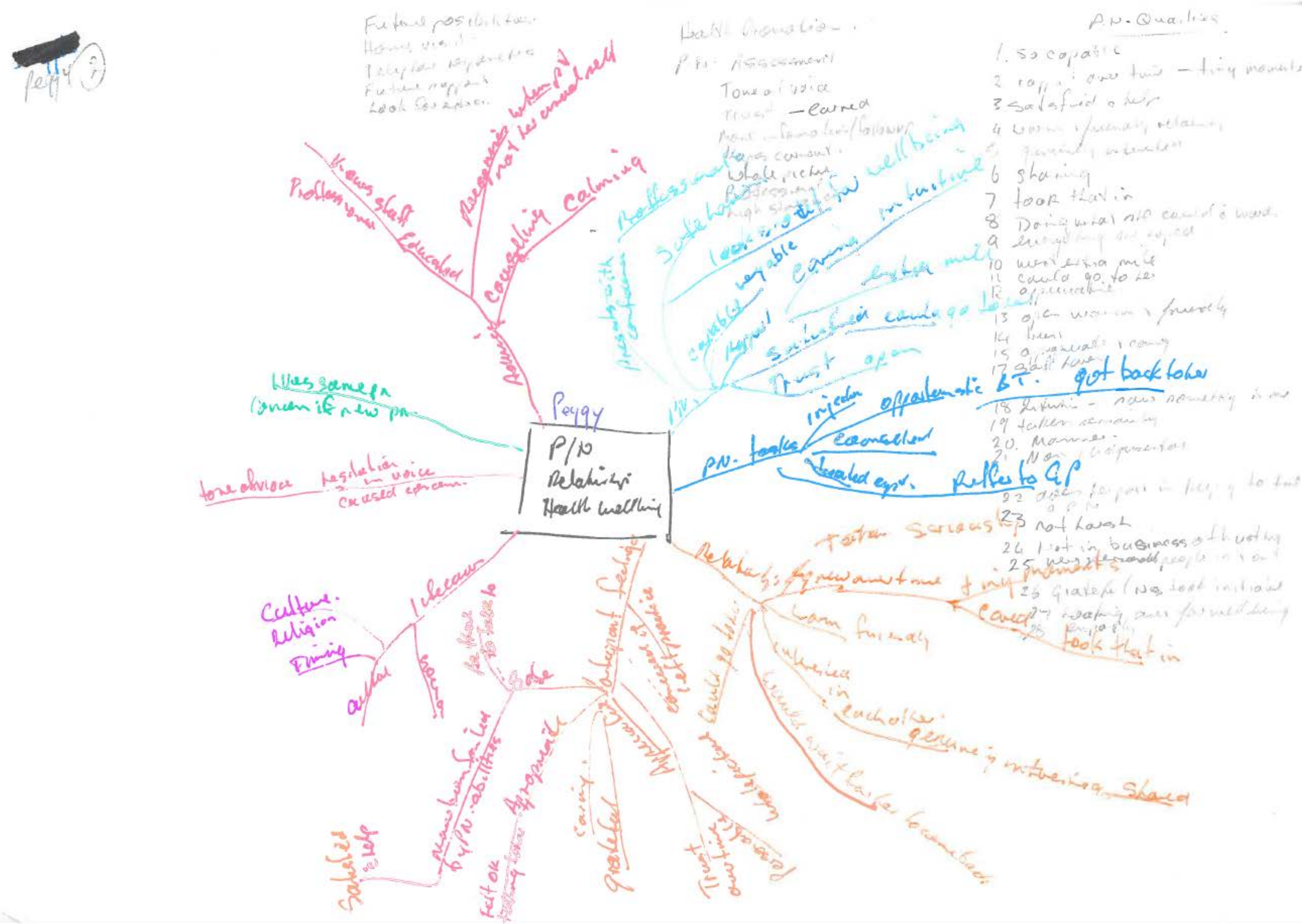




\section{References}

Abdel-Khalek, A., \& Eid, G. (2011). Religiosity and its association with subjective well-being and depression among Kuwaiti and Palestinian Muslim children and adolescents. Mental Health, Religion \& Culture, 14(1/2), 117-127. doi: 10.1080/13674670903540951

Aldridge, J. (2006). Chapter 2: The therapeutic relationship. In J. J. Aldridge, M. (Ed.), Person-centered practices: A therapeutic perspective (pp. 24-43). London, UK: Quay Books Mark Allen Group.

Allard, M., Frego, A., Katz, A., \& Halas, G. (2010). Exploring the role of RNs in family practice residency training programs. Canadian Nurse, 106(3), 20-24.

Anderson, R., Barbara, A., \& Feldman, S. (2007). What patients' want: A content analysis of key qualities that influence patient satisfaction. Medical Practice Management(March/April), 255-261.

Andrews, M. (2008). Never the last word: Revisiting data. In M. Andrews, C. Squire \& M. Tamboukou (Eds.), Doing narrative research (pp. 86-101). Los Angeles, London, New Delhi, Singapore Sage Publishing.

Annandale, E., \& Hunt, K. (1998). Accounts of disagreements with doctors. Social Science \& Medicine, 46(1), 119-129.

Aranda, S., \& Street, A. (1999). Being authentic and being a chameleon: Nurse-patient interaction revisited. Nursing Inquiry, 6(2), 75-82.

Arber, S., \& Sawyer, L. (1985). The role of the receptionist in general practice: A 'dragon behind the desk'? Social Science \& Medicine, 20(9), 911-921. doi: 10.1016/02779536(85)90347-8

Armstrong, D. (1983). The fabrication of nurse-patient relationships. Social Science and Medicine, 17(8), 457-460.

Asselin, M. (2003). Insider research: Issues to consider when doing qualitative research in your own setting. Journal for Nurses in Staff Development, 19(2), 99-103.

Atkinson, R. (1998). The life story interview: Qualitative research methods. Thousand Oaks: Sage Publications.

Atkinson, R. (2002). Life story interviews. In J. Gubrium, \& Holstein, J. (Ed.), Handbook of interview research: Context and method (pp. 121-140). Thousand Oaks, London, New Delhi Sage Publications.

Aujoulat, I., d'Hoore, W., \& Deccahe, A. (2006). Patient empowerment in theory and practice: Polysemy or cacophony? Patient Education and Counselling, 66(1), 13-20. doi: doi:10.1016/j.pec.2006.09.008

Austin, C. (2003). The general practice team: The foundation of the health system. Retrieved 15/6/2008, 2008, from <http://www.rnzcgp.org.nz/>

Australian General Practice Training. (2012). Australian general practice training. Retrieved 18/02/12, from http://www.agpt.com.au/

Australian Government. (2010). Building a 21st century primary health care system: Australia's first national primary health care strategy. Canberra: Author. Retrieved from

http://www.health.gov.au/internet/yourhealth/publishing.nsf/Content/3EDF5889BEC0 0D98CA2579540005F0A4/\$File/6552\%20NPHC\%201205.pdf.

Australian Government Department of Health and Ageing. (2010). Rural and regional health: Rural primary health services program. Retrieved 21/02/12, from http://www.health.gov.au/internet/main/publishing.nsf/Content/Rural-Primary-HealthServices-Program

Australian Government Department of Health and Ageing. (2011). National health reform: Primary care. Retrieved 22/02/12, from 
http://www.health.gov.au/internet/yourhealth/publishing.nsf/Content/themeprimarycare

Australian Government Department of Health and Ageing. (2012). Practice nurse employment toolkit. Retrieved 23/012, from http://www.nevdgp.org.au/files/practicesupport/practicemanagernursesupport/NURSE S/Nurses\%202009/PracNurse\%20employment\%20toolkit.pdf?PHPSESSID=332fd9d5 38f582922975df9353af9076

Australian Medical Council. (2012). Good medical practice: A code of conduct for doctors in $\begin{array}{llll}\text { Australia. } & \text { Retrieved } & \text { 3/1/13, } & \text { from }\end{array}$ http://www.amc.org.au/index.php/about/good-medical-practice

Australian Nursing and Midwifery Board (ANMB), \& Australian Health Practitioner Regulation Agency (AHPRA). (2012). Regulation and registration. Retrieved 23/02/12, from http://nurseinfo.com.au/reentering/regulationandregistration

Avert International HIV \& AIDS Charity. (2012). Who has to pay for NHS treatment in the UK? Retrieved 17/02/12, from http://www.avert.org/freenhs.htm

Bailey, P., \& Tilley, S. (2002). Storytelling and the interpretation of meaning in qualitative research. Journal of Advanced Nursing, 38(6), 574-583.

Bandura, A. (2001). Social cognitive theory: An agentic perspective. Annual Review of Psychology, 52, 1-26.

Banner, D. (2011). Qualitative interviewing: Preparation for practice. Canadian Journal of Cardiovascular Nursing, 20(3), 27-30.

Bayntum-Lees, D. (1992). Reviewing the nurse-patient relationship. Nursing Standard, 6(42), 36-39.

Benner, P., \& Wrubel, J. (1989). The primacy of caring: Stress and coping in health and illness. Menlo Park: Addison-Wesley.

Bingley, A., Thomas, C., Brown, J., Reeve, J., \& Payne, S. (2008). Developing narrative research in supportive and palliative care: The focus on illness narratives. Palliative Medicine, 22(5), 653-658.

Bleakley, A. (2005). Stories as data, data as stories: Making sense of narrative inquiry in clinical education. Medical Education, 39(5), 534-540.

Blue, I., \& Fitzgerald, M. (2002). Interprofessional relations: Case studies of working relationships between registered nurses and general practitioners in rural Australia. Journal of Clinical Nursing, 11(3), 314-321. doi: 10.1046/j.1365-2702.2002.00591.x

Boehm, J., Kivimaki, M., Peterson, C., \& Kubzansky, L. (2011). A prospective study of positive psychological well-being and coronary heart disease. Health Psychology, 30(3), 259-267. doi: 10.1037/a0023124

Bollen, M., \& Saltman, D. (2000). General practice in Australia: A history of general practice in Australia. Canberra: Australian Government Department of Health and Ageing. Retrieved from http://www.health.gov.au/internet/main/publishing.nsf/Content/health-pcdpublications-gpinoz2000-index.htm/\$FILE/chpone.pdf.

Bornstein, B., Marcus, D., \& Cassidy, W. (2000). Choosing a doctor: An exploratory study of factors influencing patients' choice of a primary care doctor. Journal of Evaluation in Clinical Practice, 6(3), 255-262.

Boscart, V. (2010). The development of nurse-patient relationship scales in chronic care. Doctor of Philosophy, University of Toronto, Toronto.

Boyd, M., \& Clark, A. (2006). Summary of practice nurses experience of providing care plus, and care for lifelong conditions: Results of the workshop held for primary health care nurses. In College of Nurses Aotearoa (NZ) Inc. (Ed.), (pp. 34-40). Wellington

Brockmeier, J. (2000). Autobiographical time. Narrative Inquiry, 10(1), 51-73. doi: 10.1075/ni.10.1.03bro 
Bruner, J. (1990). Acts of meaning. Cambridge. MA: Harvard University Press.

Bryman, A. (2004). Social research methods (2nd ed.). Oxford: Oxford University Press.

BUPA United Kingdom. (2012). GP services. Retrieved 16/02/12, from http://www.bupa.co.uk/individuals/self-pay-treatments/gp-services

Burgess-Allen, J., \& Owen-Smith, V. (2011). Using mind mapping techniques for rapid qualitative data analysis in public participation processes. Health Expectations, 13(4), 406-415. doi: 10.1111/j.1369-7625.2010.00594.x

Buzan, T. (2010). The mind map book: Unlock your creativity, boost your memory, change your Life. Harlow/GB: Pearson Education Limited.

Caldwell, B., Sclafani, M., Piren, K., \& Torre, C. (2012). The evolution of the advanced practice role in psychiatric mental health in New Jersey: 1960-2010. Issues in Mental Health Nursing, 33(4), 217-222. doi: 10.3109/01612840.2011.647253

Campbell, A. (1984). Moderated love: A theology of professional care. London: SPK.

Campbell, D. (2013, Thursday 25 July 2013). NHS faces chronic shortage of staff, warns King's Fund, Health, The Guardian. Retrieved from http://www.guardian.co.uk/society/2013/jul/25/nhs-staff-shortage-pay-kings-fund

Canadian Family Practice Nurses Association. (2011). CFPNA History. Retrieved 20/3/12, from http://www.cfpna.ca/history.cfm

Canadian Museum of Civilization Corporation. (2010). Making Medicare: The history of health care in Canada, 1914-2007. Retrieved 15/02/12, from http://www.civilization.ca/cmc/exhibitions/hist/medicare/medic-credits_e.shtml

Carson, A., \& Fairbairn, G. (2002). The whole story: Towards an ethical research methodology. Nurse Researcher, 10(1), 15-29.

Chan, B., Proudfoot, J., Zwar, N., Davies, G., \& Harris, M. (2011). Satisfaction with referral relationships between general practice and allied health professionals in Australian primary health care. Australian Journal of Primary Health, 17(3), 250-258. doi: 10.1071/py10026

Charles-Jones, H., Latimer, J., \& May, C. (2003). Transforming general practice: The redistribution of medical work in primary care. Sociology of Health \& Illness, 25, 7192.

Chase, S. (2005). Narrative inquiry: Multiple lenses, approaches and voices. In N. L. Denzin, Y (Ed.), The Sage handbook of qualitative research (4th ed., pp. 651-679). Thousand Oaks, London, New Delhi: Sage Publications.

Christensen, J. (1990). Nursing partnership: A model for nursing practice. Wellington: Daphne Brasell Associates Press.

Clandinin, J., \& Connolly, M. (2000). Narrative inquiry: Experience and story in qualitative research. San Francisco: Jossey-Bas Publishers.

Clausen, J. (1998). Reviews and life stories. In J. Giele \& G. J. Elder (Eds.), Methods of life course research (pp. 189-212). Thousand Oaks, London, New Delhi: Sage Publications.

Coppell, V. (2010). Newtown Union Health Service. Retrieved 16/3/12, from http://rnzcgp.org.nz/newtown-union-health-service/

Coyle, J. (1999). Exploring the meaning of 'dissatisfaction' with health care: The importance of 'personal identity threat'. Sociology of Health \& Illness, 21, 95.

Crengle, S. (2004). National primary medical care survey (NatMedCa). Primary care and Maori: Findings from the national primary medical care survey. Wellington: Ministry of Health

Crotty, M. (1998). The foundation of social research: Meaning and perspective in the research process. Crows Nest: Allen \& Unwin. 
Cumming, J., Mays, N., \& Gribben, B. (2008). Reforming primary health care: Is New Zealand's primary health care strategy achieving its early goals? Australia and New Zealand Health Policy, 54 (24 ). doi: 10.1186/1743-8462-5-24

Daaleman, T., \& Elder, G. (2007). Family medicine and the life course paradigm. Journal of American Board of Family Medicine, 20(1), 85-92.

De Fina, A. (2009). Narratives in interview - the case of accounts: For an interactional approach to narrative genres. Narrative Inquiry, 19(2), 233-258. doi: 10.1075/ni.19.2.03def

de Raeve, L. (2002). The modification of emotional responses: A problem for trust in nursepatient relationships? Nursing Ethics, 9(5), 465-471.

Denzin, N., \& Lincoln, Y. (Eds.). (2005). The Sage handbook of qualitative research (4th ed.). Thousand Oaks, London, New Delhi: Sage Publications.

Department of Health, U. K. (2011a). Primary care Retrieved 22/02/12, from http://www.dh.gov.uk/en/Healthcare/Primarycare/index.htm

Department of Health, U. K. (2011b). Primary medical care. London: Retrieved from http://www.dh.gov.uk/en/Healthcare/Primarycare/DH_288.

Devine, C. (2005). A life course perspective: Understanding food choices in time, social location, and history. Journal of Nutrition Education \& Behavior, 37(3), 121-128.

Devine, C., Connors, M., Bisogni, C., \& Sobal, J. (1998). Life-course influences on fruit and vegetable trajectories: Qualitative analysis of food choices. Journal of Nutrition Education and Behavior, 30(6), 361-370.

Dibley, L. (2011). Analysing narrative data using McCormack's lenses. Nurse Researcher, 18(3), 13-19.

Dickson-Swift, V., James, E. L., Kippen, S., \& Liamputtong, P. (2006). Blurring boundaries in qualitative health research on sensitive topics. Qualitative Health Research, 16(6), 853-871.

Diener, E. (2000). Subjective well-being: The science of happiness and a proposal for a national index. The American Psychologist, 55(1), 34-43.

Docherty, B. (1996). Nursing in general practice. Christchurch: Author.

Docherty, B., Sheridan, N., \& Kenealy, T. (2008). Painting a new picture for practice nurses in a capitated environment: Who holds the brush? The New Zealand Medical Journal (Online), 121(1284).

Dugdale, D., Epstein, R., \& Pantilat, S. (1999). Time and the patient-physician relationship. Journal of Internal Medicine, 14, 34-40. doi: 10.1046/j.1525-1497.1999.00263.x

Duncan, R. E., Drew, S. E., Hodgson, J., \& Sawyer, S. M. (2009). Is my mum going to hear this? Methodological and ethical challenges in qualitative health research with young people. Social Science \& Medicine, 69(11), 1691-1699. doi: 10.1016/j.socscimed.2009.09.001

Duncombe, R. (2011). Receptionists in intake in community health. Australian Health Review, 35, 164-167.

Dutton, J. (2006). Primary health care for youth in New Zealand: Are current health strategies working? Nursing Praxis in New Zealand, 22(2), 12-20.

Dutton, J. (2009). Disadvantage and access to primary health care for youth in New Zealand: Are our current health strategies reducing barriers? Support Services Journal Articles, Paper 1.

Eisner, M., \& Britten, N. (1999). What do general practice receptionists think and feel about their work? British Journal of General Practice, 49(439), 103-106.

Elder, G., \& Kirkpatrick Johnson, M. (2000). The life course and aging: Challenges, lessons, and new directions. In R. Settersten (Ed.), Invitation to the life course: Toward new understandings of later life (pp. 49-84). Chapel Hill: University of North Carolina at Chapel Hill. 
Elder, G., \& Rockwell, R. (1979). The Life-course and human development: An ecological perspective. International Journal of Behavioural Development, 2(1), 1-21. doi: $10.1177 / 016502547900200101$

Ellis, C., \& Bochner, A. (2000). Autoethography, personal narrative, reflexivity: Researcher as subject In N. Denzin, \& Lincoln, Y., (Ed.), Handbook of qualitative research (2nd ed., pp. 733-768). Thousand Oaks: Sage

Emden, C. (1998). Theoretical perspectives on narrative inquiry. Collegian, 5(2), 30-35.

Eppler, M. (2006). A comparison between concept maps, mind maps, conceptual diagrams, and visual metaphors as complementary tools for knowledge construction and sharing. Information Visualization, 5, 202-202. doi: 10.1057/palgrave.ivs.9500131

Ervin, K., Cross, M., \& Koschel, A. (2013). Working together in lifestory telling for residents in aged care facilities: A qualitative study of staff/family collaboration in aged care. Journal of Nursing Education and Practice, 3(6). doi: 10.5430/jnep.v3n6p102

Eve, R., Hodgkin, P., Quinney, D., \& Waller, J. (2000). What do practice nurses do? A study of roles, responsibilities and patterns of work. Sheffield: The Centre for Innovation in Primary Care.

Expatforum.com. (2012). Health care in Australia, from http://www.expatforum.com/articles/health/health-care-in-australia.html

Fairbairn, G., \& Carson, A. (2002). Writing about nursing research: A storytelling approach. Nurse Researcher, 10(1), 7-14.

Farrimond, H., Saukko, P., Qureshi, N., \& Evans, P. (2010). Making sense of being at 'high risk' of coronary heart disease within primary prevention. Psychology \& Health, 25(3), 289-304. doi: 10.1080/08870440802499382

Ferraro, K., Farmer, M., \& Wybraniec, J. (1997). Health trajectories: Long-term dynamics among black and white adults. Journal of Health and Social Behaviour, 38(1), 38-54.

Fielding, N., \& Thomas, H. (1993). Qualitative interviewing. In N. Gilbert (Ed.), Researching Social Life (pp. 123-144). London, Thousand Oaks, New Delhi: Sage Publications.

Find Private Clinics.ca. (2012). Canada Family Medicine Clinics. Retrieved 16/3/12, from http://www.findprivateclinics.ca/Family_Medicine/27-0.html

Finlayson, M., \& Raymont, A. (2012). Teamwork - general practitioners and practice nurses working together in New Zealand. Journal of Primary Health Care, 4(2), 150-155.

Finlayson, M., Sheridan, N., \& Cumming, J. (2009). Nursing developments in primary health care 2001-2007. Wellington: Victoria University of Wellington.

Finlayson, M., Sheridan, N., Cumming, J., \& Fowler, S. (2012). The impact of funding changes on the implementation of primary health care policy. Primary Health Care Research \& Development, 13(2), 120-129.

Fosbinder, D. (1994). Patient perceptions of nursing care: An emerging theory of interpersonal competence. Journal of Advanced Nursing, 20(6), 1085-1093. doi: 10.1046/j.1365-2648.1994.20061085.x

Frank, A. (2000). The standpoint of storyteller... a version of this article was presented as a university lecture at the University of Alberta. Qualitative Health Research, 10(3), 354-365.

Frederiksen, H., Kragstrup, J., \& Dehlholm-Lambertsen, G. (2009). It's all about recognition! Qualitative study of the value of interpersonal continuity in general practice. $B M C$ Family Practice, 10, 8p. doi: 10.1186/1471-2296-10-47

Freeman, G. (2008). Urban continuity of general practice care in the new century. NZFP. Royal New Zealand College of General Practitioners, 35(1), 5-7.

Frid, I., Ohlen, J., \& Bergbom, I. (2000). On the use of narratives in nursing research. Journal of Advanced Nursing, 32(3), 695-703.

Frost, S. (2004). Narrative approaches for research in community nursing. British Journal of Community Nursing, 9(4), 172-178. 
Funk, L. M., Stajduhar, K. I., \& Purkis, M. E. (2011). An exploration of empowerment discourse within home-care nurses' accounts of practice. Nursing Inquiry, 18(1), 6676. doi: 10.1111/j.1440-1800.2010.00502.x

Fyers, K. (2008). The nursing presence in general practice: Revealing dimensions of day-today experience of practice nurses in New Zealand. Masters, Victoria University of Wellington, Wellington.

Gastmans, C. (1998). Interpersonal relations in nursing: A philosophical-ethical analysis of the work of Hildegard E. Peplau. Journal of Advanced Nursing, 28(6), 1312-1319. doi: 10.1046/j.1365-2648.1998.00840.x

Gauld, R. (2011). International profiles of health care systems. In S. Thomson, Osborne, R., Squires, D., Reed, S., (Ed.), New Zealand health care system 2011. New York, Washington: The Commonwealth Fund.

Gemmell, I., Campbell, S., Hann, M., \& Sibbald, B. (2009). Assessing workload in general practice in England before and after the introduction of the pay-for-performance contract. Journal of Advanced Nursing, 65(3), 509-515. doi: 10.1111/j.13652648.2008.04902.x

General Medical Council. (2012). General Medical Council. Retrieved 19/12/12, from http://www.gmc-uk.org/about/index.asp

General Practice Australia. (2010). Private practice. Retrieved 26/02/12, from http://www.generalpracticeaustralia.org.au/career-information/private-practice/

Gerson, K., \& Horowitz, R. (2002). Qualitative research in action. In T. May (Ed.), Observation and interviewing: Options and choices in qualitative research (pp. 199224). London, Thousand Oaks, New Delhi: Sage Publications.

Giele, J., \& Elder, G. (Eds.). (1998). Methods of life course research: Qualitative and quantitative approaches. Thousand Oaks, London, New Delhi: Sage Publications.

Goedhuys, J., \& Jan-Joost, R. (2001). On the relationship between the efficiency and the quality of the consultation. A validity study. Family Practice, 18(6), 592-592.

Goffman, E. (1976). The presentation of self in everyday life. London: Penguin.

Golberg, B. (1998). Connection: An exploration of spirituality in nursing care. Journal of Advanced Nursing, 27(4), 836-842.

Goleman, D. (1995). Emotional intelligence. London: Bloomsbury Publishing.

Goodyear-Smith, F., \& Janes, R. (2008). New Zealand rural primary health care workforce in 2005: More than just a doctor shortage. Australian Journal of Rural Health, 16(1), 4046.

Government of Alberta. (2011a, 06/01/11). Doctors. Retrieved 18/02/12, from http://www.agpt.com.au/

Government of Alberta. (2011b). Nursing. Retrieved 23/02/12, from http://www.albertacanada.com/immigration/working/hc-nurses-overview.aspx

Green, M., Emery, C., Kozora, E., Diaz, P., \& Make, B. (2011). Religious and spiritual coping and quality of life among patients with emphysema in the national emphysema treatment trial. Respiratory Care, 56(10), 1514-1521. doi: 10.4187/respcare.01105

Greenhalgh, T., Russell, J., \& Swinglehurst, D. (2005). Narrative methods in quality improvement research. Quality \& Safety in Health Care, 14(6), 443-449.

Griffith, A. (1998). Insider/outsider: Epistemological privilege and mothering work Human Studies, 21(4), 361-376. doi: 10.1023/A:1005421211078

Groleau, D., Zelkowitz, P., \& Cabral, I. (2009). Enhancing generalisability: Moving from an intimate to a political voice. Qualitative Health Research, 19(3), 416-426. doi: $10.1177 / 1049732308329851$

Gubrium, J., \& Holstein, J. (2002). Handbook of interview research: Context and method. Thousand Oaks, London, New Delhi: Sage Publications. 
Guerette, A., \& Smedema, S. (2011). The relationship of perceived social support with wellbeing in adults with visual impairments. Journal of Visual Impairment \& Blindness, 105(7), 425-439.

Guillemin, M., \& Heggen, K. (2009). Rapport and respect: Negotiating ethical relations between researcher and participant. Medicine, Health Care, and Philosophy, 12(3), 291-299. doi: 10.1007/s11019-008-9165-8

Halcomb, E., Patterson, E., \& Davidson, P. (2006). Evolution of practice nursing in Australia. Journal of Advanced Nursing, 55(3), 376-388. doi: 10.1111/j.1365-2648.2006.03908 1.X

Halcomb, E., Peters, K., \& Davies, D. (2013). A qualitative evaluation of New Zealand consumers perceptions of general practice nurses. BMC Family Practice, 14(1).

Halldorsdottir, S. (2008). The dynamics of the nurse-patient relationship: Introduction of a synthesized theory from the patient's perspective. Scandinavian Journal of Caring Sciences, 22(4), 643-652.

Harling Stalker, L. (2009). A tale of two narratives: Ontological and epistemological narratives. Narrative Inquiry, 19(2), 199-218. doi: 10.1075/ni.19.2.01she.

Harrison, A., Gregory, S., Mundle, C., \& Boyle, S. (2011). International profiles of health care systems, 2011. In S. Thomson, Osborne, R., Squires, D., Reed, S., (Ed.), The English health care system (pp. 38-44). New York, Washington The Commonwealth Fund.

Hartrick Doane, G., \& Varcoe, C. (2005). Family nursing as relational inquiry. Philalelphia, Baltimore, New York, London, Buenos Aires, Hong Kong, Sydney, Tokyo: Lippincott Williams \& Wilkins.

Hartrick, G. (1998). Developing health promoting practices: A transformative process. Nursing Outlook, 46(5), 219-225.

Hartrick, G. (2002). Beyond interpersonal communication: The significance of relationship in health promoting practice In L. Young, Hayes, V. (Ed.), Transforming health promotion practice: Concepts, issues and application (pp. 49-58). Philadelphia: FA Davis.

Haskard, K., DiMatteo, M., \& Heritage, J. (2009). Affective and instrumental communication in primary care interactions: Predicting the satisfaction of nursing staff and patients. Health Communication, 24(1), 21-32.

Hays, J. (2002). Living arrangements and health status in later life: A review of recent literature. Public Health Nursing, 19(2), 136-151.

Healey-Ogden, M., \& Austin, W. (2010). Uncovering the lived experience of well-being. Qualitative Health Research, 21(1), 85-96. doi: 10.1177/1049732310379113

Health Canada. (2004). Health care system: Primary health. Retrieved 22/02/12, from http://www.hc-sc.gc.ca/hcs-sss/prim/index-eng.php

Health Canada. (2006). Health care system: About primary health. Retrieved 17/2/12, from http://www.hc-sc.gc.ca/hcs-sss/prim/about-apropos-eng.php

Health Canada. (2012). Factsheet: Harper Government funds research project: The Nature of Nursing Practice in Rural and Remote Canada II Retrieved 3/2/13, from http://www.hc-sc.gc.ca/ahc-asc/media/nr-cp/_2012/2012-39bk-eng.php

Health Workforce New Zealand. (2011). New roles and scopes: Primary care practice assistants FAQs. Retrieved 20/02/12, from http://www.healthworkforce.govt.nz/newroles-and-scopes/primary-care-practice-assistants/pcpa-faqs

Healy, J., \& Hall, J. (2011). International profiles of health care systems, 2011 In S. Thomson, Osborne, R., Squires, D., Reed, S. (Ed.), The Australian health care system, 2011 (pp. 11-20). New York, Washington: The Commonwealth fund.

Heaphy, B. (2007). Practice nurse - Information for New Zealand parents. 
Hefford, M., Cumming, J., Finlayson, M., Raymont, A., Love, T., \& van Essen, E. (2010). Practice nurse cost benefit analysis: Report to the Ministry of Health Wellington: Ministry of Health. Retrieved from http://www.health.govt.nz/publication/practicenurse-cost-benefit-analysis-report-ministry-health.

Hewitt, H., McCloughan, L., \& McKinstry, B. (2009). Front desk talk: Discourse analysis of receptionist-patient interaction. British Journal of General Practice, 59(565), 571-577. doi: 10.3399/bjgp09X453774

Hinchman, L., \& Hinchman, J. (Eds.). (1997). Memory, identity, community: The idea of narrative in human sciences. Albany: SUNY Press.

Hoare, K., Mills, J., \& Francis, K. (2012). The role of Government policy in supporting nurseled care in general practice in the United Kingdom, New Zealand and Australia: An adapted realist review. Journal of Advanced Nursing, 68(5), 963-980. doi: 10.1111/j.1365-2648.2011.05870.x

Hochschild, A. (1979). Emotion work, feeling rules, and social structure. The American Journal of Sociology, 85(3), 551-575.

Holloway, I., Freshwater, D., \& McKenzie, R. (2007). Vulnerable story telling: Narrative research in nursing... with review by McKenzie R. Journal of Research in Nursing, 12(6), 703.

Holstein, J., \& Gubrium, J. (2000). Constructing the life course (2nd ed.). New York: General Hall Inc.

Hounsell, D. (2000). History of practice nursing in New Zealand. The Practice Nurse, 1(1), 89.

Howell, S., \& Coates, C. (1997). Utilizing narrative inquiry to evaluate a nursing doctorate program professional residency. Journal of Professional Nursing, 13(2), 110-123.

Hrabe, D. P. (2005). Peplau in cyberspace: An analysis of Peplau's interpersonal relations theory and computer-mediated communication. Issues in Mental Health Nursing, 26(4), 397-414.

Huber, M., Knottnerus, A., Green, L., van der Horst, H., Kromhout, D., Leonard, B., et al. (2011). How should we define health? BMJ, 43:d4163. doi: 10.1136/bmj.d4163

Hudon, C., St-Cyr Tribble, D., Legare, F., Bravo, G., Fortin, M., \& Almirall, J. (2010). Assessing enablement in clinical practice: A systematic review of available instruments. Journal of Evaluation in Clinical Practice, 16(6), 1301-1308. doi: 10.1111/j.1365-2753.2009.01332.x

Hudson, M. L., \& Russell, K. (2009). The Treaty of Waitangi and research ethics in Aotearoa. Journal of Bioethical Inquiry, 6(1), 61-68.

Hughes, J. M. (2003). Department of Health research initiative on nutrition - Phase 2: A summary of the findings and recommendations. Nutrition Bulletin, 28(3), 289-302.

International Society for Ecology and Culture. (2011). The economics of happiness Retrieved 10/9/13, 2013, from http://www.theeconomicsofhappiness.org/about-the-film

Jack, K. (2002). Practice nurses are not handmaidens to GPs. [Letter to Editor of Practice Nurse]. Practice Nurse, 24(3), 18.

Jacobson, L., Richardson, G., Parry-Langdon, N., \& Donovan, C. (2001). How do teenagers and primary healthcare providers view each other? An overview of key themes. British Journal of General Practice, 51, 811-816.

Jadelhack, R. (2012). Health promotion in nursing and cost-effectiveness. Journal of Cultural Diversity, 19(2), 65-68.

Jarrin, O. (2007). An integral philosophy and definition of nursing. Journal of Integral Theory and Practice, 2(4), 79-101.

Jatrana, S., \& Crampton, P. (2009). Gender diferences in general practice utilisation in New Zealand. Journal of Primary Health Care, 1(4), 261-269. 
Jonsdottir, H., Litchfield, M., \& Pharris, M. D. (2004). The relational core of nursing practice as partnership... including commentary by Watson J. Journal of Advanced Nursing, 47(3), 241-250. doi: 10.1111/j.1365-2648.2004.03088 1.x

Kane, D. (2005). Clinical governance: A guide for primary health organisations. Dunedin: BPAC.

Kanuha, V. K. (2000). "Being" native versus "going native": Conducting social work research as an insider. Social Work, 45(5), 439-447. doi: 10.1093/sw/45.5.439

Karnieli-Miller, O., Strier, R., \& Pessach, L. (2009). Power relations in qualitative research. Qualitative Health Research, 19(2), 279-289. doi: 10.1177/1049732308329306

Kearns, R., Myers, J., Adair, V., Coster, H., \& Coster, G. (2006). What makes 'place' attractive to overseas-trained doctors in rural New Zealand? Health \& Social Care in the Community, 14(6), 532-540.

Keleher, H., Joyce, C., Parker, R., \& Piterman, L. (2007). Practice nurses in Australia: Current issues and future directions. Medical Journal of Australia, 187(2), 108-110.

Keleher, H., Parker, R., Abdulwadud, O., \& Francis, K. (2009). Systematic review of the effectiveness of primary care nursing. International Journal of Nursing Practice, 15(1), 16-24. doi: 10.1111/j.1440-172X.2008.01726.x

Kenten, C., Bowling, A., Lambert, N., Howe, A., \& Rowe, G. (2010). A study of patient expectations in a Norfolk general practice. Health Expectations, 13(3), 273-284. doi: 10.1111/j.1369-7625.2010.00603.x

King, A. (2001). The Primary Health Care Strategy. Wellington: Ministry of Health. Retrieved from http://www.moh.govt.nz/moh.nsf/indexmh/primary-health-carestrategy-2001?Open.

King, G., Cathers, T., Brown, E., Specht, J., Willoughby, C., Polgar, J., et al. (2003). Turning points and protective processes in the lives of people with chronic disabilities. Qualitative Health Research, 13(2), 184-206.

Kleiman, S. (2009). Human centred nursing: The foundation of quality care. Philadelphia: F.A Davis Company.

Koch, T. (1998). Story telling: Is it really research? Journal of Advanced Nursing, 28(6), 1182-1190. doi: 10.1046/j.1365-2648.1998.00853.x

Kooker, B. M., Shoultz, J., \& Codier, E. E. (2007). Identifying emotional intelligence in professional nursing practice. Journal of Professional Nursing, 23(1), 30-36.

Kralik, D., Koch, T., \& Wotton, K. (1997). Engagement and detachment: Understanding patients' experiences with nursing. Journal of Advanced Nursing, 26(2), 399-407. doi: 10.1046/j.1365-2648.1997.1997026399.x

Kuo, C.-C., Chin, C.-C., \& Chou, F.-H. (2012). Reflecting on nurse-patient relationships using core postmodernist concepts [Chinese]. Journal of Nursing, 59(1), 72-76.

Kvale, S. (1996). InterViews: An introduction to qualitative research. Thousand Oaks, London, New Delhi: Sage Publications.

Labov, W. (1972). Language in the inner city: Studies in the black english vernacular. Oxford: Blackwell.

Labov, W. (2006). Narrative pre-construction. Narrative Inquiry, 16(1), 37-45.

Lakeman, R. (2012). Remembering Hildegard Peplau, from http://www.testandcalc.com/richard/resources/remembering\%20peplau\%20$\% 20$ vision\%20-\%20lakeman.pdf

Lally, E. (2002). An exploration of language and nursing practice to improve communication in the context of ear syringing. Master of Arts (Applied) in Nursing Victoria University of Wellington, Wellington. 
Laurant, M., Reeves, D., Hermens, R., Braspenning, J., Grol, R., \& Sibbald, B. (2007). Substitution of doctors by nurses in primary care (Review). In C. Review (Ed.), (Vol. 3): The Cochrane Library.

Lawler, S. (2002). Narrative in social research. In T. May (Ed.), Qualitative research in action (pp. 242-258). London, Thousand Oaks, New Delhi: Sage Publications.

Legislation.govt.UK. (2002). The Nursing and Midwifery Order 2001. Retrieved 23/02/12, from http://www.legislation.gov.uk/uksi/2002/253/part/II/made

Li, S. (2002). Symbiotic niceness: A study of psychosocial care in palliative care settings. $\mathrm{PhD}$, University of London, London.

Lincoln, Y., \& Guba, E. (1985). Naturalistic inquiry. Newbury Park, London, New Delhi: Sage Publications.

Little, P., Everitt, H., Williamson, I., Warner, G. et al. (2001). Observational study of effect of patient centredness and positive approach on outcomes of general practice consultations. British Medical Journal, 323(7318), 908-911.

Llywodraeth Cymru Welsh Government. (2011). A working paper produced by the Rural Health Implementation Group in support of the Welsh Rural Health Plan. Cardiff: Welsh Assembly Government.

London, M., \& Saul, L. (2005). Your guide to New Zealand general practice. Wellington: Royal New Zealand College of General Practitioners.

MacQueen, J. S. (2007). Florence Nightingale's nursing practice. Nursing History Review, 15, 29-49.

Magnello, M. E. (2012). Florence Nightingale museum. [Media review]. Nursing History Review, 20, 209-211. doi: 10.1891/1062-8061.20.209

Makarenko, J. (2010). Canada's health care system: An overview of public and private participation. Health Education and Social Welfare. Retrieved 17/02/12, from http://www.mapleleafweb.com/features/canada-s-health-care-system-overview-publicand-private-participation

Manderson, L., Bennett, E., \& Andajani-Sutjahjo, S. (2006). The social dynamics of the interview: age, class, and gender. Qualitative Health Research, 16(10), 1317-1334.

Marshall, T. (2003). The silent revolution: recent developments in the organisation of general practice in New Zealand. Business Review, 5(1), 1-9.

Martin, F. (1998). Tales of transition: Self-narrative and direct scribing in exploring careleaving. Child \& Family Social Work, 3(1), 1-12.

Mason, J. (1996). Qualitative researching. London: Sage.

Mason, J. (2002). Qualitative interviewing: Asking listening and interpreting. In T. May (Ed.), Qualitative research in action (pp. 225-241). London, Thousand Oaks, New Delhi: Sage Publications.

Mathias, K. (2002). Youth-specific primary health care - access, utilisation and health outcomes. (N. Z. H. T. A. (NZHTA), Trans.) NZHTA Report 2002 (Vol. 5). Christchurch: University of Otago

May, C. (1992). Nursing work, nurses' knowledge, and the subjectification of the patient. Sociology of Health \& Illness, 14(4), 472-487.

McAllister, M. M. (2001). In harm's way: A postmodern narrative inquiry. Journal of Psychiatric \& Mental Health Nursing, 8(5), 391-397. doi: 10.1046/j.13652850.2001.00408.x

McCarthy, C. T., \& Aquino-Russell, C. (2009). A comparison of two nursing theories in practice: Peplau and Parse. Nursing Science Quarterly, 22(1), 34-40. doi: 10.1177/0894318408329339

McConnell-Henry, T., James, A., Chapman, Y., \& Francis, K. (2009). Researching with people you know: issues in interviewing. Contemporary Nurse: A Journal for the Australian Nursing Profession, 34(1), 2-9. doi: 10.5172/conu.2009.34.1.002 
McCormack, C. (2000). From interview transcript to interpretive story: Part $1-$ Viewing the transcript through multiple lenses. Field Methods, 12(4), 282-297. doi: $0.1177 / 1525822$ X0001200402

McCormack, C. (2001). Times of our lives: Women, leisure and postgraduate research. $\mathrm{PhD}$, University of Wollongong.

McDonald, R., Rogers, A., \& Macdonald, W. (2008). Dependence and identity: Nurses and chronic conditions in a primary care setting. Journal of Health Organization and Management, 22(3), 294-308. doi: 10.1108/14777260810883558

McEldowney, R. (2002). Shape-shifting: Stories of teaching for change in nursing. Doctor of Philosophy Victoria University of Wellington, Wellington.

McKenzie, R. (2007). Review: Vulnerable story telling: Narrative research in nursing. Journal of Research in Nursing, 12, 713-714. doi: 10.1177/1744987107084670

McKinlay, E. (2006). New Zealand practice nursing in the third millennium: Key issues in 2006. New Zealand Family Physician, 33 (3), 162-168.

McKinstry, B., Watson, P., Pinnock, H., Heaney, D., \& Sheikh, A. (2009). Confidentiality and the telephone in family practice: A qualitative study of the views of patients, clinicians and administrative staff. Family Practice, 26(5), 344-350. doi: 10.1093/fampra/cmp032

McLennan, L. (1983). A survey of the fully subsidised practice nurse subsidy in New Zealand. Royal New Zealand College of General Practitioners, Wellington.

McWhinney, I. (1998). Primary care: Core values in a changing world. British Medical Journal., 316, 1807-1809.

Meadley, L., Conway, J., \& McMillan, M. (2004). Education and training needs of nurses in general practice. Australian Journal of Primary Health, 10(1), 21-27.

Meadows, K. A. (2011). Patient-reported outcome measures: an overview. British Journal of Community Nursing, 16(3), 146-151.

Medical Council of Canada. (2012). About us. Retrieved 3/1/13, 2012, from http://www.mcc.ca/en/about/

Medical Council of New Zealand. (2011). About us, from http://www.menz.org.nz/about-us/

Medical Research Council: Social and Public Health Sciences Unit. (1986). West of Scotland Twenty-07 study: Health in the community Retrieved 4/8/13, from http://2007study.sphsu.mrc.ac.uk/about-twenty-07.html

Mehlsen, M., Thomsen, D. K., Viidik, A., Olesen, F., \& Zachariae, R. (2005). Cognitive processes involved in the evaluation of life satisfaction: Implications for well-being. Aging \& Mental Health, 9(3), 281-290.

Mercer, S., Jani, B., Maxwell, M., Wong, S., \& Watt, G. (2012). Patient enablement requires physician empathy: A cross-sectional study of general practice consultations in areas of high and low socioeconomic deprivation in Scotland. BMC Family Practice, 13(1), 6.

Millar, E., Garland, C., Ross, F., Kendrick, T., \& Burns, T. (1999). Practice nurses and the care of patients receiving depot neuroleptic treatment: Views on training, confidence and use of structured assessment. Journal of Advanced Nursing, 29(6), 1454-1461. doi: 10.1046/j.1365-2648.1999.01033.x

Miller, J., \& Glassner, B. (1997). The 'inside' and the 'outside': Finding realities in interviews. In D. Silverman (Ed.), Qualitative research: Theory, method and practice (pp. 125139). London, Thousand Oaks, New Delhi: Sage.

Miller, K., Reeves, S., Zwarenstein, M., Beales, J. D., Kenaszchuk, C., \& Conn, L. G. (2008). Nursing emotion work and interprofessional collaboration in general internal medicine wards: A qualitative study. Journal of Advanced Nursing, 64(4), 332-343.

Mills, J., \& Fitzgerald, M. (2008). The changing role of practice nurses in Australia: An action research study. Australian Journal of Advanced Nursing (Online), 26(1), 16-20. 
Ministry of Health. (2003a). Health Practitioners Competence Assurance Act 2003 Wellington: Author. Retrieved from http://www.moh.govt.nz/hpca.

Ministry of Health. (2003b). Investing in Health: Whakatohutia te Oranga Tangata: A framework for activating primary health care in New Zealand. Wellington: Author Retrieved

from http://www.moh.govt.nz/notebook/nbbooks.nsf/0/3595173DEE935F45CC25713D006 EFB30/\$file/InvestingInHealth.pdf.

Ministry of Health. (2003c). Primary Health Care and Community Nursing Workforce Survey 2001. Wellington: Author. Retrieved from http://www.moh.govt.nz/notebook/nbbooks.nsf/0/C621693E7803A9C3CC257837007 CF433?opendocument.

Ministry of Health. (2007). Primary health care: Care plus Wellington: Author Retrieved from http://www.moh.govt.nz

Ministry of Health. (2008a). A portrait of health: Key results of the 2006/07 New Zealand health survey. Wellington: New Zealand Government.

Ministry of Health. (2008b). A portrait of health: Key results of the 2006/07 New Zealand health survey. Wellington: Author.

Ministry of Health. (2011a). Green prescriptions. Retrieved 2011, from http://www.health.govt.nz/our-work/preventative-health-wellness/physicalactivity/green-prescriptions

Ministry of Health. (2011b). Overview of the health system. Retrieved 15/3/12, from http://www.health.govt.nz/new-zealand-health-system/overview-health-system

Ministry of Health. (2011c). Primary health care. Wellington: Author Retrieved from http://www.health.govt.nz/our-work/primary-health-care.

Ministry of Health. (2011d). Very low cost access payments. Retrieved 25/02/12, from http://www.health.govt.nz/our-work/primary-health-care/primary-health-care-servicesand-projects/very-low-cost-access-payments

Ministry of Health. (2011e). Visiting a doctor. Retrieved 23/3/12, from http://www.health.govt.nz/yourhealth-topics/health-care-services/visiting-doctor

Ministry of Health. (2012a). Healthline. Retrieved 15/3/12, 2012, from http://www.health.govt.nz/yourhealth-topics/health-care-services/healthline

Ministry of Health. (2012b). Rural innovation fund. Retrieved 21/02/12, from http://www.health.govt.nz/our-work/populations/rural-health/rural-innovation-fund

Ministry of Health. (2012c). Standing order guidelines. Wellington: Author.

Minto, R. (2004). Practice nurses as providers: To be or not to be? The Practice Nurse, 4(2), 11-12.

Minto, R. (2006). The future of practice nursing. New Zealand Family Physician, 33(3), 169172.

Mishler, E. G. (1986). Research interviewing: Context and narrative. Cambridge, M A: Harvard University Press.

Morgan, P. A., \& Moffatt, C. J. (2008a). Non healing leg ulcers and the nurse-patient relationship. Part 1: The patient's perspective. International Wound Journal, 5(2), 340348.

Morgan, P. A., \& Moffatt, C. J. (2008b). Non healing leg ulcers and the nurse-patient relationship. Part 2: The nurse's perspective. International Wound Journal, 5(2), 332339.

Naess, O., Hernes, F. H., \& Blane, D. (2006). Life-course influences on mortality at older ages: Evidence from the Oslo mortality study. Social Science \& Medicine, 62(2), 329336.

National Health Committee. (2010). Rural health: Challenges of distance: Opportunities for Innovation. 
http://nhc.health.govt.nz/sites/nhc.health.govt.nz/files/documents/publications/ruralhealth-challenges-opportunities.pdf.

Neimeyer, R., Currier, J., Coleman, R., Tomer, A., \& Samuel, E. (2011). Confronting suffering and death at the end of life: The impact of religiosity, psychosocial factors, and life regret among hospice patients. Death Studies, 35(9), 777-800. doi: 10.1080/07481187.2011.583200

Nelson Marlborough District Health Board. (2011). Health Workforce New Zealand (HWNZ) Postgraduate V Nursing funded training 2012. Retrieved 18/6/13, from http://www.healthworkforce.govt.nz/sites/all/files/1B57\%20Postgraduate\%20Nursing $\% 20$ Training\%20specification.doc_1.pdf

New Zealand Nurses Organisation. (1995). Code of Ethics. Wellington: Author.

New Zealand Nurses Organisation. (1998). Statement on ethics of nursing research. Nursing Research Section of New Zealand Nurses Organisation Retrieved 26/7/2009, from http://www.nursingresearch.co.nz/about/etics.php3

New Zealand Nurses Organisation, \& College of Nurses Aotearoa (NZ). (2007). Investing in health 2007: An update to the recommendations of investing in health:A framework for activating primary health care nursing (2003, Ministry of Health) Wellington: Author.

New Zealand Parliament. (2009). New Zealand Health System Reforms Retrieved 18/7/13, from http://www.parliament.nz/en-nz/parl-support/researchpapers/00PLSocRP09031/new-zealand-health-system-reforms

New Zealandnow.govt.nz. (2012). Life in New Zealand. Private health care. Retrieved 16/3/12, from http://www.newzealandnow.govt.nz/private-healthcare 281.html

Nuffieldtrust. (2013). The coalition governments' health and social care reforms Retrieved 17/7/13, from http://www.nuffieldtrust.org.uk/our-work/projects/coalitiongovernments-health-and-social-care-reforms

Nursing and Midwifery Council. (2009). Accountability. Retrieved 28/3/12, from http://www.nmc-uk.org/Nurses-and-midwives/Regulation-in-practice/

Nursing Council of New Zealand. (2009). Competencies for registered nurses. Wellington: Author.

Nursing Council of New Zealand. (2011). The New Zealand nursing workforce. Wellington: Author.

Nystrom, M. (2007). A patient-oriented perspective in existential issues: A theoretical argument for applying Peplau's interpersonal relation model in healthcare science and practice. Scandinavian Journal of Caring Sciences, 21(2), 282-288.

O'Connor, M. E. (2009). Freed to care, proud to nurse: 100 years of the New Zealand Nurses Organisation Wellington: Steel Roberts.

Overcash, J. A. (2004). Narrative research: A viable methodology for clinical nursing. Nursing Forum, 39(1), 15-22.

Paley, J., \& Eva, G. (2005). Narrative vigilance: The analysis of stories in health care. Nursing Philosophy, 6(2), 83-97.

Paterson, J., \& Zderad, L. (1976). Humanistic nursing. New York: Wiley \& Sons.

Patterson, E., Del Mar, C., \& Najman, J. (2000). Medical receptionists in general practice: Who needs a nurse? International Journal of Nursing Practice, 6(5), 229-236.

Patterson, E., Forrester, K., Price, K., \& Hegney, D. (2004). Risk reduction in general practice and the role of the receptionist. Journal of Law and Medicine, 12(3), 340-347.

Patterson, E., \& McMurray, A. (2003). Collaborative practice between registered nurses and medical practitioners in Australian general practice: Moving from rhetoric to reality. Australian Journal of Advanced Nursing, 20(4), 43-48.

Patterson, E., Price, K., \& Hegney, D. (2005). Primary health care and general practice nurses: What is the nexus? Australian Journal of Primary Health 11(1), 57-54. 
Patterson, W. (2008). Narratives of events: Labovian narrative analysis and its limitations. In M. Andrews, Squire, C., \& Tamboukou, M. (Ed.), What is narrative research? (pp. 22). Los Angles, London, New Delhi, Singapore: Sage Publishers.

Patton, M. (2002). Qualitative research and evaluation methods. Thousand Oaks, London, New Delhi: Sage Publications.

Pellico, L. H., \& Chinn, P. L. (2007). Narrative criticism: A systematic approach to the analysis of story. Journal of Holistic Nursing, 25(1), 58.

Penckofer, S., Byrn, M., Mumby, P., \& Estwing Ferrans, C. (2011). Improving subject recruitment, retention, and participation in research through Peplau's theory of interpersonal relations. Nursing Science Quarterly, 24(2), 146-151. doi: $10.1177 / 0894318411399454$

Peplau, H. E. (1992). Interpersonal Relations: A theoretical framework for application in nursing practice. Nursing Science Quarterly, 5(1), 13-18.

Peplau, H. E. (1997). Peplau's theory of interpersonal relations. Nursing Science Quarterly, 10(4), 162-167. doi: 10.1177/089431849701000407

Peters, S., Wearden, A., Morriss, R., Dowrick, C., \& Lovell, K., et al. (2011). Challenges of nurse delivery of psychological interventions for long-term conditions in primary care: A qualitative exploration of the case of chronic fatigue syndrome/myalgic encephalitis. Implementation Science, 6(1).

Phillips, C. (2010). Snapshot of Australian primary health care research 2010: The roles of general practice practice nurses. Canberra: Australian National University.

Phillips. C., Pearce, C., Hall, S., Kljakovic, M., Sibbald, B., Dwan, K. et al. (2009). Enhancing care, improving quality: The six roles of the general practice nurse Medical Journal of Australia, 191(2).

Plunket. (2012). PlunketLine 0800933 922, 15/3/12, from http://www.plunket.org.nz/whatwe-do/what-we-offer/plunketline/

Practice Managers and Administrators New Zealand. (2011). New qualifications approved Retrieved 15/02/12, from http://www.rgpn.org.nz/Resources/PMAANZ.aspx

Price, K. (2007). Nurses in general practice settings: Roles and responsibilities. Contemporary Nurse: A Journal for the Australian Nursing Profession, 26(1), 7-14. doi: 10.5172/conu.2007.26.1.7

Proudfoot, J., Jayasinghe, U., Holton, C., Grimm, J., Amoroso, C., Beilby, J. et al. (2007). Team climate for innovation: What difference does it make in general practice? International Journal for Quality in Health Care, 19(3), 164-169. doi: 10.1093/intqhc/mzm005

Pruskus, V. (2009). Purpose and validity of rumours: Political aspects. Santalka Filosofija, 17(1). doi: 10.3846/1822-430X.2009.17.1.29-40

Pullon, S. (2008a). Competence, respect and trust: Key features of successful interprofessional nurse-doctor relationships. Journal of Interprofessional Care, 22(2), 133-147.

Pullon, S. (2008b). What is the place of general practice within primary health care - in the Aotearoa New Zealand context? Royal New Zealand College of General Practitioners, $35(5)$.

Pullon, S., McKinlay, E., Stubbe, M., Todd, L., \& Badenhorst, C. (2011). Patients' and health professionals' perceptions of teamwork in primary care. Journal of Primary Health Care, 3(2), 128-135.

Quin, P. (2009). New Zealand health system reforms. Retrieved 2012, from http://www.parliament.nz/NR/rdonlyres/95A6438C-A5FF-486E-ABB8CBA2DFD0CE95/102573/TheNewZealandhealthsystemreformsFinal1.pdf 
Raymont, A., \& Cumming, J. (2009). Evaluation of the implementation and intermediate outcomes of the primary health care strategy. Third report: Status and activities of general medical practices. Wellington: Health Services Research Centre.

Redwood, S. (2008). Ethics and reflexivity in practitioner enquiry. In J. Lees \& D. Freshwater (Eds.), Practitioner based research: Power discourse and transformation (pp. 115141). London: Karnac Books Ltd.

Reinshaiz, S., \& Chase, S. (2002). Interviewing women. In J. Gubrium, Holstein, J., (Ed.), Handbook of interview research: Context and method (pp. 221-238). Thousand Oaks, London, New Delhi: Sage Publications.

Remote and Rural Steering Group. (2007). Delivering for remote and rural health care: The final report of the remote and rural workstream remote and rural seeting group. Edinburgh: The Scottish Government.

Ricoeur, P. (1981). Hermeneutics and the human sciences (J. Thompson, Trans.). Cambridge: Cambridge University Press.

Ricoeur, P. (1984). Time and narrative. Chicago: The University of Chicago Press.

Riessman, C. (1993). Narrative analysis: Qualitative research methods. Newbury Park: Sage.

Riessman, C. (2008). Narrative methods for the human sciences. Thousand Oaks, New Delhi, London, Singapore: Sage Publications.

Rodenburg, H., Dryden, H., \& Rodrigo, R. (2007). Long-term conditions and care plus: Local implementation. New Zealand Family Practice, 34(5), 330-334.

Roscoe, F. (2012). Nurse partners in general practice. Journal of Community Nursing, 26(1), 17-19.

Rosenthal, G. (1993). Reconstruction of life stories: Principles of selection in generating stories for narrative biographical interviews In R. Josselson, Lieblich, A. (Ed.), The narrative study of lives (Vol. 1, pp. 59-91). Newbury Park: CA: Sage.

Ross, J., \& Kenrick, K. (2011). Continuity of care in New Zealand primary health services. The New Zealand Medical Journal (Online), 124(1329).

Roulston, K. (2010). Considering quality in qualitative interviewing. Qualitative Research, 10(2), 199-228. doi: 10.1177/1468794109356739

Royal College of General Practitioners. (2012). GP qualifications. Retrieved 18/02/12, from http://www.rcgp.org.uk/default.aspx?page=1367

Royal College of Nursing. (2012). Unit Two: Employment of general practice nurses. Retrieved 23/02/12, from http://www.rcn.org.uk/development/general_practice_nurse_toolkit/unit_two

Royal New Zealand College of General Practitioners. (2009). Cornerstone General Practice Accreditation Standards and policy. Wellington: Author.

Royal New Zealand College of General Practitioners. (2012). Royal New Zealand College of General Practitioners response to meeting the challenge. Wellington.

Royal New Zealand College of General Practitioners. (2013). History of the College. Royal New Zealand College of General Practitioners. Retrieved 18/6/13, from https://www.rnzcgp.org.nz/history-of-the-college/

Rutter, M. (1979). Social competence in children. In M. Kent \& J. Rolf (Ed.), Protective factors in children's responses to stress and disadvantage (pp. 49-74). Hanover, NH: University Press of New England.

Rutter, M. (1987). Psychosocial resilience and protective mechanisms. American Journal of Orthopsychiatry, 57, 316-331.

Rutter, M. (1990). Psychosocial resilience and protective mechanisms. In A. M. J. Rolf, D. Cicchetti, K. Neuchterlein \& S. Weintraub (Ed.), Risk and protective factors in the development of psychopathology (pp. 181-214). Cambridge, MA: Cambridge University Press. 
Ryan, F., Coughlan, M., \& Cronin, P. (2009). Interviewing in qualitative research: The oneto-one interview. International Journal of Therapy \& Rehabilitation, 16(6), 309-314.

Sacker, A., Wiggins, R. D., Bartley, M., \& McDonough, P. (2007). Self-rated health trajectories in the United States and the United Kingdom: A comparative study. American Journal of Public Health, 97(5), 812-818. doi: 10.2105/ajph.2006.092320

Salisbury, C. (1989). How do people choose their doctor? . British Medical Journal, 299, 608610.

Sandelowski, M. (1991). Telling stories: Narrative approaches in qualitative research. Image Journal of Nursing Scholarship, 23(3). doi: 10.1111/j.1547-5069.1991.tb00662.x

Sandelowski, M. (2002). Keynote address: Second annual advances in qualitative methods conference. Reembodying qualitative inquiry. Qualitative Health Research, 12(1), 104-115.

Schantz, M. L. (2007). Compassion: A concept analysis. Nursing Forum, 42(2), 48-55.

Schickler, P. (2005). Achieving health or achieving wellbeing? Learning in Health \& Social Care, 4(4), 217-227.

Schmidt, S. (2004). Mindfulness and healing intention: concepts, practice, and research evaluation... Toward optimal healing environments in health care: Second American Samueli Symposium, January 22-24, 2004. Journal of Alternative \& Complementary Medicine, 10, S-7-s-14.

Scott-Jones, J. (2009). Defining the role of the GP in a primary health care team: The GP genome and phenotype 2009-2020. Auckland: Royal New Zealand College of General Practitioners.

Scott-Jones, J., \& Lawrenson, R. (2008). Doctors and nurses: Standing orders in primary care: A literature review. Royal New Zealand College of General Practitioners, 35(2), 107111.

Settersten, R. (2008). Navigating the new adulthood. The Futurist, 42(2), 26-28.

Shattell, M. (2005). Nurse bait: Strategies hospitalized patients use to entice nurses within the context of the interpersonal relationship. Issues in Mental Health Nursing, 26(2), 205223.

Shaw, I. (2008). Ethics and the practice of qualitative research. Qualitative Social Work, 7(4), 400-414.

Sheridan, N., Kenealy, T., Kidd, J., Schmidt-Busby, J., Hand, J., Raphael, D. et al. (2012). Patients' engagement in primary care: Powerlessness and compounding jeopardy. A qualitative study. Health Expectations. doi: 10.1111/hex.12006

Silverman, D. (1993). Interpreting qualitative data: Methods for analysing talk and interaction. London, Thousand Oaks, New Delhi: Sage Publications.

Silverman, D. (2000). Doing qualitative research: A practical hand book. London, Thousand Oaks, New Deli: Sage.

Silverman, D. (2001). Interpreting qualitative data: Methods for analysing talk, text and interaction (2nd ed.). London: Sage Publications.

Silverman, D. (2010). Doing qualitative research (3rd ed.). London, Thousand Oaks, New Delhi, Singapore: Sage Publications.

Silverman, D. (Ed.). (1997). Qualitative research: Theory, method and practice. London, Thousand Oaks, New Delhi: Sage Publications.

Simon, C. (2009). From generalism to specialty: A short history of general practice. Oxford Journals 2(1), 2-9. doi: 10.1093/innovait/inn171

Smith, J., \& Mottram, E. (1976). Extended use of nursing services in general practice. British Medical Journal, 4(5580), 672-674.

Smith, K. B., Profetto-McGrath, J., \& Cummings, G. G. (2009). Emotional intelligence and nursing: An integrative literature review. International Journal of Nursing Studies, 46(12), 1624-1636. doi: 10.1016/j.ijnurstu.2009.05.024 
Smith, P. (1991). The nursing process: Raising the profile of emotional care in nurse training. Journal of Advanced Nursing, 16(1), 74-81. doi: 10.1111/j.1365-2648.1991.tb01500.x

SmithBattle, L., Diekemper, M., \& Drake, M. A. (1999). Articulating the culture and tradition of community health nursing. Public Health Nursing, 16(3), 215-222.

Squire, C. (2008). Experience-centred and culturally-oriented approaches to narrative. In M. Andrews, C. Squire \& M. Tamboukou (Eds.), Doing narrative research (pp. 41-63). Los Angles, London, New Delhi, Singapore: Sage Publishing.

Squire, C., Andrews, M., \& Tamboukou, M. (2008). What is narrative research? In M. Andrews, C. Squire \& M. Tamboukou (Eds.), Doing narrative research (pp. 1-17). Los Angeles, London, New Delhi, Singapore: Sage Publications.

Staudt, M., Lodato, G., \& Hickman, C. (2012). Therapists talk about the engagement process. Community Mental Health Journal, 48(2), 212-218. doi: 10.1007/s10597-011-9377-x

Stein, E. (1916/1989). On the problem of Empathy (3rd ed.). Washington: ICS Publications.

Stewart, J., Dyas, J., Brown, K., \& Kendrick, D. (2006). Achieving blood pressure targets: Lessons from a study with practice nurses. Journal of Diabetes Nursing, 10(5), 186193.

Stickley, T., \& Freshwater, D. (2002). The art of loving and the therapeutic relationship. Nursing Inquiry, 9(4), 250-256.

Stoddart, K., \& Bugge, C. (2012). Uncovering the features of negotiation in developing the patient-nurse relationship. British Journal of Community Nursing, 17(2), 77-84.

Street, A. F. (1995). Nursing Replay: Researching nursing culture together. Melbourne. London. New York: Churchill Livingstone.

Taggart, J., Schwartz, A., Harris, M. F., Perkins, D., Davies, G. P., Proudfoot, J., et al. (2009). Facilitating teamwork in general practice: Moving from theory to practice. Australian Journal of Primary Health, 15(1), 24-28.

Taliaferro, L., Rienzo, B., Pigg, R., Miller, M., \& Dodd, V. (2009). Spiritual well-being and suicidal ideation among college students. Journal of American College Health, 58(1), 83-90. doi: 10.3200/jach.58.1.83-90

Tarlier, D. S. (2004). Beyond caring: The moral and ethical bases of responsive nurse-patient relationships. Nursing Philosophy, 5(3), 230-241.

Tarrant, C., Windbridge, K., Boulton, M., Baker, G., \& Freeman, G. (2003). Qualitative study of the meaning of personal care in general practice. British Medical Journal, 326(June). doi: 10.1136/bmj.326.7402.1310

Tattersall, C., Watts, A., \& Vernon, S. (2007). Mind mapping as a tool in qualitative research. Nursing Times, 103(26), 32-33.

Tetley, J., Grant, G., \& Davies, S. (2009). Using narratives to understand older people's decision-making processes. Qualitative Health Research, 19(9), 1273-1283. doi: $10.1177 / 1049732309344175$

The Commonwealth Fund. (2011). International profiles of health care systems, 2011. Australia, Canada, Denmark, England, France, Germany, Italy, Japan, the Netherlands, New Zealand, Norway, Sweden, Switzerland, and the United States. New York: Author.

The Commonwealth Fund. (2012). International profiles of health care systems: Australia, Canada, Denmark, England, France, Germany, Iceland, Italy, Japan, the Netherlands, New Zealand, Norway, Sweden, Switzerland, and the United States. In S. Thomson, R. Osborn, D. Squires \& M. Jun (Eds.). New York.

The King's Fund. (2013). Patient care under threat as pressures mount on London's NHS. Retrieved 18/7/13, from http://www.kingsfund.org.uk/press/press-releases/patientcare-under-threat-pressures-mount-londons-nhs

Theodosius, C. (2008). Emotional intelligence in health care: The unmanaged heart of nursing. London, New York: Routledge. 
Thompson, R. (2011). Using life story work to enhance care. Nursing Older People, 23(8), $16-21$.

Topham-Kindley, L. (2010). Business models. November 2010. Retrieved from http://www.nzdoctor.co.nz/in-print/2010/november-2010/3-november-2010/businessmodels.aspx

Tracy, S. J. (2010). Qualitative Quality: Eight "Big-Tent" Criteria for Excellent Qualitative Research. Qualitative Inquiry, 16(10), 837-851. doi: 10.1177/1077800410383121

Turner, D., Tarrant, C., Windridge, K., Bryan, S., Boulton, M., Freeman, G. et al. (2007). Do patients value continuity of care in general practice? An investigation using stated preference discrete choice experiments. Journal of Health Services Research and Policy, 12(3), 132.

Van De Mheen, H., Stronks, K., Van Den Bos, J., \& Mackenbach, J. (1997). The contribution of childhood environment to the explanation of socio-economic inequalities in health in adult life: A retrospective study. Social Science Medicine, 44, 13-24.

Vothknecht, S., Schoevers, R., \& de Haan, L. (2010). Subjective well-being in schizophrenia as measured with the subjective well-being under neuroleptic treatment scale: A review. Australian \& New Zealand Journal of Psychiatry, 45(3), 182-192. doi: 10.3109/00048674.2010.545984

Walker, A., Wilkes, L., \& White, K. (2000). How do patients perceive support from nurses? Professional Nurse, 16(2), 902-904.

Walsh, N., Roe, B., \& Huntington, J. (2003). Delivering a different kind of primary care? Nurses working in personal medical service pilots. Journal of Clinical Nursing, 12(3), 333-340.

Wandel, M. (1995). Dietary intake of fruits and vegetables in Norway: Influence of life phase and socio-economic factors. International Journal of Food Sciences and Nutrition, 43(3), 291-301.

Warelow, P., Edward, K., \& Vinek, J. (2008). Care: What nurses say and what nurses do. Holistic Nursing Practice, 22(3), 146-153.

Watson, J. (1988). Nursing: Human science and human care. New York: National League for Nursing.

Watson, J. (1999). Postmodern nursing and beyond. New York: Harcourt-Brace.

Watt, H. C., Carson, C., Lawlor, D., Patel, R., \& Ebrahim, S. (2009). Influence of life course socioeconomic position on older women's health behaviors: Findings from the British women's heart and health study. American Journal of Public Health, 99(2), 320-327. doi: 10.2105/ajph.2007.129288

Watts, I., Foley, E., Hutchinson, R., Pascoe, T., Whitecross, L., \& Snowdon, T. (2004). General practice nursing in Australia. Melbourne: Royal Australian College of General Practitioners \& Royal College of Nursing, Australia.

White, S. C. (2010). Analysing wellbeing: A framework for development practice. Development in Practice, 20(2). doi: 10.1080/09614520903564199

Whittemore, R., Chase, S. K., \& Mandle, C. L. (2001). Pearls, pith, and provocation: Validity in qualitative research. Qualitative Health Research, 11(4), 522-537.

Wilkes, L., \& Beale, B. (2005). Role conflict: Appropriateness of a nurse researcher's actions in the clinical field. Nurse Researcher, 12(4), 57-70.

Williams, A. (2001). A literature review on the concept of intimacy in nursing. Journal of Advanced Nursing, 33(5), 660-667. doi: 10.1046/j.1365-2648.2001.01701.x

Williams, Z. (2013). Health, The Guardian. Retrieved from http://www.guardian.co.uk/commentisfree/2013/jul/26/charging-gp-visits-prohibitpoor

Wilson, S. C., \& Carryer, J. (2008). Emotional competence and nursing education: A New Zealand study. Nursing Praxis in New Zealand, 24(1), 36-47. 
Wolf, Z. R. (2008). Nurses' stories: Discovering essential nursing. MEDSURG Nursing, 17(5), 324-329.

Woodroffe, E. (2006). Nurse-led general practice: The changing face of general practice? British Journal of General Practice, 56(529), 632-633.

Woodward, V. (2006). Commentary on Halcomb E.J., Patterson E. \& Davidson P.M. (2006) Evolution of practice nursing in Australia Journal of Advanced Nursing, 55(3), 388390. doi: 10.1111/j.1365-2648.2006.03908 2.x

World Health Organisation. (1986). The Ottawa charter for health promotion. Geneva: Author.

World Health Organisation. (1998). Health promotion glossary: Primary health care (pp. 3). Geneva: Author.

World Health Organisation. (2008). The world health report Primary health care: Now more than ever. Geneva.

World Health Organisation. (2012). About WHO: Definition of health. Retrieved 15/4/2012, from https://apps.who.int/aboutwho/en/definition.html

Yerrell, P., \& Reed, A. (1997). The anachronism of policy for nursing in general practice: Conceptualising a way forward. NT Research, 2(4), 245-257.

$\mathrm{Yu}$, S. (2006). Editor's choice. The life-course approach to health. American Journal of Public Health, 96(5), 768-768. doi: 10.2105/ajph.2006.088617 